\title{
Botulinum toxins for the prevention of migraine in adults (Review)
}

Herd CP, Tomlinson CL, Rick C, Scotton WJ, Edwards J, Ives N, Clarke CE, Sinclair A

Herd CP, Tomlinson CL, Rick C, Scotton WJ, Edwards J, Ives N, Clarke CE, Sinclair A.

Botulinum toxins for the prevention of migraine in adults.

Cochrane Database of Systematic Reviews 2018, Issue 6. Art. No.: CD011616.

DOI: 10.1002/14651858.CD011616.pub2.

www.cochranelibrary.com 
TABLE OF CONTENTS

ABSTRACT

PLAIN LANGUAGE SUMMARY

SUMMARY OF FINDINGS

BACKGROUND

OBJECTIVES

METHODS

RESULTS

Figure 1.

Figure 2.

Figure 3.

Figure 4.

Figure 5.

Figure 6.

DISCUSSION

AUTHORS' CONCLUSIONS

ACKNOWLEDGEMENTS

REFERENCES

CHARACTERISTICS OF STUDIES

DATA AND ANALYSES

Analysis 1.1. Comparison 1 Botulinum toxin type A versus placebo, Outcome 1 Number of migraine days.

Analysis 1.2. Comparison 1 Botulinum toxin type A versus placebo, Outcome 2 Number of headache days.

Analysis 1.3. Comparison 1 Botulinum toxin type A versus placebo, Outcome 3 Number of migraine attacks.

Analysis 1.4. Comparison 1 Botulinum toxin type A versus placebo, Outcome 4 Severity of migraine (Visual Analogue Score 0-10).

Analysis 1.5. Comparison 1 Botulinum toxin type A versus placebo, Outcome 5 Use of rescue medication.

Analysis 1.6. Comparison 1 Botulinum toxin type A versus placebo, Outcome 6 Total adverse events.

Analysis 1.7. Comparison 1 Botulinum toxin type A versus placebo, Outcome 7 Adverse event - blepharoptosis.

Analysis 1.8. Comparison 1 Botulinum toxin type A versus placebo, Outcome 8 Adverse event - muscle weakness. ..................

Analysis 1.9. Comparison 1 Botulinum toxin type A versus placebo, Outcome 9 Adverse event - neck pain.

Analysis 1.10. Comparison 1 Botulinum toxin type A versus placebo, Outcome 10 Adverse event - injection site pain. ..............

Analysis 1.11. Comparison 1 Botulinum toxin type A versus placebo, Outcome 11 Total treatment related adverse events. .....

Analysis 1.12. Comparison 1 Botulinum toxin type A versus placebo, Outcome 12 Withdrawals due to adverse events in trials with multiple rounds of treatment..

Analysis 2.1. Comparison 2 Botulinum toxin type A versus other established prophylactic agent, Outcome 1 Migraine impact and disability assessment scores.

Analysis 2.2. Comparison 2 Botulinum toxin type A versus other established prophylactic agent, Outcome 2 Total adverse events.

Analysis 2.3. Comparison 2 Botulinum toxin type A versus other established prophylactic agent, Outcome 3 Total treatment related adverse events.

Analysis 2.4. Comparison 2 Botulinum toxin type A versus other established prophylactic agent, Outcome 4 Withdrawals due to adverse events in trials with multiple rounds of treatment..

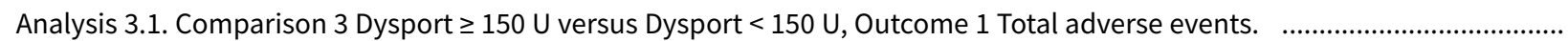

Analysis 4.1. Comparison 4 Botox dosing studies, Outcome 1 Number of migraine days.

Analysis 4.2. Comparison 4 Botox dosing studies, Outcome 2 Adverse event - muscle weakness.

Analysis 4.3. Comparison 4 Botox dosing studies, Outcome 3 Adverse event - blepharoptosis.

Analysis 4.4. Comparison 4 Botox dosing studies, Outcome 4 Adverse event - neck pain.

Analysis 4.5. Comparison 4 Botox dosing studies, Outcome 5 Adverse event - injection site pain. 
[Intervention Review]

\section{Botulinum toxins for the prevention of migraine in adults}

Clare P Herd ${ }^{1}$, Claire L Tomlinson², Caroline Rick², W J Scotton³ ${ }^{3}$ Julie Edwards ${ }^{4}$, Natalie Ives², Carl E Clarke ${ }^{4}$, Alexandra Sinclair $3,5,6$

1Institute of Applied Health Research, University of Birmingham, Birmingham, UK. 2Birmingham Clinical Trials Unit, University of Birmingham, Birmingham, UK. ${ }^{3}$ Metabolic Neurology, Institute of Metabolism and Systems Research, The University of Birmingham, Birmingham, UK. ${ }^{4}$ Department of Neurology, City Hospital, Sandwell and West Birmingham Hospitals NHS Trust, Birmingham, UK. ${ }^{5}$ Centre for Endocrinology, Diabetes and Metabolism, Birmingham Health Partners, Birmingham, UK. 6Department of Neurology, University Hospitals Birmingham NHS Foundation Trust, Birmingham, UK

Contact address: Alexandra Sinclair, Metabolic Neurology, Institute of Metabolism and Systems Research, The University of Birmingham, Birmingham, UK. a.b.sinclair@bham.ac.uk.

Editorial group: Cochrane Pain, Palliative and Supportive Care Group.

Publication status and date: New, published in Issue 6, 2018.

Citation: Herd CP, Tomlinson CL, Rick C, Scotton WJ, Edwards J, Ives N, Clarke CE, Sinclair A. Botulinum toxins for the prevention of migraine in adults. Cochrane Database of Systematic Reviews 2018, Issue 6. Art. No.: CD011616. DOI: 10.1002/14651858.CD011616.pub2.

Copyright ( 2018 The Cochrane Collaboration. Published by John Wiley \& Sons, Ltd.

\section{A B S T R A C T}

\section{Background}

Migraine occurs in around $15 \%$ of adults and is ranked as the seventh most disabling disease amongst all diseases globally. Despite the available treatments many people suffer prolonged and frequent attacks which have a major impact on their quality of life. Chronic migraine is defined as 15 or more days of headache per month, at least eight of those days being migraine. People with episodic migraine have fewer than 15 headache days per month. Botulinum toxin type A has been licensed in some countries for chronic migraine treatment, due to the results of just two trials.

\section{Objectives}

To assess the effects of botulinum toxins versus placebo or active treatment for the prevention or reduction in frequency of chronic or episodic migraine in adults.

\section{Search methods}

We searched CENTRAL, MEDLINE \& MEDLINE in Process, Embase, ClinicalTrials.gov and World Health Organization International Clinical Trials Registry (to December 2017). We examined reference lists and carried out citation searches on key publications. We sent correspondence to major manufacturers of botulinum toxin.

\section{Selection criteria}

Randomised, double-blind, controlled trials of botulinum toxin (any sero-type) injections into the head and neck for prophylaxis of chronic or episodic migraine in adults. Eligible comparators were placebo, alternative prophylactic agent or different dose of botulinum toxin.

\section{Data collection and analysis}

Two review authors independently selected trials and extracted data. For continuous outcomes we used mean change data when available. For dichotomous data we calculated risk ratios (RRs). We used data from the 12-week post-treatment follow-up time point. We assessed the evidence using GRADE and created two 'Summary of findings' tables.

\section{Main results}

\section{Description of trials}


We found 90 articles describing 28 trials (4190 participants), which were eligible for inclusion. The longest treatment duration was three rounds of injections with three months between treatments, so we could not analyse long-term effects. For the primary analyses, we pooled data from both chronic and episodic participant populations. Where possible, we also separated data into chronic migraine, episodic migraine and 'mixed group' classification subgroups. Most trials (21 out of 28 ) were small (fewer than 50 participants per trial arm). The risk of bias for included trials was low or unclear across most domains, with some trials reporting a high risk of bias for incomplete outcome data and selective outcome reporting.

\section{Botulinum toxin versus placebo}

Twenty-three trials compared botulinum toxin with placebo. Botulinum toxin may reduce the number of migraine days per month in the chronic migraine population by 3.1 days (95\% confidence interval $(\mathrm{Cl})-4.7$ to $-1.4,4$ trials, 1497 participants, low-quality evidence). This was reduced to -2 days ( $95 \% \mathrm{Cl}-2.8$ to $-1.1,2$ trials, 1384 participants; moderate-quality evidence) when we removed small trials.

A single trial of people with episodic migraine $(\mathrm{N}=418)$ showed no difference between groups for this outcome measure $(P=0.49)$.

In the chronic migraine population, botulinum toxin reduces the number of headache days per month by 1.9 days $(95 \% \mathrm{Cl}-2.7$ to $-1.0,2$ trials, 1384 participants, high-quality evidence). We did not find evidence of a difference in the number of migraine attacks for both chronic and episodic migraine participants ( 6 trials, $N=2004, P=0.30$, low-quality evidence). For the population of both chronic and episodic migraine participants a reduction in severity of migraine rated during clinical visits, on a $10 \mathrm{~cm}$ visual analogue scale (VAS) of $3.3 \mathrm{~cm}$ ( $95 \%$ $\mathrm{Cl}-4.2$ to -2.5 , very low-quality evidence) in favour of botulinum toxin treatment came from four small trials ( $\mathrm{N}=209)$; better reporting of this outcome measure from the additional eight trials that recorded it may have improved our confidence in the pooled estimate. Global assessment and quality-of-life measures were poorly reported and it was not possible to carry out statistical analysis of these outcome measures. Analysis of adverse events showed an increase in the risk ratio with treatment with botulinum toxin over placebo $30 \%$ (RR 1.28 , $95 \% \mathrm{Cl} 1.12$ to 1.47 , moderate-quality evidence). For every 100 participants 60 experienced an adverse event in the botulinum toxin group compared with 47 in the placebo group.

\section{Botulinum toxin versus other prophylactic agent}

Three trials studied comparisons with alternative oral prophylactic medications. Meta-analyses were not possible for number of migraine days, number of headache days or number of migraine attacks due to insufficient data, but individually trials reported no differences between groups for a variety of efficacy measures in the population of both chronic and episodic migraine participants. The global impression of disease measured using Migraine Disability Assessment (MIDAS) scores were reported from two trials that showed no difference between groups. Compared with oral treatments, botulinum toxin showed no between-group difference in the risk of adverse events ( 2 trials, $N=114$, very low-quality evidence). The relative risk reduction (RRR) for withdrawing from botulinum toxin due to adverse events compared with the alternative prophylactic agent was $72 \%(P=0.02,2$ trials, $N=119)$.

\section{Dosing trials}

There were insufficient data available for the comparison of different doses.

\section{Quality of the evidence}

The quality of the evidence assessed using GRADE methods was varied but mostly very low; the quality of the evidence for the placebo and active control comparisons was low and very low, respectively for the primary outcome measure. Small trial size, high risk of bias and unexplained heterogeneity were common reasons for downgrading the quality of the evidence.

\section{Authors' conclusions}

In chronic migraine, botulinum toxin type A may reduce the number of migraine days per month by 2 days compared with placebo treatment. Non-serious adverse events were probably experienced by $60 / 100$ participants in the treated group compared with $47 / 100$ in the placebo group. For people with episodic migraine, we remain uncertain whether or not this treatment is effective because the quality of this limited evidence is very low. Better reporting of outcome measures in published trials would provide a more complete evidence base on which to draw conclusions.

\section{PLAIN LANGUAGE SUMMARY}

\section{Botulinum toxin injections for preventing migraine in adults}

\section{Bottom line}

People with chronic (persisting) migraine treated with botulinum toxin injections had two fewer migraine days per month than people treated with placebo (fake treatment). It is unclear if this improvement was large enough to make a meaningful difference to their lives. More work is needed to show whether botulinum toxin is better than oral treatments (treatments that are swallowed), that prevent migraine. The evidence for botulinum toxin for people with episodic (occasional) migraine was uncertain. Treatment with botulinum toxin did not cause many side effects. 


\section{Background}

Migraine occurs in three in 20 adults and three in every four sufferers are female. People who have 15 or more days of headache in a month, with eight or more of those days being migraine, have chronic migraine. People with fewer than 15 days of headache in a month have episodic migraine. We included trials that compared botulinum toxin treatment with placebo injections of salt water, different doses of botulinum toxin, or other oral treatments to prevent migraine. We collected information for the following outcomes: number of migraine days in a month (our preferred measure); migraine severity; use of medications for migraine symptoms; disease-rating scales; quality-oflife scales; side effects; and cost effectiveness of treatment.

\section{Trial characteristics}

We found 28 clinical trials involving 4190 participants. Their average age was 42 years and eight in 10 were female. It is likely that we found all relevant trials published before December 2017. Trials were short, the longest lasting nine months. Around half the participants had chronic migraine symptoms and half episodic. Trial doses ranged from 6 to 300 units. The dose recommended for chronic migraine in the UK and USA is 155-195 units. Sixteen trials, involving 8 in 10 participants, were funded by botulinum toxin manufacturers.

\section{Key results}

Disappointingly, there was not enough detail in the trial reports about many important measures of disease for us to study them.

People with chronic migraine treated with the recommended dose of botulinum toxin had two fewer migraine days in a month than people treated with placebo. Six trials in both chronic and episodic migraine also reported the number of migraine attacks per month. Botulinum toxin was not proven to be better than placebo at reducing the number of attacks suffered per month. Botulinum toxin may reduce the severity of migraines but we need larger trials to have confidence in this result.

Three trials also compared botulinum toxin (at least 100 units) with oral treatments (sodium valproate and topiramate). There was no difference in the improvement in number of days with migraine; these data came from one trial. Botulinum toxin was no better or worse than oral treatments at reducing the scores on a migraine disability questionnaire (Migraine Disability Assessment) for people with chronic migraine. As all the results for comparison with oral treatments came from a few small trials it is likely that further large trials would change these results and so we cannot be confident in them.

Of the participants treated with botulinum toxin, 60 in 100 reported side effects (most common was drooping eyelid or muscle weakness), which was a little higher than the number receiving placebo (47 in 100). No difference was seen in the risk of side effects between botulinum toxin and oral treatments. Participants from two small trials were nearly four times less likely to stop their treatment if they were given botulinum toxin than if they had oral treatments. Information about side effects was reported for 8 in 10 trial participants.

\section{Quality of the evidence}

We rated the quality of the evidence from trials using four levels: very low, low, moderate or high. Very low-quality evidence means that we are very uncertain about the results. High-quality evidence means that we are very confident in the results. The results for the change in migraine days for people with chronic migraine and the number of side effects experienced were based on moderate-quality evidence. All other results discussed in this summary were low or very low-quality evidence, so the true effect is likely to be different to these results. 


\section{SUMMARY OF FINDINGS}

\section{Summary of findings for the main comparison. Botulinum toxin type A compared to placebo for the prevention of migraine in adults}

\section{Botulinum toxin type A compared to placebo for the prevention of migraine in adults}

Patient or population: adults with migraine

Setting: outpatient clinic

Intervention: botulinum toxin type A

Comparison: placebo

\begin{tabular}{|c|c|c|c|c|c|}
\hline Outcomes & Result with placebo & $\begin{array}{l}\text { Result with botulinum } \\
\text { toxin type } A\end{array}$ & $\begin{array}{l}\text { Relative effect } \\
(95 \% \mathrm{Cl})\end{array}$ & $\begin{array}{l}\text { № of participants } \\
\text { (trials) }\end{array}$ & $\begin{array}{l}\text { Quality of the evi- } \\
\text { dence } \\
\text { (GRADE) }\end{array}$ \\
\hline $\begin{array}{l}\text { Number of migraine days per } \\
\text { month: chronic migraine only }\end{array}$ & $\begin{array}{l}\text { The mean number of migraine days } \\
\text { (chronic migraine only) ranged from } 12 \\
\text { to } 20 \text { days }\end{array}$ & $\begin{array}{l}\text { MD } 3.1 \text { days lower } \\
\text { (4.7 lower to } 1.4 \text { lower) }\end{array}$ & - & $\begin{array}{l}1497 \\
\text { (4 RCTs) }\end{array}$ & $\begin{array}{l}\oplus \oplus \oplus \ominus \\
\text { Lowa,b }^{a}\end{array}$ \\
\hline $\begin{array}{l}\text { Number of migraine days per } \\
\text { month }\end{array}$ & $\begin{array}{l}\text { The mean number of migraine days } \\
\text { ranged from } 4 \text { to } 20 \text { days }\end{array}$ & $\begin{array}{l}\text { MD } 2.4 \text { days lower } \\
\text { (4.0 lower to } 0.8 \text { lower) }\end{array}$ & - & $\begin{array}{l}1915 \\
\text { (5 RCTs) }\end{array}$ & $\begin{array}{l}\oplus \ominus \odot \odot \\
\text { Very lowa,b,c }\end{array}$ \\
\hline $\begin{array}{l}\text { Number of headache days per } \\
\text { month: chronic migraine only }\end{array}$ & $\begin{array}{l}\text { The mean number of headache days } \\
\text { (chronic migraine only) ranged from } 13 \\
\text { to } 13.4 \text { days }\end{array}$ & $\begin{array}{l}\text { MD } 1.9 \text { days lower } \\
\text { (2.7 lower to } 1.0 \text { lower) }\end{array}$ & - & $\begin{array}{l}1384 \\
(2 \mathrm{RCTs})\end{array}$ & $\begin{array}{l}\oplus \oplus \oplus \oplus \\
\text { High }\end{array}$ \\
\hline Number of migraine attacks & $\begin{array}{l}\text { The mean number of migraine attacks } \\
\text { ranged from } 1.9 \text { to } 7.8 \text { attacks }\end{array}$ & $\begin{array}{l}\text { MD } 0.5 \text { attacks lower } \\
\text { (1.3 lower to } 0.4 \text { higher) }\end{array}$ & - & $\begin{array}{l}2004 \\
(6 \mathrm{RCTs})\end{array}$ & $\begin{array}{l}\oplus \oplus \oplus \ominus \\
\text { Lowd,e }\end{array}$ \\
\hline $\begin{array}{l}\text { Headache intensity measure } \\
\text { (Visual Analogue Score 0-10) }\end{array}$ & $\begin{array}{l}\text { The mean severity of migraine (Visual } \\
\text { Analogue Score 0-10) ranged from } 6.2 \\
\text { to } 9.2 \mathrm{~cm}\end{array}$ & $\begin{array}{l}\text { MD } 3.3 \mathrm{~cm} \text { lower } \\
\text { (4.2 lower to } 2.5 \text { lower) }\end{array}$ & - & $\begin{array}{l}209 \\
(4 \mathrm{RCTs})\end{array}$ & $\begin{array}{l}\oplus \ominus \ominus \ominus \\
\text { Very lowf,g }\end{array}$ \\
\hline $\begin{array}{l}\text { Global impression scale } \\
\text { assessed with Headache Im- } \\
\text { pact Test- } 6\end{array}$ & $\begin{array}{l}\text { The mean global impression scale was } \\
58.6 \text { points }\end{array}$ & $\begin{array}{l}\text { MD } 1.6 \text { points higher } \\
\text { ( } 2.1 \text { lower to } 5.3 \text { higher) }\end{array}$ & - & $\begin{array}{l}45 \\
(1 \mathrm{RCT})\end{array}$ & $\begin{array}{l}\oplus \ominus \ominus \ominus \\
\text { Very lowf,g }\end{array}$ \\
\hline \multirow{2}{*}{$\begin{array}{l}\text { Total number of participants } \\
\text { experiencing an adverse } \\
\text { event }\end{array}$} & Trial population & & \multirow{2}{*}{$\begin{array}{l}\text { RR } 1.28 \\
\text { (1.12 to } 1.47)\end{array}$} & \multirow{2}{*}{$\begin{array}{l}3325 \\
(13 \text { RCTs) }\end{array}$} & \multirow{2}{*}{$\begin{array}{l}\oplus \oplus \oplus \ominus \\
\text { Moderateh }\end{array}$} \\
\hline & 471 per 1000 & $\begin{array}{l}603 \text { per } 1000 \\
\text { (528 to } 693)\end{array}$ & & & \\
\hline
\end{tabular}

CI: confidence interval; $\mathbf{M D}$ : mean difference; $\mathbf{R C T}$ : randomised controlled trial; $\mathbf{R R}$ : risk ratio 
GRADE Working Group grades of evidence

High quality: we are very confident that the true effect lies close to that of the estimate of the effect.

Moderate quality: we are moderately confident in the effect estimate: the true effect is likely to be close to the estimate of the effect, but there is a possibility that it is substantially different.

Low quality: our confidence in the effect estimate is limited: the true effect may be substantially different from the estimate of the effect.

Very low quality: we have very little confidence in the effect estimate: the true effect is likely to be substantially different from the estimate of effect.

aDowngraded once due to inconsistency: statistical heterogeneity observed despite similarities in populations and doses.

bDowngraded once due to imprecision: sensitivity analysis testing robustness of result suggested small trials may be overestimating treatment effect. The result of this sensitivity analysis for the chronic migraine group (MD 2 days lower, $95 \% \mathrm{Cl} 2.8$ days lower to 1.1 days lower, $2 \mathrm{RCTs}, \mathrm{N}=1384$, results with placebo $12-13$ days) is not affected by imprecision and so we judged it to be moderate-quality evidence.

cDowngraded once due to indirectness: insufficient evidence to form subgroups representing our distinct populations of interest.

dDowngraded once due to indirectness: sensitivity of this outcome measure at risk of being too low to detect clinically meaningful differences.

eDowngraded once due to publication bias: evidence found of trials that have never been published that record this outcome.

fDowngraded once due to risk of bias: high or unclear risk of selective reporting bias and poor reporting of this outcome measure had a large effect on numbers analysed.

gDowngraded twice due to imprecision: trial size small, new trial evidence likely to change result.

howngraded once due to imprecision: trial size small, new trial evidence likely to change result.

Summary of findings 2. Botulinum toxin type A compared to other established prophylactic agent for the prevention of migraine in adults

\section{Botulinum toxin type A compared to other established prophylactic agent for the prevention of migraine in adults}

Patient or population: adults with migraine

Setting: outpatient clinic

Intervention: botulinum toxin type A

Comparison: other established prophylactic agent

\begin{tabular}{|c|c|c|c|c|c|}
\hline Outcomes & $\begin{array}{l}\text { Result with other estab- } \\
\text { lished prophylactic agent }\end{array}$ & $\begin{array}{l}\text { Result with botulinum } \\
\text { toxin type } A\end{array}$ & $\begin{array}{l}\text { Relative effect } \\
(95 \% \mathrm{CI})\end{array}$ & $\begin{array}{l}\text { № of participants } \\
\text { (trials) }\end{array}$ & $\begin{array}{l}\text { Quality of the evi- } \\
\text { dence } \\
\text { (GRADE) }\end{array}$ \\
\hline $\begin{array}{l}\text { Number of migraine days per month: } \\
\text { chronic migraine only }\end{array}$ & \multicolumn{2}{|c|}{$\begin{array}{l}\text { One trial using topiramate in its comparison arm reported } \\
\text { narratively on this outcome stating that there was no signifi- } \\
\text { cant difference between groups. }\end{array}$} & - & $\begin{array}{l}43 \\
(1 \mathrm{RCT})\end{array}$ & $\begin{array}{l}\oplus \ominus \Theta \Theta \\
\text { Very lowa,b,c }\end{array}$ \\
\hline Number of headache days per month & $\begin{array}{l}\text { The mean number of } \\
\text { headache days was } 6.6 \text { days }\end{array}$ & $\begin{array}{l}\text { MD } 1 \text { day lower } \\
\text { ( } 4.3 \text { lower to } 2.3 \text { higher) }\end{array}$ & - & $\begin{array}{l}59 \\
(1 \mathrm{RCT})\end{array}$ & $\begin{array}{l}\oplus \ominus \ominus \ominus \\
\text { Very lowa,b }\end{array}$ \\
\hline $\begin{array}{l}\text { Number of migraine attacks per } \\
\text { month }\end{array}$ & - & - & - & - & - \\
\hline
\end{tabular}




\begin{tabular}{|c|c|c|c|c|c|c|}
\hline 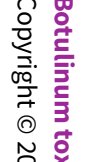 & $\begin{array}{l}\text { Headache intensity measure } \\
\text { assessed with } 5 \text {-point scale, } 5 \text { being } \\
\text { severe, } 1 \text { being mild: chronic migraine } \\
\text { only }\end{array}$ & $\begin{array}{l}\text { The mean severity of mi- } \\
\text { graine was } 2.3 \text { points }\end{array}$ & $\begin{array}{l}\text { MD } 0.4 \text { points lower } \\
\text { ( } 0.79 \text { lower to } 0.01 \text { lower) }\end{array}$ & - & $\begin{array}{l}46 \\
(1 \mathrm{RCT})\end{array}$ & $\begin{array}{l}\oplus \odot \Theta \odot \\
\text { Very lowa,b }\end{array}$ \\
\hline 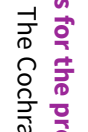 & $\begin{array}{l}\text { Global impression of disease } \\
\text { assessed with Migraine impact and } \\
\text { disability assessment scores }\end{array}$ & $\begin{array}{l}\text { The mean global impression } \\
\text { of disease ranged from } 9.8 \text { to } \\
16.5 \text { points }\end{array}$ & $\begin{array}{l}\text { MD } 4.3 \text { points higher } \\
\text { ( } 28 \text { lower to } 37 \text { higher) }\end{array}$ & - & $\begin{array}{l}101 \\
\text { (2 RCTs) }\end{array}$ & $\begin{array}{l}\oplus \ominus \ominus \ominus \\
\text { Very lowa,b }\end{array}$ \\
\hline$\stackrel{z}{=}$ & Total number of participants experi- & Trial population & & RR 0.76 & 114 & $\oplus \ominus \ominus \ominus$ \\
\hline 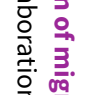 & & 862 per 1000 & $\begin{array}{l}724 \text { per } 1000 \\
(319 \text { to } 1000)\end{array}$ & & & \\
\hline
\end{tabular}

Cl: confidence interval; MD: mean difference; $\mathbf{R C T}$ : randomised controlled trial; $\mathbf{R R}$ : risk ratio

\section{GRADE Working Group grades of evidence}

High quality: we are very confident that the true effect lies close to that of the estimate of the effect.

Moderate quality: we are moderately confident in the effect estimate: the true effect is likely to be close to the estimate of the effect, but there is a possibility that it is substantially different.

Low quality: our confidence in the effect estimate is limited: the true effect may be substantially different from the estimate of the effect.

Very low quality: we have very little confidence in the effect estimate: the true effect is likely to be substantially different from the estimate of effect.

aDowngraded once due to risk of bias: unclear or high risk for selection, performance, detection and attrition bias.

bDowngraded twice due to imprecision: trial sizes small, new trial evidence likely to change result.

cDowngraded once due to imprecision: narrative description only. 


\section{B A C K G R O U N D}

\section{Description of the condition}

Migraine is a common headache disorder affecting around 15\% of adults (GBD 2016; Stovner 2010; Victor 2010), 75\% of sufferers are female (Lipton 2007). It is ranked as the seventh most disabling disease amongst all diseases globally (GBD 2016), causing significant morbidity and considerable negative impact on sufferers' quality of life (Bigal 2008). As a result, migraine has a major economic impact through days lost from work and other activities of daily living (Linde 2012). Table 1 illustrates the current descriptions and diagnostic criteria for migraine and its two subtypes, migraine without aura and migraine with aura. Migraine can be categorised as chronic or episodic and these terms are commonly used in eligibility criteria for clinical trials and systematic reviews. Diagnostic criteria for chronic migraine do, however, remain controversial. Chronic migraine was not defined in the First Edition of The International Headache Classification (ICHD-I) (IHS 1988) and first appeared in the Second Edition (ICHD-II) (IHS 2004), which described chronic migraine as migraine headache occurring on at least 15 days per month for more than three months in the absence of medication overuse headache. This definition was revised in the recent Third Edition (ICHD-III) to state that individuals must have headache for at least 15 days per month with migraine features on eight of those days (IHS 2013). Full definitions and diagnostic criteria for the various editions are given in Table 1. Episodic migraine is commonly used to describe people with symptoms of migraine who have fewer than 15 headache days per month. ICHD-III refers to episodic migraine as a term to be used for migraine that is not covered by the definition of chronic migraine (IHS 2013).

Medication overuse headache is an interaction between a therapeutic agent used excessively and a susceptible person (IHS 2004; IHS 2013). Chronic migraine can often be the pre-existing disorder in people with medication overuse headache, and the relationship between the two diagnoses has also altered between publication of ICHD-II where medication overuse headache first appeared, and ICHD-III. For a diagnosis of medication overuse headache prior to the publication of ICHD-III, the withdrawal of medications for a period of two months was required and only then with a resultant reduction in headache days could a diagnosis of medication overuse headache be suggested. People at this time would not have been given the dual diagnoses of medication overuse headache and chronic migraine. With the publication of ICHD-III, it was acknowledged that this was a somewhat artificial separation and people with symptoms of both medication overuse headache and chronic migraine were given both diagnoses. Two large trials of botulinum toxin for chronic migraine, which have influenced licensing of botulinum toxin for migraine, have included individuals with medication overuse headache (Aurora 2010; Diener 2010). As a result of these intricacies, exclusion of people with medication overuse headache from the migraine population under consideration in this review is difficult and impractical.

For the purposes of this review, the terms chronic migraine and medication overuse headache refer to the definitions that were in use at the time of publication of the particular trial under discussion.

\section{Description of the intervention}

Botulinum toxin is a natural product synthesised by an anaerobic bacterium Clostridium botulinum. It is responsible for the food poisoning disease botulism. Different strains of Clostridium botulinum produce seven distinct sero-types of botulinum neurotoxin that are labelled A through to $G$. These potent neurotoxins are metalloproteases that block the release of acetylcholine at the neuromuscular junction though the cleavage of different peptide bonds that are crucial components in synaptic vesicle membrane fusion. The resulting impairment of neuromuscular transmission causes a flaccid paralysis (Brin 2002). As a result clinical use of botulinum toxin, for conditions involving excessive muscle contractions, began in the early 1980s. It has become the first line therapy for many conditions including dystonia, spasticity, hyperhidrosis and some forms of bladder disturbance. Since then, botulinum toxin has been seen to have pain relieving properties in excess of what might be expected due to the relief of muscle contractions and its use for the treatment of migraine has developed (Aoki 2005). For treating migraine, botulinum toxin is administered by intramuscular injection to multiple sites around the head and back of the neck with regular retreatment required.

The United States Food and Drug Administration (FDA) assigns official names to subsequent versions of biopharmaceutical products made by different manufacturers to reflect the sensitivity of such drugs to changes in the manufacturing process (Table 2). Not only will there be variation in the diffusion profiles and properties between the various sero-types of botulinum toxin but also between the different preparations from numerous manufacturers within sero-types.

One preparation of botulinum toxin, onabotulinum toxin A (Botox), has recently been licensed in the USA and the UK as an agent for the prevention of chronic migraine (at least 15 migraine days per month) on the basis of two large randomised, placebo-controlled trials (Aurora 2010; Diener 2010). The recommended reconstituted dose is 155 to 195 units, administered intramuscularly as $0.1 \mathrm{~mL}$ (5 units) injections to between 31 and 39 sites around the head and back of the neck (NICE 2012a).

\section{How the intervention might work}

The mechanism by which pain in migraine is generated is not fully understood. It is commonly thought that noxious stimuli lead to the release of calcitonin gene-related peptide and substance $P$ by trigeminal peripheral nerve endings. Release of these peptides causes meningeal vasodilation resulting in stimulation of the meningeal sensory nerves and activation of trigeminovascular pathways, which in turn lead to self-sustained central sensitisation (Goadsby 2002; Pietrobon 2005).

Botulinum toxin has been reported to alleviate pain in a variety of conditions, but the mechanism of action is not well understood. It has been postulated that botulinum toxin acts to reduce pain by inhibiting the release of neuropeptides such as calcitonin generelated peptide and substance $P$, involved in the initiation of migraine (Aoki 2005; Cui 2004). Soluble N-ethylmaleimide-sensitive fusion protein attachment protein receptor (SNARE) complexes are involved in mechanotransduction of noxious stimuli (Table 1). It is thought that botulinum toxin may act to prevent migraine through cleavage of synaptosomal-associated protein 25 (SNAP-25), one of 
the SNARE-complex proteins, impairing synaptic vesicle fusion and release of neurotransmitters involved in pain sensitivity (Burstein 2014; Paterson 2014).

This inhibitory effect of botulinum toxin on pain sensation is supported by clinical observations in the treatment of peripheral neuropathy (Ranoux 2008; Yuan 2009), cervical dystonia (Jankovic 1990), chronic tennis elbow (Hayton 2005; Keizer 2002; Wong 2005), and myofascial pain (Cherkin 1998; Porta 2000; Smith 2002). It is reported that the mechanism of action of the various sero-types and preparations of botulinum toxin are similar and they are all capable of blocking the release of neurotransmitters (Aoki 2005).

\section{Why it is important to do this review}

Attempts to reduce the frequency and severity of migraine with daily agents have had mixed results (Linde 2004; Linde 2013a; Linde 2013b; Linde 2013c; Linde 2013d). Recently, two positive placebo-controlled trials of Botox in chronic migraine have been published (Aurora 2010; Diener 2010). These results and the subsequent licensing of Botox for the preventative treatment of chronic migraine were in contrast with previous trials including people with episodic migraine, which showed no effect (Aurora 2007; Cady 2008; Vo 2007). Cost of treatment and administration of botulinum toxin in the UK is around 25 times higher than usual migraine doses of propranolol and 15 times that of topiramate, the two first line treatments for the prevention of migraine as recommended by treatment guidelines (BMA/RPS 2014; NICE 2012a; NICE 2012b). Therefore, a systematic review and metaanalysis of the full literature was needed to inform patient choice and clinical practice.

An important consideration in assessing the literature surrounding this question will be the effect of including evidence from small trials. Small trials are prone to bias and random chance effects due to small amounts of data, especially in pain (Dechartres 2013; Nguyen 2017; Nüesch 2010). In this review we have addressed these potential problems by including size as a parameter in our assessment of bias, carrying out a sensitivity analysis of the effect of small trials on the pooled estimate of effect for the primary outcome measure and also by considering the extent to which small trials have contributed to the final estimate when discussing other outcome measures.

\section{OB JECTIVES}

To assess the effects of botulinum toxins versus placebo or active treatment for the prevention or reduction in frequency of chronic or episodic migraine in adults.

\section{METHODS}

\section{Criteria for considering studies for this review}

\section{Types of studies}

We considered all prospective, randomised and quasi-randomised, double-blind, controlled trials of all sero-types of botulinum toxin. We included all identified trials of this type irrespective of their publication status.

\section{Types of participants}

Participants:
- 18 years of age and over;

- suffering from migraine as defined by any edition of the International Headache Society criteria (IHS 1988; IHS 2004; IHS 2013), or meeting reasonable criteria designed to distinguish between migraine and tension-type headache. People with both chronic and episodic migraine were included in this review.

Use of botulinum toxin is currently recommended by the National Institute for Health and Care Excellence for chronic migraine only, despite the fact that the definition of chronic migraine remains controversial and is still evolving. In order to assess the effectiveness of botulinum toxin in migraine sufferers, we did not restrict our inclusion criteria to an arbitrary 15 migraine days per month cut-off point, but we have acknowledged these clinically useful definitions using subgroup analysis to determine levels of effectiveness for the different diagnoses. We did not exclude medication overuse headache or those without two months' withdrawal of headache medications, as these types of participants have been included in large and prominent trials in this area. To address the inconsistent eligibility criteria for trial participants across the available evidence, we attempted to assess the effectiveness of botulinum toxin on migraine participants with or without medication overuse headache as described in our data analysis.

\section{Types of interventions}

Injections of botulinum toxin (any sero-type) into head and neck muscles compared with placebo injections, active preventative agent or the same drug treatment with a different dose. We also included trials allowing the use of concomitant preventative or rescue treatment.

We made a note of whether rescue medications for acute migraine or concomitant medications for the prevention of migraine were permitted.

\section{Types of outcome measures}

\section{Primary outcomes}

- Number of migraine days per month (frequency with which exclusively migraine-type headaches are experienced).

\section{Secondary outcomes}

- Number of headache days per month (frequency with which any type of headache inclusive of migraine headache are experienced).

- Number of migraine attacks per month (frequency with which exclusively migraine-type attacks are experienced).

- Headache intensity measures, usually reported as migraine 'severity', measured on verbal or numerical scale.

- Headache index, measured using headache intensity score multiplied by time spent with migraine.

- Duration of migraine (hours).

- Use of rescue medication (number of days on which rescue medication is used per month or number of instances of taking any type/dose of rescue medication per month).

- Patient and clinician global impression scales.

- Generic and disease-specific quality-of-life rating scales (e.g. Headache Impact Test, Migraine Specific Quality of Life). 
- Cost effectiveness measured using incremental cost effectiveness ratio or cost per headache day avoided.

- Adverse events: we considered the following ways of recording adverse events, listed in preferred order:

- total number of participants experiencing any type of adverse event;

- total number of participants experiencing the specific adverse event types; blepharoptosis, muscle weakness, neck pain and injection site pain;

- total number of participants experiencing a treatmentrelated adverse event, as determined by trial investigators;

- withdrawals due to adverse events.

\section{Search methods for identification of studies}

\section{Electronic searches}

To identify trials for inclusion in this review, we developed detailed search strategies for each electronic database searched. These were based on the search strategy developed for MEDLINE, but revised appropriately for each database. The search strategies can be found in Appendix 1.

Our search strategy combined the subject search with the appropriate trial design filter as described in the Cochrane Handbook of Systematic Reviews of Interventions (Lefebvre 2011). The subject search involved a combination of controlled vocabulary and free-text terms. We did not add any language or date restrictions.

We carried out a systematic search of the literature to identify publications or abstracts describing relevant trials. This included searching the following databases:

- Cochrane Central Register of Controlled Trials (CENTRAL; 2017, Issue 12) via the Cochrane Register of Studies Online (CRSO), 7 December 2017;

- MEDLINE and MEDLINE in Process (via OVID) 1946 to 7 December 2017;

- Embase (via OVID) 2017 week 49.

\section{Searching other resources}

We searched the following trials registers for ongoing trials:

- The World Health Organization's International Clinical Trials Registry Platform (ICTRP)(www.who.int/ictrp/en/);

- ClinicalTrials.gov (clinicaltrials.gov/).

In addition, we screened reference lists of relevant review articles and included trial reports for additional trials; and we performed citation searches on key articles.

We contacted relevant manufacturers for unpublished trial data and additional information. Initial contact was made by email to research and development contact addresses available online; if no response was received within two weeks, we sent a follow-up letter by post requesting information. Our final contact was made by email, after a further four weeks without response, stating parties will have the opportunity to contribute to the review before a given date two weeks from the time of the email. If no information or communication indicating an intention to provide trial data was received by the stated date, we listed manufacturers as 'contacted without response'. Correspondence contained full contact details, email, postal address and telephone numbers for two authors (CPH and CEC), as well as details of the scope of the review and a data extraction form. We listed the types of information and data needed in the letter/email and referred to the data extraction form to be used as an aid or filled in directly as desired. We contacted trial authors in a similar manner where necessary for additional information. We made this contact twice by email stating a final date for contributing to the review in the second attempt: if no response was received by this date we listed trial authors as 'contacted without response'; where no contact details were available we listed trial authors as 'uncontactable'.

\section{Data collection and analysis}

\section{Selection of studies}

One author ( $\mathrm{CPH}$ ) considered all abstracts identified by the search, and three other authors (CLT, CR and AS) independently repeated this initial screening process in sections. We retrieved trial reports that appeared to qualify for inclusion in the review or for which insufficient information had been given in the abstract to allow proper assessment of eligibility. Two authors (CPH and CEC) independently assessed the trial reports for inclusion and these two authors decided separately whether each trial met the inclusion criteria. We made contact with trial authors for clarification where necessary. When information pertaining to the eligibility criteria was not provided in the available full-text articles and could not be obtained from trial authors, we excluded the trials from this review.

If the search strategy identified abstracts for which no full report could be obtained, we assessed these for inclusion. If they included only partial results of ongoing trials or contained insufficient information on the trial design or results, we listed these under trials awaiting classification.

We completed a PRISMA study flow diagram (Moher 2009) to document the screening process as recommended in the Cochrane Handbook for Systematic Reviews of Interventions (Schünemann 2011).

\section{Data extraction and management}

Six review authors ( $\mathrm{CH}, \mathrm{CLT}, \mathrm{CR}$, WS, CEC and $\mathrm{AS}$ ) were involved in independently extracting data in duplicate from all included trials. If disagreements occurred, a third review author considered the available information or if necessary we contacted the trial authors for clarification. We also attempted to contact trial authors where information required for data analysis or quality assessment of a trial was not reported. We collated multiple reports of the same trial into single trials. We extracted data onto electronic forms based on the template provided by Cochrane Pain, Palliative and Supportive Care, which we customised for this review according to the guidelines stated in the Cochrane Handbook for Systematic Reviews of Interventions (Higgins 2011a).

Trial length and time points for recording of outcome measures were likely to be variable. We standardised the unit over which headache diary data were measured at 28 days (four weeks) when possible. We used data from the 12 week time point following final treatment to maximise the likelihood of observing a real treatment effect. 
For continuous outcomes, we used change in group means, as these adjust for imbalances in the baseline scores. We used these values if they were given in the trial paper or we calculated them from mean pre-treatment and mean post-treatment scores. If change scores were not available, we used post-treatment (endpoint) means, assuming that baseline data would be balanced due to randomisation. We checked this assumption by sensitivity analysis for the primary outcome measure.

For the dichotomous outcome, proportion of responders, we considered a participant with a reduction in number of headaches of at least $50 \%$ to be a responder and a participant with less than $50 \%$ reduction in headache to be a non-responder. We intended to set out clinically significant thresholds for other outcome measures as the collected data required it; this was not required in the current version of the review but we will consider this approach for future updates.

For each trial, we recorded the proportion of participants reporting any adverse events in each arm, as well as numbers reporting blepharoptosis, muscle weakness, neck pain and injection site pain.

\section{Assessment of risk of bias in included studies}

All review authors were involved in independently assessing risk of bias in the included trials in duplicate using the criteria outlined in the Cochrane Handbook for Systematic Reviews of Interventions (Higgins 2011b) and guidelines from Cochrane Pain, Palliative and Supportive Care. We resolved any disagreements through discussion.

We assessed the following domains for each trial.

- Random sequence generation (checking for possible selection bias):

* we assessed the method used to generate the allocation sequence as: low risk of bias (any truly random process, e.g. random number table; computer random number generator); unclear risk of bias (method used to generate sequence not clearly stated); high risk of bias (trials using a non-random process (e.g. odd or even date of birth; hospital or clinic record number).

- Allocation concealment (checking for possible selection bias):

* the method used to conceal allocation to interventions prior to assignment determines whether intervention allocation could have been foreseen in advance of, or during recruitment, or changed after assignment. We assessed the methods as: low risk of bias (e.g. telephone or central randomisation; consecutively numbered, sealed, opaque envelopes); unclear risk of bias (method not clearly stated); high risk of bias (trials that do not conceal allocation (e.g. open list).

- Blinding of participants and personnel (checking for possible performance bias):

* we assessed the methods used to blind trial participants and personnel from knowledge of which intervention they received. We assessed the methods as: low risk of bias (trial states that it was blinded and describes the method used to achieve blinding, such as identical tablets matched in appearance and smell or a double dummy technique); unclear risk of bias (trial states that it was blinded but does not provide an adequate description of how blinding was achieved). We excluded trials that were not double-blind.

- Blinding of outcome assessment (checking for possible detection bias):

* we assessed the methods used to blind trial participants and outcome assessors from knowledge of which intervention a participant received. We assessed the methods as: low risk of bias (trial has a clear statement that outcome assessors were unaware of treatment allocation, and ideally describes how this was achieved); unclear risk of bias (trial states that outcome assessors were unaware of treatment allocation but does not provide an adequate description of how blinding was achieved). We excluded trials that were not double-blind.

- Incomplete outcome data (checking for possible attrition bias due to the amount, nature and handling of incomplete outcome data):

* we assessed the methods used to deal with incomplete data as: low risk ( $<10 \%$ of participants did not complete the trial and/or used 'baseline observation carried forward' analysis); unclear risk of bias (used 'last observation carried forward' analysis); high risk of bias (used 'completer' analysis).

- Selective reporting (checking for possible reporting bias)

* we assessed the likelihood that a subset of original variables had been selected for publication, based on results, as: low risk (protocol available and all outcomes reported or all reasonable expected outcomes reported); unclear risk (insufficient information available to make a judgement); high risk (protocol available and some outcomes not reported or obvious expected outcomes missing).

- Size of trial (checking for possible biases confounded by small size):

* we assessed trials as being at low risk of bias $(\geq 200$ participants per treatment arm); unclear risk of bias (50 to 199 participants per treatment arm); high risk of bias $(<50$ participants per treatment arm).

\section{Measures of treatment effect}

We used risk ratios (RRs) as the preferred statistical output for dichotomous outcomes, with 95\% confidence intervals (Cls). Where possible, we also provided number needed to treat for an additional beneficial outcome (NNTB) and the number needed to treat for an additional harmful outcome (NNTH), also with 95\% Cls.

For continuous data, we used mean differences (MDs) with 95\% $\mathrm{Cls}$. We considered results with $\mathrm{P}$ values lower than 0.05 to be statistically significant.

\section{Unit of analysis issues}

\section{Cluster-randomised trials}

Where trials employed 'cluster randomisation' techniques, we intended to carry out analysis at the allocation level as described in the Cochrane Handbook for Systematic Reviews of Interventions (Higgins 2011c). By this method, the number randomised would be reduced to the number of centres rather than the number of individuals included in the trial and consequently there would be a reduction in power for any trials that had adopted a cluster design. We did not identify any cluster-randomised trials but will consider these methods for future updates. 


\section{Cross-over trials}

As a carry-over effect from treatment with botulinum toxin cannot be ruled out, we sought data from the first phase for any cross-over trials identified.

\section{Trials with multiple treatment group}

We included relevant trials with multiple treatment arms, but we extracted and included only data from those arms that fulfilled the criteria for this review.

\section{Dealing with missing data}

When data were found to be missing or inadequate, we attempted to contact trial authors and obtain these data.

\section{Assessment of heterogeneity}

Four review authors (CH, CR, CEC and AS) assessed trial baseline characteristics to identify clinical heterogeneity during the extraction of trial information. If we confirmed clinical homogeneity and the review authors considered trials eligible for a certain comparison to be methodologically similar, we carried out metaanalysis of the data. We tested for statistical homogeneity of pooled estimates of effectiveness using the $\mathrm{Chi}^{2}$ test and the $\mathrm{I}^{2}$ statistic (Higgins 2003), for which a statistically significant ( $P$ value $\leq 0.1$ ) value of the $\mathrm{Chi}^{2}$ test together with $\mathrm{I}^{2}$ value of at least $50 \%$ indicates heterogeneity. In cases where statistical heterogeneity existed, we investigated possible causes and we have listed them in the Discussion section of this review.

\section{Assessment of reporting biases}

We considered the use of funnel plots to assess the risk of publication bias but did not carry them out. We made this decision because of the small number of trials included in the individual meta-analyses and the true heterogeneity in the trial design (dose, injection paradigm) and populations studied (migraine subclassifications), which would make it impossible to draw useful conclusions from the plots.

\section{Data synthesis}

We intended to use a fixed-effect model as our preferred model for meta-analyses, but the clinical heterogeneity present in doses, injection sites and participant populations meant that a randomeffects model was more appropriate. Our primary analysis was grouped according to the type of treatment arms used and for each outcome, and a separate forest plot was planned for the following comparisons:

- botulinum toxin versus placebo;

- botulinum toxin versus botulinum toxin with clinically relevant different dose;

- botulinum toxin versus other agent for the prevention of migraine;

- botulinum toxin with other agent for the prevention of migraine versus other agent for the prevention of migraine.

Within these comparisons, we split data into migraine classification subgroups in order to show results for chronic migraine, episodic migraine and a mixed group, for which the diagnosis could not be split. When a multi-arm trial contributed several comparisons to a meta-analysis, we divided the shared control or intervention group evenly among the comparisons. For dichotomous outcomes we split both the number of events and the total number of participants and rounded them up to the nearest integer value. For continuous outcomes, we split the number of participants in the same way but entered the mean and standard deviation unchanged in both comparisons.

\section{'Summary of findings' table}

We created two 'Summary of findings' tables to give an overview of the outcomes of interest for all included trials with data available. In order to help the readers to understand the review's primary outcomes, we discuss the clinical relevance of any statistically significant outcomes using published minimally clinically important change data where available.

We assessed the validity of our findings as well as the level of confidence suitable to any estimates of effect generated by our analyses using the GRADE approach (Guyatt 2008). We imported data from Review Manager 5 (RevMan 5) (RevMan 2014) into GRADE profiler (GRADEpro GDT 2015) to create 'Summary of findings' tables, which comprise outcome-specific information on the overall quality of the evidence and representations of the anticipated absolute effects of the intervention. We included the following outcomes:

- number of migraine days;

- number of headache days;

- number of migraine attacks;

- migraine severity measured on $10 \mathrm{~cm}$ VAS;

- global impression scales measured using Headache Impact Test-6 question version (HIT-6) or MIDAS;

- total number of participants experiencing an adverse event.

The evidence level for all outcomes was high quality to start with, as all included trials were randomised controlled trials. We downgraded the evidence by one level for serious (or by two for very serious) trial limitations (risk of bias), unexplained inconsistency of results, indirectness (population, outcome or intervention), imprecision of data or risk of publication bias. We planned to upgrade outcomes by one level if there had been evidence of a large effect or a dose-response relationship.

\section{Subgroup analysis and investigation of heterogeneity}

A number of differences in trial designs were likely to cause heterogeneity in our meta-analyses and we planned the following subgroup analyses to test for variation in effect:

- trials including medication overuse headache versus trials excluding people with this diagnosis;

- different sero-types of botulinum toxin (e.g. A versus B) and within sero-types (Dysport versus Botox);

- different types of agents for the prevention of migraine versus botulinum toxin;

- accepted and licensed 31 injection pattern versus other injection patterns used.

At least two trials and 200 participants per group were required for any particular subgroup analysis to be carried out. 


\section{Sensitivity analysis}

We carried out sensitivity analyses for our primary outcome only. We planned to test the effect of the changing definitions used for classification of migraine as chronic or episodic by reclassifying participants, if possible, using current guidelines and re-analysing the data. We planned to test the use of post-treatment means, for which the assumption is made that baselines are balanced by randomisation, if this type of data are identified and used in any meta-analyses. Some issues can only be identified as decisions are made throughout the review process and we had planned additional sensitivity analyses, as required, as a result of the individual peculiarities of the trials under investigation
(Deeks 2011). Prevailing evidence suggests that smaller trials are more likely to report stronger effect estimates than large trials (Dechartres 2013; Nüesch 2010). To assess whether these stronger effect estimates reflected the true treatment effect we carried out a sensitivity analysis in which we examined the effect of removing trials at high risk of bias from trial size.

\section{RES U LTS}

\section{Description of studies}

\section{Results of the search}

See Figure 1: PRISMA flow chart. 
Figure 1. Study flow diagram

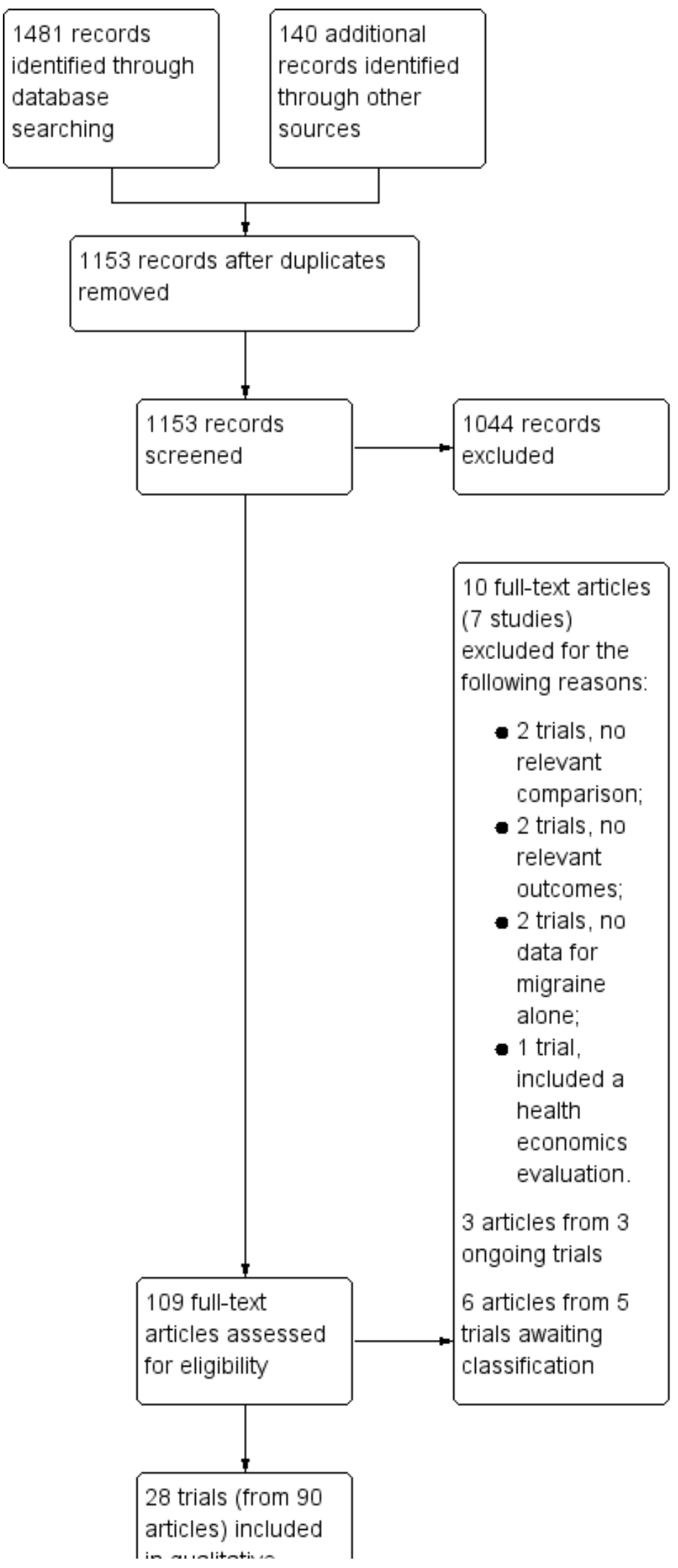


Figure 1. (Continued)

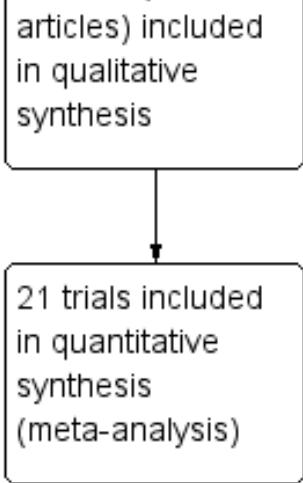

In December 2017, we searched electronic databases and trials registers and identified 1481 records. In addition, we obtained 140 records from other sources. After removal of duplicates, 1153 records remained and we screened these for inclusion. We considered full-text articles for 109 records to determine eligibility. From these we found 28 trials, from 90 associated articles, eligible for inclusion in this review and an additional three ongoing trials, which we believe will qualify for inclusion in this review once the trials are completed.

\section{Included studies}

The main features of the 28 trials included in this review are presented in the Characteristics of included studies tables.

Full publications for three of these trials are still pending and therefore only limited information was available (Allergan 2015; Jabbari 2014; Mazza 2016). Of the remaining 25 trials, all but one cited the International Headache Society (IHS) criteria for diagnosing migraine (Lauretti 2014). Pregnancy or unwillingness to prevent pregnancy during the trial period was stated by 21 of these trials as an exclusion criteria (Anand 2006; Aurora 2007; Aurora 2010; Barrientos 2003; Blumenfeld 2008; Blumenkron 2006; Cady 2008; Cady 2011; Cady 2014; Diener 2010 (PREEMPT 2); Elkind I 2006; Elkind II 2006; Freitag 2008; Hou 2015; Jabbari 2014; Jost 2011; Mathew 2009; Millán-Guerrero 2009; Relja 2007; Saper 2007; Silberstein 2000), and pregnancy in the remaining trials was not reported.

There was a small amount of variation between trials in the diary period over which number of migraines and duration outcomes were recorded. This ranged from 28 days to 30 days and some trials stated that they used a period of one month with no clarification on the exact number of days this represented. We considered making attempts to convert all diary outcomes to a period of 28 days but this was not possible without individual participant data. The diary periods stated by each trial are given in the notes sections of the Characteristics of included studies table.

Adverse events were reported over the full follow-up period of the trials, which ranged from four weeks to nine months with some using a single treatment and some giving multiple treatments at 12 -week intervals. Adverse events that would be captured by the follow-up periods used in our included trials would likely occur shortly after treatment had taken place and we therefore aggregated all available data for each of these outcomes on to single forest plots.
Funding for 16 of the trials (involving $85 \%$ of the trial participants) was provided by the manufacturer of the botulinum toxin product under investigation (Allergan 2015; Aurora 2007; Aurora 2010 (PREEMPT 1); Barrientos 2003; Blumenfeld 2008; Cady 2008; Chankrachang 2011; Diener 2010 (PREEMPT 2); Elkind I 2006; Elkind II 2006; Freitag 2008; Mathew 2009; Petri 2009; Relja 2007; Saper 2007; Silberstein 2000). Eight trials did not declare the source of their trial funding (Anand 2006; Blumenkron 2006; Cady 2011; Cady 2014; Jabbari 2014; Lauretti 2014; Mazza 2016; Millán-Guerrero 2009). The remaining four stated that they received funding from alternative sources.

\section{Participants}

Trials investigating botulinum toxin that were eligible for inclusion in this review randomised a total of 4190 participants. The average age of participants was 42 years, excluding three trials that failed to provide this information (Anand 2006; Blumenkron 2006; Mazza 2016). Only one trial did not provide information about the gender of its 94 participants (Mazza 2016). All trials that reported male to female ratios were dominated by female participants with the single exception of Jabbari 2014, which had 12 female and 13 male participants. Overall $85 \%$ (3491) of the trial participants were women. Baseline disease characteristics were not well reported and were given in varying formats. The ratio of chronic to episodic migraine sufferers was not reported by six trials involving 390 participants (Blumenkron 2006; Cady 2008; Chankrachang 2011; Jost 2011; Millán-Guerrero 2009; Vo 2007); for the remaining trials, the overall ratio was $1872 / 1928$. Due to the inclusion of chronic and episodic migraine populations in this review, the frequency and severity of migraines in the trial populations, when reported, showed a wide variation between trials. Such variation makes reporting of a meaningful point estimate or range summarising all trials impossible. Disease characteristics for individual trials are given in the 'Characteristics of included studies' tables and are discussed within individual outcome sections when relevant. People with medication overuse headache were excluded from 13 trials (Anand 2006; Aurora 2007; Barrientos 2003; Blumenfeld 2008; Cady 2011; Elkind I 2006; Elkind II 2006; Freitag 2008; Hollanda 2014; Petri 2009; Relja 2007; Saper 2007; Silberstein 2000). Three trials did not exclude people with medication overuse headache (Allergan 2015; Aurora 2010 (PREEMPT 1); Diener 2010 (PREEMPT 2)); the two PREEMPT trials gave the ratio of participants with and without this additional diagnosis; totals were 906/478, but subgroup data were not available from these groups for re-analysis in this review. One trial included only participants who were overusing acute 
medications (Millán-Guerrero 2009). The remaining 11 trials did not consider medication overuse in their eligibility criteria. The available evidence was therefore not sufficient for investigation of the effect of botulinum toxin on the medication overuse headache subgroup.

\section{Interventions and controls}

See Table 2 for details of the botulinum toxin products. Botox is the only licensed botulinum toxin product for use in chronic migraine.

Twenty-eight trials compared botulinum toxin with matched placebo injections or active control; of these, 21 had at least one arm treated with the Botox formulation (Allergan 2015; Anand 2006; Aurora 2007; Aurora 2010 (PREEMPT 1); Barrientos 2003; Blumenfeld 2008; Blumenkron 2006; Cady 2008; Cady 2011; Diener 2010 (PREEMPT 2); Elkind I 2006; Elkind II 2006; Freitag 2008; Jabbari 2014; Jost 2011; Lauretti 2014; Mathew 2009; MillánGuerrero 2009; Relja 2007; Saper 2007; Silberstein 2000), two used Dysport (Chankrachang 2011; Petri 2009), two used Prosigne (Hollanda 2014; Lauretti 2014) and one, HengLi (Hou 2015). Three trials did not state the brand used, but described the toxin as type $A$ (Cady 2014; Mazza 2016; Vo 2007). The range of doses administered in trials of Botox was 6 units to 300 units, with eight trials using doses lower than 75 units in all treated arms (Anand 2006; Barrientos 2003; Elkind I 2006; Elkind II 2006; Jost 2011; Lauretti 2014; Millán-Guerrero 2009; Saper 2007). The Chankrachang 2011 and Petri 2009 trial publications reported Dysport dose equivalency to be between 2 to 3 units: 1 units Botox, with doses of 80 units up to 240 units in treated arms. HengLi and Prosigne are two botulinum toxin preparations produced by Lanzhou Institute of Biological Products which were studied in three trials with doses ranging from 25 units to 96 units; the trial publications reported a dose equivalency to Botox of approximately 1:1 (Hollanda 2014; Hou 2015; Lauretti 2014).

Injection profiles varied with trials using between 2 and 58 injection sites in varying locations in the head and neck. Four trials used a 'follow the pain' method for injection sites and doses (Blumenfeld 2008; Hollanda 2014; Jost 2011; Mazza 2016), and six used some fixed sites and some optional 'follow the pain' sites/doses (Aurora 2007; Aurora 2010 (PREEMPT 1); Cady 2011; Cady 2014; Diener 2010 (PREEMPT 2); Mathew 2009). The remaining 18 trials adhered to fixed doses and locations of injections for all participants.

Nineteen trials gave a single treatment and the majority followed up participants for three months; exceptions to this were Jabbari 2014, which followed up participants for four weeks only, and Elkind I 2006, Freitag 2008 and Hou 2015, which carried out fourmonth follow-up to treatment. Seven trials (Allergan 2015; Aurora 2010 (PREEMPT 1); Blumenfeld 2008; Diener 2010 (PREEMPT 2); Elkind II 2006; Mathew 2009; Mazza 2016) gave two rounds of treatment, all with three months between treatments and at least three months' follow-up, with the single exception of Elkind II 2006, which had four months between treatments. Two further trials provided three rounds of treatment at months zero, three and six and with assessments carried out to nine months (Aurora 2007; Relja 2007).

Concomitant prophylactic medications at stable doses were permitted during 11 of the included trials (Anand 2006; Aurora 2007;
Cady 2014; Chankrachang 2011; Elkind I 2006; Elkind II 2006; Freitag 2008; Lauretti 2014; Saper 2007; Silberstein 2000; Vo 2007), seven trials did not report on this (Blumenkron 2006; Cady 2008; Cady 2011; Hou 2015; Jabbari 2014; Jost 2011; Mazza 2016), and the remaining ten trials did not allow their use during the trial period. Rescue medications were more commonly allowed. Five trials did not discuss the use of rescue medications during their trial periods (Allergan 2015; Blumenkron 2006; Hou 2015; Jabbari 2014; Jost 2011) but all remaining trials stated that their use was permissible or included use of rescue medications as a trial outcome.

\section{Country and language of publication}

Sixteen trials were conducted in the USA, two each in Brazil (Hollanda 2014; Lauretti 2014), Germany (Jost 2011; Petri 2009) and Mexico (Blumenkron 2006; Millán-Guerrero 2009), and one each in Chile (Barrientos 2003), China (Hou 2015), Europe (Relja 2007), India (Anand 2006), Italy (Mazza 2016) and Thailand (Chankrachang 2011). We identified only one non-English language publication (Blumenkron 2006), which was translated from Spanish to English for inclusion in the review.

\section{Excluded studies}

We excluded seven trials, which are listed in the Characteristics of excluded studies tables. Two trials did not report a relevant comparison (Cady 2012; Schwedt 2007), two trials did not report relevant outcomes (De Tommaso 2016; Guyuron 2005), two trials randomised people with non-migraine headache and investigators were not able or not willing to provide data for migraine-only participants (Evers 2004; Ondo 2004), one health economics paper reported on data taken from published material from a nonassociated trial (Ruggeri 2013).

\section{Trials awaiting classification}

We identified five trials awaiting classification, which are listed in the Characteristics of studies awaiting classification tables. One trial was published as an abstract only, no further information could be gained from the trial authors and there was insufficient information in the abstract to determine eligibility (Brin 2000). Two trials were reported only as protocol/methods papers and we could not locate any reports of trial results (Ipsen 2006; Kuper 2007). Two trials included non-migraine participants and we could not contact the trial authors or they did not respond to requests for migraineonly data (Mathew 2005; Silberstein 2005).

\section{Ongoing trials}

We identified three ongoing trials, which are listed in the Characteristics of ongoing studies tables (NCT02074163; NTR3440; NCT02291380). All three can reasonably be expected to publish in the next one to three years and will be eligible for inclusion in updates of this review.

\section{Risk of bias in included studies}

The overall risk of bias for all 28 included trials is presented graphically in Figure 2. Summary details for each trial are given in the 'Risk of bias' sections of the Characteristics of included studies tables and are illustrated in Figure 3. Of the 28 included trials, 21 had at least one source of bias rated as high risk. 
Figure 2. Risk of bias graph: review authors' judgements about each risk of bias item presented as percentages across all included trials

Random sequence generation (selection bias)

Allocation concealment (selection bias)

Blinding of participants and personnel (performance bias)

Blinding of outcome assessment (detection bias)

Incomplete outcome data (attrition bias)

Selective reporting (reporting bias)

Study size

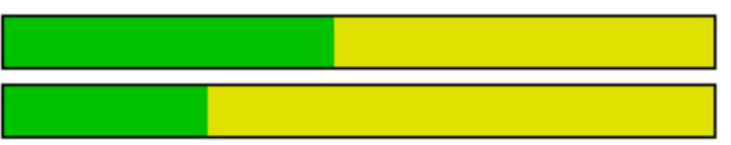

L

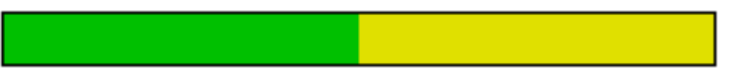

L
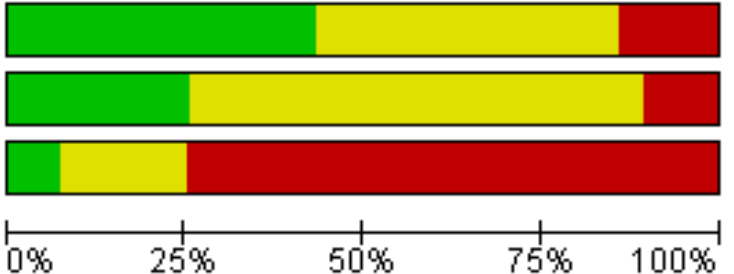

Low risk of bias

Unclear risk of bias

High risk of bias 
Figure 3. Risk of bias summary: review authors' judgements about each risk of bias item for each included trial.

\begin{tabular}{|c|c|c|c|c|c|c|c|}
\hline & 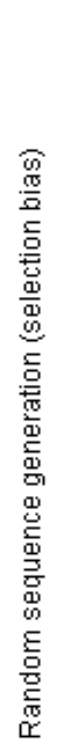 & 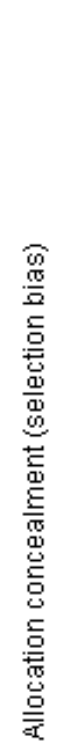 & 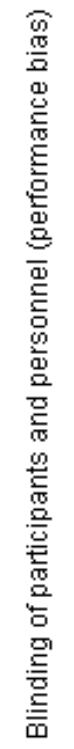 & 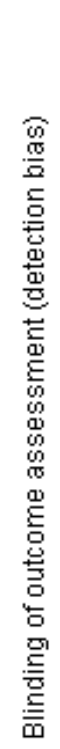 & 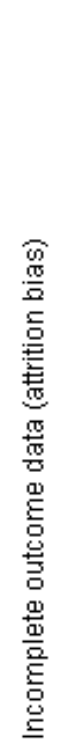 & 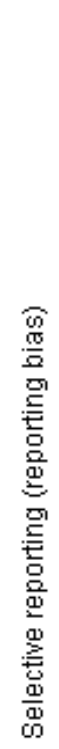 & 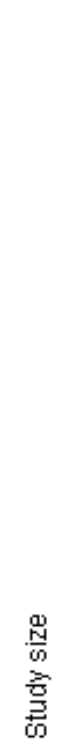 \\
\hline Allergan 2015 & $?$ & $?$ & $?$ & $?$ & $\odot$ & $?$ & 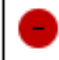 \\
\hline Anand 2006 & $?$ & $?$ & $?$ & $?$ & $\odot$ & $?$ & - \\
\hline Aurora 2007 & $\odot$ & $\odot$ & 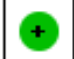 & $\odot$ & $?$ & $?$ & $?$ \\
\hline Aurora 2010 (PREEMPT 1) & $\odot$ & $\odot$ & $\odot$ & $\odot$ & $\odot$ & $\odot$ & $\odot$ \\
\hline Barrientos 2003 & $?$ & $?$ & $?$ & $?$ & $\odot$ & $?$ & - \\
\hline Blumenfeld 2008 & $?$ & $?$ & $?$ & $?$ & $\theta$ & $?$ & - \\
\hline Blumenkron 2006 & $\odot$ & $?$ & $?$ & $?$ & $?$ & $?$ & - \\
\hline Cady 2008 & $?$ & + & $\odot$ & + & $?$ & $?$ & 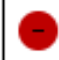 \\
\hline Cady 2011 & $?$ & + & $\odot$ & + & ? & - & - \\
\hline Cady 2014 & $\odot$ & + & + & + & $\odot$ & + & - \\
\hline Chankrachang 2011 & + & + & + & + & $?$ & $?$ & - \\
\hline Diener 2010 (PREEMPT 2) & $\odot$ & + & 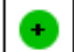 & + & $\odot$ & + & + \\
\hline Elkind I 2006 & $?$ & $?$ & $?$ & $?$ & $\odot$ & $?$ & $?$ \\
\hline Elkind II 2006 & $?$ & $?$ & $?$ & $?$ & $\odot$ & $?$ & $?$ \\
\hline Freitag 2008 & $\odot$ & $?$ & $\odot$ & + & + & + & - \\
\hline Hollanda 2014 & $\odot$ & $?$ & + & + & + & + & 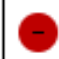 \\
\hline Hou 2015 & + & $?$ & $?$ & + & + & $\theta$ & 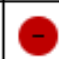 \\
\hline Jabbari 2014 & $?$ & $?$ & $?$ & $?$ & - & $?$ & 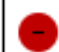 \\
\hline Jost 2011 & $?$ & $?$ & $?$ & $?$ & $?$ & - & 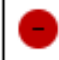 \\
\hline Lauretti 2014 & + & $?$ & + & $?$ & $\odot$ & $?$ & - \\
\hline
\end{tabular}


Figure 3. (Continued)

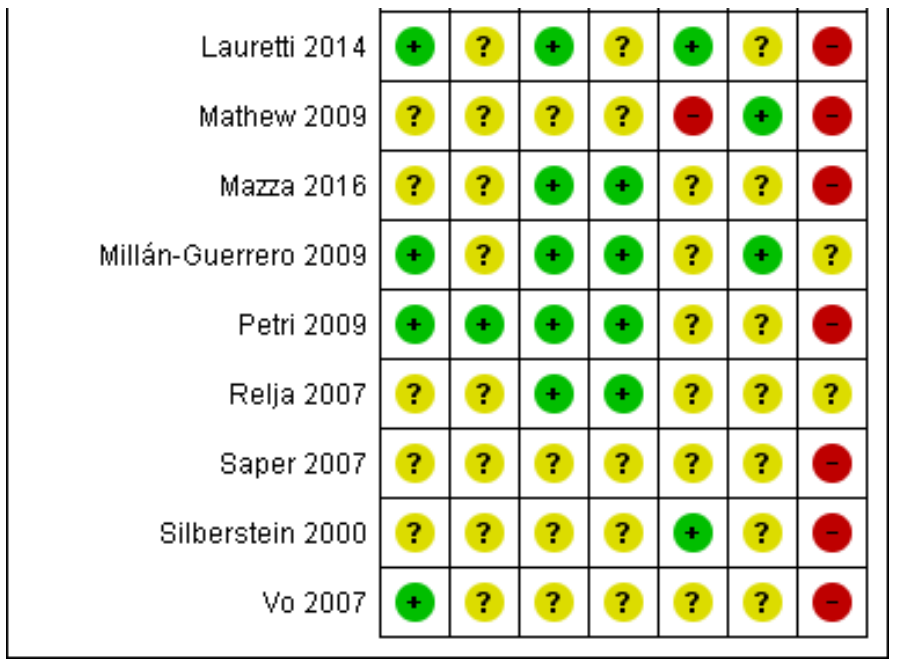

\section{Allocation}

All trials clearly stated that they were randomised, but only 13 gave details, in either published or unpublished materials, of a lowrisk method used to generate the sequence (Aurora 2007; Aurora 2010 (PREEMPT 1); Blumenkron 2006; Cady 2014; Chankrachang 2011; Diener 2010 (PREEMPT 2); Freitag 2008; Hollanda 2014; Hou 2015; Lauretti 2014; Millán-Guerrero 2009; Petri 2009; Vo 2007). The remaining trials did not provide any information from which we could evaluate the method used to randomise participants into their trials and so we judged they were at unclear risk of selection bias.

Eight trials provided adequate details to enable a judgement of a low risk of bias for the concealment of allocation (Aurora 2007; Aurora 2010 (PREEMPT 1); Cady 2008; Cady 2011; Cady 2014; Chankrachang 2011; Diener 2010 (PREEMPT 2); Petri 2009). The remaining 20 gave insufficient or no information and so we judged them to be at unclear risk of bias.

\section{Blinding}

All trials were double-blind. Fourteen trials published information on low-risk methods of blinding participants and personnel, and we judged these to be at low risk of performance bias (Aurora 2007; Aurora 2010 (PREEMPT 1); Cady 2008; Cady 2011; Cady 2014; Chankrachang 2011; Diener 2010 (PREEMPT 2); Freitag 2008; Hollanda 2014; Lauretti 2014; Mazza 2016; Millán-Guerrero 2009; Petri 2009; Relja 2007). The remaining 14 trials gave no details of how they had achieved blinding and we rated them unclear for risk of performance bias.

Fourteen trials gave details of methods used to blind personnel and assessors and we judged these to be at low risk of detection bias (Aurora 2007; Aurora 2010 (PREEMPT 1); Cady 2008; Cady 2011; Cady 2014; Chankrachang 2011; Diener 2010 (PREEMPT 2); Freitag 2008; Hollanda 2014; Hou 2015; Mazza 2016; Millán-Guerrero 2009; Petri 2009; Relja 2007). The remaining fourteen trials gave insufficient details of their methods and we judged them to be unclear for risk of detection bias.

\section{Incomplete outcome data}

Due to large numbers of participants dropping out, we judged four trials to be at high risk of attrition bias (Allergan 2015; Blumenfeld 2008; Jabbari 2014; Mathew 2009). Twelve trials gave sufficient information about dropout rates and imputation methods to be at low risk of attrition bias (Anand 2006; Aurora 2010 (PREEMPT 1); Barrientos 2003; Cady 2014; Diener 2010 (PREEMPT 2); Elkind I 2006; Elkind II 2006; Freitag 2008; Hollanda 2014; Hou 2015; Lauretti 2014; Silberstein 2000). The remaining 12 trials gave insufficient information for conclusions to be drawn and so we judged them to be at unclear risk of attrition bias.

\section{Selective reporting}

Three trials had at least one outcome mentioned in the methods section missing from the reported results and so we judged them to be at high risk of reporting bias (Cady 2011; Hou 2015; Jost 2011). Seven trials clearly reported all recorded outcomes as listed in the protocol or full methods sections and so we judged them to be at low risk of reporting bias (Aurora 2010 (PREEMPT 1); Cady 2014; Diener 2010 (PREEMPT 2); Freitag 2008; Hollanda 2014; Mathew 2009; Millán-Guerrero 2009). We found an unclear risk of reporting bias in the remaining 18 trials due to incomplete or unclear reporting of data or the absence of expected outcomes.

We made attempts to contact all trial authors if we could identify contact information. We contacted trial authors twice by email requesting further data if needed. Only two trials provided additional, unpublished data (Lauretti 2014; Mazza 2016). These remained at unclear risk of selective reporting bias as not all of the required information was provided to allow us to make this judgement.

\section{Other potential sources of bias}

\section{Trial size}

Most trials ( 21 out of 28 ) included in this review had fewer than 50 participants per trial arm, so we considered these trials to be at high risk of bias. Five trials had between 50 and 199 participants per arm and we gave a rating of unclear risk of bias (Aurora 2007; Elkind | 2006; Elkind II 2006; Millán-Guerrero 2009; Relja 2007). Only two trials included more than 200 participants in each arm and could 
be considered to have a low risk of bias from trial size (Aurora 2010 (PREEMPT 1); Diener 2010 (PREEMPT 2)).

\section{Effects of interventions}

See: Summary of findings for the main comparison Botulinum toxin type A compared to placebo for the prevention of migraine in adults; Summary of findings 2 Botulinum toxin type A compared to other established prophylactic agent for the prevention of migraine in adults

We focused upon the 12-week, post-treatment time point using data from the final treatment cycle unless otherwise stated. For continuous outcomes, five trials provided endpoint data (Anand 2006; Hollanda 2014; Hou 2015; Lauretti 2014; Mazza 2016). All remaining trials included in the meta-analysis provided change data.

\section{Botulinum toxin versus placebo}

See: Summary of findings for the main comparison

Twenty-three of the trials eligible for the review included a placebo $\operatorname{arm}(\mathrm{N}=3912)$. All used injections of saline or vehicle in matched sites and volumes to those used in the botulinum toxin treatment arm.

\section{Primary outcome: number of migraine days per month}

See: Figure 4

\section{Figure 4. Forest plot of comparison 1. Botulinum toxin type A versus placebo, outcome: 1.1 Number of migraine days. Mazza 2016 and Cady 2014 removed for sensitivity analysis of small trial effect. Data for Mazza 2016 is endpoint data.}

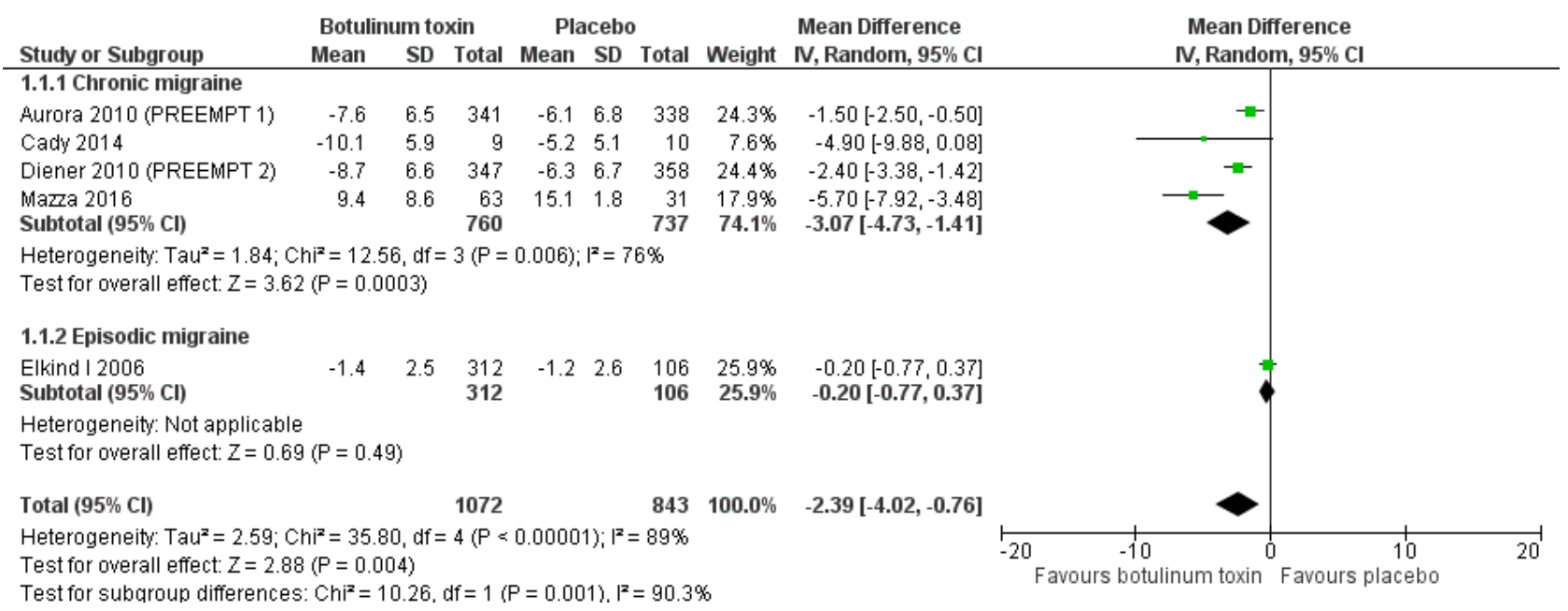

Only five trials contributed data to the meta-analysis of the primary outcome (Aurora 2010 (PREEMPT 1); Cady 2014; Diener 2010 (PREEMPT 2); Elkind I 2006; Mazza 2016); 17 did not report this outcome, and one trial reported the outcome in an unusable format (Relja 2007). Four trials of 1497 participants were in chronic migraine participants only; there were also nine chronic migraine participants inadvertently included in the Elkind I 2006 trial of episodic migraine, meaning 1506 of 1915 participants included in this meta-analysis were chronic migraine sufferers with an average baseline of more than 19 days migraine per month.

At 12 weeks post-treatment using a random-effects model, the pooled estimate for the improvement in the number of migraine days per month for the chronic migraine subgroup was -3.1 ( $95 \%$ $\mathrm{Cl}-4.7$ to $-1.4, \mathrm{I}^{2}=76 \%$ ) above that seen for the placebo group. Contributing to this pooled estimate were two trials at high risk of bias due to small size (Cady 2014; Mazza 2016); in addition to this, one of these trials provided only endpoint data (Mazza 2016). Due to these concerns we carried out a sensitivity analysis and removed these trials leaving just two larger phase III trials with 1384 participants (Aurora 2010 (PREEMPT 1); Diener 2010 (PREEMPT 2)), for which the pooled estimate for this outcome is -2.0 days $(95 \% \mathrm{Cl}$ -2.8 to $-1.1,12=37 \%)$. This sensitivity analysis raises concerns about the original estimate. We therefore focused the conclusions of this review on the more conservative estimate of a 2-day improvement in the chronic-migraine group treated with botulinum toxin, above that seen in the placebo-treated group, for this outcome.

The episodic-migraine subgroup in this analysis contained only a single trial (Elkind I 2006; $N=418$ ), the results of which showed no between-group difference in number of migraine days per month between those treated with botulinum toxin and those treated with placebo $(P=0.49)$. The test for subgroup difference showed a statistically significant heterogeneity between the results of this population and the chronic migraine subgroup for both the original and the sensitivity analyses $\left(P=0.001\right.$ for both, $\mathrm{I}^{2}=90$ and $91 \%$ respectively).

We judged the quality of the evidence for the change in number of migraine days for the chronic migraine population to be low. We downgraded by one level for inconsistency due to unexplained statistical heterogeneity and one further level for imprecision due to the lack of robustness to sensitivity analysis. We judged the quality of the results of the sensitivity analysis to be moderate, as the heterogeneity was removed and so this could be upgraded by one level.

For the whole migraine population, we downgraded the evidence one further level, to give a rating of very low quality, for indirectness 
due to insufficient evidence to form subgroups representing our distinct populations of interest.

\section{Secondary outcomes}

\section{Number of headache days per month}

Only the two PREEMPT trials contributed data for analysis of number of headache days per month with a pooled estimate of -1.9 days $\left(95 \% \mathrm{Cl}-2.7\right.$ to $\left.-1.0 ; \mathrm{I}^{2}=37 \%\right)$ in favour of treatment (Aurora 2010 (PREEMPT 1); Diener 2010 (PREEMPT 2)). All 1384 participants included in this analysis were chronic migraineurs (Analysis 1.2). Five other trials recorded this outcome: three did not clearly state their results (Anand 2006; Petri 2009; Relja 2007), one reported a reduction of two headache days in the treated group above that in the placebo group ( $P=0.018$; Freitag 2008), and the final trial stated that the difference between the two groups was not statistically significant (Cady 2008). The participants involved in Freitag 2008 were all chronic migraine sufferers, but the eligibility criteria for Cady 2008 were inclusive of chronic and episodic migraine and the ratio was not given; the differing populations may be the cause of disparity in the trial results.

We judged the quality of the evidence for the change in number of headache days to be high.

\section{Number of migraine attacks per month}

Data from six trials were available for the analysis of number of migraine attacks per month (Aurora 2007; Aurora 2010 (PREEMPT 1); Chankrachang 2011; Hou 2015; Relja 2007; Saper 2007). There was no statistically significant difference for the number of migraine attacks between botulinum toxin and placebo injections with a pooled estimate of -0.5 attacks $\left(95 \% \mathrm{Cl}-1.3\right.$ to $0.4, \mathrm{I}^{2}=89 \%, \mathrm{P}=$ 0.30 ; Analysis 1.3). This analysis included both chronic and episodic migraineurs, with a total of 2004 participants included.

Seven further trials, with a total of 380 participants, recorded this outcome. Three of these trials reported the result as not significant (Jost 2011; Petri 2009; Vo 2007), one reported a between-group difference in favour of treatment of approximately 2.5 attacks $(\mathrm{P}<$ 0.05; Barrientos 2003) and three trials reported unclear or partial data (Anand 2006; Freitag 2008; Silberstein 2000).

The proportion of responders, defined as participants with $50 \%$ or greater reduction in number of migraine attacks or migraine days, was reported fully by only one trial and no significant difference between the active and placebo arm was observed $(P=0.27$; Freitag 2008). Two further trials recorded this outcome and commented that there were no significant between-group differences, but did not provide analysable data.

We judged the quality of the evidence for the change in number of migraine attacks to be low. We downgraded by one level for indirectness, due to our concern that the sensitivity of this outcome measure was too low to detect clinically meaningful difference, and one additional level for publication bias, due to evidence of trials that recorded this outcome but have never been published.

\section{Headache intensity measures}

Only four trials contributed data for just 209 participants to the analysis of severity of migraine, measured on a $10 \mathrm{~cm}$ visual analogue scale (VAS) (Anand 2006; Hollanda 2014; Hou 2015; Lauretti 2014). It should be noted that all of the data included in this analysis were endpoint data as no mean change data were available from these trials. An improvement in the severity of migraines, measured in centimetres, in favour of treatment of $-3.3(95 \% \mathrm{Cl}-4.2$ to $-2.5,12=55 \%$; Analysis 1.4; Figure 5) was observed from this small data set. Episodic and chronic migraine populations contributed to this outcome measure, the trial and participant numbers were too low to compare these subgroups or to have confidence in the overall pooled estimate. The other trials that recorded this outcome stated that the result was not significant (Chankrachang 2011; Petri 2009; Saper 2007), or 'favouring placebo' (Aurora 2007), or gave only partial, ineligible or unclear data (Cady 2014; Jost 2011; Silberstein 2000; Vo 2007). Four trials provided data on intensity outcomes, which were not suitable for aggregation with the VAS data. Blumenkron 2006 used an alternative migraine severity scale, MIGSEV, but did not provide statistical analysis for their data. Three trials reported some other form of category data with Anand 2006 reporting that $75 \%$ of participants experienced a marked improvement in the treated group compared with $0 \%$ in the placebo arm $(P<0.05)$, and pooled data for Aurora 2010 (PREEMPT 1), and Diener 2010 (PREEMPT 2), showed that significantly more participants treated with botulinum toxin had at least one grade improvement of average daily headache severity score than in the placebo group $(P<0.001)$. 
Figure 5. Forest plot of comparison 1. Botulinum toxin type A versus placebo, outcome: 1.4 Severity of migraine (Visual Analogue Score 0-10)

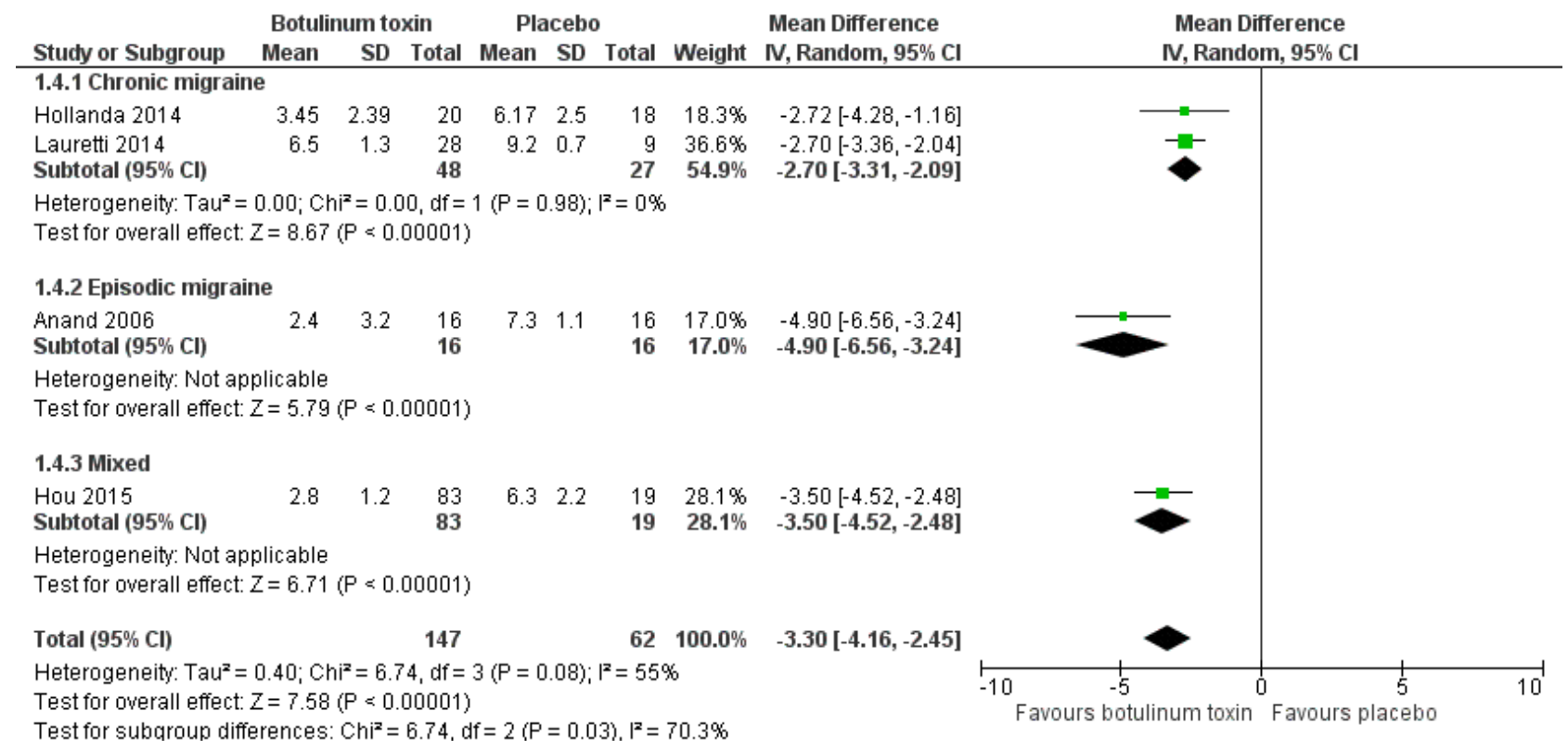

We judged the quality of the evidence for the change in VAS score to be very low. We downgraded by one level for risk of bias, due to poor reporting of the outcome, which had a large effect on number of participants included in the analysis, and two additional levels for imprecision, as all included trials were all small and new trial evidence would be very likely to change the result.

\section{Headache index}

None of the included trials reported data for this outcome. It was recorded in a single trial that reported that there was no statistically significant difference between placebo and treatment for the 12week time point (Freitag 2008).

\section{Duration of migraine}

Only one trial reported duration of migraine in a format we could use in our analysis (Hou 2015). Their results showed an improvement in duration of migraine of -5.1 hours $(95 \% \mathrm{Cl}-6.2$ to -4.0) in favour of botulinum toxin for a mixed population of 66 episodic migraine participants and 36 chronic migraine participants. Four other trials, with a total of 420 participants, reported that they found no significant difference between groups for this outcome, but provided no analysable data (Jost 2011; Petri 2009; Saper 2007; Vo 2007).

Three trials reported reduction in time with severe (or more severe) migraine: Chankrachang 2011 reported only that there was no significant between-group difference; Diener 2010 (PREEMPT 2) reported a difference of -2.5 days per month $(95 \% \mathrm{Cl}-3.4$ to -1.5 , P $<0.001$ ) in favour of botulinum treatment; Jabbari 2014 reported an improvement of 7.5 days per month in favour of treatment with botulinum toxin, but gave no confidence intervals for these data, only providing a $P$ value $(P=0.03)$.

We judged the quality of the evidence for this outcome to be very low. We downgraded by two levels due to imprecision as the single included trial was small and new trial evidence would be very likely to change the result; we downgraded by one additional level for risk of bias, due to selective reporting bias which had a large effect on number of participants included in the analysis.

\section{Use of rescue medication}

Data were provided by only two trials, with a total of 717 participants, on the use of rescue medication in chronic migraineurs (Aurora 2010 (PREEMPT 1); Hollanda 2014; Analysis 1.5). There was no statistically significant difference between groups in the reduction in number of times a participant took acute headache pain medication regardless of dose or type/number of medications taken at the same time $(P=0.16)$. Six additional trials reported that there were no significant between-group differences for this outcome (Diener 2010 (PREEMPT 2); Freitag 2008; Jost 2011; Petri 2009; Saper 2007; Vo 2007); one reported that their results favoured placebo (Aurora 2007), and one that their results favoured botulinum toxin (Barrientos 2003), but all eight failed to provide analysable data.

We judged the quality of the evidence for this outcome to be moderate. We downgraded by one level for risk of bias, due to selective reporting bias, which had a large effect on number of participants included in the analysis.

\section{Patient and clinician global impression scales}

The only trial to report analysable data for any global impression scale was Allergan 2015, which reported a small between-group difference in patient-rated Headache Impact Test-6 question version (HIT-6) scores of 1.6 points $(\mathrm{N}=45)$ without statistical significance $(P=0.40)$. Eight trials did not list any global impression scales in their recorded outcomes (Anand 2006; Cady 2014; Hollanda 2014; Hou 2015; Jabbari 2014; Lauretti 2014; Mazza 2016; Vo 2007). The remaining trials either did not provide data or reported data in a format not suitable for meta-analysis.

We judged the quality of the evidence for the change in HIT-6 score to be very low. We downgraded by one level for risk of bias, due to selective reporting bias, which had a large effect on number of 
participants included in the analysis, and two additional levels for imprecision, as the single trial was small and new trial evidence would be very likely to change the result.

\section{Generic and disease specific quality of life rating scales}

None of the trials included in this review provided data on qualityof-life measures in a format suitable for analysis. Eleven trial reports did not list quality-of-life scales as a trial outcome (Allergan 2015; Aurora 2007; Barrientos 2003; Cady 2014; Chankrachang 2011; Hollanda 2014; Hou 2015; Jost 2011; Lauretti 2014; Mazza 2016; Silberstein 2000). All remaining trials reported data in a format that could not be meta-analysed.

We could not assess the quality of the evidence due to the lack of reporting of this outcome.

\section{Cost effectiveness}

Only two trials carried out economic analysis of the intervention (Aurora 2010 (PREEMPT 1); Diener 2010 (PREEMPT 2)). A single economic analysis was conducted to support these two trials that were run by the same investigators and had the same design, with the exception of their designated primary outcome (Batty 2013). As the efficacy data were taken from these two trials, the relevance of the analysis was limited to the chronic migraine population. The incremental cost-effectiveness ratio (ICER) generated using data from the two PREEMPT trials was GBP 15,028 per quality adjusted life year gained. The trial authors calculated that the cost of treatment per headache day avoided was GBP 18. Limitations cited by the authors of this paper were the use of a placebo comparator, which does not represent real alternative treatments, and the use of extrapolation beyond the 56-week trial treatment period for modelling. Both trials included in this health economic analysis were funded by the manufacturers of the intervention.

We judged the quality of the evidence for this outcome to be high.

\section{Adverse events}

Meta-analysable data on adverse events were available from 15 trials (Allergan 2015; Anand 2006; Aurora 2007; Aurora 2010 (PREEMPT 1); Blumenkron 2006; Chankrachang 2011; Diener 2010 (PREEMPT 2); Elkind I 2006; Hollanda 2014; Hou 2015; Jabbari 2014; Petri 2009; Relja 2007; Saper 2007; Silberstein 2000). Two of these trials stated that no adverse events occurred (Anand 2006; Blumenkron 2006). Of the remaining trials five had unclear or inadequate reporting (Cady 2008; Cady 2014; Freitag 2008; Jost 2011; Mazza 2016), and three did not list adverse events as an outcome in their methods sections (Barrientos 2003; Lauretti 2014; Vo 2007).

The risk ratio of any adverse event reported by 13 trials involving 3325 participants was $1.28\left(95 \% \mathrm{Cl} 1.12\right.$ to $1.47, \mathrm{I}^{2}=63 \%$; Analysis 1.6; Figure 6). For ease of interpretation we converted this into a relative risk reduction (RRR) of treatment with placebo over treatment with botulinum toxin of $30 \%$. The number needed to treat for an additional harmful outcome (NNTH), calculated using the total adverse event data, was 7 (95\% $\mathrm{Cl} 6$ to 9). In the placebo group 47 in every 100 people experienced an adverse event, and in the treatment group 60 in every 100 treated people experienced an adverse event. 
Figure 6. Forest plot of comparison 1. Botulinum toxin type A versus placebo, outcome: 1.6 Total adverse events

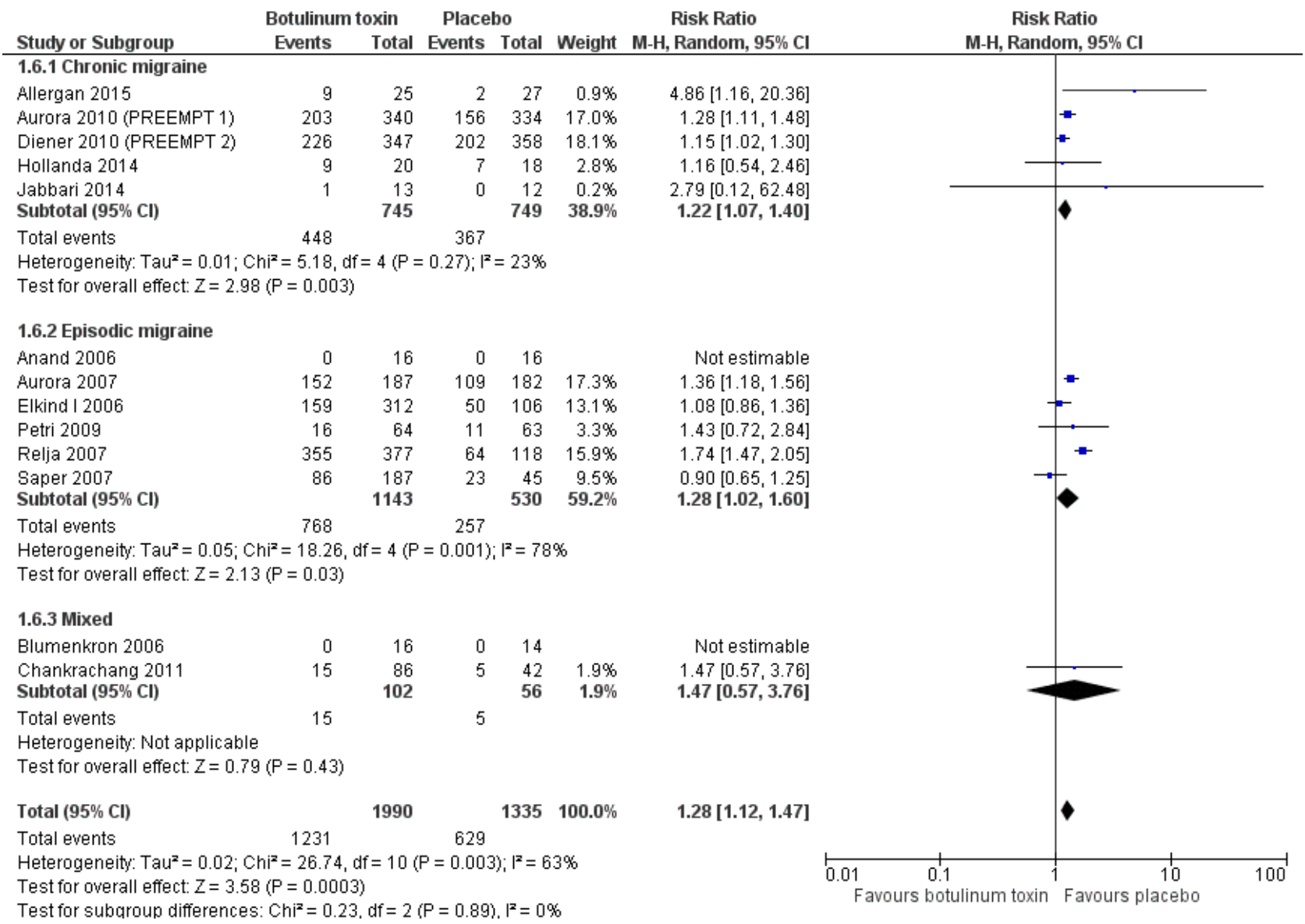

We extracted all subtypes of event to ensure any important unforeseen safety issues could be analysed in this review. We identified no such issues. We analysed four pre-specified adverse event types.

Seven trials involving 1867 participants reported data for blepharoptosis with the higher risk in the botulinum toxin arm (RR $7.29,95 \% \mathrm{Cl} 3.18$ to $16.73, \mathrm{I}^{2}=0 \%$; Analysis 1.7 ).

Six trials involving 2602 participants reported muscle weakness and showed an increased risk in the botulinum treated arm with a RR of $13.67\left(95 \% \mathrm{Cl} 6.73\right.$ to $27.75, \mathrm{I}^{2}=0 \%$; Analysis 1.8$)$.

For neck pain, participants in the treatment arm were around three times more likely to experience the event than participants receiving placebo (RR 2.98, 95\% $\mathrm{Cl} 2.06$ to $4.32,12=0 \%$; Analysis 1.9 ), with six trials in 2424 participants reporting this outcome.

Injection site pain was twice as likely to occur in the treated group than the placebo group ( $\mathrm{RR} 2.10,95 \% \mathrm{Cl} 1.02$ to $4.32, \mathrm{I}^{2}=0 \%$; Analysis 1.10). Eight trials involving 1332 participants reported this final adverse event type.

The RR of adverse events considered by trialists to be treatmentrelated in six trials with 2893 participants was 2.18 (95\% Cl 1.73 to $2.75,12=56 \%$; Analysis 1.11).

Four trials ( $\mathrm{N}=2248)$ administered more than one cycle of injections and provided data on withdrawals due to adverse events (Aurora 2007; Aurora 2010 (PREEMPT 1); Diener 2010 (PREEMPT 2); Relja 2007). Participants were three times more likely to withdraw due to adverse events in the treated group than in the placebo group (RR $3.28,95 \% \mathrm{Cl} 1.52$ to $7.07, \mathrm{I}^{2}=0 \%$; Analysis 1.12 ). The overall proportion withdrawn due to adverse events in the treated groups was $2 \%$.

We judged the quality of the evidence for the total adverse events outcome to be moderate. We downgraded by one level for imprecision, as many of the included trials were small and new trial evidence would be likely to change the result.

\section{Planned subgroup analyses}

Insufficient data were available to carry out any of the planned subgroup analyses on the primary outcome measure.

\section{Botulinum toxin versus other agent: established prophylactic agents}

See: Summary of findings 2

Three trials with 178 participants made comparisons with other established agents for migraine prophylaxis. Two trials compared 100 units fixed dose plus an optional 100 units or less of Botox with topiramate, using maximum dose of $200 \mathrm{mg}$ per day in both cases (Cady 2011; Mathew 2009). Blumenfeld 2008 compared 100 units or 
less of Botox with sodium valproate $250 \mathrm{mg}$ twice daily. Fourteen of the 59 participants involved in Cady 2011 had episodic migraine; all other participants across all three trials had chronic migraine.

\section{Primary outcome: number of migraine days per month}

Only one trial recorded the primary outcome for this review. Mathew 2009 stated that the number of migraine days decreased for both groups with no statistically significant difference between the Botox-treated group and the topiramate-treated group. All participants in this trial had a diagnosis of chronic migraine.

We judged the quality of the evidence for the change in number of migraine days to be very low. We downgraded the quality of the evidence by one level for risk of bias due to unclear or high risk for selection, performance, detection and attrition bias. We downgraded by two further levels for imprecision due to small trial size, meaning that new trial evidence would be likely to change the result, and a fourth level for imprecision, as only a narrative description of the outcome results was provided.

\section{Secondary outcomes}

\section{Number of headache days per month}

Two of the included trials (Blumenfeld 2008; Cady 2011) recorded number of headache days per month for participants. Only Blumenfeld 2008 reported meta-analysable data $(P=0.55)$, but both reported a decrease in number of headache days with no statistically significant between-group difference.

We judged the quality of the evidence for the change in number of headache days to be very low. We downgraded the quality of the evidence by one level for risk of bias due to unclear or high risk for selection, performance, detection and attrition bias. We downgraded by two further levels for imprecision due to small trial size, meaning that new trial evidence would be very likely to change the result.

\section{Number of migraine attacks per month}

Number of migraine attacks were not recorded by any of the trials included in this comparison.

\section{Headache intensity measures}

Two trials reported headache intensity measures (Blumenfeld 2008; Mathew 2009). Neither used the VAS discussed for other comparisons in this review. Both trials used a five-point scale for migraine severity. Blumenfeld 2008 reported that no differences between the groups were found, but did not report any statistical analysis for this finding, nor did they provide sufficient data to do this. Mathew 2009 showed a small difference in favour of topiramate of 0.40 ( $95 \% \mathrm{Cl} 0.79$ to 0.01 ) points, though participant numbers had to be used from other diary outcome measures as they were not clear for this outcome.

We judged the quality of the evidence for the five-point migraine severity scale scores to be very low. We downgraded the quality of the evidence by one level for risk of bias due to unclear or high risk for selection, performance, detection and attrition bias. We downgraded by two further levels for imprecision due to small trial size, meaning that new trial evidence would be very likely to change the result.

\section{Headache index}

A single trial recorded headache index scores and reported no significant between-group differences for this outcome (Blumenfeld 2008).

\section{Duration of migraine}

None of the trials included in this comparison recorded duration of migraine.

\section{Use of rescue medication}

Only one trial recorded data for this outcome measure, and their data showed no significant between-group difference $(P=0.2$; Mathew 2009).

\section{Patient and clinician global impression scales}

Two small trials reported analysable data for the MIDAS (Blumenfeld 2008; Mathew 2009; Analysis 2.1), but they showed no significant difference in change scores between the established drug treatments and injection with Botox $(P=0.80, N=101)$. Physician global assessment, HIT-6 and MIDAS scores were all reported for the participants in Cady 2011, but statistical analysis was limited to statements that the differences between the groups were not statistically significant for any of these measures.

We judged the quality of the evidence for the global impression of disease measured using MIDAS scores to be very low. We downgraded the quality of the evidence by one level for risk of bias due to unclear or high risk for selection, performance, detection and attrition bias. We downgraded by two further levels for imprecision due to small trial sizes meaning that new trial evidence would be very likely to change the result.

\section{Generic and disease-specific quality-of-life rating scales}

Blumenfeld 2008 was the only trial to record a quality-oflife outcome measure. They used the 24-Hour Migraine QoL questionnaire. They did not report full data nor discuss betweengroup comparisons in the published material.

\section{Cost effectiveness}

We did not identify any cost-effectiveness analyses for this comparison.

\section{Adverse events}

Two trials reported adverse event data for 114 participants and analysis of the risk ratio of experiencing any adverse event (Blumenfeld 2008; Mathew 2009) and of experiencing a treatmentrelated adverse event was possible. In the botulinum toxin group 73 in every 100 people experienced any adverse event, and in the alternative oral treatment group 86 in every 100 treated people experienced an adverse event; the difference in risk between groups of any adverse event was not statistically significant $(P=$ 0.67 , Analysis 2.2). The RR for the number of treatment-related adverse events was $0.76\left(95 \% \mathrm{Cl} 0.59\right.$ to $0.98 ; \mathrm{I}^{2}=0 \%$, Analysis 2.3$)$ in favour of Botox. This translates to a RRR of $24 \%$ in the botulinum toxin arm. There was also a difference in favour of Botox in the RR of withdrawing due to adverse events of $0.28(95 \% \mathrm{Cl} 0.10$ to $0.79 ;\left.\right|^{2}=0 \%$ ), which is a RRR of $72 \%$ (Analysis 2.4). The proportion dropping out from the botulinum toxin-treated arm was low at $7 \%$. These results suggest that injection with Botox is more tolerable 
than treatment with the two established agents, topiramate and sodium valproate.

We judged the quality of the evidence for the total adverse events outcome to be very low. We downgraded the quality of the evidence by one level for risk of bias due to unclear or high risk for selection, performance, detection and attrition bias. We downgraded by two further levels for imprecision due to small trial sizes, meaning that new trial evidence would be very likely to change the result.

\section{Botulinum toxin versus other agent: histamine}

Insufficient information was available to make sensible judgements about the relative safety and effectiveness of botulinum toxin versus histamine for prophylactic treatment of migraine. For a summary of the existing evidence for this comparison see Appendix 2.

\section{Botulinum toxin versus clinically relevant different dose of botulinum toxin}

Insufficient information was available to make sensible judgements about the dose-response relationship of botulinum toxin treatment to migraine. For a summary of the existing evidence for this comparison see Appendix 3.

\section{DISCUSSION}

\section{Summary of main results}

\section{Efficacy}

Uncertainty remains around the estimate of effect of botulinum toxin on our primary outcome, the number of migraine days experienced per month for people with chronic migraine. The data showed a reduction of 3 days $(-3.1,95 \% \mathrm{Cl}-4.7$ to -1.4 , low-quality evidence) for this outcome measure over and above the placebo effect. This result did not prove to be reliable when tested using sensitivity analysis for effects of small trial bias. We had greater confidence in the more conservative estimate of a 2-day improvement $(-2.0,95 \% \mathrm{Cl}-2.8$ to -1.1 , moderate-quality evidence). This came only from trials at low risk of bias from trial size (Aurora 2010 (PREEMPT 1); Diener 2010 (PREEMPT 2)). All participants included in this analysis had chronic migraine with a high baseline frequency of around 20 days per month. The data showed a large placebo effect on their symptoms of improvement of over 6 days. Just how clinically meaningful this result is remains difficult to determine. It does approach reductions observed in topiramate versus placebo trials of 3.7 (Diener 2007) and 1.5 migraine days per month (Silberstein 2007). Recent trials of the novel anti-calcitonin gene-related peptide (CGRP) monoclonal antibody treatment option found a reduction of around 2 headache days per month (Giamberardino 2016; Silberstein 2017) and up to 2 migraine days, depending on dose, when compared with placebo (Goadsby 2017). This is in keeping with previous trials with prophylactic agents. Insufficient data were available to draw conclusions for the episodic migraine population from this outcome measure as we identified only a single trial experimenting with doses well below those recommended by the UK national guidelines (Elkind I 2006). We had hoped to use subgroup analysis to investigate the effect of including people with the additional medication overuse headache diagnosis but we could not carry out this analysis as we did not identify sufficient data to create the subgroups.
Secondary outcome measures were inconsistent in showing a treatment effect. Botulinum toxin was better than placebo in reducing the number of days with any type of headache by two days per month, based on evidence judged to be high-quality. We did not observe any significant difference from placebo for number of migraine attacks per month in those with episodic migraine (lowquality evidence); this may be as a result of variable parameters in this outcome measure, which was generally poorly defined in trial reports. There was a reduction in favour of botulinum treatment of migraine severity on a visual analogue scale of 3 $\mathrm{cm}$ on a $10 \mathrm{~cm}$ scale (very low-quality evidence), compared with placebo. This difference is in excess of the minimal clinically important difference of between $1.0 \mathrm{~cm}$ and $1.4 \mathrm{~cm}$ reported for other chronic pain conditions (Hawker 2011). The migraine severity analysis included trials with episodic migraine populations and the effect size was shown to be similar to that seen for chronic migraineurs. There was no significant heterogeneity between the two population subgroups. All trials contributing to the analysis of migraine severity were small and so the quality of this evidence is very low and likely to change with the emergence of new evidence from larger, higher-quality trials. If all trials had used a uniform outcome measure for severity of migraine, we could have included an additional 2298 participants in our analyses for this outcome, giving much greater confidence in the results.

None of the included trials provided headache index, duration of migraine, or use of rescue medication data from which we could carry out meta-analyses. Patient and clinician-reported global assessment scales and quality-of-life scales were underused. When they were incorporated into trials, they were poorly reported so no meta-analyses could be performed.

It was not possible to carry out any analysis on migraine or headache frequency outcomes, severity of migraine, headache index, duration of migraine or the use of rescue medication outcome measures for head-to-head comparisons between botulinum toxin and other established agents due to lack of available data. MIDAS scores for 101 participants from two small trials, one comparing Botox with topiramate and one with sodium valproate were available and these showed no significant betweengroup difference ( $P=0.8$, very low-quality evidence). Because of the small number of trials and participants contributing towards this estimate, the apparent comparable prophylactic effect of botulinum toxin with established oral agents must be treated with caution. No data were available to assess the effects of the treatments on quality of life.

Very few data were available to analyse the effectiveness of one dose of Botox over another. Further evidence is required to explore possible non-inferiority of lower doses of Botox than the 155 units recommended in the guidance (NICE 2012a). We were unable to make comparisons between different doses of the other botulinum toxin preparations under investigation in trials included in this review due to a lack of meta-analysable data.

\section{Safety and tolerability}

Data from 23 trials included in this review reported few adverse events as a result of treatment with botulinum toxin. There was an increased risk of adverse events in the botulinum toxin group compared with placebo (moderate-quality evidence), but these events were not serious and were transient. 
Our analysis showed no statistically significant difference between total number of participants experiencing any adverse event from treatment with botulinum toxin compared with topiramate (100 $\mathrm{mg} /$ day to $200 \mathrm{mg} /$ day) and sodium valproate (250 mg twice daily) but we judged this evidence to be of very low-quality. We analysed the relative tolerability of common side effects using withdrawal due to adverse event data from Mathew 2009 and Blumenfeld 2008 and this showed a relative risk reduction in favour of Botox of $72 \%$.

The withdrawal rate due to adverse events for all six trials $(N=1312)$ administering more than one round of Botox, irrespective of the comparison arm type, was only $3 \%$. The data sets for comparisons with other prophylactic agents were small. However, published withdrawal rates from other prophylactic agents were higher at $20 \%$ for topiramate and $12 \%$ for sodium valproate (Linde 2013c; Linde 2013d). Adherence to oral migraine preventative medications is known to be poor (Hepp 2015). The low withdrawal rate from botulinum toxin suggests that participants are either more able or more willing to tolerate this treatment than the oral alternatives.

Insufficient evidence was available to allow full analysis of any dose-response relationship for adverse events.

\section{Cost}

The cost-effectiveness analysis for Botox carried out using data from the two large PREEMPT trials estimated a treatment cost of GBP 18 per headache day avoided. Other oral preventative strategies are currently much cheaper (BMA/RPS 2014; Rothrock 2014).

\section{Overall completeness and applicability of evidence}

Reporting was generally poor, with only six of 28 trials reporting data on the primary outcome measure in a usable format and an additional five providing data for number of migraine attacks. These two measures are recommended as primary outcomes in the guidelines produced by the International Headache Society (TfeltHansen 2012) and should be fully reported to allow individual trials to be placed in the context of the totality of the evidence. A large proportion of the recorded data was missing from the published reports of the included trials. When an outcome had shown no significant between-group difference, data and statistical analysis were frequently omitted from articles and in its place trial authors gave a narrative description of the results.

Number of migraine attacks was commonly used as the primary outcome, particularly in trials run before the publication of the PREEMPT trials. Use of this measure may mask a change in duration and severity of migraine attacks, which may represent a more important outcome for people with migraines. More sensitive measures would be number of days or hours spent with migraine per month coupled with a measure of intensity. Another problem with focusing on migraine attacks is the common failure to define what is meant by the term, leading to variation depending on the definition used. The definition of an attack should include the required interval to separate one attack from the next, any maximum attack length or sleep interval that causes a second attack count to be started, and the baseline duration of migraine for the population under consideration. It is these variables that lead to difficulty in interpreting the data describing migraine attacks.

Neither efficacy nor safety data were available for long-term treatment with botulinum toxin. The longest treatment period in any of the trials included in this review was three treatments with three months between treatments. Therefore, we cannot evaluate the efficacy and safety of botulinum toxin over a period longer than nine months.

Evidence concerning the efficacy implications of the inclusion of people with medication overuse headache was not available. Half of the trials in this review did not report whether or not they had included these types of participants. Of those that did describe medication overuse headache in their eligibility criteria, 11 trials excluded it (Anand 2006; Aurora 2007; Barrientos 2003; Blumenfeld 2008; Cady 2011; Freitag 2008; Hollanda 2014; Petri 2009; Relja 2007; Saper 2007; Silberstein 2000), one included only people with this additional diagnosis (Millán-Guerrero 2009), and two randomised both people with and without it (Aurora 2010 (PREEMPT 1); Diener 2010 (PREEMPT 2)). Pooled data for the two PREEMPT trials for the chronic migraine plus medication overuse subgroup ( $N=904$ ) showed that the difference between groups for both migraine and headache day frequencies was 2 days $(P<0.001)$ in favour of treatment with Botox (Silberstein 2013). These results match that generated in this review for combined populations with and without medication overuse headache. It would appear from these data that the inclusion of people with medication overuse does not change the effectiveness of Botox for prophylactic treatment of migraine.

The changing definitions of chronic migraine and medication overuse headache will have caused a small shift over time in the populations included in the various trials. Given that adequate descriptions of the populations were commonly not provided and that the trial numbers in the primary outcome analyses were low, we were unable to carry out subgroup analyses for these variables. The shift may have contributed to the significant heterogeneity seen in many of the analyses.

No randomised evidence was available for botulinum toxin serotypes other than type A, so no comparisons were possible.

\section{Quality of the evidence}

See: Characteristics of included studies tables, 'Risk of bias' summary tables, Figure 2, Figure 3, Summary of findings for the main comparison and Summary of findings 2.

The quality of the trials included in this review was mixed. We considered only the two PREEMPT trials to be at low risk of bias for trial size. More than $50 \%$ of trials, including all of those with sample sizes not considered to be high risk, were commercially sponsored. All trials were double-blind, as stated in our inclusion criteria, but only half provided adequate details of the methods used to ensure blinding of participants or assessors, or both. Selective reporting of outcomes was also a major flaw, which could have a significant impact on our results. Most data that were omitted from reports were for outcomes for which the results were often described in a narrative fashion as showing no significant difference between groups. It could be that addition of all of these missing data would alter the significance of the results.

In the placebo comparison, we rated the quality of the evidence for the primary outcome as low for chronic migraine and very low for the pooled population estimate. We downgraded once due to unexplained heterogeneity and once due to imprecision caused by small trials in both cases. We also downgraded the primary 
outcome for the pooled population due to indirectness, as the episodic migraine subgroup had insufficient data to allow distinct analysis of the two groups and combining the data would have clouded the clinical relevance of the result. We upgraded the results of the sensitivity analysis carried out for the chronic migraine population only for the primary outcome measure to moderatequality, as we excluded the small trials. We considered number of headache days and risk of treatment-related adverse events to be of high and moderate quality respectively, but we judged all other outcomes for the placebo comparison and all outcomes for the comparison with established agents to be of low or very lowquality. Most commonly, we downgraded these outcomes due to the small size of the data set, significant unexplained heterogeneity, unclear or high risk of bias, and poor reporting of non-significant data.

\section{Potential biases in the review process}

We included trials of all preparations and sero-types of botulinum toxin, which led to the inclusion of two preparations, HengLi and Prosigne, for which we could find little information. In particular we would have liked details of relative potency and whether they are the same preparation sold under two different brandings (as they are manufactured at the same site). The uncertainty about the identity of the toxins places a question over the validity of the resulting trial data and whether or not it was appropriate to include such preparations.

\section{Agreements and disagreements with other studies or reviews}

The most recently published guidance from the American Academy of Neurology bases its recommendation for treating people with chronic migraine upon the two large PREEMPT trials (Simpson 2016). While we agree with the findings that these large scale phase III trials provide evidence supporting the use of botulinum toxin type $A$ in chronic migraine, their results must be placed within the context of the totality of evidence for this treatment.

Botulinum toxin type $A$ is recommended as an option for the prophylaxis of chronic migraine only. On conversion to episodic migraine, UK guidelines state that people are no longer eligible for treatment (NICE 2012a). It seems biologically implausible that botulinum toxin would be efficacious in chronic migraine but not in high-frequency, episodic migraine. But, we were unable to find sufficient evidence to contradict this guidance.

\section{AUTHORS' CONCLUSIONS}

\section{Implications for practice}

\section{For people with migraine}

Botulinum toxin type A reduces migraine days per month by two days more than placebo in chronic migraine, based on moderatequality evidence from two large trials. We also saw a reduction of $30 \%$ more in the severity of migraines in the treated group than in the placebo group but this was based on very low-quality evidence from four small trials in chronic and episodic migraine, so our confidence in this estimate is low. There is inadequate evidence to support its use in episodic migraine. The results of this review are applicable up to the first nine months of treatment, after which no evidence was available to determine long-term treatment effects or safety.

\section{For clinicians}

Our conclusions are in line with current clinical guidelines. We could not draw conclusions about the order in which botulinum toxin and other prophylactic agents should be used to treat migraine as there was insufficient evidence on comparative efficacy and safety.

\section{For policy makers}

We did not identify sufficient data to assess whether botulinum toxin treatment should cease on reduction of headache days below the current 15-day chronic migraine cut off (NICE 2012a). There are not enough data to support or refute the use of botulinum toxin injections for episodic migraine.

\section{For funders of the intervention}

Cost effectiveness of this treatment is unclear. Data were available to show the price per quality adjusted life year gained (GBP 15,028) from treatment with botulinum toxin compared with placebo. Treatment costs are high relative to other treatments and no direct comparisons have been made to evaluate the cost effectiveness of the small degree of efficacy shown by the botulinum toxin treatment relative to oral prophylactic alternatives or to lower dose treatments with botulinum toxin.

\section{Implications for research}

\section{General}

Large trials with distinct and well-defined subgroups are required to determine the effects of botulinum toxin in migraine overuse headache and episodic migraine, and to investigate dose response, and efficacy compared to other active treatments. Testing of the validity of the requirement for 15 or more migraine days per month for treatment with botulinum toxin was not possible, as we failed to identify enough evidence for people with episodic migraine.

\section{Design}

The design and reporting of future trials should be carried out in accordance with the guidance of the International Headache Society (Tfelt-Hansen 2012). trials must be randomised, double-blind and placebo-controlled to determine effects and dose response, and ideally comparisons with other treatments should also include a placebo arm. Trials should use and fully report standard outcomes including quality-of-life measures, and consider the use of reduction in number of migraine days as their primary outcome measure (Silberstein 2008). Longer-term trials (longer than nine months) are needed for evidence of long-term safety and tolerability.

\section{Measurement}

Use of more sensitive outcome measures would enable trials to pick up reduction in migraine days and duration. Trials with botulinum toxin should be performed over longer than nine months to determine the efficacy and safety of treatment over extended periods. Longer trials would also allow analysis of the time to discontinuation, which is known to be short for first-line, oral prophylactic medication and decreases further as people with migraine cycle through multiple prophylactics (Hepp 2016).

\section{Other}

All trials should be reported using CONSORT guidelines (Schulz 2010). 


\section{A C K N OWLEDGEMENTS}

We used Cochrane Pain, Palliative and Supportive Care authoring guidelines and University of Nottingham Systematic Review Course materials to aid the preparation of the Methods section of this review.

Joanne Abbott, Information Specialist at Cochrane Pain, Palliative and Supportive Care ran searches in CENTRAL, MEDLINE and Embase.
Cochrane Review Group funding acknowledgement: this project was supported by the National Institute for Health Research, via Cochrane Infrastructure funding to Cochrane Pain, Palliative and Supportive Care (PaPaS). The views and opinions expressed therein are those of the authors and do not necessarily reflect those of the Systematic Reviews Programme, NIHR, NHS or the Department of Health.

Translation of Blumenkron 2006 was carried out by Ana Hughes, Cancer Clinical Trials Unit, University of Birmingham. 


\section{REFERE N CE S}

\section{References to studies included in this review}

Allergan 2015 \{unpublished data only\}

Allergan, Inc. Use of a treatment benefit questionnaire in patients with chronic migraine treated with onabotulinumtoxinA (BOTOX ${ }^{\circledR}$ ). clinicaltrials.gov/ct2/show/ NCT01833130 (first received 16 April 2013).

Anand 2006 \{published data only (unpublished sought but not used)\}

Anand KS, Prasad A, Singh MM, Sharma S, Bala K. Botulinum toxin type A in prophylactic treatment of migraine. American Journal of Therapeutics 2006;13(3):183-7.

Aurora 2007 \{published data only (unpublished sought but not used)\}

Aurora SK, Gawel M, Brandes JL, Pokta S, Vandenburgh AM, Group BNAEMS. Botulinum toxin type a prophylactic treatment of episodic migraine: a randomized, double-blind, placebocontrolled exploratory study. Headache 2007;47(4):486-99.

\section{Aurora 2010 (PREEMPT 1) \{published and unpublished data\}}

Allergan Inc. A study using botulinum toxin type A as headache prophylaxis for migraine patients with frequent headaches. clinicaltrials.gov/ct2/show/NCT00156910 (first received 12 September 2005).

Aurora SK, Dodick DW, Blumenfeld A, Degryse RE, Turkel CC. OnabotulinumtoxinA for chronic migraine: safety and tolerability of the effective treatment paradigm in the PREEMPT clinical program. Headache 2010;50:14-5.

Aurora SK, Dodick DW, DeGryse RE, Turkel CC. OnabotulinumtoxinA for chronic migraine: efficacy and tolerability in patients who received all 5 treatment cycles in the PREEMPT clinical program. Headache 2011;51:61.

Aurora SK, Dodick DW, DeGryse RE, Turkel CC. OnabotulinumtoxinA for chronic migraine: efficacy, safety, and tolerability in patients who received all 5 treatment cycles in PREEMPT. Journal of Headache and Pain 2012;14(Suppl 1):199.

Aurora SK, Dodick DW, Diener HC, DeGryse RE, Turkel CC, Lipton RB, et al. OnabotulinumtoxinA for chronic migraine: efficacy, safety, and tolerability in patients who received all five treatment cycles in the PREEMPT clinical program. Acto Neurologica Scandinavica 2014;129(1):61-70.

* Aurora SK, Dodick DW, Turkel CC, DeGryse RE, Silberstein SD, Lipton RB, et al. OnabotulinumtoxinA for treatment of chronic migraine: results from the double-blind, randomized, placebo-controlled phase of the PREEMPT 1 trial. Cephalalgia 2010;30(7):793-803.

Aurora SK, Halker R, Pozo-Rosich P, DeGryse RE, Adams AM, Matharu M. The impact of onabotulinumtoxinA on severe headache days: PREEMPT 24-week pooled analysis. American Journal of Physical Medicine and Rehabilitation 2016;8(Suppl 9):S296.
Aurora SK, Halker R, Pozo-Rosich P, DeGryse RE, Adams AM, Matharu M. The impact of onabotulinumtoxinA on severe headache days: PREEMPT 24-week pooled analysis. Headache 2016;56:27-8.

Aurora SK, Schim JD, Cutrer FM, Ward TN, Blumenfeld A, Lay C, et al. Botulinum neurotoxin type $A$ for treatment of chronic migraine: PREEMPT 1 trial double-blind phase. Cephalalgia 2009;29:29

Aurora SK, Silberstein SD, DeGryse RE, Turkel CC. Onabotulinumtoxin A for treatment of chronic migraine (CM): analysis of the PREEMPT chronic migraine subgroup with and without prior migraine prophylactic treatment. Cephalalgia 2011;31:18-9.

Aurora SK, Winner P, Freeman MC, Spierings EL, Heiring J, DeGryse RE, et al. Botulinum neurotoxin type A for treatment of chronic migraine: Pooled analyses of the PREEMPT clinical program 32-week open-label phase. Cephalalgia 2009;29:7-8

Aurora SK, Winner P, Freeman MC, Spierings EL, Heiring JO, DeGryse RE, et al. OnabotulinumtoxinA for treatment of chronic migraine: Pooled analyses of the 56-week PREEMPT clinical program. Headache 2011;51(9):1358-73.

Batty AJ, Hansen RN, Bloudek LM, Varon SF, Hayward EJ, Pennington BW, et al. The cost-effectiveness of onabotulinumtoxinA for the prophylaxis of headache in adults with chronic migraine in the UK. Journal of Medical Economics 2013;16(7):877-87.

Blumenfeld AM, Silberstein SD, Dodick DW, Aurora SK, Turkel CC, Binder WJ. Method of injection of onabotulinumtoxinA for chronic migraine: a safe, well-tolerated, and effective treatment paradigm based on the PREEMPT clinical program. Headache 2010;50(9):1406-18.

Blumenfeld AM, Silberstein SD, Dodick DW, Aurora SK, Turkel CC, Binder WJ. Onabotulinumtoxin-A for chronic migraine: PREEMPT trials establish a safe and effective dose and injection paradigm. Journal of Headache and Pain 2010;11:S12

Blumenfeld AM, Silberstein SD, Dodick DW, Aurora SK, Turkel CC, Binder WJ. OnabotulinumtoxinA for chronic migraine: PREEMPT trials establish a safe and effective dose and injection paradigm. Toxicon 2013;68:106-7.

Chen SP, Fuh JL, Wang SJ. OnabotulinumtoxinA: Preventive treatment for chronic migraine. Current Pain and Headache Reports 2011;15(1):4-7.

Diener HC, Dodick DW, DeGryse RE, Turkel CC. Onabotulinumtoxin-A for treatment of chronic migraine: PREEMPT 24-week pooled subgroup analysis of patients without medication overuse. European Journal of Neurology 2011;18:191.

Diener HC, Dodick DW, DeGryse RE, Turkel CC.

OnabotulinumtoxinA for treatment of chronic migraine: PREEMPT 24-week pooled subgroup analysis of patients 
without medication overuse. Journal of Headache and Pain 2012;14(Suppl 1):204.

Dodick DW, Aurora SK, DeGryse RE, Turkel CC, Silberstein SD, Lipton RB, et al. Onabotulinumtoxin-A for treatment of chronic migraine: Pooled results from the double-blind, randomized, placebo-controlled phase of the PREEMPT clinical program. Journal of Headache and Pain 2010;11:S14.

Dodick DW, Aurora SK, Turkel CC, DeGryse RE, Silberstein SD, Lipton RB, et al. Botulinum neurotoxin type a for treatment of chronic migraine: Double-blind, randomized, placebocontrolled PREEMPT trials. Cephalalgia 2009;29(12):1350.

Dodick DW, Aurora SK, Turkel CC, DeGryse RE, Silberstein SD, Lipton RB, et al. OnabotulinumtoxinA for treatment of chronic migraine: Pooled results from the double-blind, randomized, placebo-controlled phase of the PREEMPT clinical program. Toxicon 2013;68:110.

Dodick DW, Aurora SK, Turkel CC, Degryse RE, Silberstein SD, Llpton RB, et al. Botulinum neurotoxin type A for treatment of chronic migraine: the double-blind phase of the PREEMPT clinical program. Cephalalgia 2009;29:34.

Dodick DW, DeGryse RE, Turkel CC. Headache symptoms of the PREEMPT population. Journal of Headache and Pain 2013;14(Suppl 1):99.

Dodick DW, Diener HC, Degryse RE, Turkel CC. OnabotulinumtoxinA treatment reduces headache duration in adults with chronic migraine: pooled results from the doubleblind, randomized, placebo-controlled phase of the PREEMPT clinical program. Headache 2010;50:58-9.

Dodick DW, Diener HC, Turkel CC, DeGryse R, Brin M. OnabotulinumtoxinA for chronic migraine treatment: $75 \%$ responder analysis from double-blind, randomized, placebocontrolled phase of PREEMPT. Journal of Headache and Pain 2013;14(Suppl 1):197.

Dodick DW, Diener HC, Turkel CC, Degryse RE, Brin MF. Onabotulinumtoxin A for treatment of chronic migraine: $75 \%$ responder analysis results from the double-blind, randomized, placebo-controlled phase of the PREEMPT clinical program. Cephalalgia 2011;31:87.

Dodick DW, Diener HW, Turkel CC, DeGryse RE, Brin M. OnabotulinumtoxinA for treatment of chronic migraine: $75 \%$ responder analysis results from the double-blind, randomized, placebo-controlled phase of the PREEMPT clinical program. Neurology 2012;78(1):03.227.

Dodick DW, Smith TR, Becker WJ, Gendolla A, Relja M, Martin V, et al. Botulinum neurotoxin type A for treatment of chronic migraine: PREEMPT 2 trial double-blind phase. Cephalalgia 2009;29:29.

Dodick DW, Turkel CC, DeGryse RE, Aurora SK, Silberstein SD, Lipton RB, et al. OnabotulinumtoxinA for treatment of chronic migraine: pooled results from the double-blind, randomized, placebo-controlled phases of the PREEMPT clinical program. Headache 2010;50(6):921-36.
Dodick DW, Turkel CC, Degryse RE, Aurora SK, Silberstein SD, Lipton RB, et al. OnabotulinumtoxinA for treatment of chronic migraine: a response. Headache 2011;51(6):1005-8.

Gillard P, Devine B, Bloudek LM, Liu L, Varon SF, Lipton RB, et al. Quality of life among patients suffering from migraine: health utility by frequency of headache days. Value in Health 2011;14(3):A207.

Lipton RB, Manack A, Aurora SK, Buse DC, DeGryse RE, Turkel CC. Demographic characteristics of chronic migraine sufferers in PREEMPT and the AMPP study. Headache 2010;50:32.

Lipton RB, Rosen NL, Ailani J, DeGryse RE, Gillard PJ, Varon SF. OnabotulinumtoxinA improves quality of life and reduces impact of chronic migraine over one year of treatment: pooled results from the PREEMPT randomized clinical trial program. Cephalalgia 2016;36(9):899-908.

Lipton RB, Varon S, Grosberg B, McAllister P J, Freltag F, Degryse RE, et al. Botulinum neurotoxin type $A$ treatment improves health-related quality of life and reduces the impact of chronic migraine: results from the double-blind phase of the PREEMPT clinical program. Cephalalgia 2009;29:32-3.

Lipton RB, Varon SF, Aurora SK, DeGryse RE, Turkel CC. Onabotulinumtoxin-A treatment reduces adverse impact of chronic migraine (CM): PREEMPT clinical program HIT-6 results. Journal of Headache and Pain 2010;11:S11.

Lipton RB, Varon SF, Aurora SK, Degryse RE, Turkel CC. OnabotulinumtoxinA treatment reduces adverse impact of chronic migraine (CM): PREEMPT clinical program HIT-6 results. Headache 2010;50:47-8.

Lipton RB, Varon SF, Goadsby PJ, DeGryse RE, Turkel CC. Onabotulinumtoxin-A treatment improves HRQOL and reduces the impact of chronic migraine: 56 week results from the PREEMPT clinical program. Journal of Headache and Pain 2010;11:S13.

Lipton RB, Varon SF, Grosberg B, McAllister PJ, Freitag F, Aurora SK, et al. OnabotulinumtoxinA improves quality of life and reduces impact of chronic migraine. Neurology 2011;77(15):1465-72.

Matharu M, Halker R, Pozo-Rosich P, DeGryse R, Manack Adams A, Aurora SK. The impact of onabotulinumtoxinA on severe headache days: PREEMPT 24-week pooled analysis. Cephalalgia 2016;36(Suppl 1):34-5.

Silberstein SD, Aurora SK, DeGryse RE, Turkel CC. Onabotulinumtoxin-A treatment reduces pain intensity in adults with chronic migraine: pooled results from the double-blind, placebo-controlled phase of PREEMPT. Journal of Headache and Pain 2010;11:S12.

Silberstein SD, Aurora SK, DeGryse RE, Turkel CC. OnabotulinumtoxinA treatment reduces pain intensity and suffering in adults with chronic migraine: pooled results from the double-blind, randomized, placebo-controlled phase of the PREEMPT clinical program. Headache 2010;50:8. 
Silberstein SD, Blumenfeld AM, Cady RK, Turner IM, Lipton RB, Diener HC, et al. OnabotulinumtoxinA for treatment of chronic migraine: PREEMPT 24-week pooled subgroup analysis of patients who had acute headache medication overuse at baseline. Journal of the Neurological Sciences 2013;331(1-2):48-56.

Silberstein SD, Blumenfeld AM, Cady RK, Turner IM, Lipton RB, Diener HC, et al. OnabotulinumtoxinA for treatment of chronic migraine: PREEMPT 24-week pooled subgroup analysis of patients who had acute headache medication overuse at baseline. Journal of the Neurological Sciences 2013;331(1-2):48-56.

Silberstein SD, Blumenfeld AM, Cady RK, Turner IM, Sirimanne M, DeGryse RE, et al. Botulinum neurotoxin type A for treatment of chronic migraine: analysis of the PREEMPT chronic migraine subgroup with baseline acute headache medication overuse. Cephalalgia 2009;29:31.

Silberstein SD, Dodick DW, Aurora SK, Diener HC, DeGryse RE, Lipton RB, et al. Per cent of patients with chronic migraine who responded per onabotulinumtoxinA treatment cycle: PREEMPT. Journal of Neurology, Neurosurgery, and Psychiatry 2015;86(9):996-1001.

Silberstein SD, Saper JR, Stein MR, DeGryse RE, Turkel CC. Onabotulinumtoxin-A for treatment of chronic migraine: 56week analysis of the PREEMPT chronic migraine subgroup with baseline acute headache medication overuse. Journal of Headache and Pain 2010;11:S13.

Silberstein SD, Varon SF, Diener HC, DeGryse RE, Turkel CC. Onabotulinumtoxin-A treatment improves quality of life in patients with chronic migraine (CM): MSQ results from PREEMPT. Journal of Headache and Pain 2010;11:S11-2.

Silberstein SD, Varon SF, Diener HC, Degryse RE, Turkel CC. OnabotulinumtoxinA treatment improves quality of life in patients with chronic migraine (CM): MSQ results from PREEMPT. Headache 2010;50:30-1.

Silberstein SW, Dodick DW, DeGryse R, Lipton R, Turkel CC. The percent of chronic migraine patients who responded to onabotulinumtoxinA treatment per treatment cycle in the PREEMPT clinical program. Neurology 2012;78(Suppl 1):200.

Silberstein SW, Dodick DW, DeGryse RE, LiptonR, Turkel CC. The percent of chronic migraine patients who responded to onabotulinumtoxinA treatment per treatment cycle in the PREEMPT clinical program. Journal of Headache and Pain 2013;14(Suppl 1):200.

Barrientos 2003 \{published data only (unpublished sought but not used)\}

Barrientos N, Chana P. Botulinum toxin type A in prophylactic treatment of migraine headaches: a preliminary study. Journal of Headache and Pain 2003;4(3):146-51.
Blumenfeld 2008 \{published data only (unpublished sought but not used)\}

Blumenfeld AM, Schim JD, Chippendale TJ. Botulinum toxin type $A$ and divalproex sodium for prophylactic treatment of episodic or chronic migraine. Headache 2008;48(2):210-20.

Blumenkron 2006 \{published data only (unpublished sought but not used)\}

Blumenkron D, Rivera C, Cuevas C. Efficacy of botulinum toxin type $A$ in patients with migraine [Eficacia del tratamiento con toxina botulinica tipo A en pacientes con migrana]. Medicina Interna de Mexico 2006;22(1):25-31.

Cady 2008 \{published data only (unpublished sought but not used)\} Cady R, Schreiber C. Botulinum toxin type A as migraine preventive treatment in patients previously failing oral prophylactic treatment due to compliance issues. Headache 2008;48(6):900-13.

Cady 2011 \{published data only (unpublished sought but not used)\}

* Cady RK, Schreiber CP, Porter JA, Blumenfeld AM, Farmer KU. A multi-center double-blind pilot comparison of onabotulinumtoxinA and topiramate for the prophylactic treatment of chronic migraine. Headache 2011;51(1):21-32.

Taylor FR. A comparison of the two evidence-based drug therapies for chronic migraine. Current Pain and Headache Reports 2011;15(3):153-6.

Cady 2014 \{published data only (unpublished sought but not used)\} Cady R. Calcitonin gene-related peptide levels in chronic migraine. clinicaltrials.gov/ct2/show/NCT01071096 (first received 19 February 2010).

Cady R, Durham P, Turner I, Vause C, Harding T, Browning R. Analysis of salivary CGRP and cytokine levels in chronic migraine subjects treated with onabotulinumtoxinA. Headache 2012;52(5):893.

* Cady R, Turner I, Dexter K, Beach ME, Cady R, Durham P. An exploratory study of salivary calcitonin gene-related peptide levels relative to acute interventions and preventative treatment with onabotulinumtoxinA in chronic migraine. Headache 2014;54(2):269-77.

Turner IM, Cady RK, Durham P, Dexter JK, Cady R, Browning R. An exploratory study of calcitonin gene-related peptide in chronic migraineurs receiving onabotulinumtoxinA: implications to pathophysiology and treatment responsiveness. Cephalalgia 2013;33:63-4.

Chankrachang 2011 \{published data only (unpublished sought but not used)\}

Chankrachang S, Arayawichanont A, Poungvarin N, Nidhinandana S, Boonkongchuen P, Towanabut S, et al. Efficacy and safety of botulinum toxin type A (Dysport) in the prophylaxis of migraine without aura. Journal of the Neurological Sciences 2009;285(Suppl 1):S150.

* Chankrachang S, Arayawichanont A, Poungvarin N, Nidhinandana S, Boonkongchuen P, Towanabut S, et al. 
Prophylactic botulinum type A toxin complex (Dysport) for migraine without aura. Headache 2011;51(1):52-63.

Federal University of Bahia. Botulinum toxin type $A$ in treatment of cranial allodynia in patients with headache. clinicaltrials.gov (NCT01357798) first received (23 May 2011).

Ipsen. Dysport ${ }^{\circledast}$ in migraine without aura prophylaxis: DIMWAP Study. clinicaltrials.gov/ct2/show/NCT00258609 (first received 24 November 2005).

\section{Diener 2010 (PREEMPT 2) \{published data only (unpublished} sought but not used)\}

Allergan Inc. A study using botulinum toxin type $A$ as headache prophylaxis for migraine patients with frequent headaches. clinicaltrials.gov/ct2/show/NCT00168428 (first received 15 September 2005).

Aurora SK, Dodick DW, Blumenfeld A, Degryse RE, Turkel CC. OnabotulinumtoxinA for chronic migraine: safety and tolerability of the effective treatment paradigm in the PREEMPT clinical program. Headache 2010;50:14-5.

Aurora SK, Dodick DW, DeGryse RE, Turkel CC. OnabotulinumtoxinA for chronic migraine: efficacy, safety, and tolerability in patients who received all 5 treatment cycles in PREEMPT. Journal of Headache and Pain 2012;14(Suppl 1):199.

Aurora SK, Dodick DW, DeGryse RE, Turkel CC. Onabotulinumtoxina for chronic migraine: efficacy and tolerability in patients who received all 5 treatment cycles in the PREEMPT clinical program. Headache 2011;51:61.

Aurora SK, Dodick DW, Diener HC, DeGryse RE, Turkel CC, Lipton RB, et al. OnabotulinumtoxinA for chronic migraine: efficacy, safety, and tolerability in patients who received all five treatment cycles in the PREEMPT clinical program. Acta Neurologica Scandinavica 2014;129(1):61-70.

Aurora SK, Halker R, Pozo-Rosich P, DeGryse R, Adams A M, Matharu M. The impact of onabotulinumtoxinA on severe headache days: PREEMPT 24-week pooled analysis. American Journal of Physical Medicine and Rehabilitation 2016;8(Suppl 9):S296.

Aurora SK, Halker R, Pozo-Rosich P, DeGryse R, Adams A, Matharu $M$. The impact of onabotulinumtoxinA on severe headache days: PREEMPT 24-week pooled analysis. Headache 2016;56:27-8.

Aurora SK, Silberstein SD, DeGryse RE, Turkel CC. Onabotulinumtoxin A for treatment of chronic migraine (CM): analysis of the PREEMPT chronic migraine subgroup with and without prior migraine prophylactic treatment. Cephalalgia 2011;31:18-9.

Aurora SK, Winner P, Freeman MC, Spierings EL, Heiring J, DeGryse RE, et al. Botulinum neurotoxin type A for treatment of chronic migraine: pooled analyses of the PREEMPT clinical program 32-week open-label phase. Cephalalgia 2009;29:7-8.

Aurora SK, Winner P, Freeman MC, Spierings EL, Heiring JO, DeGryse RE, et al. OnabotulinumtoxinA for treatment of chronic migraine: pooled analyses of the 56-week PREEMPT clinical program. Headache 2011;51(9):1358-73.

Batty AJ, Hansen RN, Bloudek LM, Varon SF, Hayward EJ, Pennington BW, et al. The cost-effectiveness of onabotulinumtoxinA for the prophylaxis of headache in adults with chronic migraine in the UK. Journal of Medical Economics 2013;16(7):877-87.

Blumenfeld AM, Silberstein SD, Dodick DW, Aurora SK, Turkel CC, Binder WJ. Method of injection of onabotulinumtoxinA for chronic migraine: a safe, well-tolerated, and effective treatment paradigm based on the PREEMPT clinical program. Headache 2010;50(9):1406-18.

Blumenfeld AM, Silberstein SD, Dodick DW, Aurora SK, Turkel CC, Binder WJ. Onabotulinumtoxin-A for chronic migraine: PREEMPT trials establish a safe and effective dose and injection paradigm. Journal of Headache and Pain 2010;11:S12.

Blumenfeld AM, Silberstein SD, Dodick DW, Aurora SK, Turkel CC, Binder WJ. OnabotulinumtoxinA for chronic migraine: PREEMPT trials establish a safe and effective dose and injection paradigm. Toxicon 2013;68:106-7.

Chen SP, Fuh JL, Wang SJ. OnabotulinumtoxinA: preventive treatment for chronic migraine. Current Pain and Headache Reports 2011;15(1):4-7.

* Diener HC, Dodick DW, Aurora SK, Turkel CC, DeGryse RE, Lipton RB, et al. OnabotulinumtoxinA for treatment of chronic migraine: results from the double-blind, randomized, placebo-controlled phase of the PREEMPT 2 trial. Cephalalgia 2010;30(7):804-14.

Diener HC, Dodick DW, DeGryse RE, Turkel CC. Onabotulinumtoxin-A for treatment of chronic migraine: PREEMPT 24-week pooled subgroup analysis of patients without medication overuse. European Journal of Neurology 2011;18:191.

Diener HC, Dodick DW, DeGryse RE, Turkel CC. OnabotulinumtoxinA for treatment of chronic migraine: PREEMPT 24-week pooled subgroup analysis of patients without medication overuse. Journal of Headache and Pain 2012;14(Suppl 1):204

Dodick DW, Aurora SK, DeGryse RE, Turkel CC, Silberstein SD, Lipton RB, et al. Onabotulinumtoxin-A for treatment of chronic migraine: pooled results from the double-blind, randomized, placebo-controlled phase of the PREEMPT clinical program. Journal of Headache and Pain 2010;11:S14.

Dodick DW, Aurora SK, Turkel CC, DeGryse RE, Silberstein SD, Lipton RB, et al. Botulinum neurotoxin type a for treatment of chronic migraine: double-blind, randomized, placebocontrolled PREEMPT trials. Cephalalgia 2009;29(12):1350.

Dodick DW, Aurora SK, Turkel CC, DeGryse RE, Silberstein SD, Lipton RB, et al. OnabotulinumtoxinA for treatment of chronic migraine: pooled results from the double-blind, randomized, placebo-controlled phase of the PREEMPT clinical program. Toxicon 2013;68:110. 
Dodick DW, DeGryse RE, Turkel CC. Headache symptoms of the PREEMPT population. Journal of Headache and Pain 2012;14(Suppl 1):99.

Dodick DW, Diener HC, Degryse RE, Turkel CC.

OnabotulinumtoxinA treatment reduces headache duration in adults with chronic migraine: pooled results from the doubleblind, randomized, placebo-controlled phase of the PREEMPT clinical program. Headache 2010;50:58-9.

Dodick DW, Diener HC, Turkel CC, DeGryse RE, Brin M. OnabotulinumtoxinA for chronic migraine treatment: $75 \%$ responder analysis from double-blind, randomized, placebocontrolled phase of PREEMPT. Journal of Headache and Pain 2012;14(Suppl 1):197.

Dodick DW, Diener HC, Turkel CC, DeGryse RE, Brin M. OnabotulinumtoxinA for treatment of chronic migraine: $75 \%$ responder analysis results from the double-blind, randomized, placebo-controlled phase of the PREEMPT clinical program. Neurology 2012;78(1):03.227.

Dodick DW, Diener HC, Turkel CC, Degryse RE, Brin MF. Onabotulinumtoxin A for treatment of chronic migraine: $75 \%$ responder analysis results from the double-blind, randomized, placebo-controlled phase of the PREEMPT clinical program. Cephalalgia 2011;31:87.

Dodick DW, Smith TR, Becker WJ, Gendolla A, Relja M, Martin V, et al. Botulinum neurotoxin type $A$ for treatment of chronic migraine: PREEMPT 2 trial double-blind phase. Cephalalgia 2009;29:29.

Dodick DW, Smith TR, Becker WJ, Gendolla A, Relja M, Martin V, et al. Botulinum neurotoxin type $A$ for treatment of chronic migraine: PREEMPT 2 trial double-blind phase. Cephalalgia 2009;29:29.

Dodick DW, Turkel CC, DeGryse RE, Aurora SK, Silberstein SD, Lipton RB, et al. OnabotulinumtoxinA for treatment of chronic migraine: pooled results from the double-blind, randomized, placebo-controlled phases of the PREEMPT clinical program. Headache 2010;50(6):921-36.

Dodick DW, Turkel CC, Degryse RE, Aurora SK, Silberstein SD, Lipton RB, et al. OnabotulinumtoxinA for treatment of chronic migraine: a response. Headache 2011;51(6):1005-8.

Dodlck DW, Aurora SK, Turkel CC, Degryse RE, Silberstein SD, Llpton RB, et al. Botulinum neurotoxin type A for treatment of chronic migraine: The double-blind phase of the PREEMPT clinical program. Cephalalgia 2009;29:34.

Gillard P, Devine B, Bloudek LM, Liu L, Varon SF, Lipton RB, et al. Quality of life among patients suffering from migraine: Health utility by frequency of headache days. Value in Health 2011;14(3):A207.

Lipton RB, Manack A, Aurora SK, Buse DC, DeGryse RE, Turkel CC. Demographic characteristics of chronic migraine sufferers in PREEMPT and the AMPP study. Headache 2010;50:32.
Lipton RB, Rosen NL, Ailani J, DeGryse RE, Gillard PJ, Varon SF. OnabotulinumtoxinA improves quality of life and reduces impact of chronic migraine over one year of treatment: Pooled results from the PREEMPT randomized clinical trial program. Cephalalgia 2016;36(9):899-908.

Lipton RB, Varon S, Grosberg B, McAllister PJ, Freltag F, Degryse RE, et al. Botulinum neurotoxin type $A$ treatment improves health-related quality of life and reduces the impact of chronic migraine: Results from the double-blind phase of the PREEMPT clinical program. Cephalalgia 2009;29:32-3.

Lipton RB, Varon SF, Aurora SK, DeGryse RE, Turkel CC. Onabotulinumtoxin-A treatment reduces adverse impact of chronic migraine (CM): PREEMPT clinical program HIT-6 results. Journal of Headache and Pain 2010;11:S11.

Lipton RB, Varon SF, Aurora SK, Degryse RE, Turkel CC. OnabotulinumtoxinA treatment reduces adverse impact of chronic migraine (CM): PREEMPT clinical program HIT-6 results. Headache 2010;50:47-8.

Lipton RB, Varon SF, Goadsby PJ, DeGryse RE, Turkel CC. Onabotulinumtoxin-A treatment improves $\mathrm{HRQOL}$ and reduces the impact of chronic migraine: 56 week results from the PREEMPT clinical program. Journal of Headache and Pain 2010;11:S13.

Lipton RB, Varon SF, Grosberg B, McAllister PJ, Freitag F, Aurora SK, et al. OnabotulinumtoxinA improves quality of life and reduces impact of chronic migraine. Neurology 2011;77(15):1465-72.

Matharu M, Halker R, Pozo-Rosich P, DeGryse R, Manack Adams A, Aurora SK. The impact of onabotulinumtoxinA on severe headache days: PREEMPT 24-week pooled analysis. Cephalalgia 2016;36(Suppl 1):34-5.

Silberstein SD, Aurora SK, DeGryse RE, Turkel CC. Onabotulinumtoxin-A treatment reduces pain intensity in adults with chronic migraine: pooled results from the double-blind, placebo-controlled phase of PREEMPT. Journal of Headache and Pain 2010;11:S12.

Silberstein SD, Aurora SK, DeGryse RE, Turkel CC. OnabotulinumtoxinA treatment reduces pain intensity and suffering in adults with chronic migraine: pooled results from the double-blind, randomized, placebo-controlled phase of the PREEMPT clinical program. Headache 2010;50:8.

Silberstein SD, Blumenfeld AM, Cady RK, Turner IM, Lipton RB, Diener $\mathrm{HC}$, et al. OnabotulinumtoxinA for treatment of chronic migraine: PREEMPT 24-week pooled subgroup analysis of patients who had acute headache medication overuse at baseline. Journal of the Neurological Sciences 2013;331(1-2):48-56.

Silberstein SD, Blumenfeld AM, Cady RK, Turner IM, Lipton RB, Diener $\mathrm{HC}$, et al. OnabotulinumtoxinA for treatment of chronic migraine: PREEMPT 24-week pooled subgroup analysis of patients who had acute headache medication overuse at baseline. Journal of the Neurological Sciences 2013;331(1-2):48-56. 
Silberstein SD, Blumenfeld AM, Cady RK, Turner IM, Sirimanne M, DeGryse RE, et al. Botulinum neurotoxin type A for treatment of chronic migraine: analysis of the PREEMPT chronic migraine subgroup with baseline acute headache medication overuse. Cephalalgia 2009;29:31.

Silberstein SD, Dodick DW, Aurora SK, Diener HC, DeGryse RE, Lipton RB, et al. Per cent of patients with chronic migraine who responded per onabotulinumtoxinA treatment cycle: PREEMPT. Journal of Neurology, Neurosurgery, and Psychiatry 2015;86(9):996-1001.

Silberstein SD, Dodick DW, DeGryse RE, Lipton R, Turkel CC. The percent of chronic migraine patients who responded to onabotulinumtoxinA treatment per treatment cycle in the PREEMPT clinical program. Journal of Headache and Pain 2013;14(Suppl 1):200.

Silberstein SD, Saper JR, Stein MR, DeGryse RE, Turkel CC. Onabotulinumtoxin-A for treatment of chronic migraine: 56week analysis of the PREEMPT chronic migraine subgroup with baseline acute headache medication overuse. Journal of Headache and Pain 2010;11:S13.

Silberstein SD, Varon SF, Diener HC, DeGryse RE, Turkel CC. Onabotulinumtoxin-A treatment improves quality of life in patients with chronic migraine $(\mathrm{CM})$ : MSQ results from PREEMPT. Journal of Headache and Pain 2010;11:S11-2.

Silberstein SD, Varon SF, Diener HC, Degryse RE, Turkel CC. OnabotulinumtoxinA treatment improves quality of life in patients with chronic migraine (CM): MSQ results from PREEMPT. Headache 2010;50:30-1.

Silberstein SW, Dodick DW, DeGryse RE, Lipton RB, Turkel CC. The percent of chronic migraine patients who responded to onabotulinumtoxinA treatment per treatment cycle in the PREEMPT clinical program. Neurology 2012;78(Suppl 1):200.

Elkind I 2006 \{published data only (unpublished sought but not used)\}

Elkind AH, O'Carroll P, Blumenfeld A, DeGryse R, Dimitrova R, BoNTASG. A series of three sequential, randomized, controlled studies of repeated treatments with botulinum toxin type $A$ for migraine prophylaxis. Journal of Pain 2006;7(10):688-96.

Elkind II 2006 \{published data only (unpublished sought but not used)\}

Elkind AH, O'Carroll P, Blumenfeld A, DeGryse R, Dimitrova R, Bo NTASG. A series of three sequential, randomized, controlled studies of repeated treatments with botulinum toxin type $A$ for migraine prophylaxis. Journal of Pain 2006;7(10):688-96.

Freitag 2008 \{published data only (unpublished sought but not used)\}

Freitag FG, Diamond S, Diamond M, Urban G. Botulinum toxin type $A$ in the treatment of chronic migraine without medication overuse. Headache 2008;48(2):201-9.

Hollanda 2014 \{published data only (unpublished sought but not used)\}

* Hollanda L, Monteiro L, Melo AS. Botulinum toxin type

A for cephalic cutaneous allodynia in chronic migraine: a randomized, double-blinded, placebo-controlled trial. Neurology International 2014;6(4):70-3.

Monteiro L, Hollanda L, Melo A. Botulinum toxin type A for the treatment of cephalic cutaneous allodynia in chronic migraine: a randomized, double-blinded, placebo-controlled pilot trial. Movement Disorders 2013;28:S425.

Hou 2015 \{published data only (unpublished sought but not used)\}

* Hou M, Xie JF, Kong XP, Zhang Y, Shao YF, Wang C, et al. Acupoint injection of onabotulinumtoxin $A$ for migraines. Toxins 2015;7(11):4442-54.

Shao YF, Zhang Y, Zhao P, Yan WJ, Kong XP, Fan LL, et al. Botulinum toxin type $A$ therapy in migraine: preclinical and clinical trials. Iranian Red Crescent Medical Journal 2013;15(10):e7704.

Jabbari 2014 \{unpublished data only\}

* Jabbari B. Investigation of efficacy and safety of botulinum toxin A (BOTOX-Allergan Inc.) in migraine headaches. clinicaltrials.gov/ct2/show/NCT00660192 (first received 17 April 2008).

Richardson D, Jabbari B. Botulinum toxin treatment of chronic migraine-a double blind study with a novel technique employing fewer injections. Neurology 2016;86(Suppl 16):4.124.

Jost 2011 \{published data only (unpublished sought but not used)\} Jost W, Neidhardt S, Klasser M. Low-dosed botulinum toxin in migraine without aura: a randomized, double-blind placebocontrolled crossover study. Klinische Neurophysiologie Conference 2010;41(1):2.

* Jost WH. Low-dosed botulinum toxin A in the prophylactic management of unilateral migraine: a randomized doubleblind placebo-controlled crossover study. Open Pain Journal 2011;4(1):4-7.

Lauretti 2014 \{published and unpublished data\}

* Lauretti GR, Rosa CP, Kitayama A, Lopes BCP. Comparison of Botox or Prosigne and facial nerve blockade as adjuvant in chronic migraine. Journal of Biomedical Science and Engineering 2014;7:446-52.

Lauretti GR, Rosa CP, Lima ICPR, Almeida R, Resende CS. Randomized, double-blind, controlled trial of botulinum toxin type-A (Prosigne-Chinese or Botox) as coadjuvant for chronic daily headache. European Journal of Pain 2009;13:S126.

\section{Mathew 2009 \{published data only\}}

Mathew NT. A double-blind comparison of botulinum toxin type A (BoNTA) and topiramate for the prophylactic treatment of transformed migraine headaches: a pilot study. European Journal of Neurology 2008;15(Suppl 3):328.

* Mathew NT, Jaffri SF. A double-blind comparison of onabotulinumtoxinA (BOTOX) and topiramate (TOPAMAX) for the prophylactic treatment of chronic migraine: a pilot study. Headache 2009;49(10):1466-78. 
Mazza 2016 \{published and unpublished data\}

Mazza MR, Ferrigno G, Vescio B, Quattrone A, Bono F. Subcutaneous botulinum toxin type $A$ treatment for prophylaxis of headaches in chronic migraine: a new therapeutic strategy. Cephalalgia 2016; Vol. 36:35.

Millán-Guerrero 2009 \{published data only (unpublished sought but not used)\}

Millán-Guerrero RO, Isais-Millán S, Barreto-Vizcaíno S, RiveraCastaño L, Rios-Madariaga C. Subcutaneous histamine versus botulinum toxin type $A$ in migraine prophylaxis: a randomized, double-blind study. European Journal of Neurology 2009;16(1):88-94.

Petri 2009 \{published data only (unpublished sought but not used)\} Petri S, Tölle T, Straube A, Pfaffenrath V, Stefenelli U, CeballosBaumann A, et al. Botulinum toxin as preventive treatment for migraine: a randomized double-blind study. European Neurology 2009;62(4):204-11.

Relja 2007 \{published data only (unpublished sought but not used)\} Relja M, Poole AC, Schoenen J, Pascual J, Lei X, Thompson C, et al. A multicentre, double-blind, randomized, placebocontrolled, parallel group study of multiple treatments of botulinum toxin type A (BoNTA) for the prophylaxis of episodic migraine headaches. Cephalalgia 2007;27(6):492-503.

Saper 2007 \{published data only (unpublished sought but not used)\}

Saper JR, Mathew NT, Loder EW, DeGryse R, VanDenburgh AM, BoNTASG. A double-blind, randomized, placebo-controlled comparison of botulinum toxin type a injection sites and doses in the prevention of episodic migraine. Pain Medicine 2007;8(6):478-85.

Silberstein 2000 \{published data only (unpublished sought but not used)\}

Silberstein S, Mathew N, Saper J, Jenkins S. Botulinum toxin type $A$ as a migraine preventive treatment. Headache 2000;40(6):445-50.

Vo 2007 \{published data only (unpublished sought but not used)\} Vo AH, Satori R, Jabbari B, Green J, Killgore WD, Labutta R, et al. Botulinum toxin type-a in the prevention of migraine: a double-blind controlled trial. Aviation Space and Environmental Medicine 2007;78(Suppl 5):B113-8.

\section{References to studies excluded from this review}

\section{Cady 2012 \{published data only\}}

Cady R. A study to evaluate the tolerability of Botox and topiramate or Botox and placebo and effect on cognitive efficiency. clinicaltrials.gov/ct2/show/NCT01700387 (first received 4 October 2012).

\section{De Tommaso 2016 \{published data only\}}

Franco G, Vecchio E, Delussi M, Ricci K, Montemurno A, De Tommaso M. Mechanism of action and clinical evidence of botulinum toxin in chronic migraine. Journal of Headache and Pain 2015;16(Suppl 1):A138.
* de Tommaso M, Delussi M, Ricci K, Montemurno A, Carbone I, Vecchio $E$. Effects of onabotulintoxinA on habituation of laser evoked responses in chronic migraine. Toxins 2016;8:163.

\section{Evers 2004 \{published data only\}}

Evers S, Vollmer-Haase J, Schwaag S, Rahmann A, Husstedt I $W$, Frese $A$. Botulinum toxin A in the prophylactic treatment of migraine - a randomized, double-blind, placebo-controlled study. Cephalalgia 2004;24(10):838-43.

Guyuron 2005 \{published data only\}

* Guyuron B, Kriegler JS, Davis J, Amini SB. Comprehensive surgical treatment of migraine headaches. Plastic and Reconstructive Surgery 2005;115(1):1-9.

Guyuron B, Kriegler JS, Davis J, Amini SB. Five-year outcome of surgical treatment of migraine headaches. Plastic and Reconstructive Surgery 2011;127(2):603-8.

Guyuron B, Tucker T, Davis J. Surgical treatment of migraine headaches. Plastic and Reconstructive Surgery 2002;109:2183-9.

\section{Ondo 2004 \{published data only\}}

Ondo WG, Vuong KD, Derman HS. Botulinum toxin A for chronic daily headache: a randomized, placebo-controlled, parallel design study. Cephalalgia 2004;24(1):60-5.

Ruggeri 2013 \{published data only\}

Ruggeri M, Carletto A, Marchetti M. Cost-effectiveness of onabotulinumtoxinA for the prophylaxis of chronic migraine [Valutazione economica della tossina botulinica per la profilassi dell'emicrania cronica]. Pharmaco Economics 2013;15(1):19-33.

Schwedt 2007 \{published data only\}

Schwedt TJ, Hentz JG, Dodick DW. Factors associated with the prophylactic effect of placebo injections in subjects enrolled in a study of botulinum toxin for migraine. Cephalalgia 2007;27(6):528-34.

\section{References to studies awaiting assessment}

Brin 2000 \{published data only\}

Brin M, Swope D, O'Brien C, Abbasi S, Pogoda JM. Botox for migraine: double-blind, placebo-controlled, region specific evaluation. Cephalalgia 2000;20:421-2.

Ipsen 2006 \{published data only\} Ipsen. Efficacy and safety study of Dysport used for migraine prophylaxis. clinicaltrials.gov/ct2/show/NCT00301665 (first received 13 March 2006).

\section{Kuper 2007 \{published data only\}}

Kuper M, Diener H C. Botulinum toxin type $A$ in migraine prophylaxis: placebo effect or efficacy? [Botulinumtoxin A in der migraneprophylaxe: plazeboeffekt oder wirksamkeit?]. Aktuelle Neurologie 2007;34(8):464-5.

Mathew 2005 \{published data only\}

Dodick DW, Mauskop A, Elkind AH, DeGryse R, Brin MF, Silberstein SD, et al. Botulinum toxin type a for the prophylaxis of chronic daily headache: subgroup analysis 
of patients not receiving other prophylactic medications: a randomized double-blind, placebo-controlled study. Headache 2005;45(4):315-24.

* Mathew NT, Frishberg BM, Gawel M, Dimitrova R, Gibson J, Turkel C, et al. Botulinum toxin type A (BOTOX) for the prophylactic treatment of chronic daily headache: a randomized, double-blind, placebo-controlled trial. Headache 2005;45(4):293-307.

\section{Silberstein 2005 \{published data only\}}

Silberstein SD, Stark SR, Lucas SM, Christie SN, Degryse RE, Turkel CC, et al. Botulinum toxin type A for the prophylactic treatment of chronic daily headache: a randomized, doubleblind, placebo-controlled trial. Mayo Clinic Proceedings 2005;80(9):1126-37.

\section{References to ongoing studies \\ NCT02074163 \{published data only\}}

NCT02074163. ASIS for Botox in Chronic Migraine. clinicaltrials.gov/ct2/show/NCT02074163 (first received 28 February 2014).

\section{NCT02291380 \{published data only\}}

NCT02291380. A study to evaluate botulinum toxin type A for injection (HengLi) for prophylactic treatment of chronic migraine. clinicaltrials.gov/ct2/show/NCT02291380. clinicaltrials.gov, (first received 14 November 2014): (NCT02291380).

\section{NTR3440 \{published data only\}}

NTR3440. Chronification and reversibility of migraine. apps.who.int/trialsearch/Trial2.aspx?TriallD=NTR3440 (first received 15 May 2012).

\section{Additional references}

\section{Aoki 2005}

Aoki KR. Review of a proposed mechanism for the antinociceptive action of botulinum toxin type A. First International Porto Pirgos Conference on Advances in Neuroscience 2005;26(5):785-93. [DOI: 10.1016/ j.neuro.2005.01.017]

\section{Aurora 2010}

Aurora SK, Dodick DW, Turkel CC, DeGryse RE, Silberstein SD, Lipton RB, et al. PREEMPT 1 Chronic Migraine Study Group. OnabotulinumtoxinA for treatment of chronic migraine: results from the double-blind, randomized, placebo-controlled phase of the PREEMPT 1 trial. Cephalalgia 2010;30(7):793-803. [DOI: 10.1177/0333102410364676]

\section{Batty 2013}

Batty AJ, Hansen RN, Bloudek LM, Varon SF, Hayward EJ, Pennington BW, et al. The cost-effectiveness of onabotulinumtoxinA for the prophylaxis of headache in adults with chronic migraine in the UK. Journal of Medical Economics 2013;16(7):877-87.

\section{Bigal 2008}

Bigal ME, Serrano D, Reed M, Lipton RB. Chronic migraine in the population - burden, diagnosis, and satisfaction with treatment. Neurology 2008;71(8):559-66. [DOI: 10.1212/01.wnl.0000323925.29520.e7]

\section{BMA/RPS 2014}

British Medical Association and the Royal Pharmaceutical Society. British National Formulary (BNF). Available from www.bnf.org accessed 12 February 2015.

\section{Brin 2002}

Brin MF, Hallett M, Jankovic J. Scientific and Therapeutic Aspects of Botulinum Toxin. Philadelphia: Lippincott Williams \& Wilkins, 2002.

\section{Burstein 2014}

Burstein R, Zhang X, Levy D, Aoki KR, Brin MF. Selective inhibition of meningeal nociceptors by botulinum neurotoxin type A: therapeutic implications for migraine and other pains. Cephalalgia 2014;34(11):853-69. [DOI: 10.1177/0333102414527648]

\section{Cherkin 1998}

Cherkin DC, Wheeler KJ, Barlow W, Deyo RA. Medication use for low back pain in primary care. Spine 1998;23:607-14. [DOI: 10.1097/00007632-199803010-00015]

\section{Cui 2004}

Cui M, Khanijou S, Rubino J, Aoki KR. Subcutaneous administration of botulinum toxin A reduces formalin-induced pain. Pain 2004;107:125-33. [DOI: 10.1016/j.pain.2003.10.008]

\section{Dechartres 2013}

Dechartres A, Trinquart L, Boutron I, Ravaud P. Influence of trial sample size on treatment effect estimates: metaepidemiological study. BMJ 2013;346:f2304.

\section{Deeks 2011}

Deeks JJ, Higgins JPT, Altman DG (editors). Chapter 9: Analysing data and undertaking meta-analyses. In: Higgins JPT, Green $\mathrm{S}$ (editors). Cochrane Handbook for Systematic Reviews of Interventions Version 5.1.0 (updated March 2011). The Cochrane Collaboration, 2011. Available from handbook.cochrane.org.

\section{Diener 2007}

Diener HC, Bussone G, Van Oene JC, Lahaye M, Schwalen S, Goadsby PJ, et al. Topiramate reduces headache days in chronic migraine: a randomized, double-blind, placebo-controlled study. Cephalalgia 2007;27:814-23.

\section{Diener 2010}

Diener HC, Dodick DW, Aurora SK, Turkel CC, DeGryse RE, Lipton RB, et al. OnabotulinumtoxinA for treatment of chronic migraine: results from the double-blind, randomized, placebo-controlled phase of the PREEMPT 2 trial. Cephalalgia 2010;30(7):804-14. [DOI: 10.1177/0333102410364677]

\section{Elkind 2006}

Elkind AH, O'Carroll P, Blumenfeld A, DeGryse R, Dimitrova R, BoNTASG. A series of three sequential, randomized, controlled 
studies of repeated treatments with botulinum toxin type A for migraine prophylaxis. Journal of Pain 2006;7(10):688-96.

\section{GBD 2016}

GBD 2015 Disease and Injury Incidence and Prevalence Collaborators. Global, regional, and national incidence, prevalence, and years lived with disability for 310 diseases and injuries, 1990-2015: a systematic analysis for the Global Burden of Disease Study 2015. Lancet 2016;388:1545-602.

\section{Giamberardino 2016}

Giamberardino MA, Affaitati G, Curto M, Negro A, Costantini R, Martelletti P. Anti-CGRP monoclonal antibodies in migraine: current perspectives. Internal and Emergency Medicine 2016;11(8):1045-57.

\section{Goadsby 2002}

Goadsby PJ, Lipton RB, Ferrari MD. Migraine: current understanding and treatment. Drug Therapy 2002;346:257-70. [DOI: 10.1056/NEJMra010917]

\section{Goadsby 2017}

Goadsby PJ, Reuter U, Hallstrom Y, Broessner G, Bonner JH, Zhang $\mathrm{F}$, et al. A controlled trial of erenumab for episodic migraine. New England Journal of Medicine 2017;377(22):2123-32.

\section{Goodsell 2013}

Goodsell D. SNARE proteins. Research Collaboratory for Structural Bioinformatics (RCSB) Protein Data Bank (PDB). November 2013. Available from www.rcsb.org/pdb/101/ motm.do?momID=167 [accessed on 27/07/2017]. [DOI: 10.2210/ rcsb_pdb/mom_2013_11]

\section{GRADEpro GDT 2015 [Computer program]}

McMaster University. GRADEpro GDT. Version accessed 1 March 2017. Hamilton (ON): McMaster University (developed by Evidence Prime), 2015.

\section{Guyatt 2008}

Guyatt GH, Oxman AD, Vist GE, Kunz R, Falck-Ytter Y, AlonsoCoello $P$, et al. GRADE: an emerging consensus on rating quality of evidence and strength of recommendations. $B M J$ 2008;336(7650):924-6. [DOI: 10.1136/bmj.39489.470347.AD]

\section{Hawker 2011}

Hawker GA, Mian S, Kendzerska T, French M. Measures of adult pain: Visual Analog Scale for Pain (VAS Pain), Numeric Rating Scale for Pain (NRS Pain), McGill Pain Questionnaire (MPQ), Short-Form McGill Pain Questionnaire (SF-MPQ), Chronic Pain Grade Scale (CPGS), Short Form-36 Bodily Pain Scale (SF-36 BPS), and Measure of Intermittent and Constant Osteoarthritis Pain (ICOAP). Arthritis Care and Research 2011;63 Suppl 11:S240-52.

\section{Hayton 2005}

Hayton MJ, Santini AJ, Hughes PJ, Frostick SP, Trail IA, Stanley JK. Botulinum toxin injection in the treatment of tennis elbow. A double-blind, randomized, controlled, pilot study. Journal of Bone \& Joint Surgery 2005;87(3):503-7. [DOI: 10.2106/ JBJS.D.01896]

\section{Hepp 2015}

Hepp Z, Dodick DW, Varon SF, Gillard P, Hansen RN, Devine EB. Adherence to oral migraine-preventive medications among patients with chronic migraine. Cephalalgia 2015;35(6):478-88.

\section{Hepp 2016}

Hepp Z, Dodick DW, Varon SF, Chia J, Matthew N, Gillard P, et al. Persistence and switching patterns of oral migraine prophylactic medications among patients with chronic migraine: a retrospective claims analysis. Cephalalgia 2016;37(5):470-85.

\section{Higgins 2003}

Higgins JPT, Thompson SG, Deeks JJ, Altman DG. Measuring inconsistency in meta-analyses. BMJ 2003;327:557-60.

\section{Higgins 2011a}

Higgins JPT, Green S (editors). Chapter 7: Selecting studies and collecting data. In: Higgins JPT, Green S (editors), Cochrane Handbook for Systematic Reviews of Interventions Version 5.1.0 (updated March 2011). The Cochrane Collaboration, 2011. Available from handbook.cochrane.org.

\section{Higgins 2011b}

Higgins JPT, Altman DG, Sterne JAC (editors). Chapter 8: Assessing risk of bias in included studies. In: Higgins JPT, Green $\mathrm{S}$ (editors). Cochrane Handbook for Systematic Reviews of Interventions Version 5.1.0 (updated March 2011). The Cochrane Collaboration, 2011. Available from handbook.cochrane.org.

\section{Higgins 2011c}

Higgins JPT, Deeks JJ, Altman DG (editors). Chapter 16: Special topics in statistics. In: Higgins JPT, Green S (editors), Cochrane Handbook for Systematic Reviews of Interventions Version 5.1.0 (updated March 2011). The Cochrane Collaboration, 2011. Available from handbook.cochrane.org.

\section{IHS 1988}

Headache Classification Committee of the International Headache Society. Classification and diagnostic criteria for headache disorders, cranial neuralgias and facial pain. Cephalalgia 1988;8(Suppl. 7):1-96. [DOI: 10.1111/j.1468-2982.1991.tb00021.x/10.1111/ j.1468-2982.1991.tb00022.x]

\section{IHS 2004}

Headache Classification Committee of the International Headache Society. The International Classification of Headache Disorders, 2nd edition, 1st revision. Cephalalgia 2004;24(Suppl 1):1-160. [DOI: 10.1111/j.1468-2982.2004.00653.x]

\section{IHS 2013}

Headache Classification Committee of the International Headache Society (IHS). The international classification of headache disorders, 3rd edition. Cephalalgia 2013;33(9):629-808. [DOI: 10.1177/0333102413485658]

\section{Jankovic 1990}

Jankovic J, Schwartz K. Botulinum toxin injections for cervical dystonia. Neurology 1990;40:277-80. [DOI: 10.1212/ WNL.40.2.277] 


\section{Keizer 2002}

Keizer SB, Rutten HP, Pilot P, Morré HH, v Os JJ, Verburg AD. Botulinum toxin injection versus surgical treatment for tennis elbow: a randomized pilot study. Clinical Orthopaedics and Related Research 2002;401:125-31.

\section{Lefebvre 2011}

Lefebvre C, Manheimer E, Glanville J. Chapter 6: Searching for studies. In: Higgins JPT, Green S (editors). Cochrane Handbook for Systematic Reviews of Interventions Version 5.1.0 (updated March 2011). The Cochrane Collaboration, 2011. Available from handbook.cochrane.org.

\section{Linde 2004}

Linde K, Rossnagel K. Propranolol for migraine prophylaxis. Cochrane Database of Systematic Reviews 2004, Issue 2. [DOI: 10.1002/14651858.CD003225.pub2]

\section{Linde 2012}

Linde M, Gustavsson A, Stovner LJ, Steiner TJ, Barré J, Katsarava Z, et al. The cost of headache disorders in Europe: the Eurolight project. European Journal of Neurology 2012;19:703-11. [DOI: 10.1111/j.1468-1331.2011.03612.x]

\section{Linde 2013a}

Linde M, Mulleners WM, Chronicle EP, McCrory DC. Gabapentin or pregabalin for the prophylaxis of episodic migraine in adults. Cochrane Database of Systematic Reviews 2013, Issue 6. [DOI: 10.1002/14651858.CD010609]

\section{Linde 2013b}

Linde M, Mulleners WM, Chronicle EP, McCrory DC. Antiepileptics other than gabapentin, pregabalin, topiramate, and valproate for the prophylaxis of episodic migraine in adults. Cochrane Database of Systematic Reviews 2013, Issue 6. [DOI: 10.1002/14651858.CD010608]

\section{Linde 2013c}

Linde M, Mulleners WM, Chronicle EP, McCrory DC. Topiramate for the prophylaxis of episodic migraine in adults. Cochrane Database of Systematic Reviews 2013, Issue 6. [DOI: 10.1002/14651858.CD010610]

\section{Linde 2013d}

Linde M, Mulleners WM, Chronicle EP, McCrory DC. Valproate (valproic acid or sodium valproate or a combination of the two) for the prophylaxis of episodic migraine in adults. Cochrane Database of Systematic Reviews 2013, Issue 6. [DOI: 10.1002/14651858.CD010611]

\section{Lipton 2007}

Lipton RB, Bigal ME, Diamond M, Freitag F, Reed ML, Stewart WF. Migraine prevalence, disease burden, and the need for preventive therapy. Neurology 2007;68(5):343-9.

\section{Moher 2009}

Moher D, Liberati A, Tetzlaff J, Altman DG, The PRISMA Group (2009). Preferred Reporting Items for Systematic Reviews and Meta-Analyses: The PRISMA Statement. PLoS Medicine 6;7:e1000097. [DOI: 10.1371/journal.pmed1000097]

\section{Nguyen 2017}

Nguyen TL, Collins GS, Lamy A, Devereaux PJ, Daures JP, Landais $P$, et al. Simple randomization did not protect against bias in smaller trials. Journal of Clinical Epidemiology 2017;84:105-13. [PUBMED: 28257927]

\section{NICE 2012a}

National Institute for Health and Care Excellence. Botulinum toxin type $\mathrm{A}$ for the prevention of headaches in adults with chronic migraine. NICE technology appraisal guidance [TA260]. Available from www.nice.org.uk/guidance/ta260 accessed 27 July 2017.

\section{NICE 2012b}

National Institute for Health and Care Excellence. Headaches: Diagnosis and management of headaches in young people and adults. NICE guidelines [CG150]. Available from www.nice.org.uk/guidance/cg150 accessed 27 July 2017.

\section{Nüesch 2010}

Nüesch E, Trelle S, Reichenbach S, Rutjes AW, Tschannen B, Altman DG, et al. Small study effects in meta-analyses of osteoarthritis trials: meta-epidemiological study. BMJ 2010;341:c3515.

\section{Paterson 2014}

Paterson K, Lolignier S, Wood JN, McMahon SB, Bennett DLH. Botulinum toxin-A treatment reduces human mechanical pain sensitivity and mechanotransduction. Annals of Neurology 2014;75(4):591-6. [DOI: 10.1002/ana.24122]

\section{Pietrobon 2005}

Pietrobon D. Migraine: new molecular mechanisms. Neuroscientist 2005;11(4):373-86. [DOI: $10.1177 / 1073858405275554]$

\section{Porta 2000}

Porta M. A comparative trial of botulinum toxin type A and methylprednisolone for the treatment of myofascial pain syndrome and pain from chronic muscle spasm. Pain 2000;85:101-5. [DOI: 10.1016/S0304-3959(99)00264-X]

\section{Ranoux 2008}

Ranoux D, Attal N, Morain F, Bouhassira D. Botulinum toxin type $A$ induces direct analgesic effects in chronic neuropathic pain. Annals of Neurology 2008;64:274-83. [DOI: 10.1002/ana.21427]

\section{RevMan 2014 [Computer program]}

Nordic Cochrane Centre, The Cochrane Collaboration. Review Manager 5 (RevMan 5). Version 5.3. Copenhagen: Nordic Cochrane Centre, The Cochrane Collaboration, 2014.

\section{Rothrock 2014}

Rothrock JF, Bloudek LM, Houle TT, AndressRothrock D, Varon SF. Real-world economic impact of onabotulinumtoxinA in patients with chronic migraine. Headache 2014;54(10):1565-73. 


\section{Schulz 2010}

Schulz KF, Altman DG, Moher D, for the CONSORT Group. CONSORT 2010 Statement: updated guidelines for reporting parallel group randomised trials. BMJ 2010;340:c332.

\section{Schünemann 2011}

Schünemann HJ, Oxman AD, Higgins JPT, Vist GE, Glasziou P, Guyatt GH. Chapter 11: Presenting results and 'Summary of findings' tables. In: Higgins JPT, Green S (editors), Cochrane Handbook for Systematic Reviews of Interventions Version 5.1.0 (updated March 2011). The Cochrane Collaboration, 2011. Available from handbook.cochrane.org.

\section{Silberstein 2007}

Silberstein SD, Lipton RB, Dodick DW, Freitag FG, Ramadan N, Mathew N, et al. Efficacy and safety of topiramate for the treatment of chronic migraine: a randomized, double-blind, placebo-controlled trial. Headache 2007;47(2):170-80.

\section{Silberstein 2008}

Silberstein S, Tfelt-Hansen P, Dodick DW, Limmroth V, Lipton RB, Pascual J, et al. Guidelines for controlled trials of prophylactic treatment of chronic migraine in adults. Cephalalgia 2008;28(5):484-95.

\section{Silberstein 2013}

Silberstein SD, Blumenfeld AM, Cady RK, Turner IM, Lipton RB, Diener HC, et al. OnabotulinumtoxinA for treatment of chronic migraine: PREEMPT 24-week pooled subgroup analysis of patients who had acute headache medication overuse at baseline. Journal of the Neurological Sciences 2013;331(1-2):48-56.

\section{Silberstein 2017}

Silberstein SD, Dodick DW, Bigal ME, Yeung PP, Goadsby PJ, Blankenbiller T, et al. Fremanezumab for the preventive treatment of chronic migraine. New England Journal of Medicine 2017;377(22):2113-22.

\section{Simpson 2016}

Simpson DM, Hallett M, Ashman E, Comella CL, Green MW, Gronseth GS, et al. Practice guideline update summary:

\section{CHARACTERISTICS OF STUDIES}

Characteristics of included studies [ordered by study ID] botulinum neurotoxin for the treatment of blepharospasm, cervical dystonia, adult spasticity, and headache. Report of the Guideline Development Subcommittee of the American Academy of Neurology. Neurology 2016; Vol. 86, issue 19:1818-26.

\section{Smith 2002}

Smith HS, Audette J, Royal MA. Botulinum toxin in pain management of soft tissue syndromes. Clinical Journal of Pain 2002;18:S147-54. [DOI: 10.1097/00002508-200211001-00006]

\section{Stovner 2010}

Stovner LJ, Andree C. Prevalence of headache in Europe: a review for the Eurolight project. Journal of Headache and Pain 2010;11(4):289-99. [DOI: 10.1007/s10194-010-0217-0]

\section{Tfelt-Hansen 2012}

Tfelt-Hansen P, Pascual J, Ramadan N, Dahlof C, D'Amico D, Diener $\mathrm{HC}$, et al. Guidelines for controlled trials of drugs in migraine: third edition. A guide for investigators. Cephalalgia 2012; Vol. 32, issue 1:6-38.

\section{Victor 2010}

Victor T, Hu X, Campbell J, Buse D, Lipton R. Migraine prevalence by age and sex in the United States: a lifespan study. Cephalalgia 2010;30(9):1065-72. [DOI: 10.1177/0333102409355601]

\section{Wong 2005}

Wong SM, Hui AC, Tong PY, Poon DW, Yu E, Wong LK. Treatment of lateral epicondylitis with botulinum toxin: a randomized, double-blind, placebo-controlled trial. Annals of Internal Medicine 2005;143:793-7. [DOI: 10.7326/0003-4819-143-11-200512060-00007]

\section{Yuan 2009}

Yuan RY, Sheu JJ, Yu JM, Chen WT, Tseng IJ, Chang HH, et al. Botulinum toxin for diabetic neuropathic pain: a randomised double-blind crossover trial. Neurology 2009;72:1473-8. [DOI: 10.1212/01.wnl.0000345968.05959.cf]

* Indicates the major publication for the study

\section{Allergan 2015}

Methods Randomised, double-blind, placebo-controlled, parallel-group, sites unclear

2 treatments, 12 weeks FU per treatment

Fixed injections of Botox vs placebo

Assessments carried out at baseline and at week 12, week 22, week 24

Participants Inclusion criteria: history of $\mathrm{CM}$ for at least 6 months prior to the screening visit; $\geq 15$ headache $d$ during the 4-week screening period; $\geq 4$ headache episodes lasting $\geq 4 \mathrm{~h}$ and $\geq 50 \%$ of headache days were migraine 
Allergan 2015 (Continued)

Exclusion criteria: conditions causing chronic facial pain such as temporomandibular disorder and fibromyalgia; use of headache prophylaxis medication within 4 weeks of the screening visit; diagnosis of myasthenia gravis, Eaton-Lambert Syndrome, amyotrophic lateral sclerosis; previous use of any BTX of any sero-type for any reason; skin infections or acne that would interfere with the injection sites; acupuncture, TENS, cranial traction, dental splints for headache, nociceptive trigeminal inhibition, occipital nerve block treatments, or injection of anaesthetics/steroids within 4 weeks of screening

$\mathrm{N}=52$, mean age 43, M 13/F 39

$\mathrm{CM}$ only eligible, $\mathrm{MOH}$ eligible $\mathrm{Y} / \mathrm{N}$ not reported

Baseline disease characteristics not stated

\begin{tabular}{ll}
\hline Interventions & Intervention: Botox $155 \mathrm{U}$, number and location of injection sites not reported \\
& Control: matched placebo injections \\
\hline Outcomes & Assessment of CM impacts questionnaire \\
& Assessment of CM symptoms questionnaire \\
& HIT-6 \\
Migraine-specific questionnaire \\
\hline Notes & Protocol NCT01833130 \\
& Funder: Allergan, Inc., Irvine, California (manufacturer of Botox) \\
No diary data recorded
\end{tabular}

\section{Risk of bias}

Bias Authors' judgement Support for judgement

Random sequence genera- Unclear risk Method not stated

tion (selection bias)

\begin{tabular}{lll}
\hline $\begin{array}{l}\text { Allocation concealment } \\
\text { (selection bias) }\end{array}$ & Unclear risk nothod not stated \\
\hline
\end{tabular}

\begin{tabular}{|c|c|c|}
\hline $\begin{array}{l}\text { Blinding of participants } \\
\text { and personnel (perfor- } \\
\text { mance bias) } \\
\text { All outcomes }\end{array}$ & Unclear risk & $\begin{array}{l}\text { Double-blind: subject, caregiver and investigator blind, participant blinded } \\
\text { with matched placebo injections; no methods given for blinding of personnel }\end{array}$ \\
\hline
\end{tabular}

\begin{tabular}{|c|c|c|}
\hline $\begin{array}{l}\text { Blinding of outcome as- } \\
\text { sessment (detection bias) } \\
\text { All outcomes }\end{array}$ & Unclear risk & Double-blind: no methods given for blinding of personnel \\
\hline $\begin{array}{l}\text { Incomplete outcome data } \\
\text { (attrition bias) } \\
\text { All outcomes }\end{array}$ & High risk & Dropouts at $56 \%$ \\
\hline $\begin{array}{l}\text { Selective reporting (re- } \\
\text { porting bias) }\end{array}$ & Unclear risk & Not yet published, information and data from trial registry only \\
\hline Study size & High risk & $<50$ participants per treatment arm \\
\hline
\end{tabular}


Anand 2006

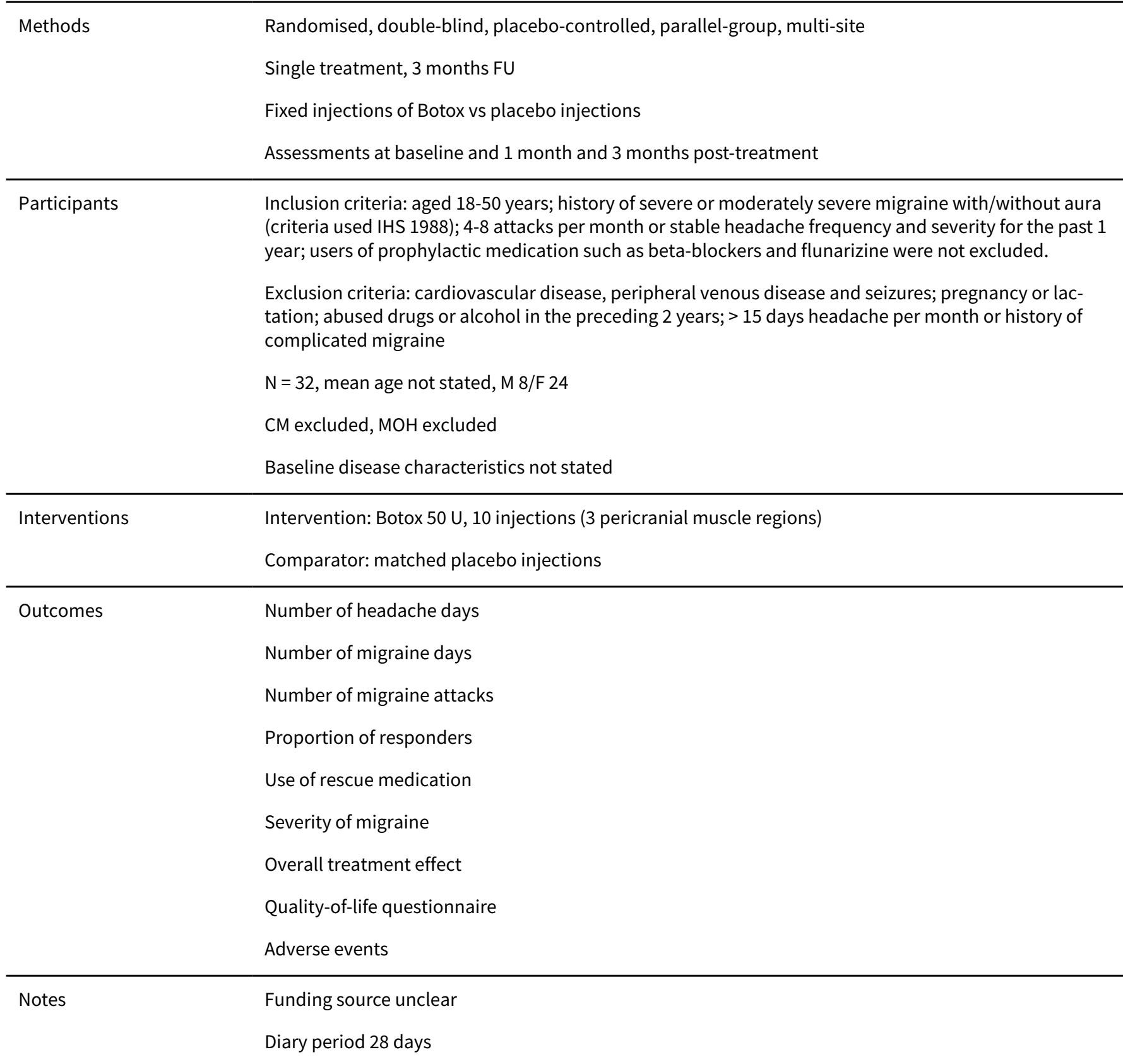

\section{Risk of bias}

Bias Authors' judgement Support for judgement

Random sequence genera- Unclear risk Method not stated
tion (selection bias)

\begin{tabular}{lll}
\hline $\begin{array}{l}\text { Allocation concealment } \\
\text { (selection bias) }\end{array}$ & Unclear risk & Method not stated \\
\hline $\begin{array}{l}\text { Blinding of participants } \\
\text { and personnel (perfor- } \\
\text { mance bias) }\end{array}$ & Unclear risk & $\begin{array}{l}\text { Double-blind: participant blinded with matched placebo injections no meth- } \\
\text { ods given for blinding of personnel }\end{array}$ \\
\hline
\end{tabular}


Anand 2006 (Continued)

All outcomes

Blinding of outcome as-
sessment (detection bias) $\quad$ Unclear risk Double-blind: no methods given for blinding of personnel

sessment (detection bias)

All outcomes

Incomplete outcome data Low risk Appears to be no dropouts
(attrition bias)

All outcomes

\begin{tabular}{lll}
\hline $\begin{array}{l}\text { Selective reporting (re- } \\
\text { porting bias) }\end{array}$ & Unclear risk & Data reported in unusual format \\
\hline Study size & High risk & $<50$ participants per treatment arm \\
\hline
\end{tabular}

\section{Aurora 2007}

Randomised, double-blind, placebo-controlled, parallel-group, multi-site
3 treatments, 90 days FU per treatment
'Follow the pain' (fixed for occipitalis) injections of Botox vs placebo injections
Assessments carried out at baseline and 30 days, 60 days and 90 days post-treatment for each treat-
ment

Participants

Inclusion criteria: aged 18-65 years; average of at least 4 moderate-to-severe migraine episodes but $\leq$ 15 headache $\mathrm{d} /$ month (criteria used ICHD-I); migraine episodes for at least 1 year prior to enrolment and first diagnosed before age 50 years; stable medical condition; chronic medication regimens, if any, stable including migraine prophylactic medications $\geq 3$ months prior to baseline period; willing and able to stay on current medications during the course of the study

Exclusion criteria: any medical condition or used any agent that may have put them at risk with exposure to this formulation of Botox; infection or skin problem at any of the injection sites or a known allergy or sensitivity to the trial medication or its components; history of "complicated" migraine; inadequate response (in the investigator's opinion) to $\geq 2$ prophylactic treatments after an adequate trial; psychiatric problems severe enough to interfere with trial implementation; previous therapy with BTX of any sero-type, or injection of anaesthetics or steroids into the trial-targeted muscles during the $30 \mathrm{~d}$ immediately prior to initiation baseline period; overusing or abusing symptomatic medication, alcohol, or drugs; concurrent chronic use or chronic use in the 3 months prior to the screening period of muscle relaxants; concurrently participating in another investigational trial or participated in such a trial in the $30 \mathrm{~d}$ immediately prior to baseline; condition that in the investigator's opinion might have put person at significant risk, might have confounded the trial or might have interfered with participation in the trial; pregnancy, breastfeeding, or planning a pregnancy during the trial; unable or unwilling to use a reliable form of contraception during the trial

$\mathrm{N}=369$, mean age 45 years, $M$ 40/F 329

CM excluded, $\mathrm{MOH}$ excluded

Years since diagnosis of migraine 23 years, number migraine attacks during baseline diary period 6.5

Interventions Intervention: Botox 110-260 U, 23-58 injections (frontal/glabellar 25-40 U, occipitalis $20 \mathrm{U}$, temporalis 20-50 U, masseter optional; 0-50 U, trapezius 20-60 U, semispinalis 10-20 U, splenius capitis 10-20 U)

Comparator: matched placebo injections

\section{Outcomes}

$$
\text { Number of headache days }
$$

Number of migraine attacks 
Aurora 2007 (Continued)

Proportion of responders

Use of rescue medication

Severity of migraine

Patient global assessment

Adverse events

\begin{tabular}{|c|c|}
\hline \multirow[t]{4}{*}{ Notes } & $\begin{array}{l}\text { Trial includes 30-day, single-blind, placebo run-in phase to identify placebo responders and placebo } \\
\text { non-responders }\end{array}$ \\
\hline & Funder: Allergan, Inc., Irvine, California (manufacturer of Botox) \\
\hline & Diary period 30 days \\
\hline & Contacted without response \\
\hline
\end{tabular}

\section{Risk of bias}

\begin{tabular}{|c|c|c|}
\hline Bias & Authors' judgement & Support for judgement \\
\hline $\begin{array}{l}\text { Random sequence genera- } \\
\text { tion (selection bias) }\end{array}$ & Low risk & Block randomisation used \\
\hline $\begin{array}{l}\text { Allocation concealment } \\
\text { (selection bias) }\end{array}$ & Low risk & $\begin{array}{l}\text { Neither the investigator nor the participant knew the treatment stratum or } \\
\text { random block size. An individual with no other trial involvement reconstituted } \\
3 \text { vials of trial medication and drew the trial drug into the syringes for adminis- } \\
\text { tration. The syringes were then given to the investigator for injection }\end{array}$ \\
\hline $\begin{array}{l}\text { Blinding of participants } \\
\text { and personnel (perfor- } \\
\text { mance bias) } \\
\text { All outcomes }\end{array}$ & Low risk & $\begin{array}{l}\text { Double-blind: participant blinded with matched placebo injections, an indi- } \\
\text { vidual with no other trial involvement reconstituted } 3 \text { vials of trial medication } \\
\text { and drew the trial drug into the syringes for administration. The syringes were } \\
\text { then given to the investigator for injection }\end{array}$ \\
\hline $\begin{array}{l}\text { Blinding of outcome as- } \\
\text { sessment (detection bias) } \\
\text { All outcomes }\end{array}$ & Low risk & $\begin{array}{l}\text { Double-blind: an individual with no other trial involvement reconstituted } 3 \\
\text { vials of trial medication and drew the trial drug into the syringes for adminis- } \\
\text { tration. The syringes were then given to the investigator for injection }\end{array}$ \\
\hline $\begin{array}{l}\text { Incomplete outcome data } \\
\text { (attrition bias) } \\
\text { All outcomes }\end{array}$ & Unclear risk & Dropout rate per group not given \\
\hline $\begin{array}{l}\text { Selective reporting (re- } \\
\text { porting bias) }\end{array}$ & Unclear risk & $\begin{array}{l}\text { Data not provided for secondary outcomes - narrative description of results } \\
\text { only }\end{array}$ \\
\hline Study size & Unclear risk & 50-199 participants per arm \\
\hline
\end{tabular}

Aurora 2010 (PREEMPT 1)

$\begin{array}{ll}\text { Methods } & \text { Randomised, double-blind, placebo-controlled, parallel-group, multi-site } \\ 2 \text { treatments, } 12 \text { weeks FU per treatment } \\ \text { Fixed plus optional 'follow the pain' injections of Botox vs placebo }\end{array}$


Aurora 2010 (PREEMPT 1) (Continued)

Assessments carried out at baseline and 4 weeks, 8 weeks and 12 weeks after each treatment out to 24 weeks, (further 3 treatments and 32 weeks of assessments in OL phase)

\section{Participants}

Inclusion criteria: aged 18-65 years; migraine meeting the diagnostic criteria listed in ICHD-II (2004), migraine, with the exception of "complicated migraine" (i.e. hemiplegic migraine, basilar-type migraine, ophthalmoplegic migraine, migrainous infarction); provided diary data on $\geq 20$ of 28 days during baseline; $\geq 15$ headache days with each day consisting of $\geq 4 \mathrm{~h}$ of continuous headache and with $\geq 50 \%$ of days being migraine or probable migraine days during baseline period; $\geq 4$ distinct headache episodes, each lasting $\geq 4 \mathrm{~h}$

Exclusion criteria: any medical condition that might put participants at increased risk if exposed to onabotulinumtoxinA (e.g. neuromuscular diseases); other primary or secondary headache disorders; use of any headache prophylactic medication within 28 days before start of baseline; Beck Depression Inventory score of $>24$ at baseline; fibromyalgia; psychiatric disorders that could have interfered with trial participation; previous exposure to any botulinum neurotoxin sero-type; women of childbearing potential must have had a negative urine pregnancy test prior to each injection and have been using a reliable means of contraception; investigators were trained not to enrol participants who frequently used opioids as acute pain medication

$N=679$, mean age 42 years, M 85/F 594

CM only eligible, MOH eligible Y/N 462/217

Years since onset of CM 20, number of migraine days during baseline diary period 19 tal $40 \mathrm{U}$. PREEMPT paradigm: frontalis $20 \mathrm{U}$ in 4 sites; corrugator $10 \mathrm{U}$ in 2 sites; procerus $5 \mathrm{U}$ in 1 site; occipitalis $30 \mathrm{U}$ in 6 sites up to $40 \mathrm{U}$ in 8 sites; temporalis $40 \mathrm{U}$ in 8 sites up to $50 \mathrm{U}$ in 10 sites; trapezius $30 \mathrm{U}$ in 6 sites; cervical paraspinal $20 \mathrm{U}$ in 4 sites

Control: matched placebo injections

Number of headache days
Number of migraine days
Number of migraine attacks
Proportion of responders ( $\geq 50 \%$ reduction in migraine)
Use of rescue medication
HIT-6
Headache impact score
Migraine specific quality of life questionnaire
HRQoL
Adverse events
QALYs
Incremental cost-effectiveness ratio

\section{Notes}

Protocol NCT00156910

Funder: Allergan, Inc., Irvine, California (manufacturer of Botox)

Diary period 28 days

\section{Risk of bias}


Aurora 2010 (PREEMPT 1) (Continued)

\begin{tabular}{lll} 
Bias & Authors' judgement & Support for judgement \\
\hline $\begin{array}{l}\text { Random sequence genera- } \\
\text { tion (selection bias) }\end{array}$ & Low risk & $\begin{array}{l}\text { Computer-generated randomisation sequence } \\
\text { Allocation concealment } \\
\text { (selection bias) }\end{array}$ \\
\end{tabular}

\begin{tabular}{ll}
\hline $\begin{array}{l}\text { Blinding of participants } \\
\text { and personnel (perfor- }\end{array}$ & Low risk \\
souble-blind: placebo arm, prepacked medication kits with number for as- \\
signment
\end{tabular}

$$
\text { mance bias) }
$$

All outcomes

\begin{tabular}{|c|c|c|}
\hline $\begin{array}{l}\text { Blinding of outcome as- } \\
\text { sessment (detection bias) } \\
\text { All outcomes }\end{array}$ & Low risk & $\begin{array}{l}\text { Double-blind: placebo arm, prepacked medication kits with number for as- } \\
\text { signment }\end{array}$ \\
\hline $\begin{array}{l}\text { Incomplete outcome data } \\
\text { (attrition bias) } \\
\text { All outcomes }\end{array}$ & Low risk & Withdrawals balanced across groups and adjusted LOCF method used \\
\hline $\begin{array}{l}\text { Selective reporting (re- } \\
\text { porting bias) }\end{array}$ & Low risk & All expected outcomes reported \\
\hline Study size & Low risk & $\geq 200$ participants per treatment arm \\
\hline
\end{tabular}

\section{Barrientos 2003}

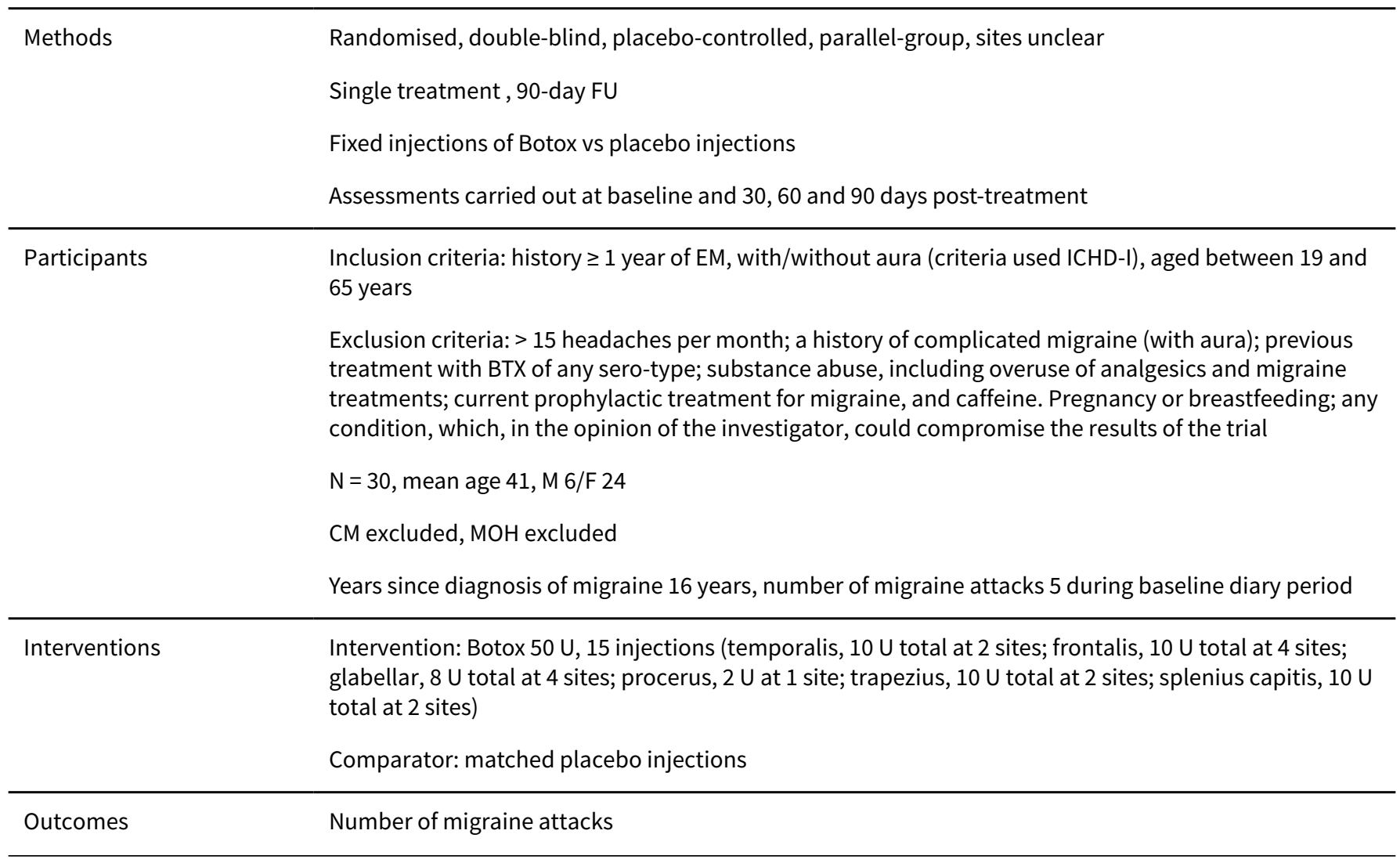


Barrientos 2003 (Continued)

\section{Duration of migraine}

Use of rescue medication

Participant- and investigator-related 6-point global effectiveness evaluation scale

Adverse events

\begin{tabular}{ll}
\hline Notes & Funder: Allergan, Inc., Irvine, California (manufacturer of Botox) \\
& Diary period 30 days \\
& Uncontactable \\
\hline
\end{tabular}

\section{Risk of bias}

\begin{tabular}{|c|c|c|}
\hline Bias & Authors' judgement & Support for judgement \\
\hline $\begin{array}{l}\text { Random sequence genera- } \\
\text { tion (selection bias) }\end{array}$ & Unclear risk & Method not stated \\
\hline $\begin{array}{l}\text { Allocation concealment } \\
\text { (selection bias) }\end{array}$ & Unclear risk & Method not stated \\
\hline $\begin{array}{l}\text { Blinding of participants } \\
\text { and personnel (perfor- } \\
\text { mance bias) } \\
\text { All outcomes }\end{array}$ & Unclear risk & $\begin{array}{l}\text { Double-blind: participant blinded with matched placebo injections no meth- } \\
\text { ods given for blinding of personnel }\end{array}$ \\
\hline $\begin{array}{l}\text { Blinding of outcome as- } \\
\text { sessment (detection bias) } \\
\text { All outcomes }\end{array}$ & Unclear risk & Double-blind: no methods given for blinding of assessors \\
\hline $\begin{array}{l}\text { Incomplete outcome data } \\
\text { (attrition bias) } \\
\text { All outcomes }\end{array}$ & Low risk & All participants completed \\
\hline $\begin{array}{l}\text { Selective reporting (re- } \\
\text { porting bias) }\end{array}$ & Unclear risk & Group means reported without standard errors or standard deviations \\
\hline Study size & High risk & $<50$ participants per treatment arm \\
\hline
\end{tabular}

\section{Blumenfeld 2008}

\begin{tabular}{ll}
\hline Methods & Randomised, double-blind, active control, parallel-group, single-site \\
& 2 rounds of treatment, 3 months FU for first treatment and 6 months for second \\
& Follow the pain injections of Botox plus placebo vs sodium valproate tablets plus placebo injections \\
& Assessments carried out at baseline and 1 month, 3 months, 6 months and 9 months post-treatment \\
\hline Participants & $\begin{array}{l}\text { Inclusion criteria: EM or CM (criteria used for diagnosis not clear, ICHD-II cited in Background); aged be- } \\
\text { tween } 18-65 \text { years with EM (defined for this trial as } \geq 3 \text { migrainous headaches but }<15 \mathrm{~d} / \text { month) or CM } \\
\text { (defined for this trial as migrainous headaches on } \geq 15 \mathrm{~d} / \text { month); stable headache severity and pattern }\end{array}$ \\
& $\begin{array}{l}\text { Exclusion Criteria: any medical condition or use of any agent that might expose them to risk if they re- } \\
\text { ceived Botox; prior exposure, allergy, or sensitivity to any component of BTX of any sero-type or to di- } \\
\text { valproex; skin problems, infections, profound atrophy, or excessive weakness in the target areas of the }\end{array}$ \\
\hline
\end{tabular}


Blumenfeld 2008 (Continued)

injection sites; concomitant prophylactic migraine therapy or a history of overusing symptomatic medication; headache disorders outside of the classification strata outlined; pregnancy, breastfeeding, or planning a pregnancy during the trial

$\mathrm{N}=59$, mean age $42, \mathrm{M} 9 / \mathrm{F} 50$

EM/CM 45/14, MOH excluded

Number of headache days 11.7 during baseline diary period, headache severity 3.5 on 5-point scale where 5 is most severe

\begin{tabular}{|c|c|}
\hline Interventions & $\begin{array}{l}\text { Intervention: Botox } \leq 100 \mathrm{U} \text {, number of injections unclear (proce } \\
\text { is } 25 \mathrm{U} \text {, temporalis } 7.5-20 \mathrm{U} \text {, splenius capitis } 2.5-10 \mathrm{U} \text {, sternocleic } \\
\text { occipitalis } 2.5-5 \mathrm{U} \text {, cervical paraspinalis } 7.5-15 \mathrm{U} \text {, semispinalis ca } \\
\text { Comparator: sodium valproate tablets, } 250 \mathrm{mg} \text { twice daily }\end{array}$ \\
\hline Outcomes & $\begin{array}{l}\text { Number of headache days } \\
\text { Proportion of responders ( } \geq 50 \% \text { reduction in migraine) } \\
\text { Headache severity } \\
\text { Headache index } \\
\text { MIDAS } \\
\text { HIT-6 } \\
24 \text { hr migraine QoL } \\
\text { Adverse events }\end{array}$ \\
\hline Notes & $\begin{array}{l}\text { Funder: Allergan, Inc., Irvine, California (manufacturer of Botox). } \\
\text { Diary period } 1 \text { month }\end{array}$ \\
\hline
\end{tabular}

\section{Risk of bias}

\begin{tabular}{|c|c|c|}
\hline Bias & Authors' judgement & Support for judgement \\
\hline $\begin{array}{l}\text { Random sequence genera- } \\
\text { tion (selection bias) }\end{array}$ & Unclear risk & Method not stated \\
\hline $\begin{array}{l}\text { Allocation concealment } \\
\text { (selection bias) }\end{array}$ & Unclear risk & Method not stated \\
\hline $\begin{array}{l}\text { Blinding of participants } \\
\text { and personnel (perfor- } \\
\text { mance bias) } \\
\text { All outcomes }\end{array}$ & Unclear risk & $\begin{array}{l}\text { Double-blind: double dummy, participant blinded with matched placebo in- } \\
\text { jections or placebo tablets, no methods given for blinding of personnel }\end{array}$ \\
\hline $\begin{array}{l}\text { Blinding of outcome as- } \\
\text { sessment (detection bias) } \\
\text { All outcomes }\end{array}$ & Unclear risk & Double-blind: double dummy, no methods given for blinding of personnel \\
\hline $\begin{array}{l}\text { Incomplete outcome data } \\
\text { (attrition bias) } \\
\text { All outcomes }\end{array}$ & High risk & Dropouts at $44 \%$ \\
\hline
\end{tabular}


Blumenfeld 2008 (Continued)

Selective reporting (re- Unclear risk $\quad$ Some time points not reported for some outcomes
porting bias)

Study size $\quad$ High risk $\quad<50$ participants per treatment arm

Blumenkron 2006

\begin{tabular}{|c|c|}
\hline \multirow[t]{4}{*}{ Methods } & Randomised, double-blind, placebo-controlled, parallel-group, unclear sites \\
\hline & Single treatment, appears to be 3 months FU \\
\hline & Fixed injections of Botox $100 \mathrm{U}$ vs matched placebo injections \\
\hline & Assessments carried out at baseline and 1 month, 2 months and 3 months post-treatment \\
\hline \multirow[t]{5}{*}{ Participants } & $\begin{array}{l}\text { Inclusion criteria: age > } 18 \text { years; migraine (IHS 1988); previous history of conventional treatment fail- } \\
\text { ure and functional disability }\end{array}$ \\
\hline & $\begin{array}{l}\text { Exclusion criteria: non adherence to the protocol and non-acceptance by participant; pregnancy; lacta- } \\
\text { tion; treatment with aminoglycosides; acne conglobata; Lambert-Eaton myasthenic syndrome; history } \\
\text { of hypersensitivity to the components of the BTX and secondary headache }\end{array}$ \\
\hline & $\mathrm{N}=30$, mean age not stated, M 5/F 25 \\
\hline & EM/CM unclear, $\mathrm{MOH}$ eligibility unclear \\
\hline & Baseline disease characteristics not stated \\
\hline \multirow[t]{2}{*}{ Interventions } & $\begin{array}{l}\text { Intervention: Botox } 100 \mathrm{U} \text { from } 25 \text { injections ( } 4 \text { front points total } 10 \mathrm{U}, 1 \text { application in procerus muscle } \\
\text { and } 1 \text { application in each corrugator muscle total } 10 \mathrm{U}, 3 \text { points each temporalis muscle total } 30 \mathrm{U}, 5 \\
\text { points in each trapezius muscle total } 50 \mathrm{U} \text { ) }\end{array}$ \\
\hline & Comparator: matched placebo injections \\
\hline \multirow[t]{4}{*}{ Outcomes } & MIDAS \\
\hline & MIGSEV \\
\hline & Quality-of-life measure \\
\hline & Adverse events \\
\hline \multirow[t]{3}{*}{ Notes } & Funding source unclear \\
\hline & No diary data \\
\hline & Contacted without response \\
\hline
\end{tabular}

\section{Risk of bias}

Bias Authors' judgement Support for judgement

Random sequence genera- Low risk Computer-generated randomisation sequence tion (selection bias)

\begin{tabular}{l}
$\begin{array}{l}\text { Allocation concealment } \\
\text { (selection bias) }\end{array}$ \\
\hline
\end{tabular}


Blumenkron 2006 (Continued)

Blinding of participants Unclear risk Double-blind: participant blinded with matched placebo injections no methand personnel (perforods given for blinding of personnel mance bias)

All outcomes

\begin{tabular}{lll}
$\begin{array}{l}\text { Blinding of outcome as- } \\
\text { sessment (detection bias) } \\
\text { All outcomes }\end{array}$ & Unclear risk & Double-blind: no method \\
\hline $\begin{array}{l}\text { Incomplete outcome data } \\
\text { (attrition bias) }\end{array}$ & Unclear risk & Dropouts not mentioned \\
All outcomes & &
\end{tabular}

Selective reporting (re- Unclear risk No protocol and no migraine frequency data
porting bias)

Study size High risk <50 participants per treatment arm

Cady 2008

Methods Randomised, double-blind, placebo-controlled, parallel-group, single-site

Single treatment, 3-month FU (optional OL treatment at end of trial for placebo arm)

Fixed injections of Botox versus placebo injections

Assessments carried out at baseline and 1 month, 2 months and 3 months post-treatment

Participants

Inclusion criteria: age > 18 years; history ( $\geq 6$ months) of headache (ICHD-II diagnosis 1.1 (migraine without aura), 1.2 (migraine with aura), 1.7 (migrainous disorder not fulfilling above criteria), or 2.2 (chronic tension-type headache)); onset before the age of 50 years; HIT-6 score > 56; episodic chronic headache; stable headache severity and pattern; failed at least 1 attempt with preventive medications because of compliance, adherence, or AE issues; women of childbearing potential taking approved birth control measures and having a negative urine pregnancy test prior to administration of trial medications

Exclusion criteria: any medical condition that might put them at risk with Botox exposure (e.g. myasthenia gravis, Eaton-Lambert Syndrome, amyotrophic lateral sclerosis); any disease that might interfere with neuromuscular function; uncontrolled systemic disease; abnormal pathology contributing to headaches; concurrent infection at proposed injection sites; pregnant or breast-feeding; currently using aminoglycoside antibiotics, curare-like agents, or other agents that might interfere with neuromuscular function; undergone injection of anaesthetics or steroids, within 1 month immediately prior to enrolment, into the muscles to be injected in the trial; previous BTX treatment with any sero-type; currently participating in another drug or device trial or had done so within the 30 days before the baseline period; suspected hypersensitivity to Botox or any of the ingredients in the proprietary formulation; known or suspected drug or alcohol abuse

$\mathrm{N}=61$, mean age 42 years, $M 9 / F 52$

EM/CM unclear, $\mathrm{MOH}$ eligibility unclear

Number of headache days 8 during baseline diary period, severity of migraine (max recorded during baseline period) 2.2 (scale unclear)

Interventions

Intervention: Botox $139 \mathrm{U}, 17$ injections (corrugator 2 applications of $6 \mathrm{U}$, splenius capitis 2 applications of $10 \mathrm{U}$, trapezius 4 applications of $10 \mathrm{U}$, temporalis 4 applications of $10 \mathrm{U}$, procerus 1 application of 3 $\mathrm{U}$, frontalis 4 applications of $6 \mathrm{U}$ ) 
Cady 2008 (Continued)

Comparator: matched placebo injections

\begin{tabular}{l} 
Number of headache episodes \\
Number of headache days \\
Number of headache-free days \\
Percentage of headache episodes with aura \\
Severity of headaches \\
HIT-6 (mean in 30 days compared to baseline) \\
MIQ (MIDAS \& QoL) \\
The trial received enrolment of subjects with diagnostic criteria 1.1 and 1.2 only \\
Funder: Allergan, Inc., Irvine, California (manufacturer of Botox) \\
Diary period 30 days \\
Contacted without response \\
\hline
\end{tabular}

Risk of bias

\begin{tabular}{lll}
\hline Bias & Authors' judgement & Support for judgement \\
\hline $\begin{array}{l}\text { Random sequence genera- } \\
\text { tion (selection bias) }\end{array}$ & Unclear risk & Method not stated \\
\hline $\begin{array}{l}\text { Allocation concealment } \\
\text { (selection bias) }\end{array}$ & Low risk & $\begin{array}{l}\text { Randomisation of participants was performed by a supervisory individual not } \\
\text { associated with the trial }\end{array}$ \\
\hline $\begin{array}{l}\text { Blinding of participants } \\
\text { and personnel (perfor- } \\
\text { mance bias) } \\
\text { All outcomes }\end{array}$ & Low risk & $\begin{array}{l}\text { Double-blind: participant blinded with matched placebo injections, research } \\
\text { co-ordinator, who was not involved with the participants prepared the injec- } \\
\text { tions }\end{array}$ \\
\hline $\begin{array}{l}\text { Blinding of outcome as- } \\
\text { sessment (detection bias) }\end{array}$ & Low risk & $\begin{array}{l}\text { Double-blind: research co-ordinator, who was not involved with the partici- } \\
\text { pants prepared the injections }\end{array}$ \\
\hline $\begin{array}{l}\text { Incomplete outcome data } \\
\text { (attrition bias) }\end{array}$ & Unclear risk & $\begin{array}{l}\text { Treatment of missing data not described } \\
\text { All outcomes }\end{array}$ \\
\hline $\begin{array}{l}\text { Selective reporting (re- } \\
\text { porting bias) }\end{array}$ & Unclear risk & Full data not given (P values only, no AE data given) \\
\hline \begin{tabular}{l} 
Study size \\
\hline
\end{tabular} & High risk & $<50$ participants per treatment arm \\
\hline
\end{tabular}

Cady 2011

Methods Randomised, double-blind, active controlled, parallel-group multi-site

Single treatment, 12-week FU (additional treatment for all participants in OL phase) 
Cady 2011 (Continued)

Fixed plus follow the pain injections of Botox plus placebo tablets vs placebo injections and topiramate tablets

Assessments carried out at baseline and 4 weeks and 12 weeks post-treatment

\section{Participants}

Inclusion criteria: CM (criteria used ICHD-II); aged 18-65 years; female participants of child-bearing potential with a negative urine pregnancy test who practiced reliable contraception throughout the trial period

Exclusion criteria: pregnancy, breastfeeding, or planning pregnancy during the time frame of the trial; headache disorders other than CM; medical disorders that increase risk with exposure to Botox; significant liver or renal impairment including kidney stones; ketogenic diets; previous use of BTX or topiramate; recent alcohol/drug abuse or overuse of acute medication

$N=59$, mean age 40 years, M 5/F 54

$\mathrm{CM}$ only eligible, $\mathrm{MOH}$ excluded

Years since diagnosis of migraine 16 years, severity of migraine 2.8 on 3-point scale

Interventions

Intervention: Botox up to $200 \mathrm{U}$, number and location of injections not reported (100 U fixed locations + up to $100 \mathrm{U}$ in follow the pain), average dose $109 \mathrm{U}$

Comparator: topiramate $25 \mathrm{mg}$ escalated to max $200 \mathrm{mg}$ (average $136 \mathrm{mg}$ )

\begin{tabular}{ll}
\hline Outcomes & Number headache days \\
Number migraine attacks & Proportion of responders ( $\geq 50 \%$ reduction in migraine) \\
Money spent on rescue medication & Physician's global assessment \\
HIT- 6 & MIDAS \\
MIQ & Severity of migraine \\
Funding source unclear \\
Diary period 28 days \\
Contacted without response
\end{tabular}

\section{Risk of bias}

\begin{tabular}{lll}
\hline Bias & Authors' judgement & Support for judgement \\
\hline $\begin{array}{l}\text { Random sequence genera- } \\
\text { tion (selection bias) }\end{array}$ & Unclear risk & Method not stated \\
\hline $\begin{array}{l}\text { Allocation concealment } \\
\text { (selection bias) }\end{array}$ & Low risk & $\begin{array}{l}\text { A sealed card marked with participant's trial number was delivered via FedEx } \\
\text { to the trial site. A research co-ordinator, not involved with the trial, would } \\
\text { open the card, note the treatment assignment, prepare treatment, and hand } \\
\text { to trial co-ordinator, who assisted the investigator with the injections }\end{array}$ \\
\hline
\end{tabular}




\section{Cady 2011 (Continued)}

Blinding of participants Low risk Double-blind: participant blinded with matched placebo injections, research and personnel (performance bias)

All outcomes co-ordinator, who was not involved with the trial, prepared the injections

\begin{tabular}{|c|c|c|}
\hline $\begin{array}{l}\text { Blinding of outcome as- } \\
\text { sessment (detection bias) }\end{array}$ & Low risk & $\begin{array}{l}\text { Double-blind: research co-ordinator, who was not involved with the trial, pre- } \\
\text { pared the injections }\end{array}$ \\
\hline
\end{tabular}

All outcomes

Incomplete outcome data Unclear risk Unclear reporting of attrition
(attrition bias)
All outcomes

\begin{tabular}{lll}
\hline $\begin{array}{l}\text { Selective reporting (re- } \\
\text { porting bias) }\end{array}$ & High risk & Some outcomes missing from results (severity/MIQ/AEs) \\
\hline Study size & High risk & $<50$ participants per treatment arm \\
\hline
\end{tabular}

Cady 2014

Randomised, double-blind, placebo-controlled, cross-over, multi-site
Single treatment, 3-month FU (additional treatment given post cross-over)
Fixed plus follow the pain injections of OnabotulinumtoxinA vs placebo injections
Assessments carried out at baseline and 1 month, 2 months, and 3 months post-treatment

Participants

Inclusion criteria: CM (criteria used ICHD-II); aged 18-65; history of CM according to the criteria proposed as an appendix diagnosis in 2006 by the Headache Classification Committee; preventive medications were of a stable dose for at least 6 weeks prior to screening and maintained throughout trial period; women of childbearing potential agreed to urine pregnancy test at screening and a medically acceptable form of contraception

Exclusion criteria: pregnancy, planning pregnancy during the trial period, breastfeeding, or of childbearing potential and not practicing a reliable form of birth control (see inclusion criteria); headache disorders outside IHS-defined CM; evidence of underlying pathology contributing to headaches; pathology of the salivary glands such as sialadenitis (e.g. Sjorgen's syndrome, viral or bacterial sialadenitis) or condition or symptom that would alter the content of saliva; any medical condition that may increase their risk with exposure to BTX-A including diagnosed myasthenia gravis, Eaton-Lambert syndrome, amyotrophic lateral sclerosis, or any other significant disease that might interfere with neuromuscular function; profound atrophy or weakness of muscles in the target areas of injection; skin conditions or infections at any of the injection sites; allergy or sensitivities to any component of test medications; active major psychiatric or depressive disorders including alcohol/drug abuse; met IHS criteria for Medication Overuse with opioid- or butalbital-containing products; planning or requiring surgery during the trial; history of poor compliance with medical treatment as determined by the investigator; currently participating in an investigational drug trial or had participated in an investigational drug trial within the previous 30 days of the screening visit

$\mathrm{N}=20$, mean age 49, M 5/F 15

$\mathrm{CM}$ only eligible, $\mathrm{MOH}$ eligibility unclear

Baseline disease characteristics not stated

Interventions

Intervention: Botox $\geq 155 \mathrm{U}, 31$ injections following PREEMPT paradigm with optional follow the pain injections in occipitalis, temporalis, and trapezius 
Cady 2014 (Continued)

Comparator: matched placebo injections

\begin{tabular}{ll}
\hline Outcomes & Number of headache days \\
\hline Notes & Protocol NCT01071096 \\
& Funding source unclear \\
& Diary period 1 month \\
Contacted without response \\
\hline
\end{tabular}

\section{Risk of bias}

\begin{tabular}{|c|c|c|}
\hline Bias & Authors' judgement & Support for judgement \\
\hline $\begin{array}{l}\text { Random sequence genera- } \\
\text { tion (selection bias) }\end{array}$ & Low risk & Computer-generated randomisation sequence \\
\hline \multirow[t]{2}{*}{$\begin{array}{l}\text { Allocation concealment } \\
\text { (selection bias) }\end{array}$} & Low risk & $\begin{array}{l}\text { Third party responsible for generation of number and preparation of medica- } \\
\text { tions }\end{array}$ \\
\hline & & $\begin{array}{l}\text { Quote: "Randomisation of subjects was performed by a supervisory individ- } \\
\text { ual not associated with the trial, who numbered trial medications in a manner } \\
\text { which was blinded to subject, coordinator, and investigator" }\end{array}$ \\
\hline $\begin{array}{l}\text { Blinding of participants } \\
\text { and personnel (perfor- } \\
\text { mance bias) } \\
\text { All outcomes }\end{array}$ & Low risk & $\begin{array}{l}\text { Double-blind: participant blinded with matched placebo injections, trial med- } \\
\text { ications were numbered by a supervisory individual not associated with the } \\
\text { trial in a manner which was blind to subject, co-ordinator and investigator }\end{array}$ \\
\hline $\begin{array}{l}\text { Blinding of outcome as- } \\
\text { sessment (detection bias) } \\
\text { All outcomes }\end{array}$ & Low risk & $\begin{array}{l}\text { Double-blind: trial medications were numbered by a supervisory individual not } \\
\text { associated with the trial in a manner which was blind to subject, co-ordinator } \\
\text { and investigator }\end{array}$ \\
\hline $\begin{array}{l}\text { Incomplete outcome data } \\
\text { (attrition bias) } \\
\text { All outcomes }\end{array}$ & Low risk & Only 1 participant dropped out \\
\hline $\begin{array}{l}\text { Selective reporting (re- } \\
\text { porting bias) }\end{array}$ & Low risk & All protocol outcomes reported \\
\hline Study size & High risk & $<50$ participants per treatment arm \\
\hline
\end{tabular}

Chankrachang 2011

\begin{tabular}{ll} 
Methods & Randomised, double-blind, placebo-controlled, parallel-group, multi-site \\
& Single treatment, 3-month FU \\
& Fixed injections with Dysport vs placebo \\
& Assessments carried out at baseline and 4 weeks, 8 weeks and 12 weeks post-treatment \\
\hline Participants & $\begin{array}{l}\text { Inclusion criteria: aged 18-65 years; experienced an average of 2-8 migraine attacks per month over the } \\
\text { 3 months prior to a screening period; } 2-8 \text { migraine attacks occurred during the 4-week screening peri- } \\
\text { od; medication for acute migraine and prophylactic treatment was permitted if doses were stable. }\end{array}$
\end{tabular}


Exclusion criteria: pure migraine with aura as defined by ICHD-II; history of complicated migraine; pregnancy; lactation; not using adequate contraception; history of drug abuse; treatment with Botox within the past 6 months; previously experienced an adverse reaction to Botox; history of botulism or other neuromuscular disorders; current treatment with aminoglycoside antibiotics or other agents that could affect neuromuscular transmission; received unlicensed medication or investigational drugs within 6 months of the screening visit; any other clinically significant medical conditions that could influence trial results; liver transaminase levels had to be less than twice the upper normal values

$\mathrm{N}=128$, mean age 39, M 7/F 120 (ITT population (127) used for baseline characteristics)

$\mathrm{EM} / \mathrm{CM}$ unclear, $\mathrm{MOH}$ eligibility unclear

Years since diagnosis migraine 5 , number of migraine attacks during baseline diary period 5

Interventions Intervention (arm 1): Dysport 120 U, 6 injections -2 frontal, 2 x temporal, 2 x occipital

Intervention (arm 2): Dysport 240 U, 6 injections $-2 x$ frontal, 2 x temporal, 2 x occipital

Control: matched placebo injections

\begin{tabular}{ll} 
Outcomes & Number of migraine attacks \\
Total intensity score & MIDAS \\
& Duration of migraine \\
Number of hours per month with moderate-to-severe headache & Global assessment score \\
& Adverse events \\
\hline Notes & Protocol NCT00258609 \\
& Funder: IPSEN Group (manufacturer of Dysport) \\
& Diary period 28 days \\
& Contacted without response
\end{tabular}

\section{Risk of bias}

Bias Authors' judgement Support for judgement

Random sequence genera- Low risk Computer-generated randomisation sequence
tion (selection bias)

\begin{tabular}{|c|c|c|}
\hline $\begin{array}{l}\text { Allocation concealment } \\
\text { (selection bias) }\end{array}$ & Low risk & $\begin{array}{l}\text { Sealed envelopes with allocation, nurse performed reconstitution and had no } \\
\text { further involvement with participants }\end{array}$ \\
\hline
\end{tabular}

$\begin{array}{ll}\text { Blinding of participants } & \text { further involvement with participants } \\ \begin{array}{ll}\text { and personnel (perfor- } & \text { Low risk }\end{array} & \begin{array}{l}\text { Double-blind: participants and all other personnel, apart from nurse who per- } \\ \text { formed reconstitution of drug, were blind to allocation }\end{array}\end{array}$

$$
\text { mance bias) }
$$

All outcomes

\begin{tabular}{|c|c|c|}
\hline $\begin{array}{l}\text { Blinding of outcome as- } \\
\text { sessment (detection bias) } \\
\text { All outcomes }\end{array}$ & Low risk & $\begin{array}{l}\text { Double-blind: participants and all other personnel, apart from nurse who per- } \\
\text { formed reconstitution of drug, were blind to allocation }\end{array}$ \\
\hline
\end{tabular}

$\begin{aligned} & \text { Incomplete outcome data } \\ & \text { (attrition bias) }\end{aligned}$
All outcomes


Chankrachang 2011 (Continued)
Selective reporting (re-
Unclear risk
All expected outcomes discussed but data not always provided porting bias)

Study size

High risk

$<50$ participants per treatment arm

Diener 2010 (PREEMPT 2)

Randomised, double-blind, placebo-controlled, parallel-group, multi-site
2 treatments, 12 weeks FU per treatment
Fixed plus optional follow the pain injections of Botox vs placebo
Assessments carried out at baseline and 4 weeks, 8 weeks and 12 weeks after each treatment out to 24
weeks, (further 3 treatments and 32 weeks of assessments in OL phase)

Participants

Inclusion criteria: aged 18-65 years; migraine meeting the diagnostic criteria listed in ICHD-II (2004) section 1, migraine (1), with the exception of "complicated migraine" (i.e., hemiplegic migraine, basilar-type migraine, ophthalmoplegic migraine, migrainous infarction); provided diary data on $\geq 20$ of 28 days during baseline; $\geq 15$ headache days with each day consisting of $\geq 4 \mathrm{~h}$ of continuous headache and with $\geq 50 \%$ of days being migraine or probable migraine days during baseline period; $\geq 4$ distinct headache episodes, each lasting $\geq 4 \mathrm{~h}$

Exclusion criteria: any medical condition that might put participants at increased risk if exposed to Botox (e.g. neuromuscular diseases); other primary or secondary headache disorders; use of any headache prophylactic medication within 28 days before start of baseline; Beck Depression Inventory score of $>24$ at baseline; fibromyalgia; psychiatric disorders that could have interfered with trial participation; previous exposure to any botulinum neurotoxin sero-type; Women of childbearing potential must have had a negative urine pregnancy test prior to each injection and have been using a reliable means of contraception; investigators were trained not to enrol participants who frequently used opioids as acute pain medication

$N=705$, mean age 41 years, $M$ 103/F 602

CM only eligible, $\mathrm{MOH}$ eligible $\mathrm{Y} / \mathrm{N} 444 / 261$

Years since onset of $\mathrm{CM} 18$, number of migraine days during baseline diary period 19

Interventions

Intervention: Botox 31 fixed injections (total $155 \mathrm{U}$ ) followed by 8 optional follow the pain injections (total $40 \mathrm{U}$ ). PREEMPT paradigm: frontalis $20 \mathrm{U}$ in 4 sites; corrugator $10 \mathrm{U}$ in 2 sites; procerus $5 \mathrm{U}$ in 1 site; occipitalis $30 \mathrm{U}$ in 6 sites up to $40 \mathrm{U}$ in 8 sites; temporalis $40 \mathrm{U}$ in 8 sites up to $50 \mathrm{U}$ in 10 sites; trapezius $30 \mathrm{U}$ in 6 sites; cervical paraspinal $20 \mathrm{U}$ in 4 sites

Control: matched placebo injections

Outcomes
Number of headache days
Number of migraine days
Number of headache episodes
Monthly cumulation of headache hours
Proportion of responders ( $\geq 50 \%$ reduction in migraine)
Use of rescue medication
HIT-6
Headache impact score 
Diener 2010 (PREEMPT 2) (Continued)

Migraine specific quality of life questionnaire

HRQoL

Adverse events

QALYS

Incremental cost-effectiveness ratio

\begin{tabular}{ll}
\hline Notes & Protocol NCT00156910 \\
& Funder: Allergan, Inc., Irvine, California (manufacturer of Botox) \\
& Diary period 28 days
\end{tabular}

\section{Risk of bias}

\begin{tabular}{lll}
\hline Bias & Authors' judgement & Support for judgement \\
\hline $\begin{array}{l}\text { Random sequence genera- } \\
\text { tion (selection bias) }\end{array}$ & Low risk & Computer-generated randomisation sequence \\
\hline $\begin{array}{l}\text { Allocation concealment } \\
\text { (selection bias) }\end{array}$ & Low risk & $\begin{array}{l}\text { Upon randomisation subject number was linked to next randomisation num- } \\
\text { ber grouped within strata for that site, site was then notified of medication kit } \\
\text { assigned to that number }\end{array}$ \\
\hline
\end{tabular}

\begin{tabular}{|c|c|c|}
\hline $\begin{array}{l}\text { Blinding of participants } \\
\text { and personnel (perfor- }\end{array}$ & Low risk & $\begin{array}{l}\text { Double-blind: placebo arm, prepacked medication kits with number for as- } \\
\text { signment }\end{array}$ \\
\hline
\end{tabular}
mance bias)

All outcomes

\begin{tabular}{|c|c|c|}
\hline $\begin{array}{l}\text { Blinding of outcome as- } \\
\text { sessment (detection bias) }\end{array}$ & Low risk & $\begin{array}{l}\text { Double-blind: placebo arm, prepacked medication kits with number for as- } \\
\text { signment }\end{array}$ \\
\hline
\end{tabular}

All outcomes

Incomplete outcome data Low risk Withdrawals balanced across groups and adjusted LOCF method used
(attrition bias)

All outcomes

Selective reporting (re- Low risk All expected outcomes reported

porting bias)

Study size Low risk $\quad \geq 200$ participants per treatment arm

Elkind I 2006

Methods

Randomised, double-blind, placebo-controlled, parallel-group, multi-site

4-arm trial.

2 arms received 1 treatment before being re-randomised, 2 arms received 3 treatments before being rerandomised, 120 days FU per treatment

This paper comprised 3 trials of which this is the first. (Elkind II 2006 - included, Elkind Study III 2006 (Elkind 2006)- excluded)

3 arms with varying doses of fixed injections of Botox vs placebo injections 
Elkind I 2006 (Continued)

Assessments carried out at baseline and 30 days, 60 days, 90 days and 120 days post-treatment for each treatment cycle

\section{Participants}

Inclusion criteria: aged 18-65 years; IHS-defined migraines with or without aura; average of 4-8 moderate-severe migraines per month that occurred with a stable frequency and severity and had begun at least 1 year prior to the trial; first diagnosed with migraine before age 50 years; able to distinguish between migraine and non migraine headaches; stable medical condition; if taking chronic medications (including prophylactic migraine medications), on stable doses and regimens for at least 3 months prior to enrolment, to be continued throughout the trial

Exclusion criteria: > 15 headache d/month; history of complicated migraine or typical migraine pain localised predominantly to the occipital or suboccipital region; consistently refractory to multiple acute therapies or had never tried any acute therapies; overuse of symptomatic medications; excessive use of caffeine; alcohol/drug abuse; any medical condition or use of any agent that might have put the participant at increased risk with exposure to Botox or interfered with trial participation or the results; pregnancy, breastfeeding, or planning a pregnancy during the trial period; previous injection with any BTX or allergy to any of the components of the trial medication; prior injection of anaesthetic or steroid into the muscles to be injected in the month immediately prior to enrolment; participation in another investigational drug or device clinical trial either concurrently or in the month immediately prior to enrolment; infection or skin problems at the injection site

Participants with migraine headache at the time of treatment may have been randomised/injected at a later date within 2 weeks of the scheduled visit

$N=418$, mean age 44 years, $M$ 64/F 354

Some CM inadvertently included against protocol EM/CM 409/9, MOH excluded

Years since onset of migraine 21, number of migraine attacks in baseline diary period 6

Intervention (arm 1): 50 U Botox total of 11 injections - frontal 4 sites, temporal 2 sites, glabellar 5 sites

Intervention (arm 2): $25 \mathrm{U}$ Botox total of 11 injections - frontal 4 sites, temporal 2 sites, glabellar 5 sites

Intervention (arm 3): $7.5 \mathrm{U}$ Botox total of 11 injections - frontal 4 sites, temporal 2 sites, glabellar 5 sites

Control: matched placebo injections

$\begin{array}{ll}\text { Outcomes } & \text { Number of migraine attacks } \\ \text { Secondary endpoint: } \\ \text { Proportion of responders ( } \geq 50 \% \text { reduction in migraine) } \\ \text { Maximum migraine headache severity } \\ \text { Use of rescue medication } \\ \text { Severity of migraine } \\ \text { Maximum migraine duration } \\ \text { Number of days with aura } \\ \text { Number of days with migraine-associated symptoms } \\ \text { Patient global assessment score } \\ \text { SF-36 } \\ \text { Migraine-Specific Measure of Quality of Life } \\ \text { Migraine Impact Questionnaire } \\ \text { Headache Pain Specific Quality of Life Questionnaire } \\ \text { Adverse events }\end{array}$

Notes

Funder: Allergan, Inc., Irvine, California (manufacturer of Botox)

Diary period 30 days

Contacted without response

\section{Risk of bias}


Elkind I 2006 (Continued)

\begin{tabular}{lll} 
Bias & Authors' judgement & Support for judgement \\
\hline $\begin{array}{l}\text { Random sequence genera- } \\
\text { tion (selection bias) }\end{array}$ & Unclear risk & Method not stated \\
\hline $\begin{array}{l}\text { Allocation concealment } \\
\text { (selection bias) }\end{array}$ & Unclear risk & Method not stated \\
\hline $\begin{array}{l}\text { Blinding of participants } \\
\text { and personnel (perfor- } \\
\text { mance bias) }\end{array}$ & Unclear risk & $\begin{array}{l}\text { Double-blind: participant blinded with matched placebo injections no meth- } \\
\text { All outcomes }\end{array}$ \\
\hline
\end{tabular}

$\begin{array}{ll}\text { Blinding of outcome as- } & \text { Unclear risk }\end{array}$ Double-blind: no methods given for blinding of personnel

All outcomes

\begin{tabular}{lll}
\hline $\begin{array}{l}\text { Incomplete outcome data } \\
\text { (attrition bias) } \\
\text { All outcomes }\end{array}$ & Low risk & Missing data low and balanced across groups \\
\hline $\begin{array}{l}\text { Selective reporting (re- } \\
\text { porting bias) }\end{array}$ & Unclear risk & All expected outcomes discussed but data not always provided \\
\hline Study size & Unclear risk & $50-199$ participants per arm \\
\hline
\end{tabular}

Randomised, double-blind, placebo-controlled, parallel-group, multi-site
2 treatment cycles, 120 days FU per treatment. Follows on from Elkind I 2006
Fixed injections of Botox dosing trial
Assessments carried out at baseline and 30 days, 60 days, 90 days and 120 days post-treatment for each
treatment cycle

Inclusion criteria: aged 18-65 years; IHS-defined migraines with or without aura; average of 4-8 moderate-severe migraines per month that occurred with a stable frequency and severity and had begun at least 1 year prior to the trial; first diagnosed with migraine before age 50 years; able to distinguish between migraine and non migraine headaches; stable medical condition; if taking chronic medications (including prophylactic migraine medications), on stable doses and regimens for at least 3 months prior to enrolment, to be continued throughout the trial

Exclusion criteria: > 15 headache d/month; history of complicated migraine or typical migraine pain localised predominantly to the occipital or suboccipital region; consistently refractory to multiple acute therapies or had never tried any acute therapies; overuse of symptomatic medications; excessive use of caffeine; alcohol/drugs abuse; any medical condition or use of any agent that might have put the participant at increased risk with exposure to Botox or interfered with trial participation or the results; pregnancy, breastfeeding, or planning a pregnancy during the trial period; previous injection with any BTX or allergy to any of the components of the trial medication; prior injection of anaesthetic or steroid into the muscles to be injected in the month immediately prior to enrolment; participation in another investigational drug or device clinical trial either concurrently or in the month immediately prior to enrolment; infection or skin problems at the injection site

participants with migraine headache at the time of treatment may have been randomised/injected at a later date within 2 weeks of the scheduled visit 
Elkind II 2006 (Continued)

$\mathrm{N}=183$, baseline data given for Elkind I 2006 participant set only. Some attrition of participants between end of study I and start of study II not described in detail

Some $\mathrm{CM}$ inadvertently included against protocol EM/CM unclear, $\mathrm{MOH}$ excluded

Interventions

Intervention (arm 1): 50 U Botox total of 11 injections - frontal 4 sites, temporal 2 sites, glabellar 5 sites

Intervention (arm 2): 25 U Botox total of 11 injections - frontal 4 sites, temporal 2 sites, glabellar 5 sites

\begin{tabular}{ll}
\hline Outcomes & Number of migraine attacks \\
Secondary endpoint: & Proportion of responders ( $\geq 50 \%$ reduction in migraine) \\
& Maximum migraine headache severity \\
Use of rescue medication & Severity of migraine \\
Maximum migraine duration \\
Number of days with aura \\
Number of days with migraine-associated symptoms \\
Patient global assessment score \\
SF-36 \\
Migraine-Specific Measure of Quality of Life \\
Migraine Impact Questionnaire \\
Headache Pain Specific Quality of Life Questionnaire \\
Adverse events
\end{tabular}

Notes

Funder: Allergan, Inc., Irvine, California (manufacturer of Botox)

Diary period 30 days

Contacted without response

\section{Risk of bias}

\begin{tabular}{|c|c|c|}
\hline Bias & Authors' judgement & Support for judgement \\
\hline $\begin{array}{l}\text { Random sequence genera- } \\
\text { tion (selection bias) }\end{array}$ & Unclear risk & Method not stated \\
\hline $\begin{array}{l}\text { Allocation concealment } \\
\text { (selection bias) }\end{array}$ & Unclear risk & Method not stated \\
\hline $\begin{array}{l}\text { Blinding of participants } \\
\text { and personnel (perfor- } \\
\text { mance bias) } \\
\text { All outcomes }\end{array}$ & Unclear risk & $\begin{array}{l}\text { Double-blind: participant blinded with matched placebo injections no meth- } \\
\text { ods given for blinding of personnel }\end{array}$ \\
\hline $\begin{array}{l}\text { Blinding of outcome as- } \\
\text { sessment (detection bias) } \\
\text { All outcomes }\end{array}$ & Unclear risk & Double-blind: no methods given for blinding of personnel \\
\hline $\begin{array}{l}\text { Incomplete outcome data } \\
\text { (attrition bias) } \\
\text { All outcomes }\end{array}$ & Low risk & $\begin{array}{l}\text { Missing data at } 22 \% \text { vs } 16 \% \text { of total participant numbers balanced across } \\
\text { groups }\end{array}$ \\
\hline $\begin{array}{l}\text { Selective reporting (re- } \\
\text { porting bias) }\end{array}$ & Unclear risk & All expected outcomes discussed but data not always provided \\
\hline Study size & Unclear risk & 50-199 participants per arm \\
\hline
\end{tabular}


Fixed injections of Botox vs placebo

Assessments carried out at baseline and at 4 weeks, 8 weeks, 12 weeks and 16 weeks post-treatment

Participants

Inclusion criteria: 6-month history, prior to baseline, of CM; migraine episodes meeting the criteria 1.1 or 1.2 of the ICHD-I; 15 headache days during the prospective baseline phase; anyone taking preventive medications must have been on stable dosages for 60 days prior to trial entry and willing to remain at same doses for the duration of the trial; women were required to be practicing an acceptable method of contraception and have a pregnancy test or to be incapable of pregnancy

Exclusion criteria: previous treatment with BTX of any sero-type for any therapeutic reason; history of myasthenia gravis, Eaton-Lambert syndrome, amyotrophic lateral sclerosis or other disorder of neuromuscular function; concomitant use of aminoglycoside antibiotics, curare-like agents or other agents that might interfere with neuromuscular function; diagnoses of migraine beginning for the first time after age 50 years; cluster headaches or basilar, ophthalmoplegic, hemiplegic migraine, or exclusively having migraine aura without headache; more painful condition than their migraine pain, progressive neurological disorders, or a structural disorder of the brain from birth, trauma, or past infection; received injections or oral corticosteroids within 30 days prior to the baseline diary initiation visit; significant major psychiatric disorder; receiving antipsychotic medication; Beck Inventory of Depression Scores > 24; received an investigational drug or used an investigational device within 30 days of trial entry; taking triptans $>3$ days per week, ergotamine $>2$ days per week, or dihydroergotamine $>2$ days per week or any combination of the above medications $>3$ days per week; consuming caffeine from dietary and medicinal sources $>500 \mathrm{mg} / \mathrm{d}$ on a daily basis $>28$ days prior to trial enrolment; taking opioids $>2$ days per week; taking simple analgesics on average $>2$ tablets $/ d \geq 5$ days per week for at least 28 days; taking combination analgesics on average $>3$ tablets per day and $\geq 3$ days per week for at least 28 days; using a combination of any of the previous on $\geq 4$ days per week for at least 28 days

$\mathrm{N}=41$, mean age 42 years, $M$ 11/F 30

$\mathrm{CM}$ only eligible, $\mathrm{MOH}$ excluded

Baseline disease characteristics not stated

Interventions Intervention: Botox 100 U, 22 injections (glabella 20 U, 4 sites; temporal 20 U, 4 sites; frontal $10 \mathrm{U}, 4$ sites; suboccipital 30 U, 6 sites; trapezius 20 U, 4 sites)

Control: matched placebo injections

Outcomes

Number of migraine episodes

Number of headache days

Headache index (HAI)

Proportion of $50 \%$ responders

Use of rescue medication

MIDAS

Headache Pain Specific Quality of Life measure

Adverse events

Notes

Funder: Allergan, Inc., Irvine, California (manufacturer of Botox)

Diary period 28 days

\section{Risk of bias}


Freitag 2008 (Continued)

Random sequence genera- Low risk Computer-generated randomisation sequence tion (selection bias)

\begin{tabular}{lll}
\hline $\begin{array}{l}\text { Allocation concealment } \\
\text { (selection bias) }\end{array}$ & Unclear risk & Method not stated \\
\hline $\begin{array}{l}\text { Blinding of participants } \\
\text { and personnel (perfor- } \\
\text { mance bias) }\end{array}$ & Low risk & $\begin{array}{l}\text { Double-blind: participant blinded, with matched placebo injections, research } \\
\text { nurse who was not involved with the trial participants prepared the injections, } \\
\text { trial medication was delivered to treating physician in identical looking sy- } \\
\text { ringes }\end{array}$ \\
\hline
\end{tabular}

$\begin{array}{ll}\begin{array}{l}\text { Blinding of outcome as- } \\ \text { sessment (detection bias) }\end{array} & \text { Low risk } \\ \text { All outcomes } & \begin{array}{l}\text { Double-blind: research nurse, who was not involved with the trial participants } \\ \text { prepared the injections, trial medication was delivered to treating physician in } \\ \text { identical looking syringes }\end{array}\end{array}$

$\begin{array}{ll}\begin{array}{l}\text { Incomplete outcome data } \\ \text { (attrition bias) }\end{array} & \text { Low risk } \\ \text { All outcomes } & \begin{array}{l}\text { Missing data low and balanced across groups at 10\% vs 14\% of total partici- } \\ \text { pant numbers }\end{array}\end{array}$

All outcomes

\begin{tabular}{lll}
\hline $\begin{array}{l}\text { Selective reporting (re- } \\
\text { porting bias) }\end{array}$ & Low risk & $\begin{array}{l}\text { All expected outcomes reported but standard errors or equivalent not report- } \\
\text { ed and some interim time points missing }\end{array}$ \\
\hline Study size & High risk & $<50$ participants per treatment arm \\
\hline
\end{tabular}

Hollanda 2014

Methods
Randomised, double-blind, placebo-controlled, parallel-group, single-site
3 cycles of treatment at 4-week intervals (some uncertainty as to whether participants were treated at
each visit or just at first visit), trial length 12 weeks in total
Follow the pain injections of Prosigne vs placebo
Assessments carried out at baseline, 4 weeks, 8 weeks and 12 weeks
Inclusion criteria: aged $18-85$ years; diagnosis of CM associated with cutaneous allodynia, according to
the ICHD (edition revised, 2006)
Exclusion criteria: diagnosis of neuromuscular diseases (myasthenia gravis, Eaton-Lambert syndrome
and amyotrophic lateral sclerosis); conditions that could affect pericranial muscles; other primary or
secondary headaches; complicated migraine; CM associated with analgesic overuse; severe systemic
diseases; other neurologic or psychiatric disorders; fibromyalgia; myofascial syndrome; temporo-
mandibular disorder
$\mathrm{N}=38$, mean age $45, \mathrm{M} 9 / \mathrm{F} 29$
CM only eligible, MOH excluded
Severity of migraine $7.3 \mathrm{~cm}$ on $10 \mathrm{~cm}$ VAS

Interventions Intervention: Prosigne 12-24 injections, maximum dose $96 \mathrm{U}$ (frontal 2-4 sites on each side $3 \mathrm{U}$ per site; temporal 2-4 sites on each side $4 \mathrm{U}$ per site; occipital 2-4 sites on each side $5 \mathrm{U}$ per site)

Control: matched placebo injections

$\begin{array}{ll}\text { Outcomes } & \text { Number of migraine episodes with cutaneous allodynia } \\ \text { Severity of headache pain (VAS) }\end{array}$


Hollanda 2014 (Continued)

Use of rescue medication

Adverse events

Notes

Funder: Brazilian National Institutes of Science

Diary period 30 days

Protocol NCT01357798

\section{Risk of bias}

\begin{tabular}{|c|c|c|}
\hline Bias & Authors' judgement & Support for judgement \\
\hline $\begin{array}{l}\text { Random sequence genera- } \\
\text { tion (selection bias) }\end{array}$ & Low risk & Computer-generated randomisation sequence \\
\hline $\begin{array}{l}\text { Allocation concealment } \\
\text { (selection bias) }\end{array}$ & Unclear risk & Method not stated \\
\hline $\begin{array}{l}\text { Blinding of participants } \\
\text { and personnel (perfor- } \\
\text { mance bias) } \\
\text { All outcomes }\end{array}$ & Low risk & $\begin{array}{l}\text { Double-blind: participant blinded, with matched placebo injections, } 1 \text { desig- } \\
\text { nated investigator who had access to randomisation sequence provided the } \\
\text { trial medication to the principal investigator according to the allocation list } \\
\text { generated }\end{array}$ \\
\hline $\begin{array}{l}\text { Blinding of outcome as- } \\
\text { sessment (detection bias) } \\
\text { All outcomes }\end{array}$ & Low risk & $\begin{array}{l}\text { Double-blind: } 1 \text { designated investigator who had access to randomisation se- } \\
\text { quence provided the trial medication to the principal investigator according to } \\
\text { the allocation list generated }\end{array}$ \\
\hline $\begin{array}{l}\text { Incomplete outcome data } \\
\text { (attrition bias) } \\
\text { All outcomes }\end{array}$ & Low risk & Appear to be no dropouts \\
\hline $\begin{array}{l}\text { Selective reporting (re- } \\
\text { porting bias) }\end{array}$ & Low risk & All outcomes in protocol and methods reported \\
\hline Study size & High risk & $<50$ participants per treatment arm \\
\hline
\end{tabular}

Hou 2015

Methods

Randomised, double-blind, placebo-controlled, parallel-group, single-site

Single treatment with 4-month FU

3-arm trial, HengLi fixed muscle site injections vs HengLi acupoint site injections vs placebo

Assessments carried out at baseline and 1 month, 2 months, 3 months and 4 months postbaseline

Participants

Inclusion criteria: EM and CM, criteria used ICHD-I; aged 18-57 years; history of migraines with or without aura for 1-16 years; experienced headache $\geq 15 \mathrm{~d} /$ month were diagnosed as CM; women of childbearing potential were required to be taking approved birth control measures and to have a negative urine pregnancy test prior to administration of trial medications

Exclusion criteria: any medical or neurological conditions that might put them at risk with Botox exposure, such as amyotrophic lateral sclerosis, myasthenia gravis, Eaton-Lambert Syndrome; any disease that might interfere with neuromuscular function; abnormal pathology contributing to migraine; uncontrolled systemic disease; concurrent infection at proposed injection sites; pregnant or breast-feeding; currently using aminoglycoside antibiotics, curare-like agents, or other agents that might interfere 
Hou 2015 (Continued)

with neuromuscular function; undergone injection of anaesthetics or steroids, within 1 month immediately prior to enrolment, into the muscles to be injected in the trial; previously received Botox treatment with any sero-type; currently participating in another drug or device trial or had done so within the 30 days before the baseline period; suspected hypersensitivity to Botox or any of the ingredients in the proprietary formulation; known or suspected drug or alcohol abuse

$\mathrm{N}=102$, mean age 41, M 21/F 81

EM/CM 66/36, MOH eligibility unclear

Years since diagnosis of migraine 6 , number of migraine attacks during baseline diary period 7 , severity of migraine $7.4 \mathrm{~cm}$ on $10 \mathrm{~cm}$ VAS

Interventions

Intervention (arm 1): HengLi fixed muscle site, 10 injections of $2.5 \mathrm{U}$ each, total dose $25 \mathrm{U}$ ( 1 on each side for frontal and occipital belly of occipitofrontalis, corrugator supercilii, temporalis and superior part of trapeziuem)

Intervention (arm 2): HengLi acupoint site, 10 injections of $2.5 \mathrm{U}$ each, total dose $25 \mathrm{U}$ (Yintang EX-HN3, at the midpoint of the line connecting the 2 medial ends of eyebrows; Taiyang EX-HN5, at the point of intersection of the continuations of the eyebrow and the lower eyelid in the lateral direction, on the lateral border of the orbit; Baihui GV20, at the middle of the vertex, on the line connecting the apexes of the 2 ears; Shuaigu GB8, directly above the ear apex, 1.5 inches above the hairline; Fengchi GB20, at the posterior lateral aspect of the neck, in the fossa between the superior margins of the trapezius and sternocleidomastoid muscles; and Tianzhu BL10, 1.3 inches lateral to the point 0.5 inches directly above the midpoint of the posterior hairline, in the depression lateral to the border of the trapezius muscle

Control: placebo injections matched to fixed muscle site arm

\begin{tabular}{|c|c|c|}
\hline \multirow[t]{5}{*}{ Outcomes } & \multicolumn{2}{|c|}{ Number of migraine attacks } \\
\hline & \multicolumn{2}{|l|}{ Duration of migraine } \\
\hline & \multicolumn{2}{|l|}{ Severity of migraine } \\
\hline & \multicolumn{2}{|c|}{ Frequency of migraine symptoms } \\
\hline & \multicolumn{2}{|l|}{ Adverse events } \\
\hline \multirow[t]{2}{*}{ Notes } & \multicolumn{2}{|c|}{ Funder: Scientific and Technique Support Project of Gansu Province (090NKCA112), China } \\
\hline & \multicolumn{2}{|l|}{ Diary period 1 month } \\
\hline \multicolumn{3}{|l|}{ Risk of bias } \\
\hline Bias & Authors' judgement & Support for judgement \\
\hline $\begin{array}{l}\text { Random sequence genera- } \\
\text { tion (selection bias) }\end{array}$ & Low risk & Computer-generated randomisation sequence \\
\hline $\begin{array}{l}\text { Allocation concealment } \\
\text { (selection bias) }\end{array}$ & Unclear risk & Method not stated \\
\hline \multirow{4}{*}{$\begin{array}{l}\text { Blinding of participants } \\
\text { and personnel (perfor- } \\
\text { mance bias) } \\
\text { All outcomes }\end{array}$} & \multirow[t]{4}{*}{ Unclear risk } & Double-blind \\
\hline & & Quote: "participant blind with matched placebo injections, a research coordi- \\
\hline & & $\begin{array}{l}\text { nator who was not directly involved with the subjects managed the randomi- } \\
\text { sation and preparation of injections." }\end{array}$ \\
\hline & & $\begin{array}{l}\text { Since dummy injections are not mentioned it cannot be the case that person- } \\
\text { nel carrying out injections are blind to active assignment }\end{array}$ \\
\hline
\end{tabular}


Hou 2015 (Continued)

Blinding of outcome as- Low risk Double-blind: a research co-ordinator who was not directly involved with the sessment (detection bias)

All outcomes participants managed the randomisation and preparation of injections, analysis of the diary data was conducted by investigators who did not know the exact group of each participant

Incomplete outcome data Low risk Appear to be no dropouts

(attrition bias)

All outcomes

\begin{tabular}{lll}
\hline $\begin{array}{l}\text { Selective reporting (re- } \\
\text { porting bias) }\end{array}$ & High risk & Use of rescue medications recorded but not reported \\
\hline Study size & High risk & $<50$ participants per treatment arm \\
\hline
\end{tabular}

\section{Jabbari 2014}

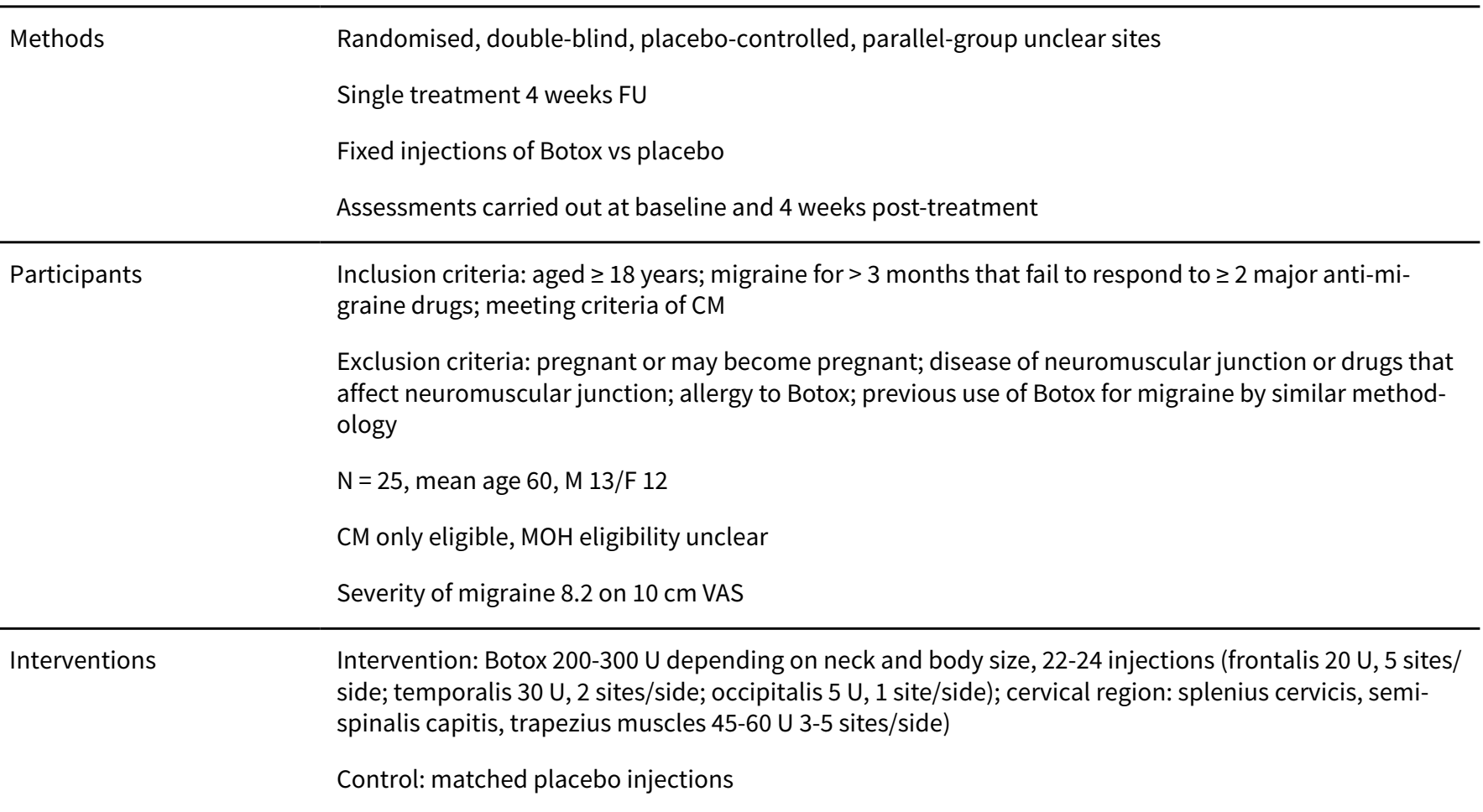

\begin{tabular}{ll}
\hline Outcomes & Severity of migraine \\
Global assessment score \\
Pain impact questionnaire \\
HIT-6 \\
Migraine-specific quality of life \\
Adverse events \\
\hline Notes & Protocol NCT00660192 \\
Funding source unclear \\
Diary period 28 days
\end{tabular}




\section{Risk of bias}

\begin{tabular}{lll}
\hline Bias & Authors' judgement & Support for judgement \\
\hline $\begin{array}{l}\text { Random sequence genera- } \\
\text { tion (selection bias) }\end{array}$ & Unclear risk & Method not stated \\
\hline $\begin{array}{l}\text { Allocation concealment } \\
\text { (selection bias) }\end{array}$ & Unclear risk & Method not stated \\
\hline $\begin{array}{l}\text { Blinding of participants } \\
\text { and personnel (perfor- } \\
\text { mance bias) }\end{array}$ & Unclear risk & Double-blind: participant and investigator blind \\
$\begin{array}{l}\text { All outcomes } \\
\text { Blinding of outcome as- } \\
\text { sessment (detection bias) } \\
\text { All outcomes }\end{array}$ & Unclear risk & Double-blind: participant and investigator blind \\
\hline $\begin{array}{l}\text { Incomplete outcome data } \\
\text { (attrition bias) } \\
\text { All outcomes }\end{array}$ & High risk & 20\% dropped out N = 5 \\
\hline $\begin{array}{l}\text { Selective reporting (re- } \\
\text { porting bias) }\end{array}$ & Unclear risk & Not yet published, information and data from trial registry only \\
\hline \begin{tabular}{l} 
Study size \\
\hline
\end{tabular} & High risk & $<50$ participants per treatment arm \\
\hline
\end{tabular}

Jost 2011

Methods Randomised, double-blind, placebo-controlled, cross-over, unclear sites

Single treatment with 4 months FU precross-over

Unclear method of injections of Botox vs placebo

Assessments carried out at baseline and 6 weeks and 4 months post-treatment

Participants

Inclusion criteria: aged 18-70 years; clinically confirmed diagnosis of migraine without aura, criteria used ICHD, edition not stated; duration of illness, so far refractory to conservative treatment (physiotherapy, massages, stretching exercises, peroral medication) at least 2 years

Exclusion criteria: participation in another clinical trial within the past 3 months; specific pain in neck/ shoulder region in need of different specific treatment (i.e. acute nerve irritation with disc prolapse, manifest inflammatory processes etc.); contraindication of treatment with BTX (ascertained sensitivity to clostridial toxin or to 1 of the other ingredients and generalised disorders of muscular activity, e.g. myasthenia gravis or Lambert-Eaton syndrome); pregnancy or breastfeeding or inadequate or no contraception in women of childbearing age; serious concomitant illnesses involving the internal organs in particular; systemic diseases; serious neurologic disorders; abuse of alcohol, drugs and narcotics; medication with anticoagulants and heparin preparation (topically applied heparin unguents excluded), thrombocyte aggregation inhibitors, amino-glycoside antibiotics, spectinomycin or muscle relaxants of the tubocurarine type

$\mathrm{N}=22$, mean age $45, \mathrm{M} \mathrm{5/F} 17$

$\mathrm{EM} / \mathrm{CM}$ unclear, $\mathrm{MOH}$ eligibility unclear 
Jost 2011 (Continued)

Baseline disease characteristics not stated

Interventions Intervention: Botox $10 \mathrm{U} 2$ injections in total into corrugator muscle and occipitalis muscle of the side affected

Control: matched placebo injections

\begin{tabular}{|c|c|}
\hline \multirow[t]{10}{*}{ Outcomes } & Pain intensity (severity) VAS \\
\hline & Number of headache attacks \\
\hline & Use of rescue medication \\
\hline & Short form-McGill Pain Questionnaire \\
\hline & Northwick Park Neck Pain Questionnaire \\
\hline & International quality of life assessment \\
\hline & SF 36 \\
\hline & Scale of attitudes toward disabled persons \\
\hline & Oswestry low back pain disability questionnaire \\
\hline & Adverse events \\
\hline \multirow[t]{2}{*}{ Notes } & $\begin{array}{l}\text { Funder: German society of Neurology (statistical analysis only). States no funds came from manufactur- } \\
\text { ers of BTX }\end{array}$ \\
\hline & Diary period unclear \\
\hline
\end{tabular}

\section{Risk of bias}

Bias Authors' judgement Support for judgement

Random sequence genera- Unclear risk Method not stated

tion (selection bias)

\begin{tabular}{lll}
\hline $\begin{array}{l}\text { Allocation concealment } \\
\text { (selection bias) }\end{array}$ & Unclear risk & Method not stated \\
\hline $\begin{array}{l}\text { Blinding of participants } \\
\text { and personnel (perfor- } \\
\text { mance bias) }\end{array}$ & Unclear risk & $\begin{array}{l}\text { Double-blind: participant blinded with matched placebo injections no meth- } \\
\text { ods given for blinding of personnel }\end{array}$ \\
\begin{tabular}{l} 
All outcomes \\
\hline
\end{tabular} &
\end{tabular}

\begin{tabular}{lll}
\hline $\begin{array}{l}\text { Blinding of outcome as- } \\
\text { sessment (detection bias) } \\
\text { All outcomes }\end{array}$ & Unclear risk & Double-blind: no methods given for blinding of personnel \\
\hline $\begin{array}{l}\text { Incomplete outcome data } \\
\text { (attrition bias) } \\
\text { All outcomes }\end{array}$ & Unclear risk & $\begin{array}{l}\text { Not stated from which group dropouts (3) occurred. Participants lost to FU not } \\
\text { analysed }\end{array}$ \\
\hline $\begin{array}{l}\text { Selective reporting (re- } \\
\text { porting bias) }\end{array}$ & High risk & AEs recorded but not reported or commented upon \\
\hline Study size & High risk & $<50$ participants per treatment arm \\
\hline
\end{tabular}


Lauretti 2014

\section{Methods}

Randomised, double-blind, placebo-controlled, parallel-group, single-site

Single treatment with 12 weeks FU

4-arm trial fixed injections Botox vs Prosigne ( 2 dosing arms) vs saline

Assessments carried out at baseline and 4 weeks, 8 weeks and 12 weeks post-treatment

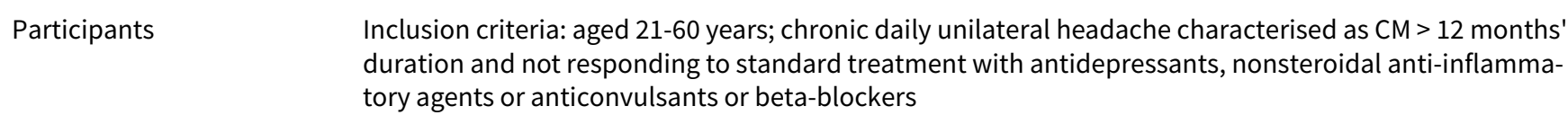

Exclusion criteria: presence of an infectious process at the site of application; associated immunological diseases; previous history of allergy to Botox; application of Botox during the last year; diabetes mellitus

$\mathrm{N}=40$, mean age 46 years, $M$ 14/F 26

$\mathrm{CM}$ only eligible, $\mathrm{MOH}$ eligibility unclear

Years since diagnosis of CM 16, severity of migraine 10.0 on $10 \mathrm{~cm}$ VAS

Interventions

Intervention (arm 1): Botox 10 injections, total dose $25 \mathrm{U}$ (8 different sites in the frontal region and 2 sites in the temporal region, 1 site on each side)

Intervention (arm 2): Prosigne 10 injections, total dose $25 \mathrm{U}$ (8 different sites in the frontal region and 2 sites in the temporal region, 1 site on each side)

Intervention (arm 3): Prosigne 10 injections, total dose $33.3 \mathrm{U}$ (8 different sites in the frontal region and 2 sites in the temporal region, 1 site on each side)

Control: matched placebo injections

\begin{tabular}{|c|c|c|}
\hline \multirow[t]{3}{*}{ Outcomes } & \multicolumn{2}{|c|}{ Number of headache attacks } \\
\hline & \multicolumn{2}{|l|}{ Severity of headache } \\
\hline & \multicolumn{2}{|l|}{ Time to $50 \%$ pain relief } \\
\hline \multirow[t]{2}{*}{ Notes } & \multicolumn{2}{|l|}{ Funding source unclear } \\
\hline & \multicolumn{2}{|l|}{ Diary period 4 weeks } \\
\hline \multicolumn{3}{|l|}{ Risk of bias } \\
\hline Bias & Authors' judgement & Support for judgement \\
\hline $\begin{array}{l}\text { Random sequence genera- } \\
\text { tion (selection bias) }\end{array}$ & Low risk & Computer-generated randomisation sequence \\
\hline $\begin{array}{l}\text { Allocation concealment } \\
\text { (selection bias) }\end{array}$ & Unclear risk & Method not stated \\
\hline $\begin{array}{l}\text { Blinding of participants } \\
\text { and personnel (perfor- } \\
\text { mance bias) } \\
\text { All outcomes }\end{array}$ & Low risk & $\begin{array}{l}\text { Double-blind: participant blind with matched placebo injections, } 1 \text { of the tri- } \\
\text { al authors prepared injections and a second trial author, who was unaware of } \\
\text { the content of the previously prepared syringes delivered the treatment }\end{array}$ \\
\hline
\end{tabular}


Lauretti 2014 (Continued)

Blinding of outcome as- Unclear risk Double-blind: 1 of the trial authors prepared injections and a second trial ausessment (detection bias) thor, who was unaware of the content of the previously prepared syringes deAll outcomes

Incomplete outcome data $\quad$ Low risk $\quad$ Missing data balanced across groups $(1 / 1 / 0 / 1)$
(attrition bias)

All outcomes

Selective reporting (re- Unclear risk AEs not mentioned at all in report

porting bias)

Study size High risk < < $\quad$ participants per treatment arm

Mathew 2009

\begin{tabular}{|c|c|}
\hline \multirow[t]{2}{*}{ Methods } & Randomised, double-blind, active control, parallel-group, single site \\
\hline & 2 treatments with 3 months between treatments and 6 months FU after second treatment \\
\hline
\end{tabular}

Assessments carried out at baseline and 1 month, 3 months, 6 months and 9 months after first treatment

Participants

Inclusion criteria: outpatient; aged 18-65 years; diagnosed CM not attributable to another cause; CM headache was defined as migraine headache with or without aura occurring on $\geq 15 \mathrm{~d} /$ month for $>3$ months in the absence of medication overuse with at least 2 of the following characteristics: unilateral location, pulsating quality, moderate or severe pain intensity, and/or aggravation by or causing avoidance of routine physical activity (e.g. walking or climbing stairs); at least 1 of the following occurred during headache: nausea and/or vomiting or photophobia and/or phonophobia; stable headache severity and pattern; headache data for at least 6 months prior to trial drug administration

Exclusion criteria: pregnancy or planning to become pregnant during the trial period; breastfeeding; of childbearing potential and not practicing a reliable method of birth control; people with chronic tension-type headaches based on recognised criteria; evidence of underlying conditions judged to preclude treatment with either test medication; previously used trial medications for any reason; unable to discontinue any prohibited medication(s), including carbonic anhydrase inhibitors (e.g. acetazolamide, dichlorphenamide), digoxin, metformin, central nervous system depressants (including alcohol), non-trial migraine prophylaxis medications (e.g. propranolol, amitriptyline, sodium valproate), non-trial anticonvulsant or antiepileptic medications, agents that might interfere with neuromuscular function (e.g. aminoglycoside antibiotics, curare-like agents), or hormonal contraceptives; evidence of recent alcohol/drug abuse or acute medication overuse

$\mathrm{N}=60$, mean age $37, \mathrm{M} 6 / \mathrm{F} 54$

$\mathrm{CM}$ only eligible, $\mathrm{MOH}$ eligibility unclear

Number of headache/migraine days during baseline period 16, migraine severity 2.9 on 5-point scale

Interventions Intervention: Botox $200 \mathrm{U}, 100 \mathrm{U}$ fixed site and $100 \mathrm{U}$ follow the pain, number and location of injection sites not reported plus placebo tablets

Control: TOPAMAX (topiramate) $100-200 \mathrm{mg} / \mathrm{d}$, plus matched placebo injections

$\begin{array}{ll}\text { Outcomes } & \text { Number of migraine attacks } \\ \text { Proportion of } 50 \% \text { responders }\end{array}$


Severity of migraine

Use of rescue medication

MIDAS

MIQ

Adverse events

\begin{tabular}{ll}
\hline Notes & Funder: Allergan, Inc., Irvine, California (manufacturer of Botox) \\
& Diary period 1 month \\
& Uncontactable \\
\hline
\end{tabular}

\section{Risk of bias}

\begin{tabular}{|c|c|c|}
\hline Bias & Authors' judgement & Support for judgement \\
\hline $\begin{array}{l}\text { Random sequence genera- } \\
\text { tion (selection bias) }\end{array}$ & Unclear risk & Method not stated \\
\hline $\begin{array}{l}\text { Allocation concealment } \\
\text { (selection bias) }\end{array}$ & Unclear risk & Method not stated \\
\hline $\begin{array}{l}\text { Blinding of participants } \\
\text { and personnel (perfor- } \\
\text { mance bias) } \\
\text { All outcomes }\end{array}$ & Unclear risk & $\begin{array}{l}\text { Double-blind: double dummy, participant blinded with matched placebo in- } \\
\text { jections or placebo tablets, no methods given for blinding of personnel }\end{array}$ \\
\hline $\begin{array}{l}\text { Blinding of outcome as- } \\
\text { sessment (detection bias) } \\
\text { All outcomes }\end{array}$ & Unclear risk & Double-blind: double dummy, no methods given for blinding of personnel \\
\hline $\begin{array}{l}\text { Incomplete outcome data } \\
\text { (attrition bias) } \\
\text { All outcomes }\end{array}$ & High risk & $\begin{array}{l}\text { Numbers analysed and numbers imputed unclear. Dropouts excluded from } \\
\text { analysis higher than 10\% for all outcomes }\end{array}$ \\
\hline $\begin{array}{l}\text { Selective reporting (re- } \\
\text { porting bias) }\end{array}$ & Low risk & All expected outcomes reported \\
\hline Study size & High risk & $<50$ participants per treatment arm \\
\hline
\end{tabular}

\section{Mazza 2016}

\begin{tabular}{ll} 
Methods & Randomised, double-blind, placebo-controlled,parallel-group, unclear sites \\
& 2 treatments, 90 -day FU, unclear at what point second treatment occurred \\
Follow the pain injections of BTX-A vs placebo \\
Assessments carried out at baseline, 30 days, 60 days and 90 days \\
\hline Participants \\
Inclusion criteria: CM with no response to intramuscular injections of BTX-A \\
$\mathrm{N}=94$, mean age and M/F ratio not stated
\end{tabular}


Mazza 2016 (Continued)

Duration of disease 18 years

Interventions Intervention: subcutaneous injection of BTX-A, up to $200 \mathrm{U}$ into trigeminal or occipital area

Control: matched placebo injections

\begin{tabular}{ll}
\hline Outcomes & Number of migraine days \\
& Proportion of $50 \%$ responders \\
& Other outcomes not yet reported \\
\hline Notes & $\begin{array}{l}\text { Publication due in } 2017, \text { only skeletal information available. Unpublished information provided } \\
\text { through correspondence with trial author }\end{array}$ \\
& Funding source unclear \\
\hline
\end{tabular}

\section{Risk of bias}

\begin{tabular}{|c|c|c|}
\hline Bias & Authors' judgement & Support for judgement \\
\hline $\begin{array}{l}\text { Random sequence genera- } \\
\text { tion (selection bias) }\end{array}$ & Unclear risk & Method not stated \\
\hline $\begin{array}{l}\text { Allocation concealment } \\
\text { (selection bias) }\end{array}$ & Unclear risk & Method not stated \\
\hline $\begin{array}{l}\text { Blinding of participants } \\
\text { and personnel (perfor- } \\
\text { mance bias) } \\
\text { All outcomes }\end{array}$ & Low risk & $\begin{array}{l}\text { Double-blind: the research assistant, who had access to the randomisation } \\
\text { list, delivered verum or placebo injections to the investigator. The investiga- } \\
\text { tor who injected the headache sufferers, the participants, and the investigator } \\
\text { who assessed outcome were all blinded }\end{array}$ \\
\hline $\begin{array}{l}\text { Blinding of outcome as- } \\
\text { sessment (detection bias) } \\
\text { All outcomes }\end{array}$ & Low risk & $\begin{array}{l}\text { Double-blind: the research assistant, who had access to the randomisation } \\
\text { list, delivered verum or placebo injections to the investigator. The investiga- } \\
\text { tor who injected the headache sufferers, the participants, and the investigator } \\
\text { who assessed outcome were all blinded }\end{array}$ \\
\hline $\begin{array}{l}\text { Incomplete outcome data } \\
\text { (attrition bias) } \\
\text { All outcomes }\end{array}$ & Unclear risk & Number of dropouts not stated \\
\hline $\begin{array}{l}\text { Selective reporting (re- } \\
\text { porting bias) }\end{array}$ & Unclear risk & $\begin{array}{l}\text { Not yet published, information and data from abstract and brief trial author } \\
\text { correspondence only }\end{array}$ \\
\hline Study size & High risk & $<50$ participants per treatment arm \\
\hline
\end{tabular}

Millán-Guerrero 2009

\begin{tabular}{ll}
\hline Methods & Randomised, double-blind, active-control, parallel-group, multi-site \\
& Single treatment, 12-week FU \\
& Fixed injections of Botox vs histamine. Double dummy \\
& Assessments carried out at baseline and every 30 days out to 12 weeks post-treatment \\
\hline Participants & $\begin{array}{l}\text { Inclusion criteria: aged 18-65 years; history of migraine for several years; diagnosed migrainous using } \\
\text { criteria ICHD-II; unresponsive to available abortive (acetaminophen (paracetamol), ergotamine, dex- }\end{array}$ \\
\hline
\end{tabular}


Millán-Guerrero 2009 (Continued)

amethasone, sumatriptan) and/or prophylactic agents (beta blocker, amitriptyline, sodium valproate, topiramate) without sustained pain-free response; attack frequency of 4-6 per month; severity of 2-3; overuse of acute pharmacotherapy

Exclusion criteria: pregnant women; daily headaches; radiological tests revealing any pathology, including computer-assisted tomography

$\mathrm{N}=100$, mean age 35, M 9/F 92

$\mathrm{EM} / \mathrm{CM}$ unclear, $\mathrm{MOH} \mathrm{Y}$ only eligible

Years since diagnosis of migraine 15 , number of headache attacks during baseline diary period 4 , severity of migraine 2.9 on 3-point scale

Interventions

Intervention: Botox, $50 \mathrm{U}, 10$ injections into fixed sites including procerus, corrugator, frontalis, temporalis and occipitalis plus placebo injections into upper arm

Control: histamine, 1-10 $\mu \mathrm{g}$ injected into upper arm twice a week for 12 weeks plus placebo injections into head and neck sites

\begin{tabular}{|c|c|}
\hline \multirow[t]{6}{*}{ Outcomes } & Number of migraine attacks \\
\hline & Duration of migraine \\
\hline & Severity of migraine \\
\hline & se of rescue medication \\
\hline & MIDAS \\
\hline & Adverse events \\
\hline \multirow[t]{3}{*}{ Notes } & Funding source unclear \\
\hline & Diary period 4 weeks \\
\hline & Contacted without response \\
\hline
\end{tabular}

\section{Risk of bias}

Bias Authors' judgement Support for judgement

\begin{tabular}{lll}
\hline Random sequence genera- & Low risk & Block randomisation \\
tion (selection bias) &
\end{tabular}

\begin{tabular}{|c|c|c|}
\hline $\begin{array}{l}\text { Allocation concealment } \\
\text { (selection bias) }\end{array}$ & Unclear risk & Method not stated \\
\hline $\begin{array}{l}\text { Blinding of participants } \\
\text { and personnel (perfor- } \\
\text { mance bias) } \\
\text { All outcomes }\end{array}$ & Low risk & $\begin{array}{l}\text { Double-blind, double dummy, research collaborator prepared injections and } \\
\text { placebos for both histamine and BTX in numbered matching vials so that nei- } \\
\text { ther participants nor physicians were able to identify drug }\end{array}$ \\
\hline
\end{tabular}

\begin{tabular}{lll}
\hline $\begin{array}{l}\text { Blinding of outcome as- } \\
\text { sessment (detection bias) } \\
\text { All outcomes }\end{array}$ & Low risk & $\begin{array}{l}\text { Double-blind, double dummy, research collaborator prepared injections and } \\
\text { placebos for both histamine and BTX in numbered matching vials so that nei- } \\
\text { ther participants nor physicians were able to identify drug }\end{array}$ \\
\hline $\begin{array}{l}\text { Incomplete outcome data } \\
\text { (attrition bias) } \\
\text { All outcomes }\end{array}$ & Unclear risk & $\begin{array}{l}\text { Dropouts uneven } 10 \% \text { vs } 20 \% \text { of total participant numbers and imputation } \\
\text { method not stated }\end{array}$ \\
\hline
\end{tabular}


Millán-Guerrero 2009 (Continued)

Selective reporting (re- Low risk All expected outcomes reported
porting bias)

Study size Unclear risk 50-199 participants per arm

Petri 2009

Methods Randomised, double-blind, placebo-controlled, parallel-group, multi-site

Single treatment, 12-week FU

Fixed injections of Dysport ( 2 dosing arms) vs placebo

Assessments carried out at baseline and 4 weeks, 8 weeks and 12 weeks post-treatment

Participants

Inclusion criteria: aged 18-65 years; at least a 1-year history of migraine with or without aura; first manifestation under 50 years of age; stable frequency of 3-6 attacks per month ICHD-I; not previously received Botox; no concomitant prophylactic migraine treatment was allowed during the trial; acute medication for migraine allowed for a maximum of $10 \mathrm{~d} /$ month; participants restricted to only 1 type of escape medication that they preferably used (either analgesic or triptan)

Exclusion criteria: non-migraine headaches for $>10 \mathrm{~d}$ /month before, but not after, injection; women who were pregnant or not using adequate contraception; history of alcohol or other drug abuse; previously experienced an adverse reaction to Botox; treated with aminoglycoside antibiotics (or other medication affecting neuromuscular transmission), antidepressants, neuroleptics, antiepileptics or anticoagulants; severe psychiatric disturbance, a skin disorder at the injection site, a predisposition to bleeding, or an anticipated lack of compliance and cooperation

$\mathrm{N}=127$, mean age 46, M 20/F 102 (characteristics given for analysed population - 122)

$\mathrm{CM}$ excluded, $\mathrm{MOH}$ excluded

Years since onset of migraine 27, number of migraine attacks during baseline diary period 5

Interventions Intervention (arm 1): Dysport $210 \mathrm{U}$ from 18 injections, trapezius $45 \mathrm{U}$, splenius capitis $20 \mathrm{U}$, temporalis $20 \mathrm{U}$, frontalis $10 \mathrm{U}$, corrugator $10 \mathrm{U}$

Intervention (arm 2): Dysport $80 \mathrm{U}$ from 18 injections, trapezius $45 \mathrm{U}$, splenius capitis $20 \mathrm{U}$, temporalis $20 \mathrm{U}$, frontalis $10 \mathrm{U}$, corrugator $10 \mathrm{U}$

Control: matched placebo injections

Number of headache days
Number of migraine attacks
Duration of migraine
Severity of migraine
Use of rescue medication
Migraine related disability
Becks depression inventory
Total tenderness score
Patient global evaluation of treatment efficacy


Petri 2009 (Continued)

Adverse events

Notes

Funder: Ipsen Pharma, Ettlingen, Germany (manufacturer of Dysport)

Diary period 28 days

Contacted without response

\section{Risk of bias}

\begin{tabular}{|c|c|c|}
\hline Bias & Authors' judgement & Support for judgement \\
\hline $\begin{array}{l}\text { Random sequence genera- } \\
\text { tion (selection bias) }\end{array}$ & Low risk & Computer-generated randomisation sequence \\
\hline $\begin{array}{l}\text { Allocation concealment } \\
\text { (selection bias) }\end{array}$ & Low risk & Sealed envelopes, drug prepared by third person \\
\hline $\begin{array}{l}\text { Blinding of participants } \\
\text { and personnel (perfor- } \\
\text { mance bias) } \\
\text { All outcomes }\end{array}$ & Low risk & $\begin{array}{l}\text { Double-blind: participant blinded with matched placebo injections, third per- } \\
\text { son, who was not involved with the trial prepared the injections in a separate } \\
\text { room }\end{array}$ \\
\hline $\begin{array}{l}\text { Blinding of outcome as- } \\
\text { sessment (detection bias) } \\
\text { All outcomes }\end{array}$ & Low risk & $\begin{array}{l}\text { Double-blind: third person, who was not involved with the trial prepared the } \\
\text { injections in a separate room }\end{array}$ \\
\hline $\begin{array}{l}\text { Incomplete outcome data } \\
\text { (attrition bias) } \\
\text { All outcomes }\end{array}$ & Unclear risk & LOCF but unclear how often this had to be used \\
\hline $\begin{array}{l}\text { Selective reporting (re- } \\
\text { porting bias) }\end{array}$ & Unclear risk & Secondary outcomes analysed descriptively \\
\hline Study size & High risk & $<50$ participants per treatment arm \\
\hline
\end{tabular}

Relja 2007

Methods

Randomised, double-blind, placebo-controlled, parallel-group, multi-site

3 treatment cycles, 3 months FU per treatment

Fixed injections of Botox ( 3 dosing arms) vs placebo

Assessments carried out at baseline and 30 days, 60 days, 90 days post-treatment per cycle

Participants

Inclusion criteria: aged 18-65 years; average of at least 3 moderate-severe untreated migraine episodes per month (ICHD-I); or at least 3 treated migraine episodes of any severity per month; $\leq 15$ headache $d /$ month as confirmed by a headache diary during the baseline period; migraine episodes must have occurred for at least 1 year prior to enrolment and be first diagnosed before age 50 years; stable medical condition and acceptable blood haematology and chemistry results; willing to discontinue headache prophylactic medications for at least 3 months immediately prior to the initiation of the baseline period and had to be willing and able to stay on current medications (other than headache prophylaxis) during the course of the trial

Exclusion criteria: any medical condition or used any agent that may have put them at risk with exposure to Botox; an infection or skin problem at any of the injection sites or a known allergy or sensitivity to the trial medication or its components; inadequate response to $\geq 3$ prophylactic treatments after 
Relja 2007 (Continued)

an adequate trial; Beck Depression Inventory score of $>24$; psychiatric problems severe enough to interfere with trial participation or results; previous therapy with BTX of any sero-type; been injected with anaesthetics or steroids into the trial-targeted muscles during the 30 days immediately prior to initiation of the baseline period; overusing or abusing symptomatic medication, alcohol or drugs; concurrent chronic use or chronic use in the 3 months prior to the screening period of muscle relaxants; concurrently participating in another investigational trial or who had participated in such a trial in the 30 days immediately prior to baseline period; uncontrolled systemic disease or any condition that might have put the participant at significant risk, might have confounded the trial, or might have interfered significantly with participation in the trial; women who were pregnant, nursing, or planning a pregnancy during the trial or who were unable or unwilling to use a reliable form of contraception during the trial

$\mathrm{N}=495$, mean age $43, \mathrm{M} 60 / \mathrm{F} 435$

$\mathrm{CM}$ excluded, $\mathrm{MOH}$ excluded

Years since onset of migraine 23

Interventions

Intervention (arm 1): Botox $255 \mathrm{U}, 20$ injections, frontalis $30 \mathrm{U}, 4$ sites; corrugator $15 \mathrm{U}, 2$ sites; temporalis $30 \mathrm{U}, 4$ sites; splenius capitis $30 \mathrm{U}, 2$ sites; trapezius $60 \mathrm{U}, 4$ sites; semispinalis capitis $30 \mathrm{U}, 2$ sites; suboccipital region $30 \mathrm{U}, 2$ sites

Intervention (arm 2): Botox $150 \mathrm{U}, 20$ injections, frontalis $20 \mathrm{U}, 4$ sites; corrugator $10 \mathrm{U}, 2$ sites; temporalis $20 \mathrm{U}, 4$ sites; splenius capitis $20 \mathrm{U}, 2$ sites; trapezius $40 \mathrm{U}, 4$ sites; semispinalis capitis $20 \mathrm{U}, 2$ sites; suboccipital region $20 \mathrm{U}, 2$ sites

Intervention (arm 3): Botox $75 \mathrm{U}, 20$ injections, frontalis $10 \mathrm{U}, 4$ sites; corrugator $5 \mathrm{U}, 2$ sites; temporalis $10 \mathrm{U}, 4$ sites; splenius capitis $10 \mathrm{U}, 2$ sites; trapezius $20 \mathrm{U}, 4$ sites; semispinalis capitis $10 \mathrm{U}, 2$ sites; suboccipital region $10 \mathrm{U}, 2$ sites

Control: matched placebo injections

\begin{tabular}{|c|c|c|}
\hline \multirow[t]{9}{*}{ Outcomes } & \multirow{2}{*}{\multicolumn{2}{|c|}{$\begin{array}{l}\text { Number of headache days } \\
\text { Number of migraine days }\end{array}$}} \\
\hline & & \\
\hline & \multicolumn{2}{|c|}{ Number of migraine attacks } \\
\hline & \multicolumn{2}{|c|}{ Proportion of $50 \%$ responders } \\
\hline & \multicolumn{2}{|l|}{ Severity of migraine } \\
\hline & \multicolumn{2}{|c|}{ Use of rescue medication } \\
\hline & \multicolumn{2}{|l|}{ MIDAS } \\
\hline & \multicolumn{2}{|c|}{ Headache pain specific quality of life measure } \\
\hline & \multicolumn{2}{|l|}{ Adverse events } \\
\hline \multirow[t]{3}{*}{ Notes } & \multicolumn{2}{|c|}{ Funder: Allergan, Inc., Irvine, California (manufacturer of Botox) } \\
\hline & \multicolumn{2}{|l|}{ Diary period 30 days } \\
\hline & \multicolumn{2}{|c|}{ Contacted without response } \\
\hline \multicolumn{3}{|l|}{ Risk of bias } \\
\hline Bias & Authors' judgement & Support for judgement \\
\hline $\begin{array}{l}\text { Random sequence genera- } \\
\text { tion (selection bias) }\end{array}$ & Unclear risk & Method not stated \\
\hline
\end{tabular}


Relja 2007 (Continued)

Allocation concealment Unclear risk Method not stated
(selection bias)

\begin{tabular}{|c|c|c|}
\hline $\begin{array}{l}\text { Blinding of participants } \\
\text { and personnel (perfor- } \\
\text { mance bias) } \\
\text { All outcomes }\end{array}$ & Low risk & $\begin{array}{l}\text { Double-blind: participant blinded, with matched placebo injections, an indi- } \\
\text { vidual with no other trial involvement reconstituted vials of trial medication } \\
\text { with all dilutions carried out so that total volume in each vial was the same, } \\
\text { vials numbered according to randomisation and reconstituted according to } \\
\text { volume of diluent assigned to each randomisation number }\end{array}$ \\
\hline
\end{tabular}

Blinding of outcome as- Low risk sessment (detection bias) All outcomes
Double-blind: an individual with no other trial involvement reconstituted vials of trial medication with all dilutions carried out so that total volume in each vial was the same, vials numbered according to randomisation and reconstituted according to volume of diluent assigned to each randomisation number

Method of imputation not stated and group split of dropouts not given

\begin{tabular}{lll}
$\begin{array}{l}\text { Incomplete outcome data } \\
\text { (attrition bias) } \\
\text { All outcomes }\end{array}$ & Unclear risk & Method of imputation not stated and group split of dropouts not given \\
\hline $\begin{array}{l}\text { Selective reporting (re- } \\
\text { porting bias) }\end{array}$ & Unclear risk & $\begin{array}{l}\text { All expected outcomes reported, primary outcome data given but secondary } \\
\text { data showing no significant between-group differences not fully reported }\end{array}$ \\
\hline Study size & Unclear risk & $50-199$ participants per arm \\
\hline
\end{tabular}

\section{Saper 2007}

Methods Randomised, double-blind, placebo-controlled, parallel-group, multi-site

Single treatment, 90-day FU

Fixed injections of Botox, 4 arms with different doses and sites vs placebo in all 3 muscle sites

Assessment at baseline and at 30 days, 60 days and 90 days post-treatment

Participants

Inclusion criteria: stable medical condition with migraine headaches as defined by the ICHD - edition not stated; with or without aura; average of 4-8 moderate-severe migraine headaches per month; aged 18-65 years; first diagnosed before age 50; able to distinguish migraine from non migraine headaches; acute migraine therapy must have typically relieved their migraines to an acceptable level; headache frequency/severity must have been stable; chronic medications (if needed) must have been stable for $\geq$ 3 months prior to enrolment; prophylactic medications had been discontinued must have been at least 3 months before enrolment; previous medications, including any migraine prophylaxis treatments, stay on the same dose and regimen during the course of the trial

Exclusion criteria: typical migraine pain was localised predominantly to the occipital or suboccipital regions; > 15 headache d/month (any type); history of complicated migraine; migraine at the time of treatment were ineligible to be treated that day but could return to be enrolled on a subsequent day; infection or skin problem at the injection site; other medical condition that might have put a person at increased risk with exposure to Botox or that was severe enough to interfere with trial participation or results; using agents that interfered with neuromuscular function; overusing symptomatic medications; abusing alcohol or drugs; previously received BTX therapy; known allergy or sensitivity to the trial medication or its components; women who were pregnant, breastfeeding, or planning a pregnancy during the trial period; received an injection of anaesthetic or steroid into the muscles to be injected in the month prior to enrolment; participated in another investigational drug or device clinical trial within the past month

$N=232$, mean age 44, M 33/F 199

$\mathrm{CM}$ excluded, $\mathrm{MOH}$ excluded 
Intervention (arm 2): Botox $10 \mathrm{U}$ in frontal muscle area, 4 sites, plus matched placebo injections into temporal and glabellar muscles

Intervention (arm 3): Botox $6 \mathrm{U}$ in temporal muscle area, 2 sites, plus matched placebo injections into frontal and glabellar muscles

Intervention (arm 4): Botox $9 \mathrm{U}$ in glabellar muscle, 5 sites, plus matched placebo injections into frontal and temporal muscles

Control: placebo in all 3 muscle sites

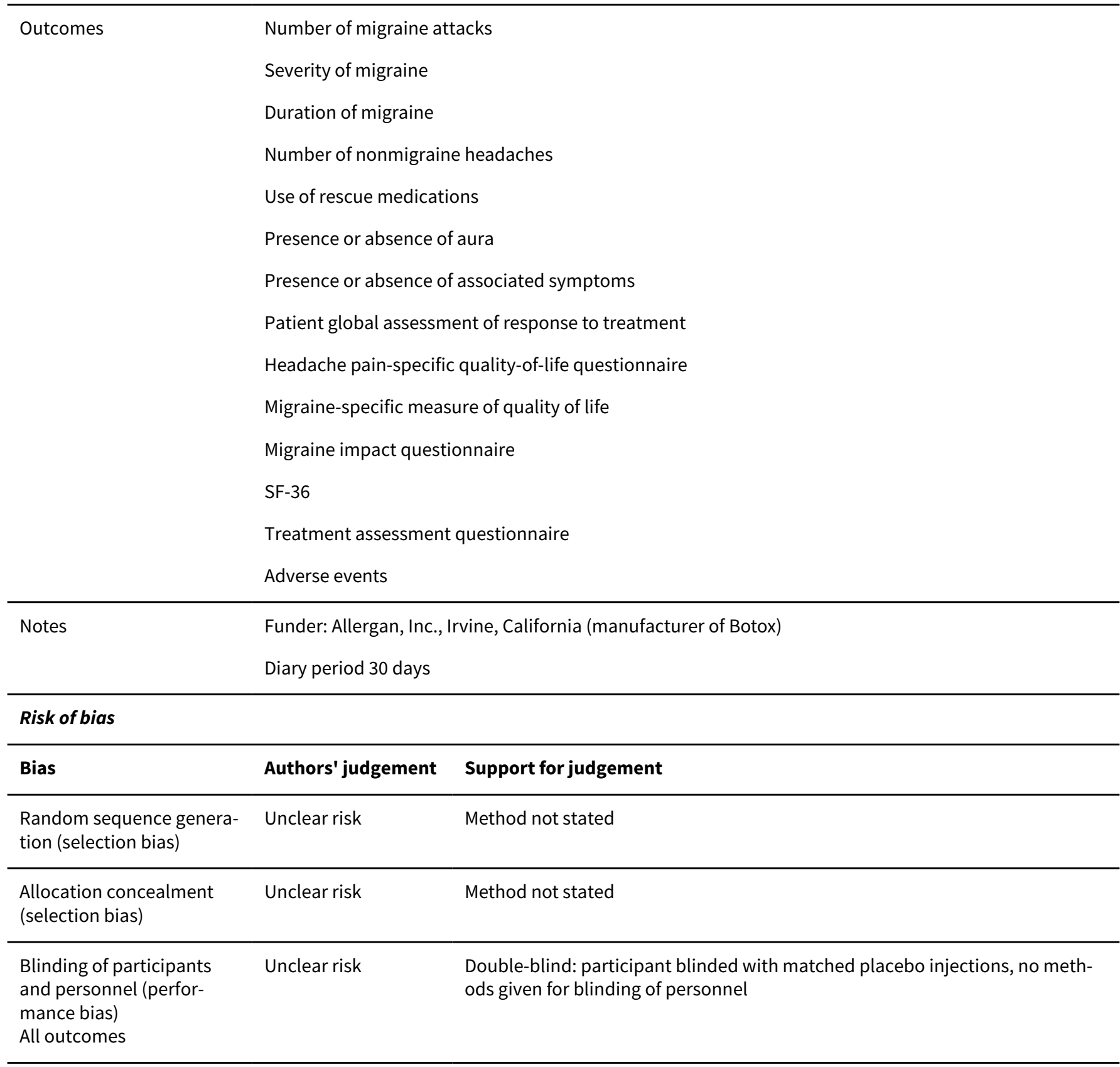


Saper 2007 (Continued)

Blinding of outcome as- Unclear risk Double-blind: no methods given for blinding of personnel sessment (detection bias)

All outcomes

\begin{tabular}{lll}
\hline $\begin{array}{l}\text { Incomplete outcome data } \\
\text { (attrition bias) } \\
\text { All outcomes }\end{array}$ & Unclear risk & Not stated from which group dropouts (7) occurred. ITT analysis stated \\
\hline $\begin{array}{l}\text { Selective reporting (re- } \\
\text { porting bias) }\end{array}$ & Unclear risk & $\begin{array}{l}\text { All expected outcomes reported, primary outcome data given but secondary } \\
\text { data with none statistically significant results were reported narratively only }\end{array}$ \\
\hline Study size & High risk & $<50$ participants per treatment arm
\end{tabular}

Silberstein 2000

Methods Randomised, double-blind, placebo-controlled, parallel-group, multi-site

Single treatment, 3-month FU

Fixed injections of Botox (2 dosing arms) vs placebo

Assessments carried out at baseline and at 1 month, 2 months and 3 months post-treatment

Participants Inclusion criteria: aged 18-65 years; history of ICHD-1 defined migraine, with or without aura; average of 2-8 moderate-severe migraines per month over the previous 3 months; $2-8$ such migraines during the 1-month baseline period; first diagnosis of migraine before the age of 50 years; able to distinguish migraine from non-migraine headaches; stable frequency and severity of migraines; no unstable medical conditions; migraines relieved to an acceptable level by acute migraine therapy; doses of concurrent prophylactic medications for migraine stable for at least 3 months immediately prior to enrolment

Exclusion criteria: any medical condition or the use of any agent that may have put the participant at risk with exposure to Botox; history of complicated migraine; typical migraine pain localised predominantly to the occipital or suboccipital region of the cranium; planned or actual pregnancy or lactation; known allergy or sensitivity to the trial medication or its components; injection of anaesthetic or steroid into the muscles to be injected in the month immediately prior to enrolment; > 15 headache $d /$ month; symptomatic medication overuse

$\mathrm{N}=123$, mean age 44, M 18/F 105

CM excluded, $\mathrm{MOH}$ excluded

Years since onset of migraine 23, number of migraine attacks during baseline diary period 4 glabellar $27 \mathrm{U}, 5$ sites)

Intervention (arm 2): Botox $25 \mathrm{U}$ in 11 injection sites (frontalis $10 \mathrm{U}, 4$ sites; temporalis $6 \mathrm{U}, 2$ sites; glabellar $9 \mathrm{U}, 5$ sites)

Control: matched placebo injections

\begin{tabular}{ll}
\hline Outcomes & Number of migraine attacks \\
Proportion of $50 \%$ responders \\
Severity of migraine \\
Use of rescue medication \\
Patient global assessment of response to treatment
\end{tabular}


Silberstein 2000 (Continued)

Adverse events

Notes $\quad$ Funder: Allergan, Inc., Irvine, California (manufacturer of Botox)

Diary period 30 days

\section{Risk of bias}

\begin{tabular}{|c|c|c|}
\hline Bias & Authors' judgement & Support for judgement \\
\hline $\begin{array}{l}\text { Random sequence genera- } \\
\text { tion (selection bias) }\end{array}$ & Unclear risk & Method not stated \\
\hline $\begin{array}{l}\text { Allocation concealment } \\
\text { (selection bias) }\end{array}$ & Unclear risk & Method not stated \\
\hline $\begin{array}{l}\text { Blinding of participants } \\
\text { and personnel (perfor- } \\
\text { mance bias) } \\
\text { All outcomes }\end{array}$ & Unclear risk & $\begin{array}{l}\text { Double-blind: participant blinded with matched placebo injections no meth- } \\
\text { ods given for blinding of personnel }\end{array}$ \\
\hline $\begin{array}{l}\text { Blinding of outcome as- } \\
\text { sessment (detection bias) } \\
\text { All outcomes }\end{array}$ & Unclear risk & Double-blind: no methods given for blinding of personnel \\
\hline $\begin{array}{l}\text { Incomplete outcome data } \\
\text { (attrition bias) } \\
\text { All outcomes }\end{array}$ & Low risk & Only 1 participant dropped out \\
\hline $\begin{array}{l}\text { Selective reporting (re- } \\
\text { porting bias) }\end{array}$ & Unclear risk & Incomplete reporting of outcomes \\
\hline Study size & High risk & $<50$ participants per treatment arm \\
\hline
\end{tabular}

Methods Randomised, double-blind, placebo-controlled, parallel-group, single-site

Single treatment, 3-month FU

Fixed injections of BTX-A (brand not reported) vs placebo

Assessments carried out at baseline and 1 month, 2 months and 3 months postbaseline

Inclusion criteria: aged 18-65; migraine headaches occurring $>5$ times/month and meeting ICHD-I crite-
ria for migraine headache with or without aura
Exclusion criteria: none stated
$\mathrm{N}=49$, (analysed population used for baseline characteristics $\mathrm{N}=32$ ) mean age $42, \mathrm{M} 5 / \mathrm{F} 27$
EM/CM unclear, $\mathrm{MOH}$ eligibility unclear
Years with migraine 20 , number of migraine days during baseline diary period 19 , severity of migraine
5.2 on $10 \mathrm{~cm}$ VAS


Vo 2007 (Continued)

Interventions

Intervention: BTX-A (brand not reported), weight-based dosing, <65 kg: $135 \mathrm{U}, \geq 65 \mathrm{~kg}: 210 \mathrm{U}, 22$ injection sites (corrugator 2 sites $5 \mathrm{U} / 5 \mathrm{U}$, frontalis 4 sites $20 \mathrm{U} / 20 \mathrm{U}$, temporalis 4 sites $20 \mathrm{U} / 40 \mathrm{U}$, posterior neck 6 sites $60 \mathrm{U} / 90 \mathrm{U}$, occipitalis 2 sites $10 \mathrm{U} / 10 \mathrm{U}$, sternocleidomastoid 4 sites $20 \mathrm{U} / 40 \mathrm{U}$ )

Control: matched placebo injections

\begin{tabular}{ll}
\hline Outcomes & Number of migraine attacks \\
Severity of migraine \\
Duration of migraine \\
Use of rescue medication \\
Migraine-specific questionnaire \\
\hline Fotes \\
Sciences award \\
Diary period 30 days \\
Contacted without response
\end{tabular}

\section{Risk of bias}

\begin{tabular}{|c|c|c|}
\hline Bias & Authors' judgement & Support for judgement \\
\hline $\begin{array}{l}\text { Random sequence genera- } \\
\text { tion (selection bias) }\end{array}$ & Low risk & Computer-generated randomisation sequence \\
\hline $\begin{array}{l}\text { Allocation concealment } \\
\text { (selection bias) }\end{array}$ & Unclear risk & Method not stated \\
\hline $\begin{array}{l}\text { Blinding of participants } \\
\text { and personnel (perfor- } \\
\text { mance bias) } \\
\text { All outcomes }\end{array}$ & Unclear risk & $\begin{array}{l}\text { Double-blind: participant blinded with matched placebo injections no meth- } \\
\text { ods given for blinding of personnel }\end{array}$ \\
\hline $\begin{array}{l}\text { Blinding of outcome as- } \\
\text { sessment (detection bias) } \\
\text { All outcomes }\end{array}$ & Unclear risk & Double-blind: no methods given for blinding of personnel \\
\hline $\begin{array}{l}\text { Incomplete outcome data } \\
\text { (attrition bias) } \\
\text { All outcomes }\end{array}$ & Unclear risk & Numbers randomised to each group and dropouts per group not stated \\
\hline $\begin{array}{l}\text { Selective reporting (re- } \\
\text { porting bias) }\end{array}$ & Unclear risk & $\begin{array}{l}\text { All expected outcomes reported, primary outcome data given but some sec- } \\
\text { ondary data with no significant between group differences were not fully re- } \\
\text { ported }\end{array}$ \\
\hline Study size & High risk & $<50$ participants per treatment arm \\
\hline
\end{tabular}

AE: adverse event; BTX: botulinum toxin; BTX-A: botulinum toxin type A; CM: chronic migraine; EM: episodic migraine; F: female; FU: followup; LOCF: last observation carried forward; HIT-6: Headache Impact Test - 6 question version; HRQoL: Health-Related Quality-of-Life score; ICHD: International Classification of Headache Disorders; IHS: International Headache Society ITT: intention-to-treat; M: male; MIDAS: Migraine Disability Assessment Score; MIGSEV: migraine severity scale; MIQ: Migraine Impact Questionnaire; MOH: medication overuse headache; OL: open-label; QUALY: quality adjusted life years; SF-36: 36-Item Short Form Health Survey; TENS: transcutaneous electrical nerve stimulation; VAS: visual analogue scale 
Characteristics of excluded studies [ordered by study ID]

\begin{tabular}{ll}
\hline Study & Reason for exclusion \\
\hline Cady 2012 & No relevant comparison, BTX used in both arms \\
\hline De Tommaso 2016 & $\begin{array}{l}\text { Clinical assessments carried out at baseline and after all participants had crossed over to receive } \\
\text { BTX, no precross-over recording of clinical outcomes took place }\end{array}$ \\
\hline Evers 2004 & $\begin{array}{l}\text { Some included participants had tension-type headache and migraine; contact with trial author } \\
\text { confirmed that data for migraine-only participants were not available }\end{array}$ \\
\hline Guyuron 2005 & Surgical removal of trigger sites in addition to BTX treatment \\
\hline Ondo 2004 & $\begin{array}{l}\text { Trial of people with chronic daily headache; contact with trial author confirmed that data for mi- } \\
\text { graine-only participants were not available }\end{array}$ \\
\hline Ruggeri 2013 & Health economics paper, data sourced from trial publications \\
\hline Schwedt 2007 & Report of placebo-treated participants only \\
\hline
\end{tabular}

BTX: botulinum toxin

Characteristics of studies awaiting assessment [ordered by study ID]

Brin 2000

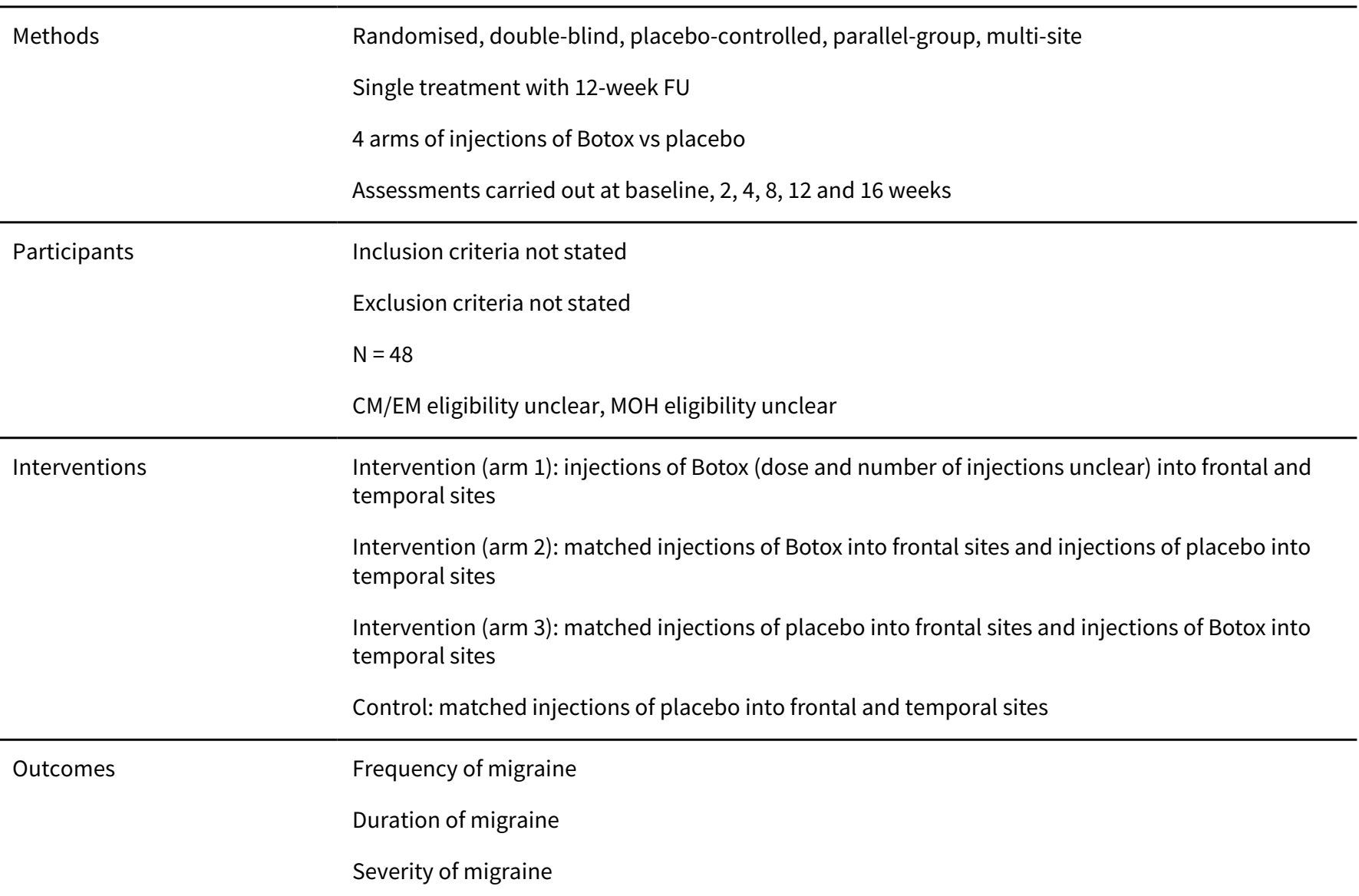


Brin 2000 (Continued)

$\begin{array}{ll}\text { Notes } & \text { Abstract only } \\ \text { Funder: Allergan Inc } \\ \text { Diary period not stated }\end{array}$

Number of treatment sessions not stated, 3-month time frame

Injections of Dysport (fixed or follow the pain not stated) vs placebo

Assessment time points not stated

Participants

Inclusion criteria: migraine without aura or with typical aura as defined by IHS criteria, migraine attacks persisting for $>1$ year; 2-6 migraine attacks/month of at least moderate severity over the 3 months preceding the pre-inclusion visit; $2-6$ migraine attacks of at least moderate severity during the screening period

Exclusion criteria: non-migraine headaches such as tension-type headaches; migraine with prolonged aura, familial hemiplegic migraine, basilar migraine, migraine aura without headache, migraine with acute onset aura, ophthalmoplegic migraine, retinal migraine, complications of migraine; onset of migraine is after age of 50; overuse of acute migraine medications (individuals who take medications for acute migraine $>10 \mathrm{~d}$ /month) or have a history of drug or alcohol abuse

Target $\mathrm{N}=150$

CM/EM included, $\mathrm{MOH}$ excluded

Interventions Intervention: Dysport injections into pericranial muscles, number and dose not stated

Control: placebo

Outcomes

Number of migraine attacks

Intensity of the migraine attacks

Duration of the migraine attacks

Use of rescue medication

Quality-of-life measure (instrument unspecified)

\begin{tabular}{ll}
\hline Notes & Protocol (NCT00301665) only, enrolment completed 2005 \\
& Funder Ipsen \\
& Diary period not stated
\end{tabular}

Kuper 2007

Methods

Not stated if randomised but is stated as double-blind, placebo-controlled, parallel-group, number of sites unclear

2 treatment cycles, 90 days between treatments 
Assessments carried out at 3 months after each treatment session

Participants

year

Exclusion criteria not stated

Target $\mathrm{N}=90$

$\mathrm{CM}$ excluded, $\mathrm{MOH}$ eligibility unclear
Intervention: Botox (25 U) in fixed muscle injection sites (temporalis, frontalis, procerus, corrugator)

Control: matched placebo injections

\begin{tabular}{ll}
\hline Outcomes & Frequency of migraine (unit not stated) \\
& Use of rescue medication \\
& Quality-of-life measure (instrument unspecified) \\
\hline Notes & Trial design publication only \\
& Funder: German Federal Ministry of Education and Research \\
& Diary period not stated \\
\hline
\end{tabular}

Mathew 2005
Randomised, double-blind, placebo-controlled, parallel-group, multi-site

3 treatment cycles, 90 days between treatments

Follow the pain injections of Botox vs placebo following a single-blind placebo run-in phase to classify participants as placebo responders or nonresponders

Assessments carried out at baseline, and every 30 days out to day 270 . An additional assessment for days -60 to -30 was carried out to make the placebo response classification

Participants

Inclusion criteria: aged 18-65 years; headaches on > 15 days of the 30-day baseline period; any combination of migraines, with/without aura, migrainous/probable migraine, and/or episodic/chronic tension-type headaches defined by ICHD-I criteria; stable medical condition; chronic medication regimens, including prophylactic medications, had to be stable for at least 3 months prior to baseline period; willing and able to stay on current medications during the course of the trial

Exclusion criteria: any medical condition or used any agent that may have put them at risk with exposure to Botox; infection or skin problem at any of the injection sites; known allergy or sensitivity to the trial medication or its components; history of "complicated" migraine; Beck Depression inventory score > 24; previous therapy with BTX of any serotype, an injection of anaesthetics or steroids into the trial-targeted muscles during the 30 days prior to baseline period; overusing or abusing symptomatic medication, alcohol, or drugs; concurrent chronic use or chronic use in the 3 months prior to the screening period of muscle relaxants; women who were pregnant, nursing, or planning a pregnancy during the trial, or who were unable or unwilling to use a reliable form of contraception during the trial

$\mathrm{N}=355$, mean age 43.5 years, M 55/F 300 (inclusive of all headache types) 
Control: matched placebo injections

\begin{tabular}{ll}
\hline Outcomes & Number of headache-free days \\
Proportion of responders & Number of headache attacks \\
& Use of rescue medication \\
& MIDAS \\
& Headache Pain-Specific Quality of life questionnaire \\
& Adverse events \\
\hline Notes & Data for migraine-only participants required for inclusion \\
Funder: Allergan Inc \\
Diary period 30 days \\
\hline
\end{tabular}

Fixed injections of Botox ( 3 dosing arms) vs placebo following a single-blind placebo run-in phase to classify participants as placebo responders or nonresponders

Assessments carried out at baseline, and every 30 days out to day 270 . An additional assessment for days -60 to -30 was carried out to make the placebo response classification

Participants

Inclusion criteria: aged 18-65 years; headaches on > 15 days during a 30-day baseline period; headaches could include any combination of migraines: those with/without aura, migrainous headache, probable migraine, and/or episodic or chronic tension-type headaches according to ICHD-I criteria; medically stable; long-term medication (including long-term prophylactic headache medications) had to be stable for at least 3 months immediately before the baseline period; acute headache pain medication could be taken as needed; willing to continue taking current medications during the course of the trial

Exclusion criteria: any medical condition (e.g. neuromuscular disorders) or used any agent that might expose them to risk if they received Botox; infection or skin problem at any of the injection sites, known allergy or sensitivity to the trial medication or to its components; cluster headache or chronic paroxysmal hemicrania, analgesic rebound headache, headache secondary to head trauma or whiplash injury, a history of "complicated" migraine (e.g. migrainous infarction, hemiplegic migraine, ophthalmoplegic migraine, or basilar migraine), a Beck Depression Inventory score $>24$, previous therapy with BTX of any serotype, an injection of anaesthetics or corticosteroids into the trial-targeted muscles during the 30 days immediately before the baseline period; abuse of symptomatic medication, alcohol, or drugs; concurrent or long-term use of muscle relaxants (e.g. cyclobenzaprine, carisoprodol, or benzodiazepines) during the 3 months before the screening period was prohibited; women who were pregnant or nursing or unable or unwilling to use a reliable form of contraception during the trial 
Silberstein 2005 (Continued)

$$
N=702 \text {, mean age } 43.4 \text { years, M 120/F } 582 \text { (inclusive of all headache types) }
$$

Baseline characteristics for migraine-only participants not stated

Interventions

Intervention (arm 1): Botox $255 \mathrm{U}, 20$ injections, frontalis $30 \mathrm{U}, 4$ sites; corrugator $15 \mathrm{U}, 2$ sites; temporalis $30 \mathrm{U}, 4$ sites; splenius capitis $30 \mathrm{U}, 2$ sites; trapezius $60 \mathrm{U}, 4$ sites; semispinalis capitis $30 \mathrm{U}, 2$ sites; suboccipital region $30 \mathrm{U}, 2$ sites

Intervention (arm 2): Botox $150 \mathrm{U}, 20$ injections, frontalis $20 \mathrm{U}, 4$ sites; corrugator $10 \mathrm{U}, 2$ sites; temporalis $20 \mathrm{U}, 4$ sites; splenius capitis $20 \mathrm{U}, 2$ sites; trapezius $40 \mathrm{U}, 4$ sites; semispinalis capitis $20 \mathrm{U}, 2$ sites; suboccipital region $20 \mathrm{U}, 2$ sites

Intervention (arm 3): Botox $75 \mathrm{U}, 20$ injections, frontalis $10 \mathrm{U}, 4$ sites; corrugator $5 \mathrm{U}, 2$ sites; temporalis $10 \mathrm{U}$, 4 sites; splenius capitis $10 \mathrm{U}, 2$ sites; trapezius $20 \mathrm{U}$, 4 sites; semispinalis capitis $10 \mathrm{U}, 2$ sites; suboccipital region $10 \mathrm{U}, 2$ sites

Control: matched placebo injections

$\begin{array}{ll}\text { Outcomes } & \text { Number of headache-free days } \\ \text { Proportion of responders } & \text { Number of headache attacks } \\ & \text { Number of moderate-severe migraines } \\ & \text { Use of rescue medication } \\ \text { MIDAS } & \text { Headache Pain-Specific Quality of life questionnaire } \\ \text { AE } & \text { Data for migraine-only participants required for inclusion } \\ \text { Funder: Allergan Inc } & \text { Diary period } 30 \text { days }\end{array}$

AE: adverse event; BTX: botulinum toxin; CM: chronic migraine; EM: episodic migraine; F: female; FU: follow-up; ICHD: International Classification of Headache Disorders; IHS: International Headache Society M: male; MIDAS: Migraine Disability Assessment Score; MOH: medication overuse headache

Characteristics of ongoing studies [ordered by study ID]

NCT02074163

\begin{tabular}{|c|c|}
\hline Trial name or title & ASIS for Botox in chronic migraine (ASISinCM) \\
\hline \multirow[t]{2}{*}{ Methods } & Randomised, double-blind, active control, parallel-group \\
\hline & $\begin{array}{l}\text { Aim } 2 \text { only relevant to this review: guided delivery of Botox into subdermal bloodless space, be- } \\
\text { tween the skin and muscle vs Botox injected intramuscularly }\end{array}$ \\
\hline \multirow[t]{2}{*}{ Participants } & $\begin{array}{l}\text { Inclusion criteria: aged 18-65 years; history of chronic migraine (with/without aura) according to } \\
\text { the criteria proposed by the Headache Classification Committee of the IHS for at least } 3 \text { months pri- } \\
\text { or to enrolment; preventive medication, if taking, must be stable for at least } 3 \text { months }\end{array}$ \\
\hline & $\begin{array}{l}\text { Exclusion criteria: headache disorders outside IHS-defined chronic migraine definition; evidence of } \\
\text { underlying pathology contributing to their headaches; any pathology of the salivary glands such as } \\
\text { sialadenitis or condition or symptom that would alter the content of saliva; any medical condition }\end{array}$ \\
\hline
\end{tabular}


NCT02074163 (Continued)

that may increase their risk with exposure to Botox including diagnosed myasthenia gravis, EatonLambert syndrome, amyotrophic lateral sclerosis, or any other significant disease that might interfere with neuromuscular function; profound atrophy or weakness of muscles in the target areas of injection

Target $\mathrm{N}=60$

Interventions

Intervention: Botox injection guided by device to delivery into subdermal bloodless space between skin and muscle at 6 muscle group sites (glabella, frontal, temporal, occipital, paraspinal, and trapezius)

Control: conventional intramuscular injections of Botox in same muscle groups (Gglabella, frontal, temporal, occipital, paraspinal, and trapezius)

\begin{tabular}{ll}
\hline Outcomes & Number of headache days \\
& Total cumulative hours of headache on headache days \\
& AE \\
\hline Starting date & January 2016 \\
\hline Contact information & Li Nguyen, MD (714)-453-7857 dr.li.nguyen@asis-inc.com \\
& Thanh Phung, MD 714-893-1915 thanhphung@idit-inc.com \\
\hline Notes & The recruitment status of this trial is unknown. The completion date has passed and the status has \\
not been verified in more than two years & Protocol: NCT:02074163 \\
Funder: ASIS Corporation listed as sponsors and collaborators
\end{tabular}

\section{NCT02291380}

\section{Trial name or title}

A study to evaluate botulinum toxin type A for injection HengLi for prophylactic treatment of chronic migraine

Methods Randomised, double-blind, placebo-controlled, parallel-group

Hypothesis relating to this review: that Botox for injection (HengLi) for prophylactic treatment with chronic migraine in adults is safe and efficacious

\section{Participants}

Inclusion criteria: age $\geq 18$ and $\leq 65$, male or female; complying with the ICHD-3( $\beta$ ) diagnostic criteria for chronic migraine

Exclusion criteria: pregnancy, nursing, or planning a pregnancy during the trial period, or women of childbearing potential, not using a reliable means of contraception; known allergy or sensitivity to trial medication or its component; accepted prophylactic treatments of migraine within the 4 weeks before screening; cardiac functional insufficiency; renal insufficiency (serum creatinine > 1.5 times upper limit of normal); hepatic diseases (alanine aminotransferase or aspartate aminotransferase > twice upper limit of normal); systemic myoneural junction diseases (e.g. myasthenia, Eaton-Lambert syndrome, amyotrophic lateral sclerosis, etc.); history of facial palsy; infection or dermatological condition at the injection sites;

other types of migraine that do not comply with the diagnostic criteria for chronic migraine; BTX therapy in the past 6 months; used aminoglycoside antibiotics in the recent week or need to use aminoglycoside antibiotics during conduct of the clinical trial; severe cognitive disorder or mental illness, alcohol or drug abuse; involved in other clinical trials over the 3 months prior to this trial 
NCT02291380 (Continued)

\section{Target $\mathrm{N}=288$}

Intervention: Botox for injection in these trials, minimum intramuscular dose of $155 \mathrm{U}$ of Botox (HengLi) administered to 31 injection sites across 7 head and neck muscles using a fixed-site, fixeddose injection paradigm (each injection was $5 \mathrm{U}$ in $0.1 \mathrm{~mL}$ ). In addition, up to $40 \mathrm{U}$ Botox, administered intramuscularly to 8 additional injection sites across 3 head and neck muscles, was allowed, using a follow-the-pain approach. Thus, the minimum dose was $155 \mathrm{U}$ and the maximum dose was $195 \mathrm{U}$

Control: matched placebo injections

Number of headache days
Number of headache attacks
Number of migraine attacks
Proportion of responders ( $\geq 50 \%$ reduction in migraine)
Use of rescue medications
Severity of migraine
Duration of migraine
MIDAS
HIT-6

\begin{tabular}{ll} 
Starting date $\quad$ September 2014 \\
\hline
\end{tabular}

Contact information Lanzhou Institute of Biological Products Co., Ltd

Notes Protocol NCT02291380

Funder: Lanzhou Institute of Biological Products Co., Ltd listed as Sponsors and Collaborators

\section{NTR3440}

\begin{tabular}{ll}
\hline Trial name or title & Chronification and reversibility of migraine (CHARM) \\
\hline Methods & Randomised, double-blind, placebo-controlled, parallel-group \\
& $\begin{array}{l}\text { Hypothesis relating to this review: treatment with BTX-A injections (at the start of the therapy) will } \\
\text { increase the success rate of withdrawal therapy or will improve quality of life during the withdraw- } \\
\text { al period }\end{array}$ \\
\hline Participants & $\begin{array}{l}\text { Inclusion criteria: suffering from chronic migraine according to the ICHD-II criteria for chronic mi- } \\
\text { graine with medication overuse according to the ICHD-II criteria }\end{array}$ \\
& $\begin{array}{l}\text { Exclusion criteria: age under } 18 \text { years; other neurological conditions that may interfere with the tri- } \\
\text { al; any oncological or psychiatric disease, any cognitive disorders and/or behavioural problems } \\
\text { which may interfere with the trial; substance abuse; use of non-triptan or non-analgesic acute an- } \\
\text { ti-headache medication; pregnancy, planned pregnancy, current nursing; specific risk factors for } \\
\text { BTX and magnetic resonance imaging } \\
\text { Target N = } 180\end{array}$ \\
\hline
\end{tabular}

Interventions

Intervention: withdrawal therapy with 1-time concomitant BTX-A injections in 31 locations according to the injection protocol by Allergan (total 155U) 
NTR3440 (Continued)

Placebo: withdrawal therapy with 1-time concomitant low-dose BTX-A injections in the facial region and $\mathrm{NaCl}$ injections in the other regions according to the injection protocol by Allergan (Total 17.5U)

Withdrawal therapy is considered standard treatment for this group and takes 3 months. During this time, participants will be guided by a trained headache-nurse

\begin{tabular}{ll}
\hline Outcomes & Number of headache days \\
& Number of migraine days \\
& Number of migraine attacks \\
& Proportion of responders ( $\geq 50 \%$ reduction in migraine) \\
& HIT-6 \\
& Depression scales \\
& SF-36 questionnaire \\
\hline Starting date & 1 September 2012 \\
\hline Contact information & G.M.Terwindt@lumc.nl \\
\hline Notes & Full publication due in 2017 \\
& Protocol NTR3440 \\
Funder: NWO (VIDI grant)
\end{tabular}

AE: adverse events; BTX: botulinum toxin; BTX-A: botulinum toxin type A HIT-6: Headache Impact Test-6 question version; ICHD: International Classification of Headache Disorders; IHS: International Headache Society; MIDAS: Migraine Disability Assessment

\section{DATA AND ANALYSES}

\section{Comparison 1. Botulinum toxin type A versus placebo}

\begin{tabular}{|c|c|c|c|c|}
\hline $\begin{array}{l}\text { Outcome or subgroup ti- } \\
\text { tle }\end{array}$ & No. of studies & $\begin{array}{l}\text { No. of partici- } \\
\text { pants }\end{array}$ & Statistical method & Effect size \\
\hline 1 Number of migraine days & 5 & 1915 & Mean Difference (IV, Random, 95\% CI) & $-2.39[-4.02,-0.76]$ \\
\hline 1.1 Chronic migraine & 4 & 1497 & Mean Difference (IV, Random, 95\% CI) & $-3.07[-4.73,-1.41]$ \\
\hline 1.2 Episodic migraine & 1 & 418 & Mean Difference (IV, Random, 95\% CI) & $-0.20[-0.77,0.37]$ \\
\hline $\begin{array}{l}2 \text { Number of headache } \\
\text { days }\end{array}$ & 2 & 1384 & Mean Difference (IV, Random, 95\% CI) & $-1.86[-2.74,-0.98]$ \\
\hline 2.1 Chronic migraine & 2 & 1384 & Mean Difference (IV, Random, 95\% CI) & $-1.86[-2.74,-0.98]$ \\
\hline $\begin{array}{l}3 \text { Number of migraine at- } \\
\text { tacks }\end{array}$ & 6 & 2004 & Mean Difference (IV, Random, 95\% CI) & $-0.46[-1.34,0.41]$ \\
\hline 3.1 Chronic migraine & 1 & 679 & Mean Difference (IV, Random, 95\% CI) & $0.10[-0.71,0.91]$ \\
\hline
\end{tabular}




\begin{tabular}{|c|c|c|c|c|}
\hline $\begin{array}{l}\text { Outcome or subgroup ti- } \\
\text { tle }\end{array}$ & No. of studies & $\begin{array}{l}\text { No. of partici- } \\
\text { pants }\end{array}$ & Statistical method & Effect size \\
\hline 3.2 Episodic migraine & 3 & 1096 & Mean Difference (IV, Random, 95\% CI) & $0.13[-0.17,0.43]$ \\
\hline 3.3 Mixed & 2 & 229 & Mean Difference (IV, Random, 95\% CI) & $-2.08[-6.78,2.63]$ \\
\hline $\begin{array}{l}4 \text { Severity of migraine (Vi- } \\
\text { sual Analogue Score 0-10) }\end{array}$ & 4 & 209 & Mean Difference (IV, Random, 95\% CI) & $-3.30[-4.16,-2.45]$ \\
\hline 4.1 Chronic migraine & 2 & 75 & Mean Difference (IV, Random, 95\% CI) & $-2.70[-3.31,-2.09]$ \\
\hline 4.2 Episodic migraine & 1 & 32 & Mean Difference (IV, Random, 95\% CI) & $-4.9[-6.56,-3.24]$ \\
\hline 4.3 Mixed & 1 & 102 & Mean Difference (IV, Random, 95\% CI) & $-3.5[-4.52,-2.48]$ \\
\hline 5 Use of rescue medication & 2 & 717 & Mean Difference (IV, Random, 95\% CI) & $-1.29[-3.09,0.52]$ \\
\hline 5.1 Chronic migraine & 2 & 717 & Mean Difference (IV, Random, 95\% CI) & $-1.29[-3.09,0.52]$ \\
\hline 6 Total adverse events & 13 & 3325 & Risk Ratio (M-H, Random, 95\% Cl) & $1.28[1.12,1.47]$ \\
\hline 6.1 Chronic migraine & 5 & 1494 & Risk Ratio (M-H, Random, 95\% Cl) & $1.22[1.07,1.40]$ \\
\hline 6.2 Episodic migraine & 6 & 1673 & Risk Ratio (M-H, Random, 95\% Cl) & $1.28[1.02,1.60]$ \\
\hline 6.3 Mixed & 2 & 158 & Risk Ratio (M-H, Random, 95\% Cl) & $1.47[0.57,3.76]$ \\
\hline $\begin{array}{l}7 \text { Adverse event - ble- } \\
\text { pharoptosis }\end{array}$ & 7 & 1867 & Risk Ratio (M-H, Random, 95\% Cl) & $7.29[3.18,16.73]$ \\
\hline 7.1 Episodic migraine & 5 & 1637 & Risk Ratio (M-H, Random, 95\% Cl) & $9.53[3.87,23.44]$ \\
\hline 7.2 Mixed & 2 & 230 & Risk Ratio (M-H, Random, 95\% Cl) & $1.58[0.18,13.59]$ \\
\hline $\begin{array}{l}8 \text { Adverse event - muscle } \\
\text { weakness }\end{array}$ & 6 & 2602 & Risk Ratio (M-H, Random, 95\% Cl) & $13.67[6.73,27.75]$ \\
\hline 8.1 Chronic migraine & 2 & 1379 & Risk Ratio (M-H, Random, 95\% Cl) & $12.68[3.49,46.05]$ \\
\hline 8.2 Episodic migraine & 4 & 1223 & Risk Ratio (M-H, Random, 95\% Cl) & $14.12[6.05,32.94]$ \\
\hline $\begin{array}{l}9 \text { Adverse event - neck } \\
\text { pain }\end{array}$ & 6 & 2424 & Risk Ratio (M-H, Random, 95\% Cl) & $2.98[2.06,4.32]$ \\
\hline 9.1 Chronic migraine & 3 & 1432 & Risk Ratio (M-H, Random, 95\% Cl) & $2.47[1.48,4.12]$ \\
\hline 9.2 Episodic migraine & 2 & 864 & Risk Ratio (M-H, Random, 95\% Cl) & $3.93[2.27,6.79]$ \\
\hline 9.3 Mixed & 1 & 128 & Risk Ratio (M-H, Random, 95\% Cl) & $0.98[0.09,10.47]$ \\
\hline $\begin{array}{l}10 \text { Adverse event - injec- } \\
\text { tion site pain }\end{array}$ & 8 & 1332 & Risk Ratio (M-H, Random, 95\% Cl) & $2.10[1.02,4.33]$ \\
\hline 10.1 Chronic migraine & 3 & 115 & Risk Ratio (M-H, Random, 95\% Cl) & $2.57[0.81,8.15]$ \\
\hline 10.2 Episodic migraine & 3 & 987 & Risk Ratio (M-H, Random, 95\% Cl) & $3.23[1.14,9.13]$ \\
\hline
\end{tabular}




\begin{tabular}{|c|c|c|c|c|}
\hline $\begin{array}{l}\text { Outcome or subgroup ti- } \\
\text { tle }\end{array}$ & No. of studies & $\begin{array}{l}\text { No. of partici- } \\
\text { pants }\end{array}$ & Statistical method & Effect size \\
\hline 10.3 Mixed & 2 & 230 & Risk Ratio $(\mathrm{M}-\mathrm{H}$, Random, 95\% Cl) & $0.20[0.03,1.58]$ \\
\hline $\begin{array}{l}11 \text { Total treatment related } \\
\text { adverse events }\end{array}$ & 6 & 2893 & Risk Ratio (M-H, Random, 95\% Cl) & $2.18[1.73,2.75]$ \\
\hline 11.1 Chronic migraine & 2 & 1379 & Risk Ratio (M-H, Random, 95\% Cl) & $2.32[1.85,2.91]$ \\
\hline 11.2 Episodic migraine & 4 & 1514 & Risk Ratio $(\mathrm{M}-\mathrm{H}$, Random, $95 \% \mathrm{Cl})$ & $2.06[1.37,3.08]$ \\
\hline $\begin{array}{l}12 \text { Withdrawals due to ad- } \\
\text { verse events in trials with } \\
\text { multiple rounds of treat- } \\
\text { ment. }\end{array}$ & 4 & 2248 & Risk Ratio $(\mathrm{M}-\mathrm{H}$, Random, $95 \% \mathrm{Cl})$ & $3.28[1.52,7.07]$ \\
\hline 12.1 Chronic migraine & 2 & 1384 & Risk Ratio $(\mathrm{M}-\mathrm{H}$, Random, $95 \% \mathrm{Cl})$ & $3.71[1.38,9.98]$ \\
\hline 12.2 Episodic migraine & 2 & 864 & Risk Ratio $(\mathrm{M}-\mathrm{H}$, Random, $95 \% \mathrm{Cl})$ & $2.73[0.81,9.19]$ \\
\hline
\end{tabular}

Analysis 1.1. Comparison 1 Botulinum toxin type A versus placebo, Outcome 1 Number of migraine days.

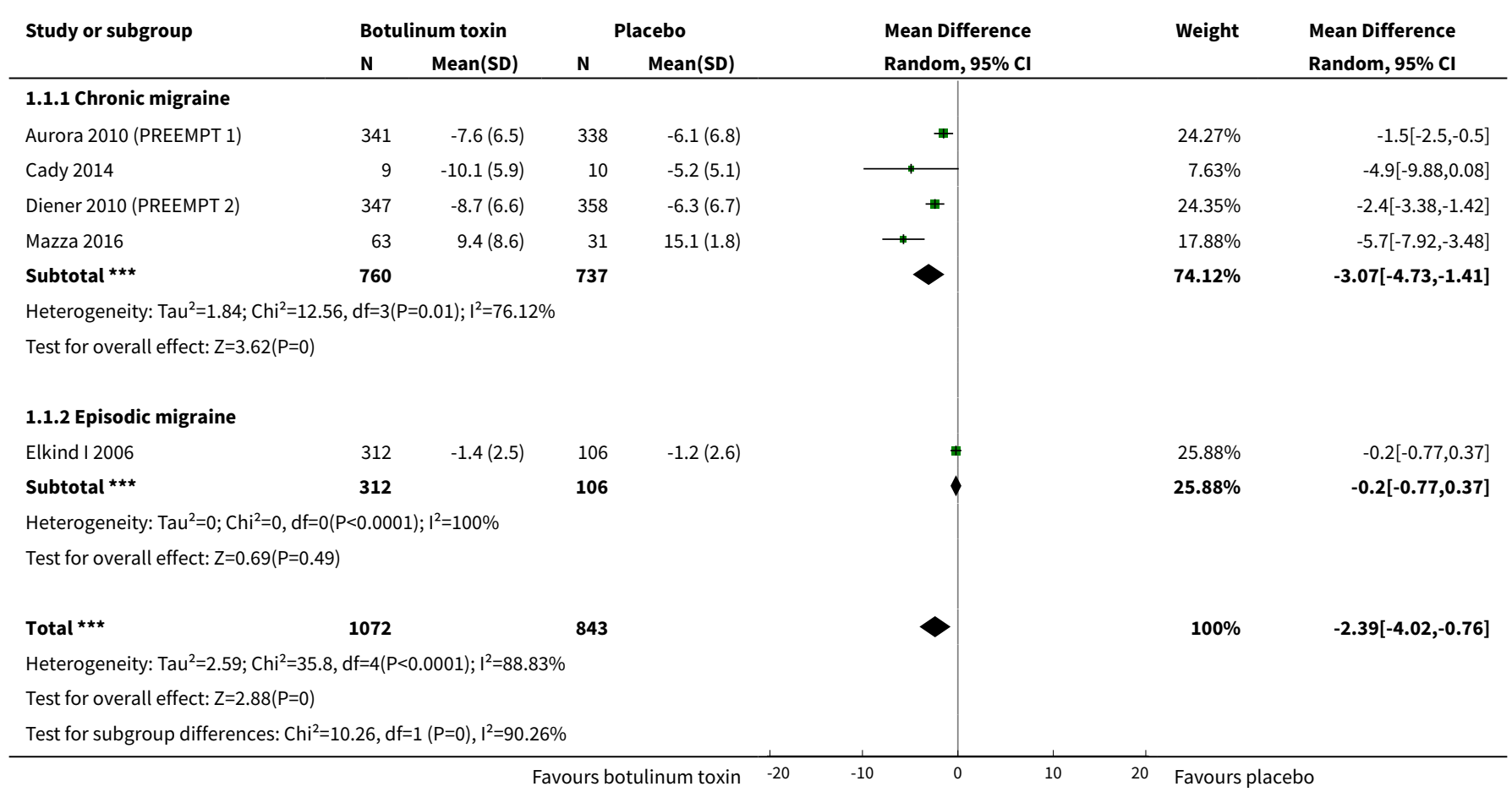


Analysis 1.2. Comparison 1 Botulinum toxin type A versus placebo, Outcome 2 Number of headache days.

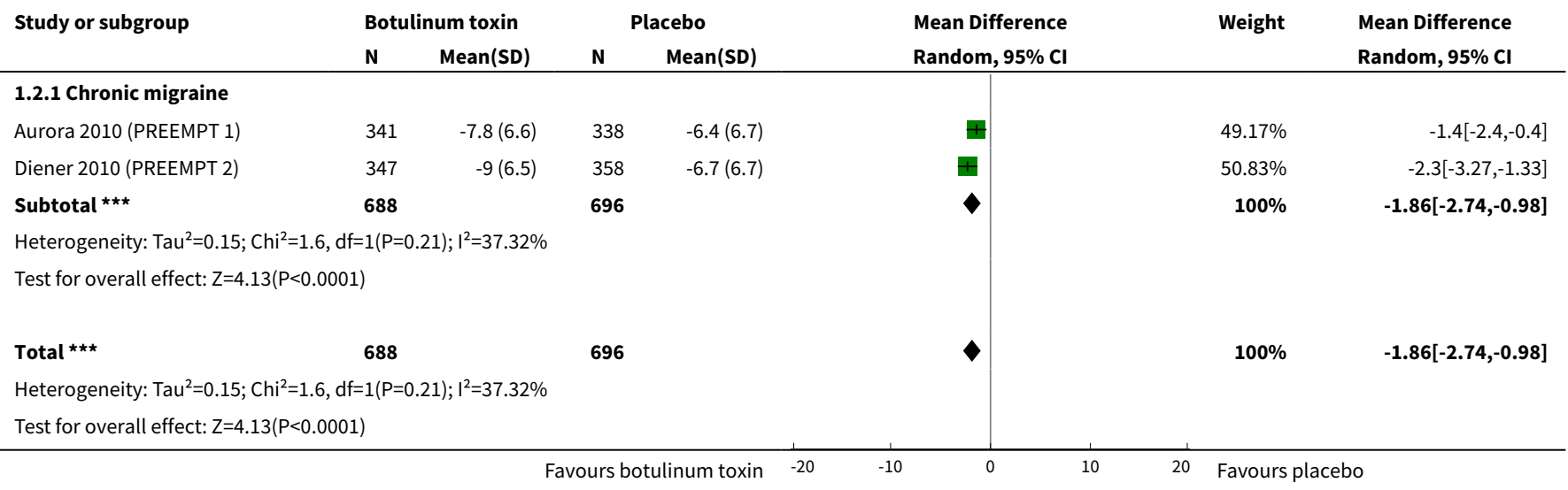

\section{Analysis 1.3. Comparison 1 Botulinum toxin type A versus placebo, Outcome 3 Number of migraine attacks.}

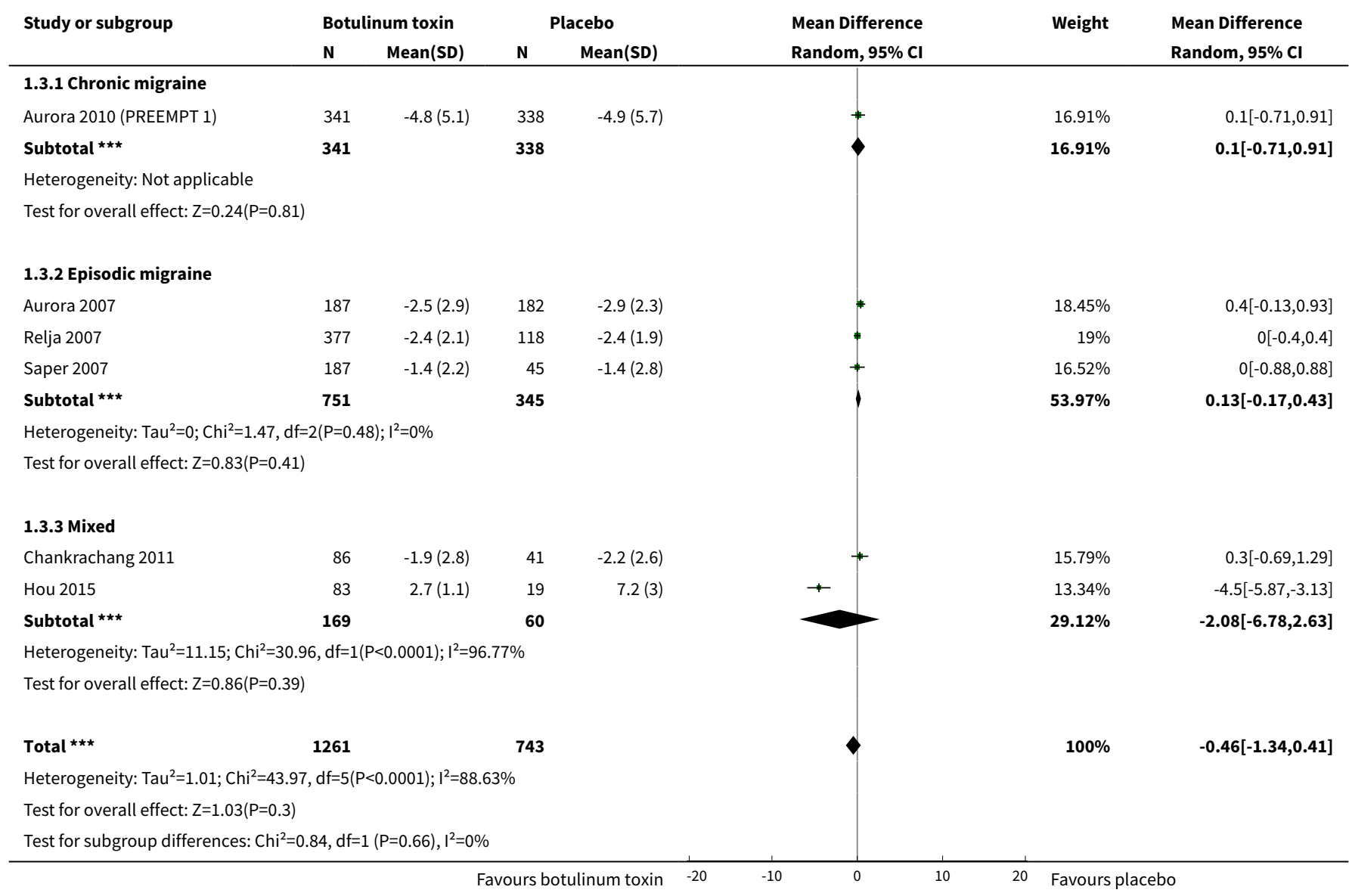


Analysis 1.4. Comparison 1 Botulinum toxin type $A$ versus placebo, Outcome 4 Severity of migraine (Visual Analogue Score 0-10).

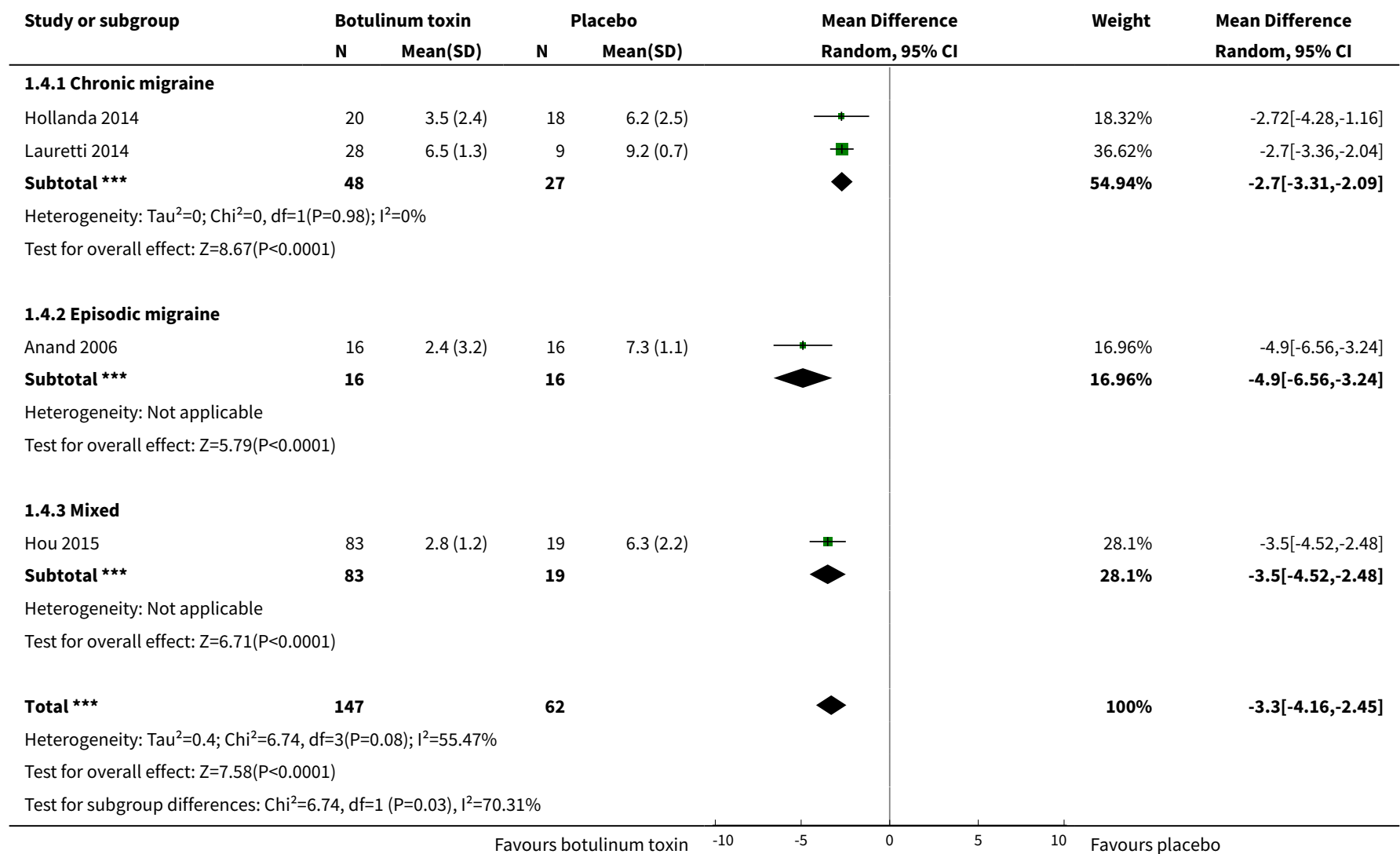

\section{Analysis 1.5. Comparison 1 Botulinum toxin type A versus placebo, Outcome 5 Use of rescue medication.}

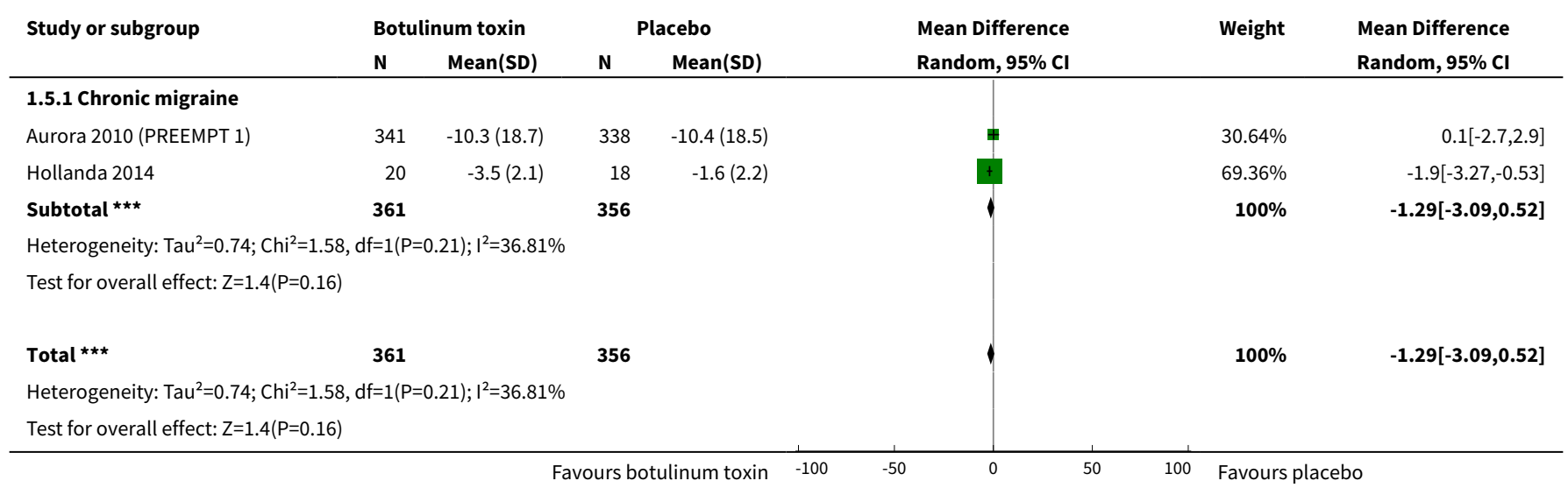


Analysis 1.6. Comparison 1 Botulinum toxin type A versus placebo, Outcome 6 Total adverse events.

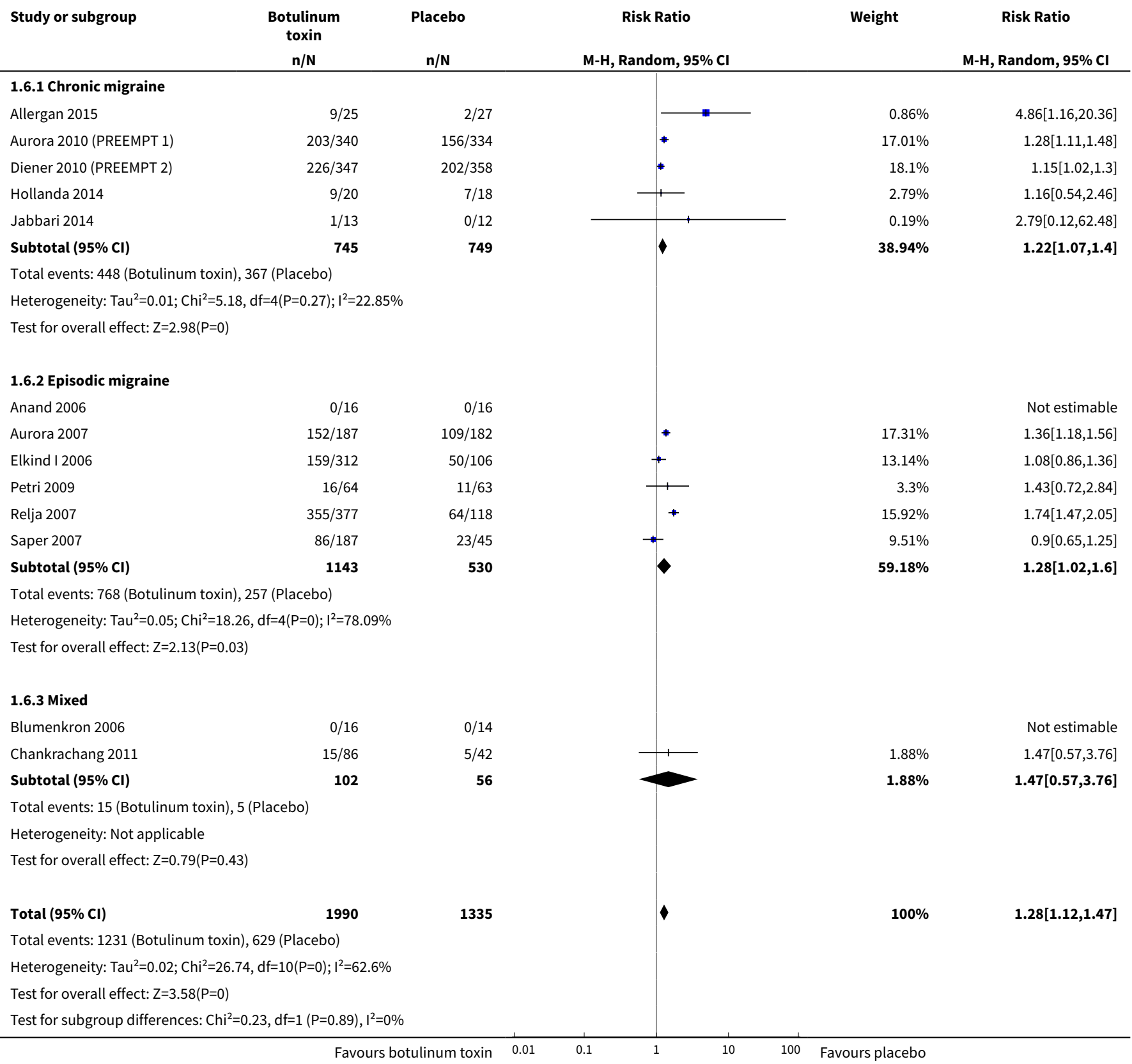

\section{Analysis 1.7. Comparison 1 Botulinum toxin type A versus placebo, Outcome 7 Adverse event - blepharoptosis.}

\begin{tabular}{|c|c|c|c|c|c|}
\hline \multirow[t]{2}{*}{ Study or subgroup } & \multirow{2}{*}{$\begin{array}{c}\text { Botulinum } \\
\text { toxin } \\
n / N\end{array}$} & \multirow{2}{*}{$\begin{array}{c}\text { Placebo } \\
\text { n/N }\end{array}$} & Risk Ratio & \multirow[t]{2}{*}{ Weight } & \multirow{2}{*}{$\begin{array}{c}\text { Risk Ratio } \\
\text { M-H, Random, } 95 \% \mathrm{Cl}\end{array}$} \\
\hline & & & M-H, Random, $95 \% \mathrm{Cl}$ & & \\
\hline \multicolumn{6}{|c|}{ 1.7.1 Episodic migraine } \\
\hline Aurora 2007 & $29 / 187$ & $3 / 182$ & 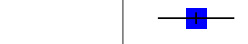 & $50.31 \%$ & $9.41[2.92,30.34]$ \\
\hline Elkind I 2006 & $15 / 312$ & $0 / 106$ & $\longrightarrow$ & $8.75 \%$ & $10.6[0.64,175.6]$ \\
\hline Relja 2007 & $33 / 377$ & $0 / 118$ & $\longrightarrow$ & $8.9 \%$ & $21.09[1.3,341.63]$ \\
\hline
\end{tabular}




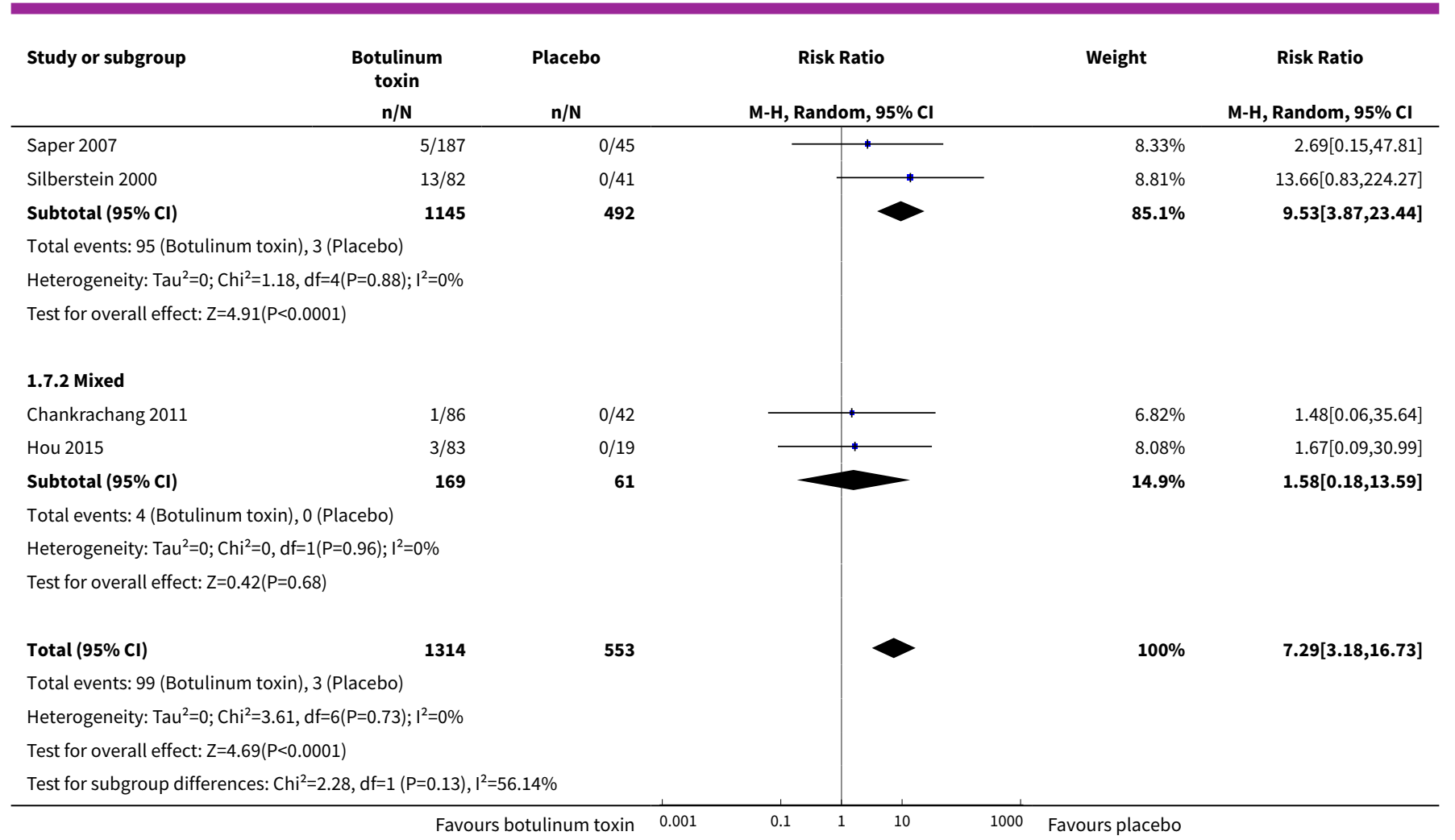

Analysis 1.8. Comparison 1 Botulinum toxin type A versus placebo, Outcome 8 Adverse event - muscle weakness.






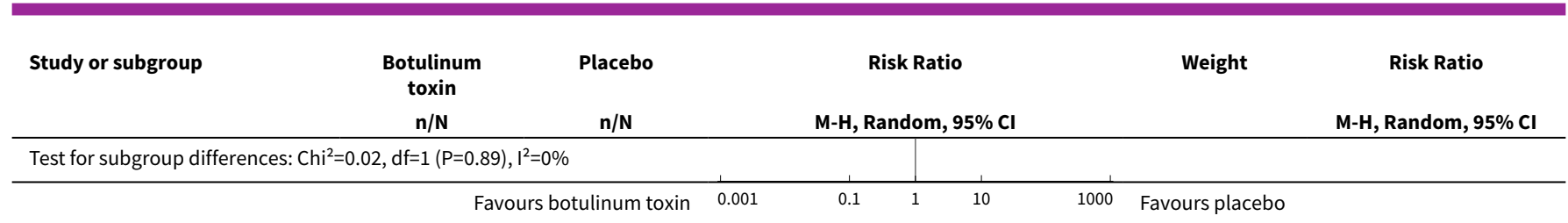

Analysis 1.9. Comparison 1 Botulinum toxin type A versus placebo, Outcome 9 Adverse event - neck pain.

\begin{tabular}{ccccc} 
Study or subgroup & $\begin{array}{c}\text { Botulinum } \\
\text { toxin } \\
\mathrm{n} / \mathrm{N}\end{array}$ & Placebo & Risk Ratio & Weight \\
& $\mathrm{n} / \mathrm{N}$ & $\mathrm{M}-\mathrm{H}, \mathrm{Random}, \mathbf{9 5 \% \mathrm { Cl }}$ & $\mathrm{M}-\mathrm{H}, \mathrm{Random}, 95 \% \mathrm{Cl}$ \\
\hline
\end{tabular}

1.9.1 Chronic migraine

Allergan 2015

Aurora 2010 (PREEMPT 1)

Diener 2010 (PREEMPT 2)

Subtotal $(95 \% \mathrm{Cl})$

Total events: 50 (Botulinum toxin), 20 (Placebo)

Heterogeneity: $\mathrm{Tau}^{2}=0 ; \mathrm{Chi}^{2}=1.66, \mathrm{df}=2(\mathrm{P}=0.44) ; \mathrm{I}^{2}=0 \%$

Test for overall effect: $\mathrm{Z}=3.45(\mathrm{P}=0)$

\subsubsection{Episodic migraine}

Aurora 2007

Relja 2007

Subtotal $(95 \% \mathrm{Cl})$

$32 / 187$

$76 / 377$

564

$\begin{array}{rr}4 / 25 & 1 / 27 \\ 20 / 341 & 11 / 334 \\ 26 / 347 & 8 / 358 \\ \mathbf{7 1 3} & \mathbf{7 1 9}\end{array}$

Total events: 108 (Botulinum toxin), 14 (Placebo)

Heterogeneity: $\mathrm{Tau}^{2}=0 ; \mathrm{Chi}^{2}=0, \mathrm{df}=1(\mathrm{P}=0.97) ; \mathrm{I}^{2}=0 \%$

Test for overall effect: $Z=4.89(P<0.0001)$

\subsubsection{Mixed}

Chankrachang 2011

Subtotal $(95 \% \mathrm{Cl})$

Total events: 2 (Botulinum toxin), 1 (Placebo)

Heterogeneity: Not applicable

Test for overall effect: $\mathrm{Z}=0.02(\mathrm{P}=0.98)$

Total events: 160 (Botulinum toxin), 35 (Placebo) Heterogeneity: $\mathrm{Tau}^{2}=0 ; \mathrm{Chi}^{2}=4.04, \mathrm{df}=5(\mathrm{P}=0.54) ; \mathrm{I}^{2}=0 \%$ Test for overall effect: $Z=5.79(P<0.0001)$

Test for subgroup differences: $\mathrm{Chi}^{2}=2.34, \mathrm{df}=1(\mathrm{P}=0.31), \mathrm{I}^{2}=14.56 \%$

$\begin{array}{lllllll}\text { Favours botulinum toxin } & 0.01 & 0.1 & 1 & 10 & 100 & \text { Favours placebo }\end{array}$

Analysis 1.10. Comparison 1 Botulinum toxin type A versus placebo, Outcome 10 Adverse event - injection site pain.

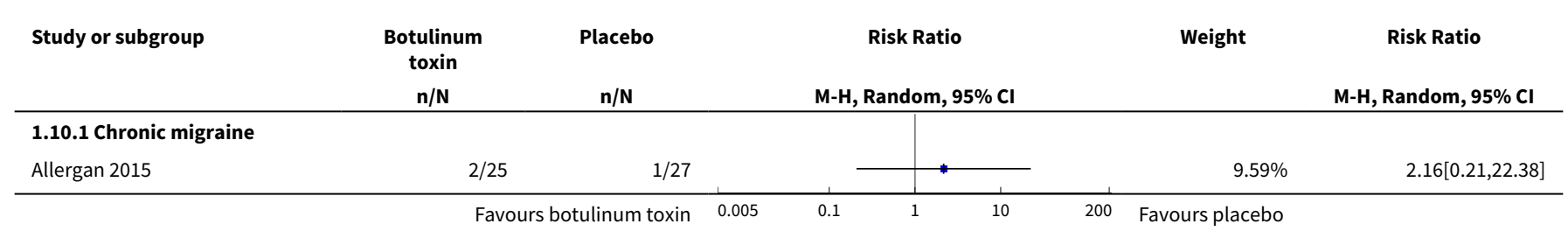




\begin{tabular}{|c|c|c|c|c|c|}
\hline Study or subgroup & $\begin{array}{c}\text { Botulinum } \\
\text { toxin } \\
n / N\end{array}$ & $\begin{array}{l}\text { Placebo } \\
\text { n/N }\end{array}$ & $\begin{array}{c}\text { Risk Ratio } \\
\text { M-H, Random, } 95 \% \mathrm{Cl}\end{array}$ & Weight & $\begin{array}{c}\text { Risk Ratio } \\
\text { M-H, Random, } 95 \% \mathrm{CI}\end{array}$ \\
\hline Hollanda 2014 & $6 / 20$ & $2 / 18$ & -1 & $24.31 \%$ & $2.7[0.62,11.72]$ \\
\hline Jabbari 2014 & $1 / 13$ & $0 / 12$ & 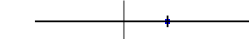 & $5.42 \%$ & $2.79[0.12,62.48]$ \\
\hline Subtotal $(95 \% \mathrm{Cl})$ & 58 & 57 & & $39.32 \%$ & $2.57[0.81,8.15]$ \\
\hline \multicolumn{6}{|c|}{ Total events: 9 (Botulinum toxin), 3 (Placebo) } \\
\hline \multicolumn{6}{|c|}{ Heterogeneity: Tau $^{2}=0 ; \mathrm{Chi}^{2}=0.03, \mathrm{df}=2(\mathrm{P}=0.99) ; \mathrm{I}^{2}=0 \%$} \\
\hline \multicolumn{6}{|c|}{ Test for overall effect: $\mathrm{Z}=1.6(\mathrm{P}=0.11)$} \\
\hline \multicolumn{6}{|c|}{ 1.10.2 Episodic migraine } \\
\hline Aurora 2007 & $4 / 187$ & $1 / 182$ & 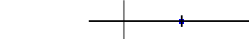 & $11.01 \%$ & $3.89[0.44,34.5]$ \\
\hline Relja 2007 & $16 / 377$ & $2 / 118$ & $-\square$ & $24.74 \%$ & $2.5[0.58,10.73]$ \\
\hline Silberstein 2000 & $9 / 82$ & $1 / 41$ & 1 & $12.7 \%$ & $4.5[0.59,34.32]$ \\
\hline Subtotal $(95 \% \mathrm{CI})$ & 646 & 341 & & $48.45 \%$ & $3.23[1.14,9.13]$ \\
\hline \multicolumn{6}{|c|}{ Total events: 29 (Botulinum toxin), 4 (Placebo) } \\
\hline \multicolumn{6}{|c|}{ Heterogeneity: $\mathrm{Tau}^{2}=0 ; \mathrm{Chi}^{2}=0.25, \mathrm{df}=2(\mathrm{P}=0.88) ; \mathrm{I}^{2}=0 \%$} \\
\hline \multicolumn{6}{|c|}{ Test for overall effect: $Z=2.21(P=0.03)$} \\
\hline \multicolumn{6}{|l|}{ 1.10.3 Mixed } \\
\hline Chankrachang 2011 & $0 / 86$ & $1 / 42$ & & $5.18 \%$ & $0.16[0.01,3.96]$ \\
\hline Hou 2015 & $1 / 83$ & $1 / 19$ & $\rightarrow$ & $7.05 \%$ & $0.23[0.01,3.5]$ \\
\hline Subtotal $(95 \% \mathrm{Cl})$ & 169 & 61 & & $12.23 \%$ & $0.2[0.03,1.58]$ \\
\hline \multicolumn{6}{|c|}{ Total events: 1 (Botulinum toxin), 2 (Placebo) } \\
\hline \multicolumn{6}{|c|}{ Heterogeneity: $\mathrm{Tau}^{2}=0 ; \mathrm{Chi}^{2}=0.02, \mathrm{df}=1(\mathrm{P}=0.88) ; \mathrm{I}^{2}=0 \%$} \\
\hline \multicolumn{6}{|c|}{ Test for overall effect: $Z=1.53(P=0.13)$} \\
\hline Total $(95 \% \mathrm{Cl})$ & 873 & 459 & & $100 \%$ & $2.1[1.02,4.33]$ \\
\hline \multicolumn{6}{|c|}{ Total events: 39 (Botulinum toxin), 9 (Placebo) } \\
\hline \multicolumn{6}{|c|}{ Heterogeneity: $\operatorname{Tau}^{2}=0 ; \mathrm{Chi}^{2}=6.06, \mathrm{df}=7(\mathrm{P}=0.53) ; \mathrm{I}^{2}=0 \%$} \\
\hline \multicolumn{6}{|c|}{ Test for overall effect: $Z=2.01(P=0.04)$} \\
\hline Test for subgroup dif & $5, d f=1(P=0.06)$, & $21 \%$ & & & \\
\hline
\end{tabular}

\section{Analysis 1.11. Comparison 1 Botulinum toxin type A versus} placebo, Outcome 11 Total treatment related adverse events.






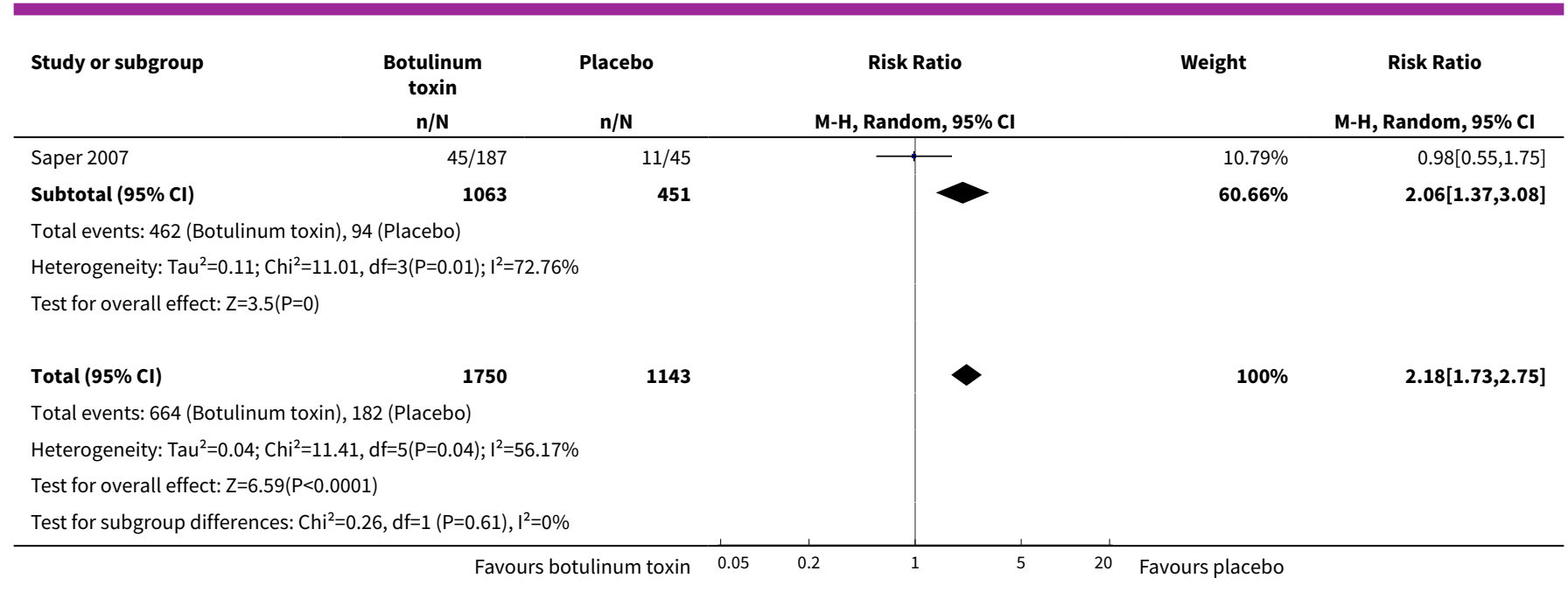

Analysis 1.12. Comparison 1 Botulinum toxin type A versus placebo, Outcome 12 Withdrawals due to adverse events in trials with multiple rounds of treatment..

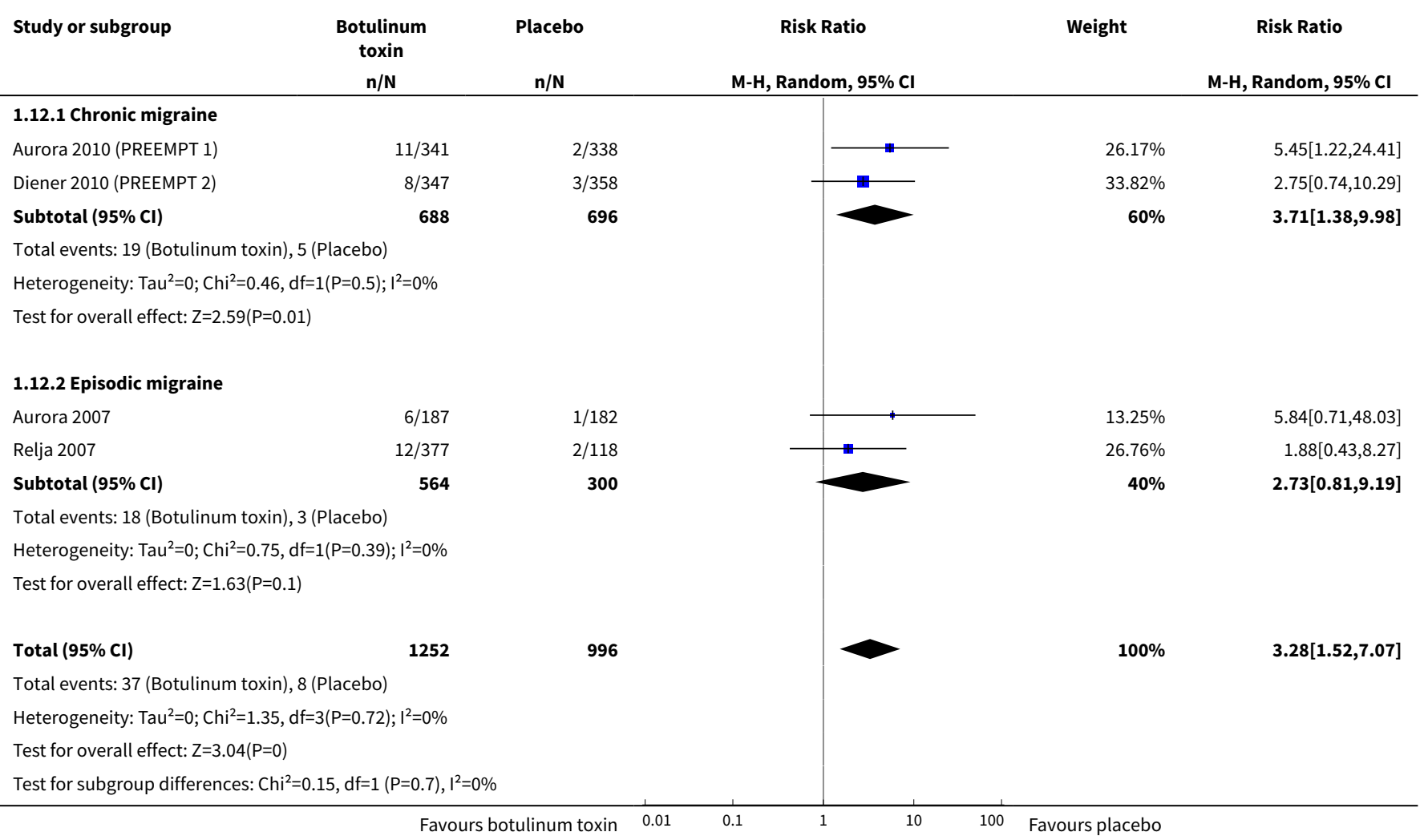


Comparison 2. Botulinum toxin type A versus other established prophylactic agent

\begin{tabular}{|c|c|c|c|c|}
\hline Outcome or subgroup title & No. of studies & $\begin{array}{l}\text { No. of partici- } \\
\text { pants }\end{array}$ & Statistical method & Effect size \\
\hline $\begin{array}{l}1 \text { Migraine impact and dis- } \\
\text { ability assessment scores }\end{array}$ & 2 & 101 & $\begin{array}{l}\text { Mean Difference (IV, Random, 95\% } \\
\mathrm{Cl} \text { ) }\end{array}$ & $4.27[-28.15,36.69]$ \\
\hline 1.1 Chronic migraine & 1 & 42 & $\begin{array}{l}\text { Mean Difference (IV, Random, 95\% } \\
\mathrm{Cl} \text { ) }\end{array}$ & $22.8[-2.56,48.16]$ \\
\hline 1.2 Mixed & 1 & 59 & $\begin{array}{l}\text { Mean Difference (IV, Random, 95\% } \\
\mathrm{Cl} \text { ) }\end{array}$ & $-10.50[-23.23,2.23]$ \\
\hline 2 Total adverse events & 2 & 114 & Risk Ratio (M-H, Random, 95\% Cl) & $0.84[0.37,1.88]$ \\
\hline 2.1 Chronic migraine & 1 & 55 & Risk Ratio (M-H, Random, 95\% Cl) & $1.03[0.94,1.14]$ \\
\hline 2.2 Mixed & 1 & 59 & Risk Ratio (M-H, Random, 95\% Cl) & $0.66[0.44,1.00]$ \\
\hline $\begin{array}{l}3 \text { Total treatment related ad- } \\
\text { verse events }\end{array}$ & 2 & 114 & Risk Ratio (M-H, Random, 95\% Cl) & $0.76[0.59,0.98]$ \\
\hline 3.1 Chronic migraine & 1 & 55 & Risk Ratio (M-H, Random, 95\% Cl) & $0.80[0.60,1.08]$ \\
\hline 3.2 Mixed & 1 & 59 & Risk Ratio (M-H, Random, 95\% Cl) & $0.64[0.38,1.09]$ \\
\hline $\begin{array}{l}4 \text { Withdrawals due to adverse } \\
\text { events in trials with multiple } \\
\text { rounds of treatment. }\end{array}$ & 2 & 119 & Risk Ratio (M-H, Random, 95\% Cl) & $0.28[0.10,0.79]$ \\
\hline 4.1 Chronic migraine & 1 & 60 & Risk Ratio (M-H, Random, 95\% Cl) & $0.38[0.11,1.28]$ \\
\hline 4.2 Mixed & 1 & 59 & Risk Ratio (M-H, Random, 95\% Cl) & $0.12[0.02,0.91]$ \\
\hline
\end{tabular}

Analysis 2.1. Comparison 2 Botulinum toxin type A versus other established prophylactic agent, Outcome 1 Migraine impact and disability assessment scores.

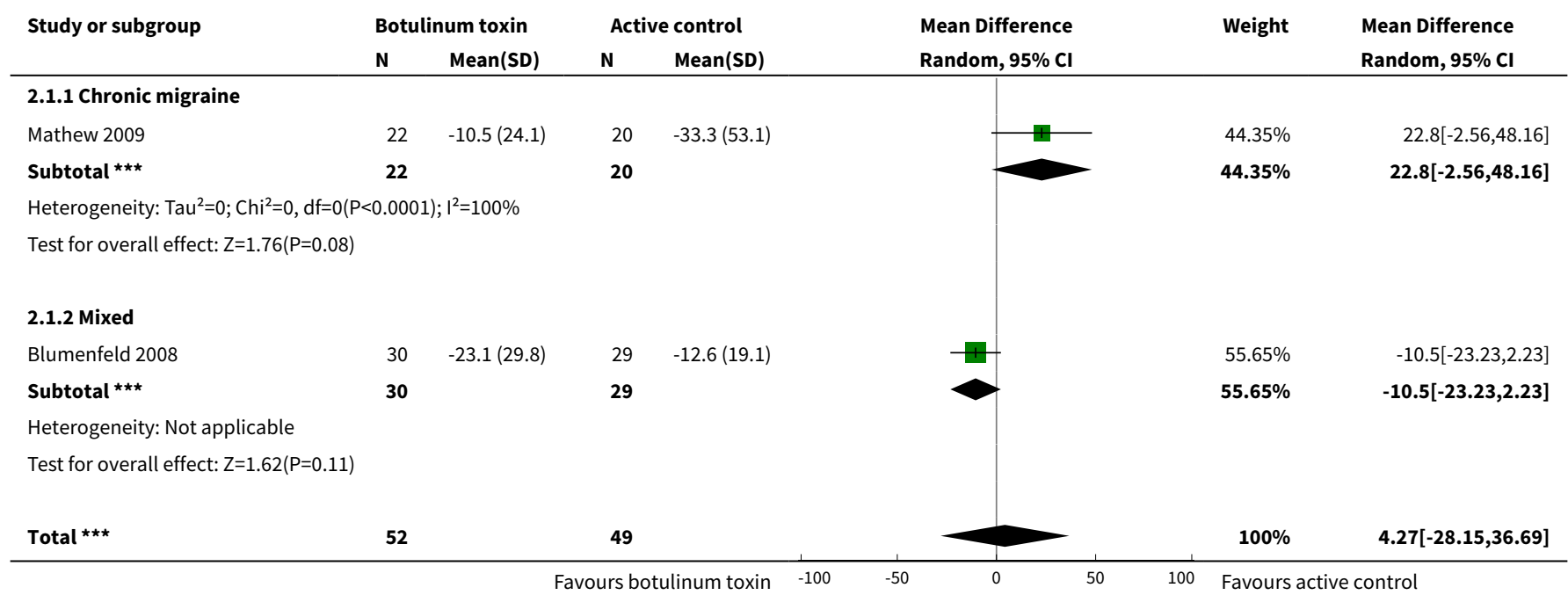




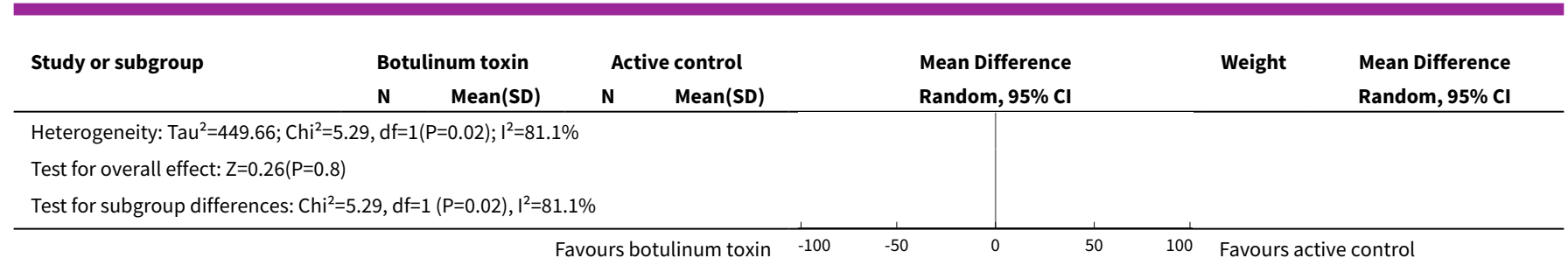

Analysis 2.2. Comparison 2 Botulinum toxin type $A$ versus other established prophylactic agent, Outcome 2 Total adverse events.



\section{Analysis 2.3. Comparison 2 Botulinum toxin type A versus other established prophylactic agent, Outcome 3 Total treatment related adverse events.}

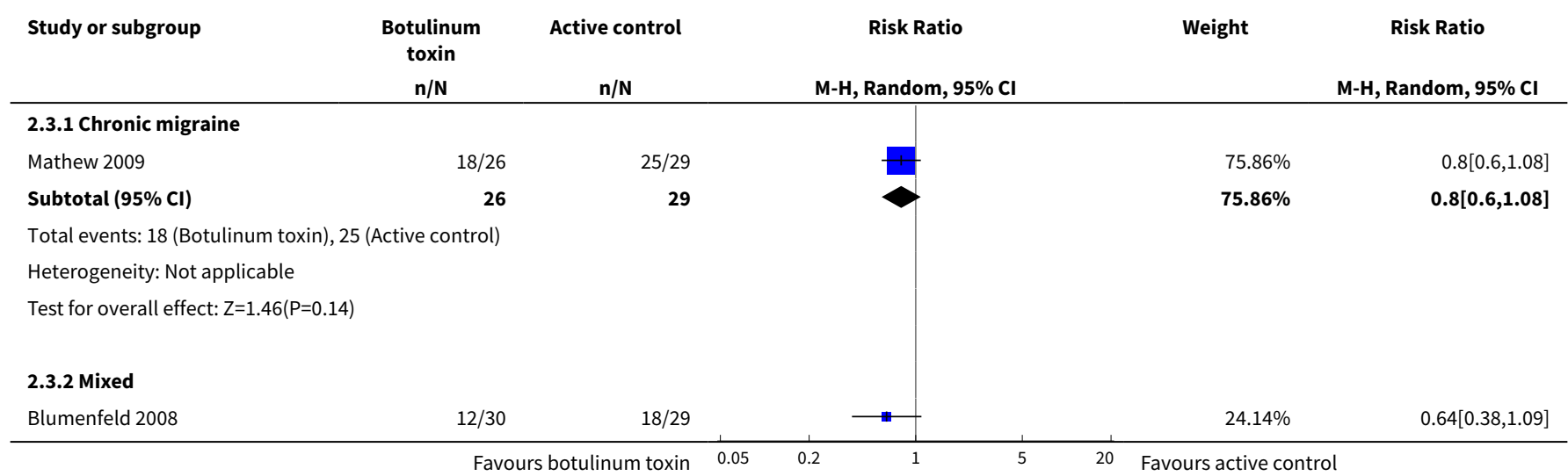




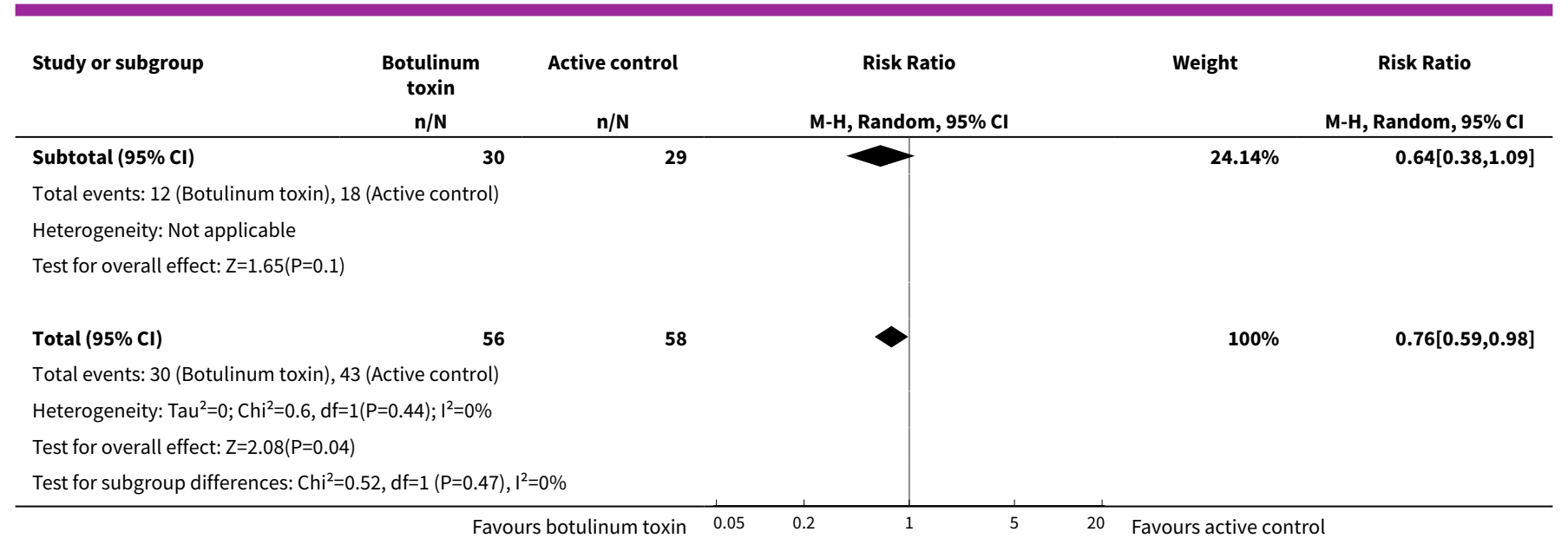

\section{Analysis 2.4. Comparison 2 Botulinum toxin type A versus other established prophylactic agent, Outcome 4 Withdrawals due to adverse events in trials with multiple rounds of treatment..}

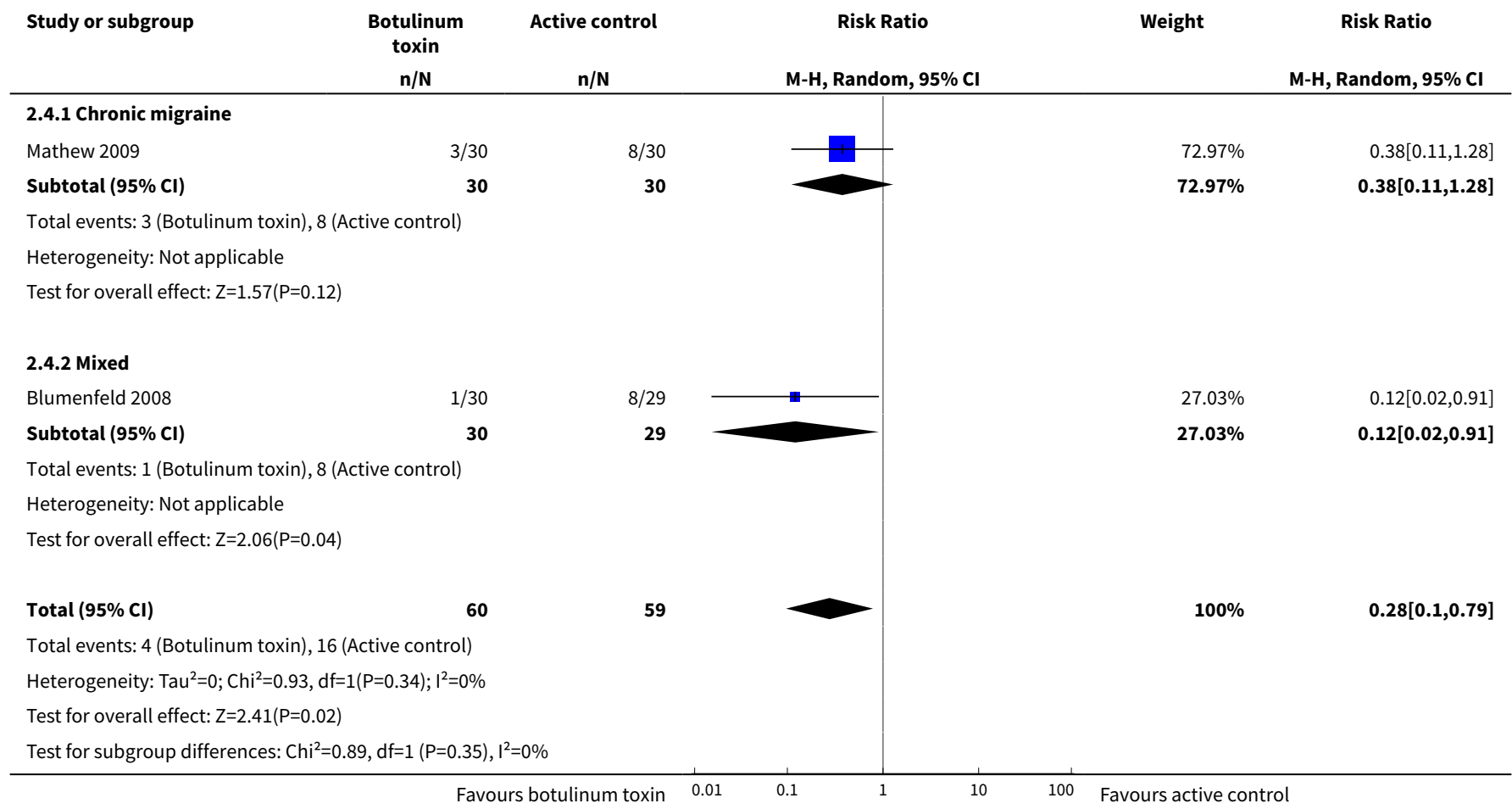

Comparison 3. Dysport $\geq 150$ U versus Dysport $<150 \mathrm{U}$

\begin{tabular}{lllll}
\hline Outcome or subgroup title & No. of studies & $\begin{array}{l}\text { No. of partici- } \\
\text { pants }\end{array}$ & Statistical method & Effect size \\
\hline 1 Total adverse events & 2 & 150 & Risk Ratio (M-H, Random, 95\% Cl) & $1.59[0.47,5.32]$ \\
\hline
\end{tabular}


Analysis 3.1. Comparison 3 Dysport $\geq 150 \mathrm{U}$ versus Dysport $<150 \mathrm{U}$, Outcome 1 Total adverse events.

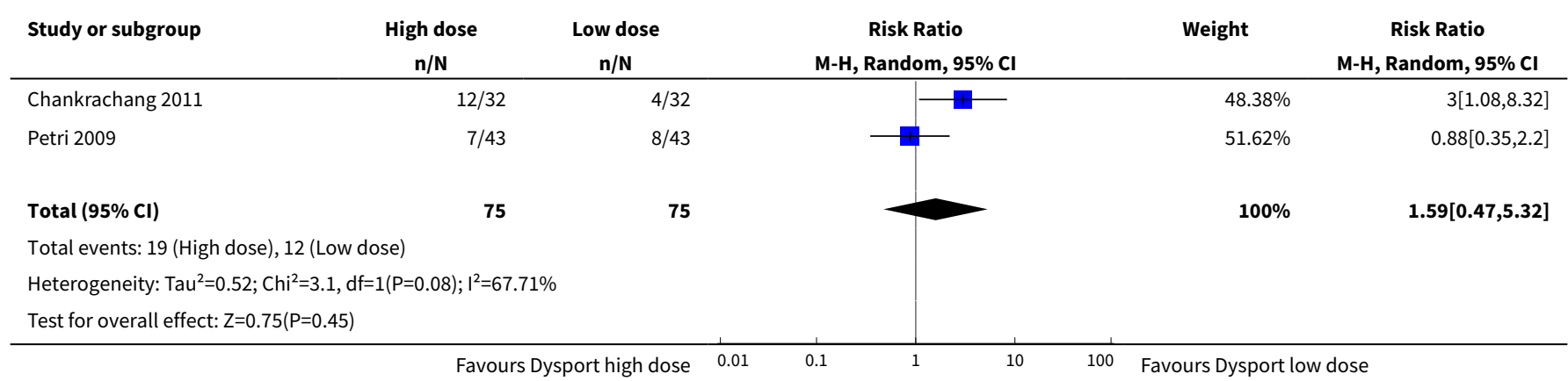

\section{Comparison 4. Botox dosing studies}

\begin{tabular}{|c|c|c|c|c|}
\hline Outcome or subgroup title & No. of studies & $\begin{array}{l}\text { No. of partici- } \\
\text { pants }\end{array}$ & Statistical method & Effect size \\
\hline 1 Number of migraine days & 2 & 353 & $\begin{array}{l}\text { Mean Difference (IV, Random, } \\
95 \% \mathrm{CI} \text { ) }\end{array}$ & $0.40[-0.19,0.99]$ \\
\hline $\begin{array}{l}\text { 1.1 Episodic migraine Botox } \geq 50 \mathrm{U} \text { vs } \\
\text { Botox }<50\end{array}$ & 2 & 353 & $\begin{array}{l}\text { Mean Difference (IV, Random, } \\
95 \% \mathrm{CI} \text { ) }\end{array}$ & $0.40[-0.19,0.99]$ \\
\hline 2 Adverse event - muscle weakness & 1 & 754 & $\begin{array}{l}\text { Risk Ratio (M-H, Random, } \\
95 \% \mathrm{Cl} \text { ) }\end{array}$ & $1.08[0.84,1.39]$ \\
\hline $\begin{array}{l}2.1 \text { Botox } \geq 200 \text { U versus Botox }<200 \\
U\end{array}$ & 1 & 377 & $\begin{array}{l}\text { Risk Ratio (M-H, Random, } \\
95 \% \mathrm{Cl} \text { ) }\end{array}$ & $1.04[0.73,1.47]$ \\
\hline $\begin{array}{l}2.2 \text { Botox } \geq 150 \text { U versus Botox }<150 \\
U\end{array}$ & 1 & 377 & $\begin{array}{l}\text { Risk Ratio (M-H, Random, } \\
95 \% \mathrm{Cl} \text { ) }\end{array}$ & $1.13[0.78,1.64]$ \\
\hline 3 Adverse event - blepharoptosis & 4 & & $\begin{array}{l}\text { Risk Ratio (M-H, Random, } \\
95 \% \mathrm{Cl} \text { ) }\end{array}$ & Subtotals only \\
\hline $\begin{array}{l}3.1 \geq 50 \mathrm{U} \text { versus }<50 \mathrm{U} \text { in frontalis } \\
\text { and/or corrugator }\end{array}$ & 1 & 377 & $\begin{array}{l}\text { Risk Ratio (M-H, Random, } \\
95 \% \mathrm{Cl} \text { ) }\end{array}$ & $2.31[1.20,4.43]$ \\
\hline $\begin{array}{l}3.2 \geq 30 \mathrm{U} \text { versus }<30 \mathrm{U} \text { in frontalis } \\
\text { and/or corrugator }\end{array}$ & 2 & 459 & $\begin{array}{l}\text { Risk Ratio (M-H, Random, } \\
95 \% \mathrm{Cl} \text { ) }\end{array}$ & $2.36[0.58,9.65]$ \\
\hline $\begin{array}{l}3.3 \geq 10 \mathrm{U} \text { versus }<10 \mathrm{U} \text { in frontalis } \\
\text { and/or corrugator }\end{array}$ & 2 & 406 & $\begin{array}{l}\text { Risk Ratio (M-H, Random, } \\
95 \% \mathrm{Cl} \text { ) }\end{array}$ & $2.42[0.99,5.94]$ \\
\hline 4 Adverse event - neck pain & 1 & 754 & $\begin{array}{l}\text { Risk Ratio (M-H, Random, } \\
95 \% \mathrm{Cl} \text { ) }\end{array}$ & $1.22[0.91,1.65]$ \\
\hline $\begin{array}{l}\text { 4.1 Botox } \geq 200 U \text { versus Botox }<200 \\
U\end{array}$ & 1 & 377 & $\begin{array}{l}\text { Risk Ratio (M-H, Random, } \\
95 \% \mathrm{Cl} \text { ) }\end{array}$ & $1.25[0.83,1.89]$ \\
\hline $\begin{array}{l}4.2 \text { Botox } \geq 150 \mathrm{U} \text { versus Botox }<150 \\
U\end{array}$ & 1 & 377 & $\begin{array}{l}\text { Risk Ratio (M-H, Random, } \\
95 \% \mathrm{Cl} \text { ) }\end{array}$ & $1.19[0.76,1.86]$ \\
\hline
\end{tabular}




\begin{tabular}{lllll}
\hline Outcome or subgroup title & No. of studies & $\begin{array}{l}\text { No. of partici- } \\
\text { pants }\end{array}$ & Statistical method & Effect size \\
\hline 5 Adverse event - injection site pain & 2 & 959 & $\begin{array}{l}\text { Risk Ratio (M-H, Random, } \\
95 \% \mathrm{Cl})\end{array}$ & $1.14[0.52,2.51]$ \\
\hline $\begin{array}{l}5.1 \text { Botox } \geq 200 \text { U versus Botox }<200 \\
\mathrm{U}\end{array}$ & 2 & 500 & $\begin{array}{l}\text { Risk Ratio (M-H, Random, } \\
95 \% \mathrm{Cl})\end{array}$ & $1.23[0.13,11.97]$ \\
\hline 5.2 Botox $\geq 150$ U versus Botox $<150 \mathrm{U}$ & 1 & 377 & $\begin{array}{l}\text { Risk Ratio (M-H, Random, } \\
95 \% \mathrm{Cl})\end{array}$ & $1.45[0.48,4.41]$ \\
\hline 5.3 Botox $\geq 50 \mathrm{U}$ versus Botox $<50 \mathrm{U}$ & 1 & 82 & $\begin{array}{l}\text { Risk Ratio (M-H, Random, } \\
95 \% \mathrm{Cl})\end{array}$ & $1.19[0.34,4.12]$ \\
\hline
\end{tabular}

Analysis 4.1. Comparison 4 Botox dosing studies, Outcome 1 Number of migraine days.

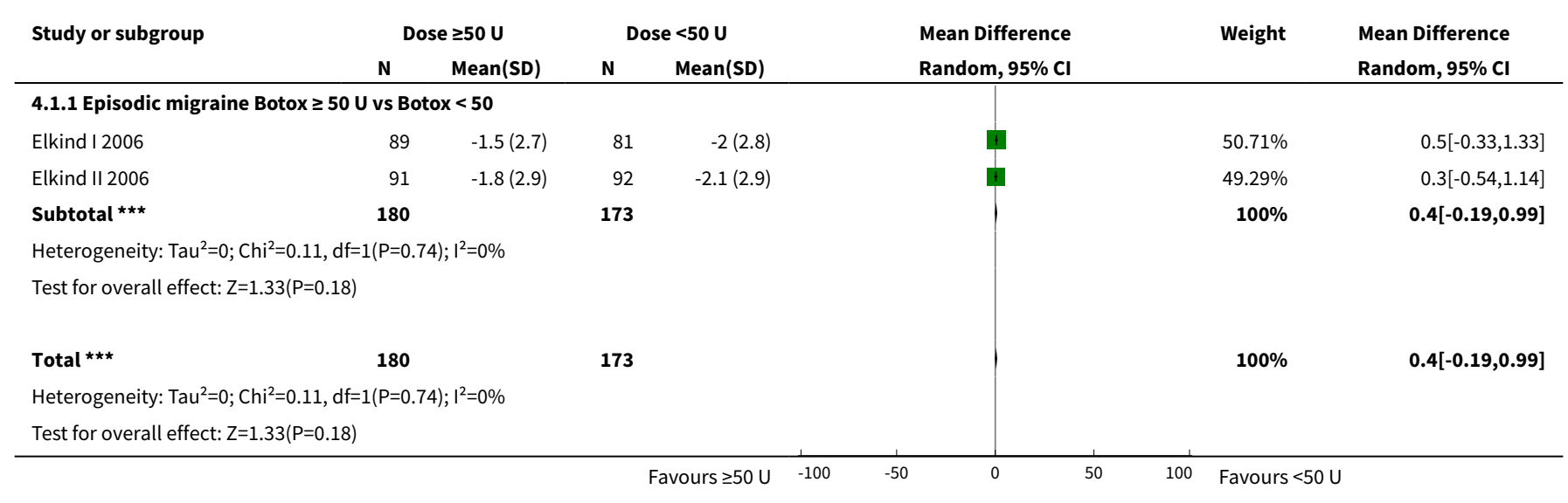

Analysis 4.2. Comparison 4 Botox dosing studies, Outcome 2 Adverse event - muscle weakness.

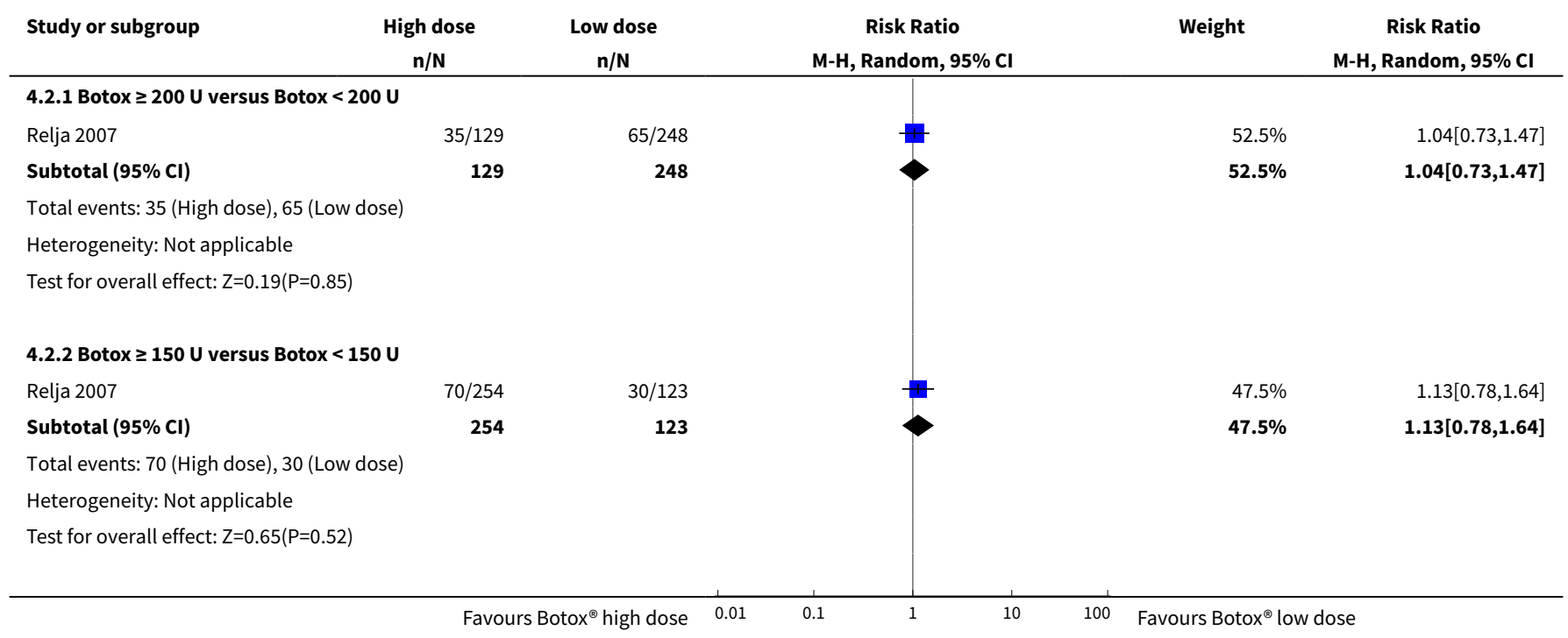




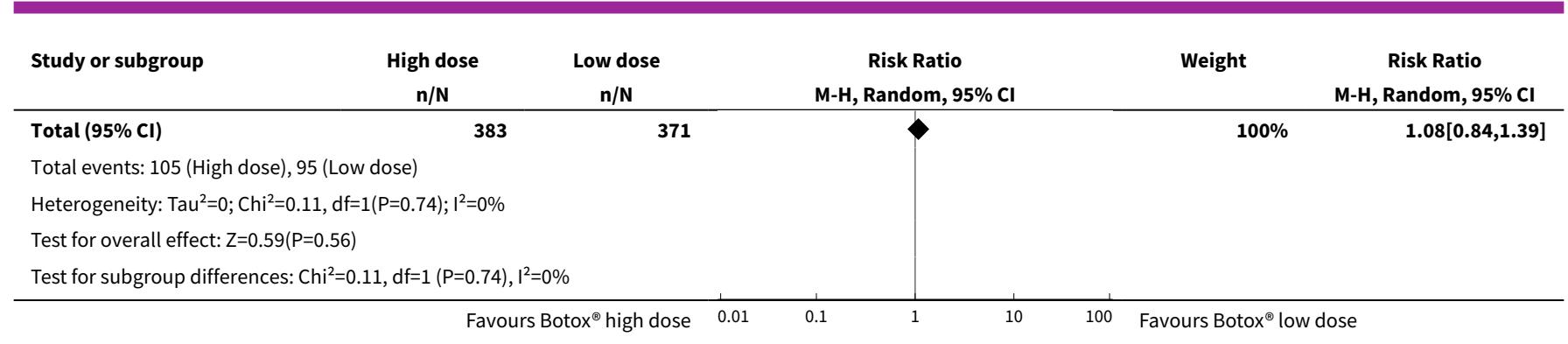

\section{Analysis 4.3. Comparison 4 Botox dosing studies, Outcome 3 Adverse event - blepharoptosis.}

\begin{tabular}{|c|c|c|c|c|c|}
\hline Study or subgroup & $\begin{array}{c}\text { High dose } \\
\mathrm{n} / \mathbf{N}\end{array}$ & $\begin{array}{c}\text { Low dose } \\
n / N\end{array}$ & $\begin{array}{c}\text { Risk Ratio } \\
\text { M-H, Random, } 95 \% \mathrm{Cl}\end{array}$ & Weight & \multirow[t]{2}{*}{$\begin{array}{c}\text { Risk Ratio } \\
\text { M-H, Random, } 95 \% \mathrm{Cl}\end{array}$} \\
\hline \multicolumn{5}{|c|}{ 4.3.1 $\geq 50 \mathrm{U}$ versus $<50 \mathrm{U}$ in frontalis and/or corrugator } & \\
\hline Relja 2007 & $18 / 129$ & $15 / 248$ & & $100 \%$ & $2.31[1.2,4.43]$ \\
\hline Subtotal $(95 \% \mathrm{Cl})$ & 129 & 248 & & $100 \%$ & $2.31[1.2,4.43]$ \\
\hline \multicolumn{6}{|c|}{ Total events: 18 (High dose), 15 (Low dose) } \\
\hline \multicolumn{6}{|c|}{ Heterogeneity: Not applicable } \\
\hline \multicolumn{6}{|c|}{ 4.3.2 $\geq 30 \mathrm{U}$ versus $<30 \mathrm{U}$ in frontalis and/or corrugator } \\
\hline Relja 2007 & $30 / 254$ & $3 / 123$ & 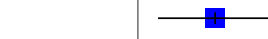 & $47.73 \%$ & $4.84[1.51,15.56]$ \\
\hline Silberstein 2000 & $7 / 40$ & $6 / 42$ & & $52.27 \%$ & $1.23[0.45,3.33]$ \\
\hline Subtotal $(95 \% \mathrm{Cl})$ & 294 & 165 & & $100 \%$ & $2.36[0.58,9.65]$ \\
\hline \multicolumn{6}{|c|}{ Total events: 37 (High dose), 9 (Low dose) } \\
\hline \multicolumn{6}{|c|}{ Test for overall effect: $Z=1.2(P=0.23)$} \\
\hline \multicolumn{6}{|c|}{ 4.3.3 $\geq 10 \mathrm{U}$ versus $<10 \mathrm{U}$ in frontalis and/or corrugator } \\
\hline Elkind I 2006 & $8 / 106$ & $7 / 206$ & & $82.64 \%$ & $2.22[0.83,5.96]$ \\
\hline Saper 2007 & $4 / 49$ & $1 / 45$ & & $17.36 \%$ & $3.67[0.43,31.65]$ \\
\hline Subtotal $(95 \% \mathrm{Cl})$ & 155 & 251 & & $100 \%$ & $2.42[0.99,5.94]$ \\
\hline \multicolumn{6}{|c|}{ Total events: 12 (High dose), 8 (Low dose) } \\
\hline \multicolumn{6}{|c|}{ Heterogeneity: $\mathrm{Tau}^{2}=0 ; \mathrm{Chi}^{2}=0.18, \mathrm{df}=1(\mathrm{P}=0.67) ; \mathrm{I}^{2}=0 \%$} \\
\hline \multicolumn{6}{|c|}{ Test for overall effect: $\mathrm{Z}=1.93(\mathrm{P}=0.05)$} \\
\hline Test for subgroup dif & $1, \mathrm{df}=1(\mathrm{P}=1), \mathrm{I}^{2}=$ & & & & \\
\hline
\end{tabular}

Analysis 4.4. Comparison 4 Botox dosing studies, Outcome 4 Adverse event - neck pain.

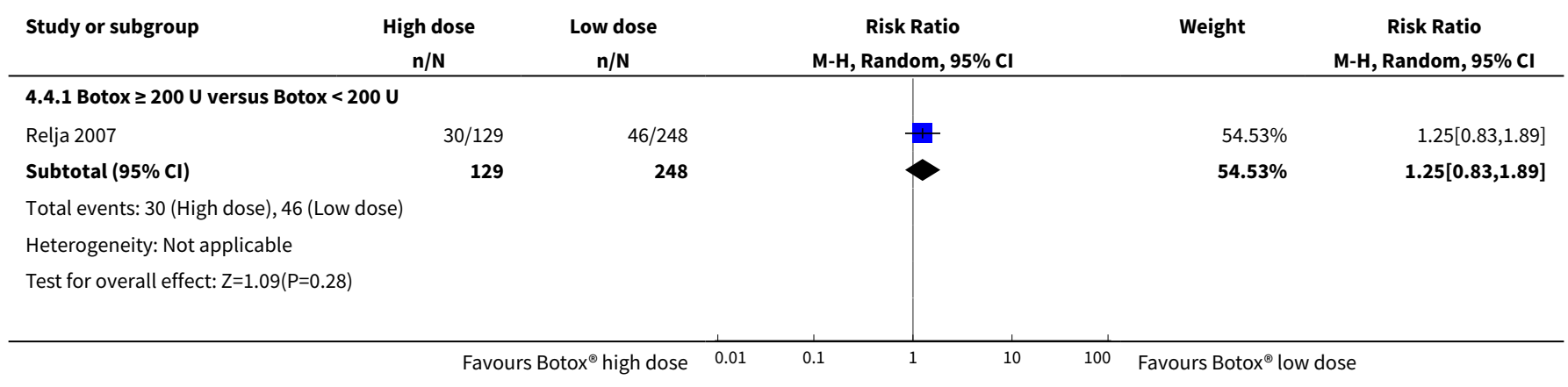




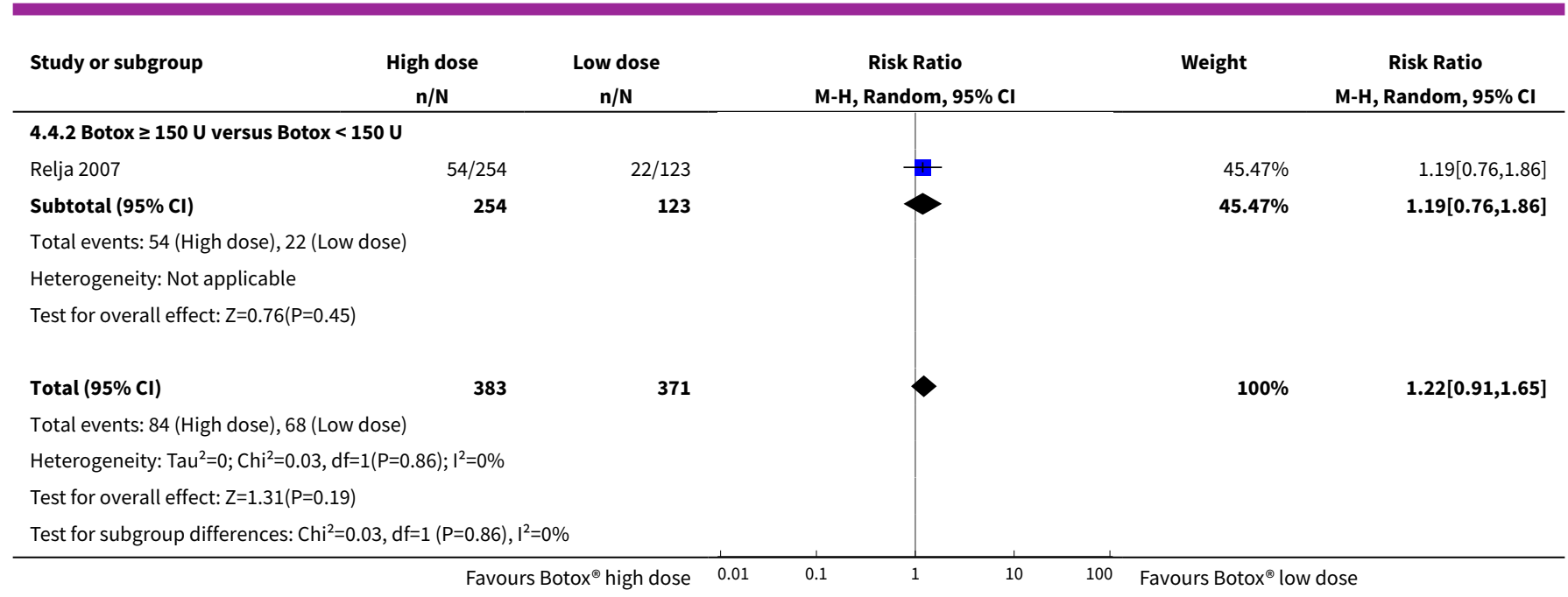

Analysis 4.5. Comparison 4 Botox dosing studies, Outcome 5 Adverse event - injection site pain.

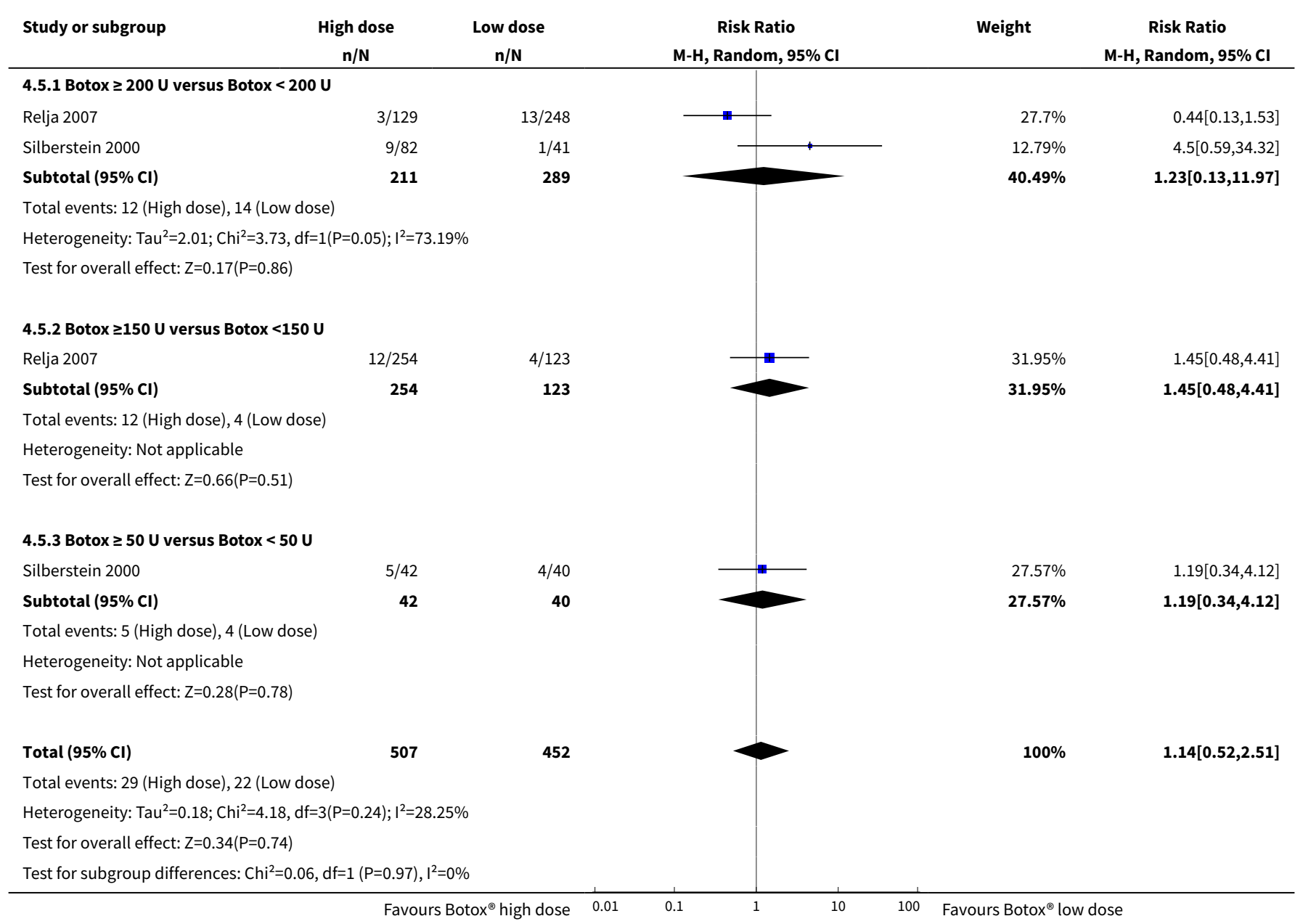


ADDITIONAL TABLES

Table 1. Glossary of terms

\begin{tabular}{ll}
\hline Term & Definition \\
\hline Chronic migraine (IHS 1988) & Not defined \\
\hline Chronic migraine (IHS 2004) & $\begin{array}{l}\text { Description: migraine headache occurring on } \geq 15 \text { days per month for }>3 \text { months in the absence of } \\
\text { medication overuse }\end{array}$ \\
& $\begin{array}{l}\text { Diagnostic criteria } \\
\text { A. Headache fulfilling criteria C and D for } 1.1 \text { migraine without aura on } 15 \text { days/month for more } \\
\text { than } 3 \text { months } \\
\text { B. Not attributed to another disorder }\end{array}$ \\
\end{tabular}

Chronic migraine (IHS 2013)

Description: headache occurring on $\geq 15$ days per month for $>3$ months, which has the features of migraine headache on at least 8 days per month

Diagnostic criteria

A. Headache (tension-type-like and/or migraine-like on $\geq 15$ days/month for $>3$ months and fulfilling criteria $\mathrm{B}$ and $\mathrm{C}$

B. Occurring in a patient who has had at least 5 attacks fulfilling criteria B-D for migraine without aura and/or criteria $B$ and $C$ for migraine with aura

C. On 8 days per month for $>3$ months, fulfilling any of the following:

- criteria $C$ and $D$ for migraine without aura;

- criteria B and C for migraine with aura;

- believed by the patient to be migraine at onset and relieved by a triptan or ergot derivative.

D. Not better accounted for by another ICHD-III diagnosis

\section{Medication overuse headache Not defined}

(IHS 1988)

Medication overuse headache (IHS 2004)

\section{Diagnostic criteria}

A. Headache present on $\geq 15$ days/month fulfilling criteria $C$ and $D$

B. Regular overuse for $>3$ months of one or more drugs that can be taken for acute and/or symptomatic treatment of headache

C. Headache has developed or markedly worsened during medication overuse

D. Headache resolves or reverts to its previous pattern within 2 months after discontinuation of overused medication

Medication overuse headache (IHS 2013)
Description: headache occurring on $\geq 15$ days/month developing as a consequence of regular overuse of acute or symptomatic headache medication (on $\geq 10$, or $\geq 15$ days/month, depending on the medication) for $>3$ months. It usually, but not invariably, resolves after the overuse is stopped.

Diagnostic criteria

A. Headache occurring on 15 days/month in a patient with a pre-existing headache disorder B. Regular overuse for more than 3 months of $\geq 1$ drugs that can be taken for acute and/or symptomatic treatment of headache

C. Not better accounted for by another ICHD-III diagnosis

\footnotetext{
Migraine (IHS 2013)
}

Migraine has 2 major subtypes.

Migraine without aura is a clinical syndrome characterised by headache with specific features and associated symptoms. 
Table 1. Glossary of terms

(Continued)

Migraine with aura is primarily characterised by the transient focal neurological symptoms that usually precede or sometimes accompany the headache.

Migraine with aura (IHS 2013) Description: recurrent attacks, lasting minutes, of unilateral fully reversible visual, sensory or other central nervous system symptoms that usually develop gradually and are usually followed by headache and associated migraine symptoms

Diagnostic criteria

A. At least 2 attacks fulfilling criteria $B$ and $C$

B. One or more of the following fully reversible aura symptoms: 1. visual, 2. sensory, 3. speech and/ or language, 4. motor, 5. brainstem, 6. retinal

C. At least 2 of the following 4 characteristics:

- at least 1 aura symptom spreads gradually over 5 minutes, and/or $\geq 2$ symptoms occur in succession;

- each individual aura symptom lasts 5-60 minutes;

- at least one aura symptom is unilateral;

- the aura is accompanied, or followed within 60 minutes, by headache.

D. Not better accounted for by another ICHD-3 diagnosis, and transient ischaemic attack has been excluded.

Migraine without aura (IHS 2013)
Description: recurrent headache disorder manifesting in attacks lasting 4-72 h. Typical characteristics of the headache are unilateral location, pulsating quality, moderate or severe intensity, aggravation by routine physical activity and association with nausea and/or photophobia and phonophobia.

Diagnostic criteria

A. At least 5 attacks 1 fulfilling criteria B-D

B. Headache attacks lasting 4-72 $\mathrm{h}$ (untreated or unsuccessfully treated)

C. Headache has at least 2 of the following 4 characteristics:

- unilateral location;

- pulsating quality;

- moderate or severe pain intensity;

- aggravation by or causing avoidance of routine physical activity (e.g. walking or climbing stairs).

D. During headache at least one of the following: 1. nausea and/or vomiting, 2. photophobia and phonophobia

E. Not better accounted for by another ICHD-III diagnosis.

Table 2. FDA-issued names for botulinum toxin products

\begin{tabular}{llll}
\hline Trade name & Manufacturer & FDA-issued name & Sero-type \\
\hline Botox & Allergan & OnabotulinumtoxinA & Botulinum toxin type A \\
\hline Botox cosmetic & Allergan & OnabotulinumtoxinA & Botulinum toxin type A \\
\hline
\end{tabular}


Table 2. FDA-issued names for botulinum toxin products (Continued)

\begin{tabular}{llll} 
Dysport & Ipsen & AbobotulinumtoxinA & Botulinum toxin type A \\
\hline HengLi & $\begin{array}{l}\text { Lanzhou Institute of biological } \\
\text { products }\end{array}$ & Not issued & Botulinum toxin type A \\
\hline Myobloc & Solstice & RimabotulinumtoxinB & Botulinum toxin type B \\
\hline Prosigne & $\begin{array}{l}\text { Lanzhou Institute of biological } \\
\text { products }\end{array}$ & Not issued & Botulinum toxin type A \\
\hline Xeomin & Merz & IncobotulinumtoxinA & Botulinum toxin type A
\end{tabular}

Allergan, Ipsen and Galderma all responded but were unable to provide additional eligible data. Merz, Solstice, and Lanzhou Institute of biological products were contacted without response.

\section{AP PE N D I C E S}

\section{Appendix 1. Search strategies}

CENTRAL (via CRSO)

\#1 MESH DESCRIPTOR headache disorders EXPLODE ALL TREES

\#2 MESH DESCRIPTOR headache EXPLODE ALL TREES

\#3 ((headache ${ }^{\star}$ or migrain ${ }^{\star}$ or cephalgi ${ }^{\star}$ or cephalalgi ${ }^{\star}$ or hemicrani $\left.\left.{ }^{\star}\right)\right): T I, A B, K Y$

\#4 \#1 OR \#2 OR\#3

\#5 MESH DESCRIPTOR botulinum toxins EXPLODE ALL TREES

\#6 ((botulin* adj toxin*)):TI,AB,KY

$\# 7$ ((botulinum ${ }^{\star}$ or oculinu* ${ }^{\star}$ or boto* or onabotulinum $\left.\left.{ }^{\star}\right)\right): \mathrm{TI}, \mathrm{AB}, \mathrm{KY}$

\#8 MESH DESCRIPTOR Botulinum Toxins, Type A EXPLODE ALL TREES

\#9 (clostridium botulinum):TI,AB,KY

$\# 10$ (clostridium botulin $\left.{ }^{\star}\right): \mathrm{TI}, \mathrm{AB}, \mathrm{KY}$

\#11 \#5 OR \#6 OR \#7 OR \#8 OR \#9 OR \#10

\#12 \#4 AND \#11

\section{MEDLINE (via OVID)}

\#1 Exp headache disorders/

\#2 headache/

\#3 (headache* or migrain ${ }^{\star}$ or cephalgi ${ }^{\star}$ or cephalalgi ${ }^{\star}$ or hemicrani ${ }^{\star}$ ).mp.

\#4 or/1-3

\#5 exp botulinum toxins/

\#6 (botulin* adj toxin*).tw

\#7 (botulinum* or oculinu* or boto* or onabotulinum*).tw.

\#8 exp botulinum toxin type $A$ / 
\#9 Exp clostridium botulinum/

\#10 clostridium botulin*.tw.

\#11 or/5-10

12 randomized controlled trial.pt.

13 controlled clinical trial.pt.

14 randomized.ab.

15 placebo.ab.

16 drug therapy.fs.

17 randomly.ab.

18 trial.ab.

19 groups.ab.

2012 or 13 or 14 or 15 or 16 or 17 or 18 or 19

21 exp animals/ not humans.sh.

2220 not 21

234 and 11 and 22

\section{Embase (via OVID)}

1 exp headache disorders/

2 headache/

3 (headache* or migrain $^{\star}$ or cephalgi* ${ }^{\star}$ or cephalalgi* or hemicrani $\left.{ }^{\star}\right)$. tw.

4 or $/ 1-3$

5 exp botulinum toxins/

6 (botulin* adj toxin $\left.{ }^{\star}\right) . t w$.

7 (botulinum ${ }^{\star}$ or oculinu* or boto* $^{\star}$ or onabotulinum ${ }^{\star}$ ).tw.

8 exp botulinum toxin type $\mathrm{A} /$

9 exp clostridium botulinum/

10 clostridium botulin ${ }^{\star}$. tw.

11 or $/ 5-10$

12 random $\$ . t w$.

13 factorial\$.tw.

14 crossover\$.tw.

15 cross over\$.tw.

16 cross-over\$.tw.

17 placebo\$.tw.

18 (doubl\$ adj blind\$).tw.

19 (singl\$ adj blind\$).tw. 
20 assign\$.tw.

21 allocat\$..tw.

22 volunteer\$.tw.

23 Crossover Procedure/

24 double-blind procedure.tw.

25 Randomized Controlled Trial/

26 Single Blind Procedure/

27 or $/ 12-26$

28 (animal/ or nonhuman/) not human/

2927 not 28

304 and 11 and 29

\section{Appendix 2. Botulinum toxin versus non-established agents summary}

\section{Botulinum toxin versus other agent: histamine}

One trial (Millán-Guerrero 2009) with 100 participants compared a single round of injections of Botox (50 U) into the head and neck muscles with injections of histamine ( 1 to $10 \mu \mathrm{g}$ ) injected into upper arm twice a week for 12 weeks. The trial publication reports that there were no significant between-group differences in number of migraine attacks per month $(P=0.52)$, duration of migraine $(P=0.21)$, headache intensity $(P=0.32)$, use of rescue medications $(P=0.12)$ and patient's global impression of disease (MIDAS score, $P=0.12)$ at the four week time point. Statistical analyses for between group comparisons are not reported for any outcome measures at the 12-week time point. Number of migraine days, number of headache days, quality-of-life measures, adverse events data and cost-effectiveness outcomes were not recorded for this trial.

\section{Appendix 3. Dosing studies summary}

\section{Botulinum toxin versus clinically relevant different dose of botulinum toxin: Botox}

Comparisons between different doses of Botox were studied in five trials and 1049 participants (Elkind I 2006; Elkind II 2006; Relja 2007; Saper 2007; Silberstein 2000). All but one (Elkind II 2006) also included a placebo arm and we discussed the results of the pooled treatment arms compared with placebo earlier. We attempted to organise data into four clinically relevant dose comparisons: $\geq 200 \mathrm{U}$ and $<200 \mathrm{U}$; $\geq 150 \mathrm{U}$ and $<150 \mathrm{U} ; \geq 100 \mathrm{U}$ and $<100 \mathrm{U} ; \geq 50 \mathrm{U}$ and $<50 \mathrm{U}$.

\section{Primary outcome: number of migraine days per month}

Two trials run in sequence (Elkind I 2006; Elkind II 2006) reported migraine days data for 353 participants comparing 50 U Botox versus 25 U Botox, we excluded the lower-dose arm (7.5 U Botox) in Elkind I 2006 from this comparison to prevent double counting, as participants from that arm were re-randomised into Elkind II 2006. No statistically significant between-group difference $(0.4$ days, $95 \% \mathrm{Cl}-0.2$ to $1.0, \mathrm{P}$ $=0.18$ ) resulted from aggregation of these data (Analysis 4.1). One additional trial (Relja 2007) recorded this outcome but did not report the results in a usable format.

\section{Secondary outcomes}

\section{Efficacy outcomes}

Two trials reported number of migraine attacks but only one of those provided meta-analysable data (Relja 2007) for 377 participants. This trial's results did not show a statistically significant between-group difference for arms treated with $\geq 200 \mathrm{U}$ compared with pooled lower doses, or for treatment with $\geq 150$ compared with $<150 \mathrm{U}(\mathrm{P}=0.21$ and $\mathrm{P}=0.65$ respectively). Silberstein 2000 randomised 82 participants into two dosing arms comparing treatment with $75 \mathrm{U}$ of Botox and treatment with $25 \mathrm{U}$, they reported a reduction in favour of the group treated with $75 \mathrm{U}$ Botox of 1.1 attacks $(\mathrm{P} \leq 0.046)$. None of the trials included in this comparison reported meta-analysable data for duration of migraine, proportion of responders or use of rescue medication. All trials recorded a measure of migraine severity, but none of the trials reported data for analysis or gave a clear description of the results for the dosing arms. All trials recorded a global impression scale, but no data were available for analysis. Two trials did not report their results in enough detail to draw comparisons between their dosing arms (Elkind I 2006; Relja 2007) and one trial failed to provide any statistical analysis comparing the two Botox-treated arms. Elkind II 2006 reported only that no consistent statistically significant differences between groups were identified for the patient global assessment score.

Quality-of-life measures were recorded by three trials (Elkind I 2006; Elkind II 2006; Relja 2007). Two of these failed to provide enough detail to allow between-group comparisons to be made for the dosing arms. Elkind II 2006 recorded data for the Migraine-Specific Measure of 
Quality of Life questionnaire, the Migraine Impact Questionnaire, and the Headache Pain Specific Quality of Life questionnaire and reported that there were no consistent statistically significant differences between groups on any measure. No cost effectiveness analyses were identified for this comparison.

\section{Safety outcomes}

Doses administered in the two trials reporting data for treatment-related adverse events were not comparable within our chosen categories. The $\geq 200 \mathrm{U}$ versus $<200 \mathrm{U}$ and $\geq 150 \mathrm{U}$ versus $<150 \mathrm{U}$ comparisons data from Relja 2007 did not show a statistically significant between-group difference in risk of treatment-related adverse events $(P=0.37$ and $P=0.61$ respectively). Elkind I 2006 compared two low dose arms ( $50 \mathrm{U}$ versus $25 \mathrm{U}$ ) and found an increased risk of a treatment-related adverse event for participants treated with the higher of these two doses, with a RR of $2.1(95 \% \mathrm{Cl} 1.4$ to 3.3$)$.

There were no between-group differences in the risk ratio (RR) of muscle weakness (200 U: RR 1.04, 95\% $\mathrm{Cl} 0.73$ to $1.47, \mathrm{P}=0.85, \mathrm{~N}=377$; $150 \mathrm{U}: \mathrm{RR} 1.13,95 \% \mathrm{Cl} 0.78$ to $1.64, \mathrm{P}=0.52, \mathrm{~N}=377$; Analysis 4.2), neck pain (200 U: RR $1.25,95 \% \mathrm{Cl} 0.83$ to $1.89, \mathrm{P}=0.28, \mathrm{~N}=377 ; 150 \mathrm{U}$ : RR 1.19, $95 \% \mathrm{Cl} 0.76$ to $1.86, \mathrm{P}=0.45, \mathrm{~N}=377$; Analysis 4.4), or injection site pain (200 U: RR 1.23, $95 \% \mathrm{Cl} 0.13$ to $11.97, \mathrm{P}=0.86, \mathrm{~N}=500$; 150 U: RR $1.45,95 \% \mathrm{Cl} 0.48$ to $4.41, \mathrm{P}=0.51, \mathrm{~N}=377 ; 50 \mathrm{U}: \mathrm{RR} 1.19,95 \% \mathrm{Cl} 0.34$ to $4.12, \mathrm{P}=0.78, \mathrm{~N}=82$; Analysis 4.5$)$ for any of the above and below dose comparisons analysed).

For the analysis of blepharoptosis-related adverse events, we considered only doses administered into the frontalis and/or corrugator muscles, so the comparisons were: $\geq 50 \mathrm{U}$ and $<50 \mathrm{U} ; \geq 30 \mathrm{U}$ and $<30 \mathrm{U}$; and $\geq 10 \mathrm{U}$ and $<10 \mathrm{U}$ of Botox (Analysis 4.3). The RR of blepharoptosis for higher doses of Botox was around 2 times that for lower doses in all cases but the result was statistically significant for the highest dose comparison only (50 U: RR 2.31, 95\% Cl 1.58 to $4.43, \mathrm{~N}=377 ; 30 \mathrm{U}$ : RR 2.36, 95\% Cl 0.58 to $9.65, \mathrm{P}=0.23, \mathrm{~N}=459 ; 10 \mathrm{U}$ : RR $2.42,95 \% \mathrm{Cl}$ 0.99 to $5.94, \mathrm{P}=0.051, \mathrm{~N}=406)$.

\section{Botulinum toxin versus clinically relevant different dose of botulinum toxin: other botulinum toxin preparations}

Two trials with 150 participants compared different dosing arms of Dysport (Chankrachang 2011; Petri 2009). Both included a placebo arm and were also involved in the relevant section earlier in this review. A further trial compared two different doses ( $33 \mathrm{U}$ and $25 \mathrm{U}$ ), in 30 participants, of a further botulinum toxin agent, Prosigne, with a Botox arm (dose $25 \mathrm{U}$ ) and a placebo arm to attempt to establish dose equivalency (Lauretti 2014).

\section{Primary outcome: number of migraine days per month}

None of the trials reporting dose comparisons of other botulinum toxins recorded the primary outcome for this review.

\section{Secondary outcomes}

\section{Efficacy outcomes}

The number of headache days was recorded by Petri 2009 only and they did not report any data, but stated that the betweengroup differences were not statistically significant. Two trials recorded number of migraine attacks (Chankrachang 2011; Petri 2009). Chankrachang 2011, $N=86$, stated that there was no significant difference between the treated groups, for which the dose comparison was 240 U Dysport vs 120 U Dysport $(P=0.87$ ). Petri $2009, N=60$, provided no statistical analysis comparing the groups treated with 210 U Dysport vs 80 U Dysport and no data to allow the analysis to be carried out by the review authors. Only Petri 2009 recorded the mean duration of migraine and frequency of use of rescue medications and again, the trial authors reported just that the difference between the groups was not statistically significant. None of the trials recorded proportion of responders. All trials recorded a measure of headache intensity. The trials studying Dysport both reported that there were no significant between-group differences in migraine severity. The trial studying dose equivalency of Botox compared with Prosigne (Lauretti 2014) reported that there was no statistically significant betweengroup difference for the 33 U Prosigne group. Chankrachang 2011 reported that there were no statistically significant between-group differences in patient or investigator global assessment scores or MIDAS scores for the regular diary period of four weeks. No betweengroup comparison was reported for patient global assessment scores by Petri 2009 and clinical global assessment scores were reported as showing no statistically significant between-group difference. Only Chankrachang 2011 recorded a quality-of-life measure. They used the SF-36 questionnaire and reported that there were no statistically significant between-group differences. No cost-effectiveness analyses were identified for this comparison.

\section{Safety outcomes}

The numbers of participants experiencing any adverse event were reported by both trials of Dysport. Meta-analysis of these data, grouping arms treating with $\geq 150 \mathrm{U}$ and $<150 \mathrm{U}$, showed no significant between group difference in the RR of experiencing an adverse event (RR $1.59,95 \% \mathrm{Cl} 0.47$ to $5.32, \mathrm{P}=0.45$; Analysis 3.1). The specific adverse event types of interest for this review were not reported in the correct format for analysis, with the single exception that Petri 2009 stated that ptosis was experienced by one participant in each treated group $(\mathrm{N}=32$ per arm).

\section{CONTRIBUTIONS OF AUTHORS}

CEC and AS conceived the review. $\mathrm{CH}$ ran searches not covered by the review group's information specialist. CH, CLT, CR and AS screened the search results. $\mathrm{CH}, \mathrm{CLT}, \mathrm{CR}, \mathrm{WS}, \mathrm{CEC}$ and AS assessed the quality of trials and extracted data. $\mathrm{CH}$ contacted trial authors, managed data 
and entered it into Review Manager 5 (RevMan 2014), and carried out data analysis. NI provided statistical advice. CH, CLT, CR, NI, CEC and AS were involved in interpretation of the results. All review authors read and edited the final version of the review.

\section{DECLARATIONS OF INTEREST}

$\mathrm{CPH}$ : none known

CLT: none known

CR: none known

WJS: none known

JE: received funding from Allergan in 2017 to attend a Master Class in Botulinum toxin.

NI: none known

CEC: none known; CEC is a specialist neurology physician and manages patients with headache.

AS: none known; AS is a specialist neurology physician and manages patients with headache.

\section{SOURCES OF SUPPORT}

\section{Internal sources}

- College of Medical \& Dental Sciences, University of Birmingham, UK.

\section{External sources}

- National Institute for Health Research (NIHR), UK.

A.S. is funded by an NIHR Clinician Scientist Fellowship (NIHR-CS-011-028)

\section{DIFFERENCES BETWEEN PROTOCOLANDREVIEW}

We updated the clinical trials registry search strategy to reflect changes in database coverage and availability. We removed the following: CentreWatch Clinical Trials listing service; metaRegister of Controlled Trials (mRCT), as they are no longer in existence. The latter is covered by The World Health Organization's International Clinical Trials Registry Platform (ICTRP) (www.who.int/ictrp/en/), which we added to the strategy.

We changed age of included participants from 'over 18 years of age' to '18 years of age and over'; the former appeared in the protocol erroneously.

We added text to search strategies to clarify that no date restrictions were used.

Section 'Types of outcome measures' extended in places to make it clearer.

Outcomes measure 'duration of migraine' replaces headache duration as it is clearer in meaning; the actual outcome measure reporting covered is the same for the two terms.

Headache index added to list of outcome measures, this measure is a combination of frequency and severity information and as such we felt it had to be assessed based on our original criteria but that we needed to add it to our outcome list to make its eligibility explicit.

For trial selection we changed text to show that trials without sufficient information were not excluded but put into the trials awaiting classification section as suggested by the Cochrane editorial group.

We extended 'Risk of bias' categories to include a separate section for performance bias and reporting bias, which should have appeared in the protocol. We removed the domain 'other'.

We activated the section 'Assessment of reporting biases' and described reasons for not carrying out funnel plots as per Cochrane editors' recommendations.

We decided to use a random-effects model for our data analysis, as the data extraction stage of the review process showed a great deal of clinical heterogeneity in the populations studied and dose and injection paradigms used for treating with botulinum toxin.

We updated our GRADE methods wording to align with current standards. 
We carried out an additional sensitivity analysis to assess the effect of small trials on the pooled estimate for our primary outcome due to concerns about the robustness of the overall estimate.

\section{INDEX TERMS}

\section{Medical Subject Headings (MeSH)}

Botulinum Toxins, Type A [ ${ }^{\star}$ therapeutic use]; Chronic Disease; Migraine Disorders [ ${ }^{\star}$ prevention \& control]; Randomized Controlled Trials as Topic

\section{MeSH check words}

Adult; Female; Humans; Male 